National Bureau of Standards

Library, E-01 Admin. Bidg.

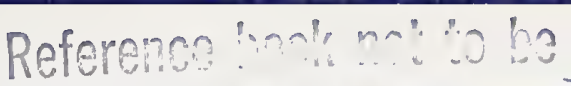

A UNITED STATES

DEPARTMENT OF

COMMERCE

PUBLICATION

NOV 251969

BUILDING SCIENCE

SERIES

25

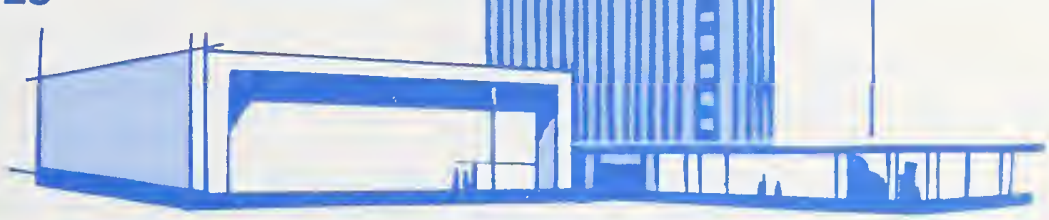

\title{
Structural Performance Evaluation Of a Building System
}

U.S. DEPARTMENT OF COMMERCE National Bureau of Standards 


\section{Announcing-The Building Science Series}

The "Building Science Series" disseminates technical information developed at the Bureau on building materials, components, systems, and whole structures. The series presents research results, test methods, and performance criteria related to the structural and environmental functions and the durability and safety characteristics of building elements and systems.

These publications, similar in style and content to the NBS Building Materials and Structure Reports (1938-59), are directed toward the manufacturing, design, and construction segments of the building industry standards organizations, officials responsible for building codes, and scientists and engineers concerned with the properties of building materials.

The material for this series originates principally in the Building Research Division of the NBS Institute for Applied Technology. Published or in preparation are:

BSS1. Building Research at the National Bureau of Standards. (In preparation).

BSS2. Interrelations Retween Cement and and Concrete Properties: Part 1, Materials and Techniques, Water Requirements and Trace Elements. 35 cents

BSS3. Doors as Rarriers to Fire and Smoke. 15 cents

RSS4. Weather Resistance of Porcelain Enamels: Effect of Exposure Site and other Variables After Seven Years. 20 cents

BSS5. Interrelations Between Cement and Concrete Properties: Part 2, Sulfate Expansion, Heat of Hydration, and Autoclave Expansion. 35 cents

BSS6. Some Properties of the Calcium Aluminoferrite Hydrates. 20 cents

RSS7. Organic Coatings. Properties, Selection, and Use. $\$ 2.50$

BSS8. Interrelations Between Cement and Concrete Properties: Part 3, Compressive Strengths of Portland Cement Test Mortars and Steam-Cured Mortars. 55 cents

BSS9. Thermal-Shock Resistance for Ruilt-Up Membranes. 20 cents

BSS10. Field Burnout Tests of Apartment Dwelling. Units. 25 cents

BSS11. Fire Resistance of Steel Deck Floor Assemblies. 25 cents

BSS12. Performance of Square-Edged Orifices and Orifice-Target Combinations as Air Mixers. 15 cents

BSS13. Shrinkage and Creep in Prestressed Concrete. 15 cents

BSS14. Experimental Determination of Eccentricity of Floor Loads Applied to a Bearing Wall. 15 cents

BSS15. Interrelations Between Cement and Concrete Properties: Part 4, Shrinkage of Hardened Portland Cement Pastes. 75 cents

BSS16. Techniques for the Survey and Evaluation of Live Floor Loads and Fire Loads in Modern Office Buildings. 40 cents

BSS17. Causes of Variation in Chemical Analyses and Physical Tests of Portland Cements. 40 cents

BSS18. Smoke and Gases Produced by Burning Aircraft Interior Materials. 3j cents

RSS19. Study of the Variables in the Saturating of Roofing Felts. 30 cents.

BSS20. Performance of Buildings-Concept and Measurement. (In press.)

BSS21. Algorithms for Psychometric Calculations. (In press.)

BSS22. Investigation of Performance Characteristics for Sanitary Plumbing Fixtures. (In press.)

BSS23. Hail Resistance of Roofing Products. 25 cents.

ISS24. Natural Weathering of Mineral Stabilized Asphalt Coatings on Organic Felt. (In press.)

Send orders with remittance to: Superintendent of Documents, U.S. Government

Printing Office, Washington, D.C. 20402. Remittances from foreign countries should include an additional one-fourth of the purchase price for postage. 


\section{Structural Performance Evaluation Of a Building System}

Edward O. Pfrang and Felix Y. Yokel

Building Research Division Institute for Applied Technology

National Bureau of Standards

Washington. D.C. 20234

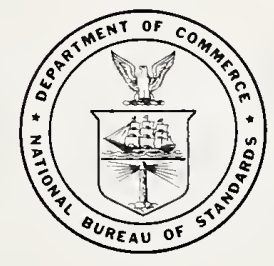

Building Science Series 25 ,

Nat. Bur. Stand. (U.S.), Bldg. Sci. Ser. 25, 127 pages (November, 1969)

CODEN : BSSNB

Issued November, 1969 
Certain proprietary and patented building systems, structural components, and bulding materials are identified in this report in order to adequately specify the test specimen and the experimental procedures. In no case does such identification imply recommendation or endorsement by the National Bureau of Standards, nor does it imply that the proprietary products identified are necessarily the best available for the purpose.

This report does not account for possible variation in the performance of these proprietary products.

The contents of this report are not to be used for advertising or promotional purposes. 


\section{Contents}

List of tables

Page

List of figures

1. Introduction

2. Objective and scope

3. Notation and conversion units

3.1. Service loads

3.2. Simulated loads on test structure

3.3. Deflections

3.4. Lengths

3.5. SI conversion units

4. Performance criteria

4.1. Introduction

4.2. Definitions

4.2.1. Length of members

4.2.2. Deflections

4.2.3. Superimposed loads

4.2.4. Failure _... 3

4.3. Test criteria

4.3.1. Model selection _._._._- 3

4.3.2. Loading

4.4. Performance criteria

4.4.1. Horizontal deflection under dead and wind load

4.4.2. Horizontal deflection under dead, live, and wind load

4.4.3. Vertical deflections under service live load

4.4.4. Sustained load deflection 4.4.5. Ultimate strength

4.5. Summary of test and performance criteria

5. Test structure

5.1. Proposed structure 5.1.1. Precast components

5.1.2. Cast-in-place topping slabs ---

5.1.3. Gypsum walls

5.1.4. Foundations, grade beams, and slabs on grade

5.2. The test structure

5.2.1. Structural simulation

5.2.2. Description of the test structure

5.3. Fidelity of simulation of field conditions by the test structure 5.3.1. Interaction between the test structure and the complete structure

5.3.2. Simulation of foundation conditions

5.3.3. Simulation of live loads

6. Load program

6.1. Introduction

6.2. Applied loads

6.3. Loading schedule iii

iv

2
6.3.1. Tests conducted on the structure with walls installed _--

6.3.2. Tests conducted on the structure after the removal of walls _-____-__-_ 12

7. Instrumentation

8. Results

9. Interpretation of results

9.1. Introduction

9.2. Vertical forces _-_-_- 14

9.2.1. Structural response to vertical loads

9.2.2. Compliance with performance criteria, vertical loads _.... 14

9.3. Horizontal forces _._._- 16

9.3.1. Horizontal loads in the North

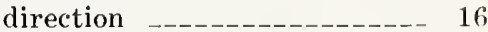

9.3.2. Horizontal loads in the East direction

9.3.3. Compliance with performance criteria, horizontal loads _._- 18

9.4. Sumnary _. 18

10. Components tests ___

10.1. Introduction

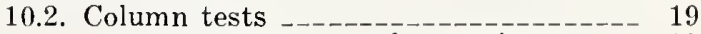

10.2.1. Short-term destructive tests - 19

10.2.2. Sustained loading (creep) tests

10.2.3. Interpretation of column tests results

10.3. Channel slab test _-_-_-_-_-_-_-- 22

10.4. Beam tests - repeated loading _...-10.4.1. Test specimens _-_-_-_--10.4.2. Beam loading --10.4.3. Test results 10.4.4. Interpretation of results

11. Material tests

11.1. Introduction

11.2. Concrete tests

11.2.1. Precast component concrete - 24

11.2.2. Floor and topping slab concrete

11.2.3. Concrete test results

12.1. Summary

12.2. Conclusions

13. Acknowledgments _._. 25

14. References _-_____- 26

15. Tables - 26

16. Figures -

Appendix A. Plotted Test Results _-_- 70

Appendix B. Discussion of column simulation _-_- 111

Appendix C. Load computations and load sched-

ules

\section{List of Tables}

Table

6.1. Simulated loads (symbols and magnitude) -- 26

6.2. Simulated loads in load schedule _._._._.-. 26

10.1. Column tests (actual dimensions and rein-

forcement cover of the columns)

10.2. Column tests (ultimate loads and failure modes)

10.3. Beam tests (insert spacing and concrete strength of specimens)

10.4. Beam tests (repeated load test results) $\ldots--\quad 29$
Table

Page

10.5. Beam tests (modes of insert failures) ---- 29

11.1. Concrete tests (concrete compressive and

splitting strength) _._. 30

11.2. Concrete tests (unit weights and air contents of concrete)

11.3 Concrete tests (modulus of elasticity of precast component concrete)

11.4. Reinforcing steel test results 
List of Figures

Figure

5.1. Typical complete structure

5.2. Structural system model

5.3. Typical bay of two-bay frame test

5.4. Assembling structural frame

5.5. Beam and column reinforcement

5.6. Elevation of column reinforcement

5.7. Long column details

5.8. Main beam reinforcement

5.9. Main beam sections

5.10. Tie-beam plan and elevation

5.11. Beam and column connection

5.12. Tie-beam end details

5.13. Plan sections of column connections

5.14. Elevation sections of column connections --

5.15. Connection detail

5.16. Floor channels

5.17. Plan section through walls

5.18. Fire wall

5.19. Fire wall (partially dismantled)

5.20. Exterior wall details

5.21. Structicore wall sections

5.22. Interior "Structicore" walls (partially dismantled)

5.23. Foundation detail

5.24. Test structure before the installation of walls

5.25. Test structure after the installation of walls

5.26. Test structure with testing equipment installed (top view)

5.27. Test structure with testing equipment installed (front view)

5.28. Column load equipment connection

5.29. Racking load equipment connection

6.1. Loading of test structure

7.1. Instrumentation location. Northeast schematic

7.2. Instrumentation location. Southwest schematic

7.3. Vertical deflection gages

7.4. Column strain gage location

9.1. Test No. 5, sustained vertical load versus midspan deflection of center main beam --

9.2. Test No. 16, Major floor load $(w)$ versus midspan deflection of center main beam ..

9.3. Diagonal tension cracking at $w=270 \mathrm{psf}$ (Test No. 16)

9.4. Interior floor load $(w)$ and total floor load $\left(w+w^{\prime}\right)$ versus midspan and column support deflection of center main beam -.-

9.5. Midspan deflection of west main beam with and without walls

9.6. Tests No, $12 \mathrm{~A}$ and $13 \mathrm{~A}$, vertical load versus north translation

9.7. Tests No. 12 and 13, vertical load versus east translation

9.8. Test No. 2, south wind load versus translation

9.9. Test No. 10, south wind load versus translation

9.10. North-south horizontal translation of structure with and without walls

9.11. Test No. 11, south wind load versus wall compression
Page

32

32

32

32

32

33

33

34

34

35

35

36

37

38

39

40

40

41

42

43

44

44

44

44

44

55

55

46

46

46

47

47

48

48

48

49

49

50

50

51

51

53
Figure

Page

9.12. Test No. 7, south wind load versus trans-

9.13. Effect of vertical loads on north-south horizontal translation

9.14. Test No. 14, south wind load versus translation ------------------

9.15. Test No. 18, south wind load versus translation _-_. 55

9.16. Test No. 3, west wind load versus trans-

9.17. Test No. 11, west wind load versus translation

9.18. East-west horizontal translation of structure with and without walls

9.19. Test No. 11, west wind load versus wall compression _...--

9.20. Drywall crack near ceiling on interior side of east wall

9.21. Test No. 8, west wind load versus translation

9.22. Effect of vertical loads on east-west horizontal translation

9.23. Test No. 15, west wind load versus trans-

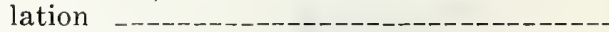

10.1. Test method for column tests (minor axis) -

10.2. Test method for column tests (major axis) -

10.3. Column under test

10.4. Short-term test on column No. 1

10.5. Short-term test on column No. 5

10.6. Short-term test on column No. 8

10.7. Short-term test on column No. 2

10.8. Short-term test on column No. 6

10.9. Short-term test on column No. 7

10.10. Short-term test on column No. 9

10.11. Columns after testing

10.12. Column ends after testing _._._-_._._- 62

10.13. Creep loading frame for columns No. 3 minor axis bending _..--

10.14. Creep loading frame for column No. 4 major axis bending -.....

10.15. Detail of base for column No. 4 creep frame

10.16. Sustained load test, column No. 4

10.17. Sustained load test, column No. 3

10.18. Columns with major axis eccentricity

10.19. Columns with minor axis eccentricity

10.20. Column creep with major axis eccentricity

10.21. Column creep with minor axis eccentricity

10.22. Channel roof slab test

10.23. Beam to slab shear connectors

10.24. Fatigue test on main beam

10.25. Fatigue loading, beam No. 5

10.26. Fatigue loading, beam No. 9

10.27. Fatigue loading, beam No. 8

10.28. Fatigue loading, beam No. 6

11.1. Sample report form

59

59

60

60

60

60

61

61

61

61

62

62

62

64

64

64

64

65

65

65

66

66

67

67

68

68

69

A. 1-A. 76. Plotted test results

$70-110$

B. 1. Column simulation effect on connection moments

111

B. 2. Moment distribution

112

C. 1. Wind loads

116 


\title{
Structural Performance Evaluation of a Building System*
}

\author{
Edward O. Pfrang and Felix Y. Yokel***
}

\begin{abstract}
A full-scale, first-story portion of a building system was tested in the laboratory in such a manner as to simulate the structural behavior of a three-story building under both service and potential ultimate loading conditions. Additional tests were performed on the system components to provide behavioral data needed for the evaluation of the system.

Performance criteria for the evaluation of the structural safety and adequacy of certain building systems were developed. This report presents the results of the physical tests performed in the evaluation of the safety and structural adequacy of one such system, and discusses their significance. The report also presents data concerning the complex interaction between components which takes place in the building system.
\end{abstract}

The primary conclusions reached were:

(1) The system, as erected in the laboratory, satisfied the performance criteria which were set for its evaluation with a substantial margin. As a system, it exhibited strength and stiffness in excess of service and ultimate load requirements.

(2) The walls of the system behaved as an integral part of the structure. They provided most of the stiffness of the system with respect to lateral loads, and provided a significant portion of the stiffness against vertical loads.

Key words: Building systems; low-income housing; performance criteria; performance testing.

\section{Introduction}

It is now recognized that the United States has a severe housing shortage, particularly in the area of low-income housing. This shortage is of such magnitude and urgency as to make questionable its solution through conventional means. It appears that only systems-type solutions taking full advantage of the innovative capabilities of our advanced technology will be capable of coping with this problem economically and within an acceptable time framework.

Traditionally, structural innovations in building construction have been evolutionary rather than revolutionary and have taken place in small, carefully considered increments. Many of these incremental steps have been based upon extensive laboratory and analytical investigation. Progress has usually been based upon component testing and upon simplified and conservative analyses which do not fully account for system interaction. Because of these simplifications, the strengthening effects of so-called nonstructural portions of a building system are, in general, neglected and the complex interaction of components is frequently overlooked. As a result, in those few cases where tests on complete building systems have been performed, results have been obtained which in most cases indicate strength and rigidity far in excess of that predicted either by component testing or by conventional

Work sponsored by the Department of Housing and Urban Development, Washington, D.C. 20410.

Associate Professor of Engineeriug on leave from School of Arlvanced Technology. State University of New York at Binghamton. New York 13901 . simplified analysis [1].' Strict reliance on these conventional concepts tends to inhibit innovative solutions to the building problem.

One solution to this dilemma would be fullscale system tests coupled with mathematical analysis. However, full-scale tests of large building systems are prohibitively expensive and time-consuming and are also difficult to interpret unless they are performed under ideal laboratory control. In addition, the development of mathematical theories generally depends upon a trial-and-error feedback process involving numerous cycles of physical testing. A more reasonable approach appears to be the execution in the laboratory of large-scale subsystem tests which simulate total system behavior. If such subsystems are carefully chosen and are tested in a manner designed to simulate the performance of the total system. and if they are supplemented by critical component tests, then they can be used as a basis for determining the structural adequacy of proposed innovative solutions. This report summarizes the results of such an evaluative study.

\section{Objective and Scope}

This report presents the results and evaluation of a structural performance test on an innovative building system. Criteria for structural performance and for performance testing are developed and are subsequently applied to system evaluation.

\footnotetext{
${ }^{1}$ Figures in brackets indicate the literature references on p. 25.
} 
The report summarizes the results obtained from a comprehensive series of load tests on a full-scale portion of the building system. The test portion of the structure was constructed in the laboratory under provisions of plans and specifications prepared for field erection of the system. The test structure was one story in height and was part of a three-story-high building, chosen and loaded in a manner that simulated the structural response of the complete building subjected to dead, live, and wind loads. The report also presents results obtained from tests on components and materials used in the test structure.

In addition to the evaluation of structural performance, significant information on structural interaction was derived from the data.

\section{Notation and Conversion Units}

The following notation is adopted for use throughout this report:

\subsection{Service Loads}

$D=$ service dead load

$L=$ service live load

$H=$ service wind load

\subsection{Simulated Loads on Test Structure (see fig. 6.1)}

$P=2 \mathrm{~d}$ story column loads

$H w=$ West wind load

$H s=$ South wind load at fire walls

$H^{\prime} s=$ South wind load between fire walls

$w=$ floor load between columns

$w^{\prime}=$ floor load-cantilever section

\subsection{Deflections}

$D v=$ vertical gross deflection

$D v r=$ residual vertical gross deflection

$d v=$ vertical net deflection

$d v r=$ residual vertical net deflection

$d v c=$ vertical net deflection at column support

$d v c r=$ residual vertical net deflection at col-

limn support

$D h=$ horizontal gross deflection

$D h r=$ residual horizontal gross deflection

$d h=$ horizontal net deflection

\subsection{Lengths}

$h=$ height above grade (ground level outside

the building)

$l=$ length of member

$t=$ depth of member

\subsection{SI Conversion Units}

In view of present accepted practice in this country in this technological area, common U.S. units of measurement have been used throughout this paper. In recognition of the position of the United States as a signatory to the General Conference on Weights and Measures, which gave official status to the metric SI system of units in 1960, we assist readers interested in making use of the coherent system of SI units by giving conversion factors applicable to U.S. units used in this paper.

Length

$$
1 \text { in }=0.0254^{*} \text { meter }
$$

$1 \mathrm{ft}=0.0348 *$ meter

Area

$$
1 \text { in }^{2}=6.4516^{*} \times 10^{-4} \text { meter }^{2}
$$

$1 \mathrm{ft}^{2}=0.09290$ meter $^{2}$

Force

$1 \mathrm{lb}(\mathrm{lbf})=4.448$ newton

1 kip $=4448$ newton

Pressure, Stress

$1 \mathrm{psi}=6895$. newton $/$ meter $^{2}$

$1 \mathrm{ksi}=6.895 \times 10^{6}$ newton $/$ meter $^{2}$

$1 \mathrm{psf}=47.88$ newton $/$ meter $^{2}$

Mass Volume meter $^{3}$

$1 \mathrm{lb} / \mathrm{ft}^{3}\left(\mathrm{lbm} / \mathrm{ft}^{3}\right)=16.02 \mathrm{kilogram} /$

Moment

$1 \mathrm{kip}$-in $=113.0 \quad$ newton $\cdot$ meter

\section{Performance Criteria}

\subsection{Introduction}

Some criteria for performance testing have been developed such as ACI 318[2] and N. Y. State Building Code[3]; however, these criteria are not sufficient for the evaluation of comprehensive building systems. The criteria developed for the purpose of this evaluation use some of the existing criteria, supplemented by new criteria where necessary.

The performance criteria used in this report are presented and discussed in this section. First certain necessary definitions are developed; these are followed by Test Criteria and then Performance Criteria. Each Test and Performance Criterion is followed by a commentary. For convenience of reference, these Criteria are summarized in section 4.5.

* Exactly 


\subsection{Definitions}

\subsubsection{Length of Members}

The length of horizontal members is taken as the distance between the center lines of their supports or the clear distance between supports plus the member depth, whichever is smaller. In the case of a cantilever beam, the "length" is taken as twice its actual length.

\subsubsection{Deflections}

Deflection is the displacement of a point in a structure caused by the application of superimposed loads.

The magnitude of the deflection at a point is the component of the displacement of the point in the specified direction, measured from its position before the application of the superimposed loads which caused the deflection.

Horizontal deflections are measured in a direction parallel to the direction of the applied horizontal forces.

Gross deflection is the total deflection of a point.

Net deflection is the part of the gross deflection at a point which is attributable solely to the deformation of a structural member or assembly between its supports.

Residual deflection is the deflection at a point after removal of superimposed loads, measured relative to the position of the point before application of the loads.

\subsubsection{Superimposed Loads}

Superimposed loads are all loads applied to the test structure to simulate the dead, live, and wind loads acting on the real structure.

\subsubsection{Failure}

Failure of the structure or any structural component is defined as one of the following:

(a) An increase in deformation of an order of magnitude as defined in sections 4.4.1 and 4.4.3, occurring within 10 minutes " without increase in applied load.

(b) The inability of the structure to resist further load.

(c) Sudden major cracking, major spalling, or structural collapse.

\subsection{Test Criteria}

In order to satisfy the requirements for a

2 This time limit was introduced in order to distinguish between long-term creep and a deformation occurring over a relatively short period of time. performance test, the following Test Criteria must be satisfied.

\subsubsection{Model Selection}

A portion of the structure which is capable of simulating the response of the entire structure, and which will represent conditions providing the least margin of safety, shall be selected for testing. Foundation conditions shall be simulated in a manner representing the most adverse anticipated conditions that may exist in a complete structure in the fiield.

Commentary on Criterion 4.3.1. A similar criterion is developed in ACI 318[2] ; however, the emphasis in this paper is on the requirement of having a section of the structure which (1) will represent the performance of the entire structure, and (2) will represent this performance in a conservative manner.

\subsubsection{Loading}

"Superimposed loads" shall be applied in a manner which will result in conditions equal to or more adverse or more adverse than the conditions in the full-scale structure and which provide the least margin of safety.

Comentary on Criterion 4.3.2. Criterion 4.3.2 requires a simulation which is conservative. It is recognized that exact duplication of field conditions cannot be achieved and should not be attempted. Instead it is required that the test simulate superimposed loads in a manner which will provide the least margin of safety that may exist under any circumstances.

\subsection{Performance Criteria}

\subsubsection{Horizontal Deflection Under Dead and and Wind Load}

At a load level of 0.9 dead +1.1 wind $(0.9 D$ $+1.1 H$ ) the Horizontal deflection due to the superimposed load of 1.1 wind $(1.1 H)$ shall not exceed the following:

$$
D h \leq 0.002 h
$$

where:

$D h=$ horizontal gross deflection

$h=$ height above grade.

Commentary on Criterion 4.4.1. Generally a structure will experience its most severe lateral deflection under a condition of minimum vertical load and maximum lateral load. This criterion is designed to prevent excessive deflection under this condition of loading, and 
provides a margin of 10 percent over the maximum lateral loads likely to occur under service conditions.

There has been limited experience with high-rise apartment structures which indicated that when such a structure is designed to permit horizontal deflection in excess of $h / 400$ to $h / 500$ under maximum service wind loads, discomfort and anxiety are experienced by some of the occupants under severe wind conditions. Although it is extremely conservative for low-rise structures, this deflection limitation is adopted here since a more comprehensive criterion has not been developed.

\subsubsection{Horizontal Deflection Under- Dead, Live, and Wind Load}

At a load level of 1.3 Dead +1.7 Live + 0.8 Wind $(1.3 D+1.7 L+0.8 H)$, the horizontal deflection due to the superimposed load of $0.3 \mathrm{D}+1.7 \mathrm{~L}+0.8 H$ shall not exceed the following:

$$
D h \leq 0.002 h \text {. }
$$

Commentary on Criterion 4.4.2. Even though the most critical loading with respect to horizontal deflections of a structure is in many cases a combination of minimum vertical and maximum lateral loads, maximum vertical loads combined with lateral loads may be more critical. This criterion imposes conditions which represent the highest loads which should cause no permanent structural damage. It would be unrealistically conservative to impose maximum lateral loads. A lesser lateral load is therefore adopted for this criterion, accounting for the low probability of simultaneous action of maximum vertical loads, combined with maximum wind forces.

\subsubsection{Vertieal Defleetions Under Service Live Load}

At a load of 1 dead and 1 live $(1 D+1 L)$, the vertical deflection due to the superimposed load of 1 live $(1 L)$ shall not exceed the following:

$$
d v \leq \frac{l}{360}
$$

where:

$d v=$ vertical net deflection.

$l=$ length of member.

Commentary on Criterion 4.4.3. Criterion 4.4 .3 is based on the proposition that $\frac{l}{480}$ rep- r'esents a reasonable maximum allowable instantaneous deflection under service loads. Prevailing codes usually set $\frac{l}{360}$ as a deflection limitation; however, studies [4] have indicated that this deflection is excessive in terms of user comfort and causes minor distress to finishes and partitions. The proposed $\frac{l}{480}$ deflection limitation reasonably represents present-day consensus based on limited knowledge in this area.

\subsubsection{Sustained Load Defleetion}

At a load level of 1.3 dead +1.7 live $(1.3 D$ $+1.7 \mathrm{~L}$ ) sustained for 24 hours, deflections due to the superimposed load of 0.3 dead + 1.7 live $(0.3 D+1.7 L)$ shall not exceed the following:

(a) $d v \leq \frac{l}{360} \times \frac{(0.3 D+1.7 L)}{L}$

(b) $D h \leq 0.002 h$.

Residual deflection due to the superimposed load of $0.3 D+1.7 L$, measured not later than 24 hours after removal of the superimposed load, shall not exceed the following:

$$
\begin{aligned}
\text { (c) } \text { If } d v & >\frac{l^{2}}{20,000 t}, \quad d v r \leq 0.25 d v . \\
\text { If } d v & \leq \frac{l^{2}}{20,000 t} \quad d v r \leq \frac{l^{2}}{80,000 t} . \\
\text { (d) } D v r & \leq d v r+0.25(D v-d v)
\end{aligned}
$$

where:

$$
\begin{aligned}
& D v=\text { vertical gross deflection } \\
& D v r=\text { residual vertical gross deflection } \\
& d v=\text { vertical net deflection } \\
& d v r=\text { residual vertical net deflection } \\
& l \quad=\text { length of member } \\
& t \quad=\text { depth of member. }
\end{aligned}
$$

Commentary on Criterion 4.4.4. Structures should not suffer large irreversible deformations under loads which are lower than their ultimate design loads. It is therefore reasonable to require structures to resist superimposed loads up to 90 percent of their ultimate design loads without suffering significant irreversible deformations.

Under most codes, $1.3 D+1.7 L$ is about 90 percent of the ultimate design load. This is therefore the highest load which should be reasonably expected to cause no permanent structural damage. The deflection limitation in 
4.4.4(a) represents an extrapolation of the service load deflection limit of $\frac{l}{480}$ with an additional allowance for creep deflection.

Criterion 4.4.4(b) is similar to criteria 4.4.1 and 4.4.2, which have been discussed earlier.

Criterion 4.4 .4 (c) requires 75 percent recovery of vertical deflections. This guards against structural systems which experience significant permanent sets in each cycle of loading that may lead to progressive incremental collapse. By permitting residual deflections of up to 25 percent of initial deflections, reasonable tolerances are provided for creep and system slack. The 75 percent recovery requirement is relaxed for very stiff structural systems $\left(d v \leq \frac{l^{\prime}}{20,000 t}\right)$, since there are invariably some small irrecoverable deformations in all structures.

Criterion 4.4.4(d) requires 75 percent recovery of deflections in excess of "net" deflections. These deflections are primarily due to deformations of columns and/or walls and this criterion provides reasonable tolerances for creep and system slack. Lower limits for recoverable deformations cannot be set in this case until further studies are conducted.

\subsubsection{Ultimate Strength}

The structure or any portion thereof shall not fail at a load smaller than the following:
(a) $1.25(1.5 D+1.8 L)$
(b) $0.9 D+1.4 H$.

Commentary on Criterion 4.4.5. Criterion 4.4.5(a) is for ultimate vertical loads. It is assumed that a structure may in extreme cases fail under loads which are as much as 20 percent below the average failure loads for similar structures (or of computed "ultimate" loads). In absence of a statistical sample of any size it is necessary to assume that if the laboratory sample has a strength of 1.0 , the structure simulated by the sample may have a strength as low as $1-0.2=0.8$. It is therefore required that the laboratory sample be capable of withstanding a load of $\frac{1}{0.8}$, or 1.25 times the design ultimate load, which was taken as $1.5 D+1.8 L$.

Criterion 4.4 .5 (b) is tentatively adopted for ultimate lateral load, following the same philosophy with an ultimate load of $1.1 \mathrm{H}$.

\subsection{Summary of Test and Performance Criteria}

The preceding Test and Performance Criteria are summarized in this section for ease of reference. The criteria numbers remain unchanged.

\subsubsection{Model Selection}

A portion of the structure which is capable of simulating the response of the entire structure, and which will represent conditions providing the least margin of safety, shall be selected for testing. Foundation conditions shall be simulated in a manner representing the most adverse anticipated conditions that may exist in a complete structure in the field.

\subsubsection{Loading}

Superimposed loads shall be applied in a manner which will result in conditions equal to or more adverse than the conditions in the full-scale structure which provide the least margin of safety.

\subsubsection{Horizontal Deflection Under Dead and Wind Load}

At a load level of $0.9 D+1.1 H$, the horizontal deflection due to the superimposed load of $1.1 \mathrm{H}$ shall not exceed the following:

$$
D h \leq 0.002 h .
$$

\subsubsection{Horizontal Deflection Under Dead. Live, and Wind Load}

At a load level of $1.3 \mathrm{D}+1.7 \mathrm{~L}+0.8 \mathrm{H}$, the horizontal deflection due to the superimposed load of $0.3 D+1.7 L+0.8 H$, shall not exceed the following:

$$
\begin{aligned}
& \qquad D \leq 0.002 h . \\
& \text { 4.4.3. Vertical Deflections Under Service } \\
& \text { Live Load }
\end{aligned}
$$

At a load level of $\mathrm{I} D+1 \mathrm{~L}$, the vertical deflection due to the superimposed load of $1 L$ shall not exceed the following:

$$
d v \leq \frac{l}{480} .
$$

\subsubsection{Sustained Load Deflection}

At a load level of $1.3 \mathrm{D}+1.7 \mathrm{~L}$ sustained for 24 hours, deflections due to the superimposed 
load of $0.3 D+1.7 L$ shall not exceed the following:
(a) $d v^{\prime} \leq \frac{l}{360} \times \frac{(0.3 D+1.7 L)}{L}$
(b) $D h \leq 0.002 h$.

Residual deflection due to the superimposed load of $0.3 D+1.7 L$, measured not later than 24 hours after removal of the superimposed load, shall not exceed the following:
(c) If $d v>\frac{l^{2}}{20,000 t}$,
If $d v \leq \frac{l^{\prime 2}}{20,000 t}$
$d v r \leq 0.25 d r$. $d v^{r} \leq \frac{l^{*}}{80,000 t}$
(d)
$D i r \leq d v r+0.25$
$(D v-d v)$

\subsubsection{Ultimate Strength}

The structure or any portion thereof shall not fail at a load smaller than the following:
(a) $1.25(1.5 D+1.8 L)$
(b) $0.9 D+1.4 H$.

\section{Test Structure}

The structure as erected and tested in the laboratory was a full-scale subsection of a modular building system. It was designed and constructed by Neal Mitchell Associates Inc. under the provisions of section 4.3 .1 of the performance criteria. The plans and specifications were prepared by Neal Mitchell Associates Inc., and are dated 9-13-67. These should be referred to for detailed information. Some typical drawings from these plans were reproduced in this report and modified for illustrative purposes with the permission of Neal Mitchell Associates, Inc."

This section of the report contains a description of the proposed structure, a description of the test structure as erected in the laboratory, and a discussion of the fidelity with which actual field conditions are simulated in this test.

\subsection{Proposed Structure}

A typical complete structure is illustrated in figure 5.1." The proposed structural system consists of :

1. Precast components;

2. Cast-in-place topping slabs;

3. Gypsum walls; and

4. Foundations, grade-beams, and slabs on grade.

\subsubsection{Precast Components}

The precast components of the proposed structure are: (1) columns, (2) main beams, (3) tie beams, and (4) floor channels. Figure 5.2 illustrates an assembled structural frame which contains all the precast components. The frame is illustrated in more detail in figure 5.3. Figure 5.4 shows the erection of a frame.

Figures 5.5 through 5.16 show detailed drawings of the precast components. Figure 5.5 is an isometric view of the main beam, tie beam, and column reinforcement at a connection. Figures 5.6 and 5.7 show typical column details. Main beam details and sections are shown in figures 5.8 and 5.9. Tie beam details are illustrated by figure 5.10 .

In accordance with the plans and specifications, main beams, tie beams, and columns are precast of cellular concrete with lightweight aggregate. The nominal wet density of the concrete is $95 \mathrm{lb} / \mathrm{ft}^{3}$ and specified nominal 28-day strength is 4,500 psi for lower-story columns and 3,500 psi for all other precast components. The wet density of this concrete is controlled by the addition of preformed foam at the time of mixing. Reinforcing bars are ASTM-A61 [5] $(60 \mathrm{ksi})^{+}$steel for primary reinforcement and ASTM-A15[6] (40 ksi) steel for stirrups, ties and other reinforcement.

Column-beam connections and end details are illustrated in figures 5.11 through 5.15. Figure 5.11 is an isometric view of a disassembled connection. Tie beam end details are shown in figure 5.12; figures 5.13 and 5.14 show the column end detail, and figure 5.15 shows the details of an assembled connection.

\footnotetext{
"Written permission has been granted by Neal Mitchell Associates to include figures $5.3,5.5$, through 5.21 and 5.23 .

All figures referred to in the text appear in the section beginning on p. 31 .
} 
Joints are connected by bolts, then grouted. The grout mix is not specified. The following grout mix was used in the test structure:

1 part Type I cement

2 parts of masonry sand

$3 \mathrm{oz}$ per $1 \mathrm{lb}$ of cement of a polyvinyl acetate emulsion.

The floor channel details are shown in figure 5.16. These elements are standard, commercially available precast concrete roof tile.

Concrete used in channel units consists of $3 / 8$-in maximum size lightweight aggregate ("block-mix"). Air'-dry unit weight of concrete is $103 \mathrm{lb} / \mathrm{ft}^{3}$ and 28-day strength ranges from $4000 \mathrm{psi}$ to $5,500 \mathrm{psi}$ (71/2 sack mix).

Reinforcement consists of a No. 4 deformed intermediate grade (ASTM-A15) steel bar in each leg of the channel and a 34-1412 wire mesh (ASTM-A185) [7] in the back of the channel with the 14-gage wire in the longitudinal direction.

The top of the channel is very rough to develop resistance to horizontal shear between the supporting channel and the topping slab.

\subsubsection{Cast-in-Place Topping Slabs}

The topping slabs have a specified nominal thickness of $2 \mathrm{in}$. Concrete is made of $3 / 1$-in maximum size lightweight aggregate, with a weight of $110 \mathrm{lb} / \mathrm{ft}^{3}$ and a nominal 28-day strength of 3,000 psi. Reinforcement is 66-1010 wire mesh (ASTM-A185) set one inch from the top of the slab. Additional reinforcement is provided at the main beams by the shear connectors and by two No. 4 bars on the first floor and two No. 3 bars on all other floors, as shown in figure 5.8. This reinforcement is ASTM-A61 steel.

\subsubsection{Gypsum Walls}

There are three kinds of gypsum walls:

(1) Fire walls,

(2) Exterior walls, and

(3) Interior walls.

The location of these walls in the structural system is illustrated in figure 5.17.

${ }^{4}$ Plans and specifications for the Neal Mitchell Housiny System permit the option of using $50 \mathrm{ksi}$ or $60 \mathrm{ksi}$ steel. The steel used in the test structure had a nominal yjeld of $60 \mathrm{ksi}$. See section 11 for the actual properties.

\subsubsection{Fire Walls}

Figure 5.18 shows a typical cross section of the fire walls. The walls are installed in every second bay in the "short" direction of the building ( $\mathrm{N}-\mathrm{S}$ in the test structure). These walls are continuous in all spaces between columns and have no openings in these spaces. The full width of a building will therefore contain two such uninterrupted firewalls in every second bay. (See figure 5.17.)

The fire walls are standard dry-wall construction. Metal channels are attached to the concrete members with power-actuated fasteners at a 6 - to 8 -in spacing. Metal studs $2 \frac{1}{2}$ in $\times$ 25 gage) are spaced 16 -in on center. Wallboards on either side of the metal studs consist of one 1/2-in gypsum backing board (ASTMC442) [8] and one $5 / 8$-in gypsum wallboard (ASTM-C36 [9].

The wallboards are fastened to the studs by screws spaced 8 to 12 in o.c., which is a closer spacing than that used in standard practice. The details of the actual fire wall installation in the test structure are illustrated in figure 5.19 .

\subsubsection{Exterior Walls}

Figure 5.20 shows a typical section of the exterior walls. "Exterior walls" as defined here are the outer walls in the long direction of the proposed building (E-W direction in the test structure). Each building will thus have two exterior walls. (See fig. 5.17.) Exterior walls are located in the outer rows of columns and fill the $10 \mathrm{ft}$ space between columns. The walls are not continuous and each panel may contain a door or a window.

Exterior walls are standard dry-wall construction. Channels and studs are as in the fire walls. Facing consists of $5 / 8$-in gypsum wallboards (ASTM-C36 on either side of the stud; screw spacing is as in the fire walls. The wall surface exposed to the atmosphere will be protected by optional siding.

\subsubsection{Interior Walls}

"Interior walls" as defined here extend along the two interior rows of columns in the long direction of the building ( $\mathrm{E}-\mathrm{W}$ direction in the test structure). Each building thus has two interior walls in the long directions. These walls fill the 10 -ft panels between columns (see fig. 5.17). A 3-ft door may be expected in every second panel. 
Several types of interior walls are used in the Mitchell System; of these the standard 21/2in "structicore" partition wall construction was deemed to have the least resistance to lateral load and was thus chosen for the laboratory structure. Figure 5.21 shows typical sections of an interior wall, and figure 5.22 shows a typical interior wall partially dismantled.

\subsubsection{Foundations, Grade Beams, and Slabs on Grade}

Foundation plans are shown in figure 5.23. All foundations are specified as ready mix concrete with a 28 -day strength of 3,000 psi. Slabs on grade are ready mix concrete with a specified 28-day strength of 2,000 psi.

Reinforcement is ASTM-A15 intermediate grade steel and ASTM-A185 welded wire mesh.

Lower-story columns are encased in the foundations. (See fig. 5.7.)

\subsection{The Test Structure}

\subsubsection{Structural Simulation}

The test structure before and after installation of the walls is illustrated in figures 5.24 and 5.25 , respectively. It comprises a part of the complete structure, made up of full-scale components and erected in the laboratory. The test structure as part of the complete structure is illustrated in figure 5.2.

The performance of the complete structure is simulated in the test structure by:

(1) applying to the test structure all live loads which under field conditions would act directly on the test structure;

(2) simulating all forces caused by dead, live, and wind loads which would be exerted on the test structure by the rest of the structure under field conditions.

The test structure is thus treated in the laboratory as a "free body." The test structure was so chosen that all aspects of structural performance in the field could be simulated under laboratory test conditions. The test structure corresponds to a part of the total structure which is cut off below the slab on grade.

\subsubsection{Description of the Test Structure}

The test structure was constructed under the provisions of the plans and specifications of the
Neal Mitchell System; however, properties of materials and structural details did not always agree with these plans. Detailed information about materials used in the test structure is presented in section 11. Deviations from plans in structural details are noted in this section. The test structure consised of :

(a) Precast components,

(b) A cast-in-place topping slab,

(c) Walls,

(d) A cast-in-place floor slab.

\subsubsection{Precast Components}

The precast components consisted of:

(a) Six precast columns, which were similar in dimensions to the lower-story columns in the proposed structure (see figs. 5.6 and 5.7) except that they were shortened to a length of $8 \mathrm{ft}-5 \mathrm{in}$, since no embedding in foundations was included.

(b) Three main beams (see figs. 5.8 and

(c) Four tie beams (see fig. 5.10).

(d) Eight 2-ft-wide and two 1-ft-wide floor channels. (See fig. 5.16.) The narrow channels were placed along the north and south edge of the structure. Reinforcement in the channel legs consisted of No. 5 deformed intermediate grade (ASTM-A15) bars, instead of the No. 4 bar's specified in the plans.

\subsubsection{Cast-in-Place Topping Slab}

The specified thickness of the cast-in-place topping slab is $2 \mathrm{in}$. The average slab thickness as built in the test structure was $2 \frac{1}{2}$ in $\pm 1 / 8$ in measured from the top of the main beam. The top of the floor channels was irregular and tended to be somewhat higher than the top of the main beam, producing a somewhat lesser average thickness than the measured $2 \frac{1}{2}$ in. But even after allowing for a thickness reduction due to floor channel irregularity, the as-built thickness was still in excess of the specified 2 -in thickness.

\subsubsection{Walls}

The test structure had the following walls:

(a) East and west walls were "fire walls" as described in section 5.1.3.a, except that $3 / 8$ in gypsum backing boards and $1 / 2$-in. wallboards were used instead of the thicker sizes called for in the plans.

(b) The south wall was an exterior wall as described in section 5.1.3.b except that the exterior siding was omitted and $1 / 2$-in thick wallboards were used instead of the $5 / 8$-in thickness shown in the plans. 
(c) The north wall was an "interior wall" as described in section 5.1.3(3).

All channels for the wall system were attached by power-actuated fasteners to the floor slab and the structural frame. Vapor seals and insulation between walls were omitted since these materials do not add to the strength of the structure. The omission of exterior siding on the south wall may have slightly decreased the stiffness of that wall, which would cause the test results to be lower than they might otherwise have been.

Each panel in the south wall contained a $5 \mathrm{ft} \times 7 \mathrm{ft}$ aluminum doorframe on its west side. This represents the least stiff condition that may be encountered in the field.

The western panel of the north wall contained a $3 \mathrm{ft} \times 7 \mathrm{ft}$ wooden doorframe on its east side. This simulates field conditions.

\subsubsection{Floor Slab}

The cast-in-place floor slab was poured on top of a vinyl sheet which was spread on the laboratory floor. The floor slab was subsequently post-tensioned against the laboratory floor by four 11/2-in-diameter bolts in order to prevent sliding due to lateral test forces applied to the structure. Tests indicated that the floor-slab concrete had a 17-day compressive strength of 5,600 psi. Slab reinforcement consisted of a 66-1010 mesh (ASTM-A185).

The slab was poured around the columns which were lined by $1 / 2$-in asphalt-impregnated fiberboard, thus forming full-depth pockets at the column seats to permit column rotation at the base. A $1 / 8$-in-thick neoprene sheet was inserted between the column base and the laboratory floor.

\subsubsection{Materials}

Standard compression tests (ASTM C33-66) were carried out on cylinders of concrete from the "cast-in-place" slabs and the precast members with the exception of the floor channels. In all cases concrete strength exceeded the strength specified in the plans.

Reinforcing bars were ASTM-A61 (60 ksi) steel wherever the plans permit the option of using 50 or $60 \mathrm{ksi}$ steel.

\subsection{Fidelity of Simulation of Field Conditions by the Test Structure}

Complete full-scale structures can be and have been tested in the field. While such field tests provide a means for the observation of the performance of a complete structure, it should also be noted that when compared with laboratory tests, field tests have many disadvantages. Some of the more obvious disadvantages are: cost; the time required to erect and test a full-scale structure in the field; changing conditions of temperature and wind; and the difficulty of precise application of loads and measurement of deformations. The major advantages of field testing are the ability to test an entire structure and a better simulation of foundation conditions.

For the case reported here, the entire test was performed inside the laboratory facilities of the National Bureau of Standards. Since it was impractical to erect a complete structure in the laboratory, it was decided to construct a portion of the structure and to test it in a manner that simulated the performance of the complete structural system. A lower-story section was selected, since lower-story components are subjected to the most critical loading conditions.

The load program to which the test structure was subjected is discussed in section 6 . The fidelity of the simulation is discussed in the following sections.

\subsubsection{Interaction Between the Test Structure and the Complete Structure}

Figure 5.2 illustrates the test structure as part of a comp?ete structure. The test structure with the testing equipment installed is shown in figures 5.26 and 5.27. In an actual building, the test structure would be connected to the remainder by:

(a) Columns,

(b) Abutting tie beams and main beams,

(c) A continuous topping slab, and

(d) Walls.

At all of these connections forces are exerted on the test structure, either by direct transmission of loads carried by the connected members or by restraining effects on motion of connected members. It is neither feasible nor necessary to simulate all these effects. Simulation of the most adverse conditions will generally lead to simplified approximations which are on the conservative side. Simulation of structural interaction at these four points of continuity is discussed in the following:

\subsubsection{Columns}

Upper-story columns will transmit to the beam-column connection most of the dead loads generated by the stories above and the live loads acting on these stories.

For the laboratory model it was assumed that the upper-story columns would transmit the following loads to the joint at their base:

(1) Dead loads of the upper stories. 
(2) Vertical live loads on the upper stories.

In reality the columns between the fire walls ivill also transmit a certain amount of horizontal wind-induced shear load. However, as will be noted later, in the presence of the partition walls, only a negligible amount of the total wind shear was carried by the columns. The wind shear from the upper stories was assumed to be calried by the walls to the top slab, which in turn will transmit the shear to the partition walls below.

It will also be noted later that some of the vertical loads are carried by the wall system directly into the foundations. The assumption that the entire vertical load is carried by the columns is a conservative assumption with respect to columns. The fact that the walls could potentially be mol'e highly stressed in the complete structure than in laboratory simulation does not appear to be of significance, since a wall failure by vertical loads would not occur without a simultaneous column failure. Column loads were applied vertically by rams at the center line of the lower-story columns as illustrated in figure 5.28. Roller's were inserted to roll in the direction of racking and to minimize frictional forces which might resist racking while vertical loads were applied.

It is recognized that upper-story columns would transmit moments as well as vertical loads, while the rams applied only axial vertical loads. It is demonstrated in Appendix B that this application of column axial loads is conservative.

\subsubsection{Abutting Tie Beams and Main Beams}

Main beams are discontinuous at both of their ends in the real structure, and this was correctly reflected in the test structure. Tie beams may be either continuous or discontinuous depending on their position in the structure. If tie beams were continuous on either or both sides of the test structure, this would result in increased load-carrying capacity and decreased deflections. Thus, it may be stated that with respect to structural continuity the test structure represents a conservative approximation.

\subsubsection{Continuty of Topping Slab}

In the complete structure, topping slabs may be continuous on three sides of the test section - west, north, and east- or on two adjacent sides of the test section. The severing of this continuity in the test structure represents a conservative approximation with lespect to both load-carrying capacity and deflection.

\subsubsection{Walls}

The wind load is imparted to the wall by
(1) shear along its upper connection to the beam above it, and (2) bearing of the windward column against the wall.

Since the floor system is very rigid in relation to beam column joints and walls, the horizontal forces acting above any floor are transmitted into this floor by the walls and in turn essentially equally distributed among the walls below this floor by a uniform displacement of the entire floor.

In the test structure, simulated wind loads equal to one-half the wind loads generated by the entire contributory portion of the threestory building were imparted at the end of each main or tie beam by a ram load, as illustrated by figure 5.26. In the case of the north direction, a wind load was also applied at the main beam on top of the column between the two fire walls. Due to the stiffness of the floor system, these wind loads have a net effect equal to the effect that may be expected on a structure in the field. The reason for applying only one-half of the wind force to each wall is the above-discussed assumption of great floor stiffness, which would distribute the wind load to two wall panels in the north direction and to more than two wall panels in the east direction.

Test results also indicate that the walls participate in the support of vertical loads. This was demonstrated by the fact that deflection of main beams connected to fire walls increased almost fivefold when these walls were removed. As will be noted later, the loading applied in Test No. 9 more than compensated for any adverse effect of vertical loads on the walls under service load conditions. Column loads were computed without regard to possible wall participation in load support. It is therefore concluded that the simulation of wall action adequately represented the most adverse conditions that may be expected in a complete structure.

\subsubsection{Simulation of Foundation Conditions}

Column foundations in the proposed building extend to a 6 -ft depth below grade for exterior columns, and $3-\mathrm{ft}$ depth below the top of the floor slab for interior columns (see fig. 5.23), Exterior column footings are also tied into the perimeter wall for added fixity. This configuration provides some degree of fixity at the column base, the degree depending on prevailing soil conditions.

In the test structure, the columns were "cut off" at the bottom of the floor slab. The lower ends of the columns were provided on all sides with a $1 / 2$-in-thick asphalt-impregnated fiberboard expansion joint against which the floor slab was cast. thus providing a detail similar to that of the real structure where a $3 / 8$-in premolded filler is placed around the 
column. The base of the column was set on a $1 / 8$-in-thick neoprene bearing pad which rested on the laboratory test floor. The resulting column connection permitted the column base to rotate, and therefore was a conservative simulation of the real structure, where the foundations provided partial column base fixity.

\subsubsection{Simulation of Live Loads}

Vertical live loads on the top slab of the specimen were simulated by air-bags which were held down by a suitable reaction system (see fig. 5.26). This created a uniformly distributed load which was able to follow the deflections of the slab. Air bags were made of 20-mil polyethylene and were designed to withstand 300 psf ( 7 times live load). The live loads applied represented a valid simulation of live load conditions as used in structural design.

Horizontal live loads were applied by horizontal 10-ton rams as illustrated in figures 5.26 and 5.29 .

The validity of wind load simulation has been discussed in section 5.3.1.d.

\section{Load Program}

\subsection{Introduction}

The load program in this test had three objectives:

(1) Evaluation of the structural adequacy of the proposed system and determination of its ability to satisfy the performance criteria established in section 4 .

(2) The acquisition of additional information about the behavior of complex structural systems and the interaction of their components.

(3) The development of suitable methods of performance testing for complex structural systems.

Section 6.2 explains the assumptions which were made with regard to the magnitude of applied live and wind loads and section 6.3 explains the load schedule. Load computations and the detailed sequence of loading used in each test, are presented in Appendix C.

\subsection{Applied Loads}

All applied loads were determined in accordance with "Minimum Design Loads in Buildings and Other Structures," USASI A58-1955 [11]." The following unit service loads were used:

\footnotetext{
5 Windloads for average Midwestern conditions were selected.

All tables mentioned in the text appear in the section beginning on p. 26.
}

Occupancy loads (floor) -40 psf

Snow loads (roof) $-30 \mathrm{psf}$

Wind loads (walls) - 20 psf

\subsection{Loading Schedule}

Figure 6.1 shows schematically how the test loads were applied to the structure. Table 6.1* explains the symbols used to represent the test loads and the magnitude of these loads. Table 6.2 summarizes the magnitude of test loads which represent the performance criteria.

Tests were conducted on the test structure with walls installed, and subsequently on the same structure after the walls were removed. All load tests were conducted between May 10, 1968, and May 22, 1968, and are listed hereafter.

\subsubsection{Tests Conducted on the Structure With Walls Installed}

Test 1: $\quad$ Column loads to $0.9 D$

Test 2: $\quad$ Column loads of $0.9 D$

South wind load to $25 \mathrm{psf}$

$(0.9 D+1.25 H)$

Test 3: $\quad$ Column loads of $0.9 D$

West wind load to $25 \mathrm{psf}$

$(0.9 D+1.25 H)$

Test 4: $\quad$ Column loads to $1.3 D+1.7 L$

Major floor load to $1.3 D+$ $1.7 \mathrm{~L}$

$(1.3 D+1.7 L)$

Test 5: $\quad$ Column loads of $1.3 D \div 1.7 \mathrm{~L}$ Major floor load of $1.3 D+$ $1.7 \mathrm{~L}$

Loads sustained for 24 hours $(1.3 D+1.7 L)$

Test 6: $\quad$ Column loads of $1.3 D+1.7 L$ Major floor load of $1.3 D+$ $1.7 \mathrm{~L}$

$(1.3 D+1.7 L)$

Test 7: $\quad$ Column loads of $1.3 D+1.7 L$

Major floor load of $1.3 D+$ $1.7 \mathrm{~L}$

South wind load to $15 \mathrm{psf}$

$(1.3 D+1.7 L+0.8 H)$

Test 8: $\quad$ Column loads of $1.3 D+1.7 L$

Major floor load of $1.3 D+$ $1.7 \mathrm{~L}$

West wind load to $15 \mathrm{psf}$

$1.3 D+1.7 L+0.8 H)$ 
Test 9: Column loads of $1 D$

Major floor load to $160 \mathrm{psf}$

$(1 D+3.5 L)$

Test 9-A: Column loads of $1 D$

Major floor load to 160 psf

Minor floor load to $160 \mathrm{psf}$

$(1 D+3.5 L)$

Test 10: Column loads of $0.9 D$

South wind load to 60 psf

$(0.9 D+3 H)$

Test 11: Column load of $0.9 D$

West wind load to $74 \mathrm{psf}$

$(0.9 D+3.7 H)$

6.3.2. Tests Conducted on the Structure After the Removal of Walls

Test 12: $\quad$ Column load of $1.3 D+1.7 L$

Major floor load to $1.3 \mathrm{D}+$ $1.7 \mathrm{~L}$

Rollers under column loads

oriented to permit sway in the east-west direction $(1.3 D+1.7 L)$

Test 12-A: Column load of $1.3 D+1.7 L$

Major floor load to $1.3 D+$ $1.7 \mathrm{~L}$

Rollers under column loads oriented to permit northsouth sway $(1.3 D+1.7 L)$

Test 13: $\quad$ Column load of $1.3 D+1.7 L$

Major floor load to $1.3 \mathrm{D}$ $1.7 \mathrm{~L}$

Minor floor load of $1.3 D+$ $1.7 \mathrm{~L}$

Rollers under column loads

oriented to permit east-west sway $(1.3 D+1.7 L)$

Test 13-A: Column load of $1.3 D+1.7 \mathrm{~L}$

Major floor load to $1.3 \mathrm{D}$ $1.7 \mathrm{~L}$

Minor floor load of $1.3 D+$ $1.7 \mathrm{~L}$

Rollers under column loads oriented to permit northsouth sway $(1.3 D+1.7 L)$

Test 14: Column loads of $0.9 D$

South wind load of $10 \mathrm{psf}$

$(0.9 D+0.5 H)$

Test 15: Column loads of $0.9 D$

West wind load of $16.5 \mathrm{psf}$

$(0.9 D+0.8 H)$
Test 16: Column loads of $1 D$

Major floor load of $280 \mathrm{psf}$ $(1 D+8.4 L)$

Test 16-A: Column loads of $1 D$

Major floor load of $370 \mathrm{psf}$

Minor floor load of $280 \mathrm{psf}$

$(1 D+6.3 L)$

Test 17:

Column load of 60 kips on four outer columns $(1 D+7 L)$

Test 18: Column load of $0.9 D$

South wind load of $10.5 \mathrm{psf}$

$(0.9 D+0.5 H)$

\section{Instrumentation}

A total of 98 electrical resistance instruments were used to monitor and record structural deformational behavior of the test model. These instruments are schematically located on figures 7.1 through 7.4 .

Figure 7.1, an isometric view taken from the southwest of the model, shows the location of load measurement and wall deformation instruments. The instrument numbers correspond to channel designation of automatic data-acquisition equipment. Instrument No. 90, a semiconductor strain-gage pressure transducer, recorded the pressure of the hydraulic system used in simulating column axial loads. Instrument No. 91 recorded the magnitude of horizontal loads. Initially this instrument was a load cell, but was subsequently replaced (after Test No. 5) by a pressure transducer. Instrument No. 91 was interchangeable in location, depending on the direction of horizontal forces. Instrument No. 92 was one of several secondary pressure transducers monitored during the tests to check horizontal force accuracy. Instrument No. 93, a pressure transducer, recorded the magnitude of uniformly distributed floor loads applied by air pressure.

Instruments No, M1 through M7 represent measurement devices employed to check load applications. These instruments were not connected to the automatic scanner, but were manually monitored. M1 and M7 represent pressure transducers located in the associated hydraulic system, while M2 through M6 were load cells attached to the jacking rams. For each test, the pertinent load instrument and deformation linear variable differential transducers (LVDTs) were also recorded by an automatic X-Y plotter.

The LVDTs in figure 7.1 recorded diagonal deformations of dry wall panels over the gage lengths shown. Gages No. 52, 54, 55, 56, and 57 designate LVDT's having readout intervals 
of $0.0001 \mathrm{in}$, while the remaining LVDT, gage No. 53, had an interval of 0.00001 in.

Figure 7.2 illustrates the northwest view of model instrumentation. Diagonal deformations were recorded by LVDT's No. 50, 51, 58, 59, 60 , and 61 , all with a $0.0001-i n$. readout interval. Horizontal deflections of the test structure were measuled by LVDT's No. 43, 44, 45, 46, and 47 with a readout interval of $0.0001 \mathrm{in}$.

Figure 7.3 is a plan view section showing vertical deflection transducer's located under the second floor of the test structure. In addition, two transducers (No. 48 and 49) were positioned horizontally on the center main beam to record any differential movement relative to the ceiling slab. In general, the vertical transducer readout interval was 0.0001 in, excepting transducers located adjacent to columns read to the nearest $0.00001 \mathrm{in}$. Transducer readings were also checked by a dial gage deflectometer capable of reading 0.0001 in, which was read visually.

Figure 7.4 shows the location of 40 type A3 electrical resistance strain gages used to measure column concrete strains. The readout increment of these strain gages was $1 \mu \mathrm{in} / \mathrm{in}$ (i.e., $0.000001 \mathrm{in} / \mathrm{in}$ ).

Calibration of load cells, pressure transducers, and deflection transducer's was performed prior to testing of the structure.

Data-acquisition equipment included a 100channel and a 50-channel automatic electronic scanner and digital recorder. Instrument readings were taken at predetermined load increments. The output data was subsequently keypunched and reduced by electronic computer.

Dial gages were also used to check against possible slip of the test structure floor slab relative to the laboratory floor slab. No such slip was observed.

\section{Results}

A total of 18 load tests were carried out on the laboratory structure. Of these, 17 involved extensive measurement and recording of loads and structural deformation. The remaining test was run simply as a proof test on column capacity.

Tests No. 1 through No. 11 were performed on the model of the total building system. Tests No. 12 through No. 18 (see section 6.3) were carried out on the system with wall panels removed.

Instrument locations are shown in figures 7.1 through 7.4. The instruments recorded loads and deformations for seventeen tests. Generally each instrument was read inmediately after the attainment of the respective increment of applied load. Reading and recording of clata was in general accomplished through the use of an automatic data-acquisition system which recorded results in digital form on printed paper tape. Total acquisition time for each set of readings consisting of all data for one load increment was somewhat less than two minutes. The data was then manually key-punched onto cards, and was automatically reduced, analyzed, and plotted by electronic computer. Approximately 40,000 measurements were thus recorded.

Computer output consisted of a complete tabulation of results, and curves of measured deformations plotted against applied load. In all, more than 2000 curves were plotted. In addition to the clata acquired by the automatic digital system, a continuous plot of critical deflection parameter versus applied load was maintained for all tests by an automatic X-Y plotter. This was used along with mechanical dial gages to provide a secondary and independent check on proper functioning of the automatic equipment.

After checking computer output for keypunching errors and malfunction of instrumentation, the results were reviewed to select the more significant information. The most pertinent results are presented and discussed in section 9; additional results are contained in Appendix A as figures. A.1 through A.77.

Each figure of Appendix A is a plot of applied load versus the model deformation as measured by the relevant instrument. The output channel number noted in the figure caption corresponds to the instrument number shown on figures 7.1 through 7.4 .

The ordinate of each curve indicates the variable load. Load symbols are defined in section 3. The abscissa indicates deformation, where zero deformation is chosen prior to any load application. Thus in tests where an initial constant load is introduced, the abscissa indicates the deformation due to both the constant load and variable load.

All vertical deformations were measured relative to the structural test floor, thus beam deflection measurements include column shortening, and slab deflection measurements include support movement.

Column concrete strain data have been excluded due to the erratic behavior of these strain gages. Columm gages were located 6 in from column ends. Their erratic behavior is attributed to the proximity of joint connections and to the relatively large quantity of steel used in connecting column end hardware to longitudinal reinforcement. 


\section{Interpretation of Results}

\subsection{Introduction}

The purpose of this section is to discuss the compliance of the structural system with the performance criteria in section 4, the structural behavior under loads, and the interaction of structural components.

It should be noted that all conclusions pertaining to structural performance are based on the structure as built in the laboratory and on erection methods and materials used therein. Variation in materials or erection methods may significantly affect structural behavior.

Data pertinent to the discussion in this section are presented in figures 9.1 thru 9.23.

\subsection{Vertical Forces}

Vertical forces were applied to the structure in the form of column loads $(P)$, distributed floor loads between the columns $\left(w^{\prime}\right)$, and distributed floor loads on the cantilever section of the second floor along the north side of the structure $\left(w^{\prime}\right)$. (For location and magnitude of applied vertical loads, refer to fig. 6.1 and tables 6.1 and 6.2.)

Vertical loads were applied in all tests. In some of the tests they were applied along with horizontal loads in order to eviluate structural response to horizontal loads combined with vertical loads. Other tests were performed for the sole purpose of evaluating structural response to vertical loads. Details of all loading sequences have been discussed in section 6 .

\subsubsection{Structural Response to Vertical Loads}

\subsubsection{General}

Figure 9.1' shows the load deflection history of the midspan of the center main beam under the application of a load of $1.3 D+1.7 L$ to the columns and main floor section. This figure also shows the effect of sustaining this load for $24 \mathrm{hr}$ and the subsequent recovery of deflections $24 \mathrm{hr}$ after removal of all loads. Deflections at one of the supports of this beam due to the same loading are also shown to permit evaluation of the order of magnitude of the "net deflections" as well as the column deflection. Examination of all test data indicates that from the point of view of magnitude of vertical deflections, this curve illustrates the most critical point in the structure.

In this figure and several of the others used in this chapter. for the sake of clarity, individual data points and the data obtained during the several intermediate cycles of unloading and reloading have not been shown. However, these results are included on figures Al through A.77 of Appendix A
The following observations can be made concerning midspan deflection of the center main beam under the application of a load of $1.3 D+1.7 L$ and its subsequent maintenance for $24 \mathrm{hl}$ (fig. 9.1):

(1) The increasing load-deformation curve for the load application portion of the cycle was reasonably linear, indicating elastic behavior;

(2) The $24 \mathrm{hr}$ creep amounted to less than $0.02 \mathrm{in}$, which is only 7 percent of the permissible cleflection set forth as a performance criterion and about 13 percent of the total observer deflection;

(3) Observed recovery was 96 percent (note that most of the creep deflection was recovered)

Figure 9.2 shows the plot of midspan deflection of the center main beam during the application of a $370 \mathrm{psf}$ load $(1 D+8.4 L)$ to the main floor span after removal of the walls from the test structure (Test 16). This load was applied after the application of $1 D+1 L$ to the columns. This test was designed to be a destructive test of the floor system of the structure; however, the capacity of the loading system (designed for 300 psf) was reached before failure of the test structure. The deflection at one of the beam supports is again plotted on this figure to illustrate the order of magnitude of the "net" deflections. Also shown is the curve for the center beam midspan deflection obtained in Test 9 before the removal of walls. In Test 9 the maximum applied floor load was 160 psf $(1 D+3.5 L)$. It is interesting to note the substantial reduction in stiffness against gross vertical deflection resulting from the removal of the walls from the system.

Two definite slope changes are evident in the curve for the midspan deflection of the structure without walls, one at 120 psf and one at 270 psf. A change in slope similar to that taking place at 120 psf is not evident in the curve for the structure with walls. It is felt that this change was probably due to some slippage at the beam column connection and was apparently of minor consequence in terms of structural performance.

The break which is evidenced at $270 \mathrm{psf}$ is more marked. At this load, diagonal tension cracks were observed close to the beam supports (fig. 9.3). Since there are stirrups in the beam (figs. 5.8 and 5.9) and since the curve shows that the structure was capable of carrying substantial additional load, this point may represent a transfer of shear stresses to the stirrups. The structure was subsequently loaded to 370 psf $(1 D+8.4 L)$ without additional signs of distress.

Both figs. 9.1 and 9.2 illustrate the case of interior span loading (load " $w$ " acting alone), since this appeared to be the more critical 
loading configuration. The relative influence of these two loading patterns is illustrated by figure 9.4, which shows center main-beam midspan deflection for 'Test 9 with interior loading (w) alone, and Test $9 \mathrm{~A}$ with interior and cantilever loading $\left(w+w^{\prime}\right)$. As would be expected, the "w" loading is more critical in ter'ms of deflection; however, only slightly so.

\subsubsection{Influence of Walls}

The influence of the walls on structural response to vertical loads is illustrated in figures 9.2 and 9.5 . Figure 9.2 compares deflections at midspan of the center main beam in Test 9 with walls, and Test 16 with walls removed. These tests had identical loading and the comparison is probably valid, although the structure may have been weakened somewhat before Test 16 by earlier tests. The location at which deflections are compared in this figure reflects the behavior of the entire structure, since most members will make some contribution to the midspan deflection. These figures indicate that the structure with the walls removed had about twice the deflection of the complete structure.

Figure 9.5 compares deflections with and without walls at the position which is likely to be most sensitive to walls; namely, the center of the west main beam which rests on a fire wall. As expected, the influence of the walls is even more marked in this case. The deflection at maximum load without walls is approximately 5 times the deflection with walls. It is thus evident that the walls contribute significantly to the support of vertical loads.

\subsubsection{Slip Between Main Beams and Topping}

Devices which were capable of measuring the slip between the center main beam and the channel slabs were monitored during all tests. These were installed as a means of measuring any differential shear movement between the topping slab (which forms the compression flange of the main beams) and the precast element which forms the tension flange. In none of the tests was there any indication of relative slip between these two components. Neither was there any visual sign of relative slip, even in Test 16 (fig. 9.2) with a load of $1 D+8.4 L$.

9.2.1.4. Translation Due to Vertical Loads (Walls Removed)

This aspect of the structural response of the frame was investigated in Tests $12,12 \mathrm{~A}$, 13 , and $13 \mathrm{~A}$, in which the floor was alternately loaded over its main span alone $(w)$ and its main span plus the cantilever span $\left(u+u^{\prime}\right)$, with roller's oriented first to roll in the northsouth direction and then in the east-west direction. The results of these tests are shown in figures 9.6 and 9.7. In each case the order of magnitude of lateral displacement under a load of $1.3 D+1.7 \mathrm{~L}$ on the columns and flool was between 0.06 in and 0.08 in and residual displacements were of the order of $0.01 \mathrm{in}$.

\subsubsection{Compliance With Performance Criteria, Vertical Loads}

\subsubsection{Performance Criterion 4.4.3, Vertical Deflections Under Service Live Load}

At a load level of $1 D+1 L$ the vertical deflections due to the superimposed load of $1 \mathrm{~L}$ shall not exceed the following:

$d v \leq \frac{l}{480}=\frac{144 \mathrm{in}}{480}=0.30 \mathrm{in}$.

where: $d v=$ vertical net deflection.

Under vertical loading of $1 D+1 L$, the most critical vertical deflection in the test structure occurred at the midspan of the center main beam. Figure 9.4 illustrates test No. 9 plotting total vertical deflection at midspan of the center main beam together with total vertical deflection at one of the column supports of the same beam. The vertical net deflection will be the difference between the midspan deflection and the deflection of the beam support. Figure 9.4 illustrates that at the level of $1 D+$ $1 L$ the critical vertical net deflection was 0.04 in, which is considerably less than the permitted 0.30 in net deflection.

Criterion 4.4..) wes therefore satisfied.

\subsubsection{Performance Criterion 4.4.4, Sustained Load} Deflections

At a load level of $1.3 \mathrm{D}+1.7 \mathrm{~L}$, sustained for 24 hours, deflections due to the superimposed load of $0.3 D+1.7 L$ shall not exceed the following:

$$
\begin{aligned}
& \text { (a) } d v \leq \frac{l}{360} \times \frac{0.3 D+1.7 L}{L}= \\
& \frac{144 \mathrm{in}}{360} \times \frac{100 \mathrm{lb}^{-}}{43 \mathrm{lb}}=0.93 \mathrm{in} \\
& \text { (b) } D h \leq 0.002 h=0.002 \times 94 \mathrm{in}=0.19 \mathrm{in}
\end{aligned}
$$

Residual deflections, measured within 24 hours after removal of loads, shall not exceed the following:

(c) If $d v>\frac{l^{2}}{20,000 t}, \mathrm{~d} v r \leq 0.25 d v$;

$$
\begin{gathered}
\text { if } d v \leq \frac{l^{2}}{20,000 t}, d v r \leq \frac{l^{2}}{80,000 t}= \\
\frac{144 \mathrm{in}}{80,000 \times 9.5}=0.03 \mathrm{in}
\end{gathered}
$$

(d) $D v r \leq d v r+0.25(D v-d v)$

\footnotetext{
i $100 \mathrm{lb} / 43 \mathrm{lb}$ represents the ratio of the simulated floor load used in this test to the simulated floor load corresponding to $1 \mathrm{~L}$.
} 
where:

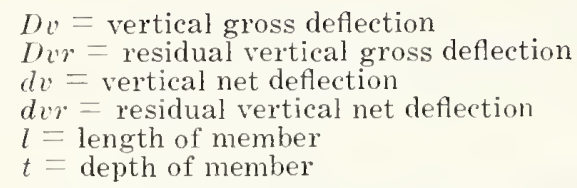

(a) Under the vertical loading of $1.3 \mathrm{D}$ $1.7 \mathrm{~L}$ sustained for $24 \mathrm{hr}$ the midspan of the center main beam exhibited the largest net vertical deflection $\left(d t^{*}\right)$. This deflection was less than 0.10 in (see fig. 9.1). The net deflection $\left(d v^{*}\right)$ should be taken as the total deflection $\left(D i^{\prime}\right)$ less the support deflection. Unfortunately, during the sustained-load portion of this test, the instruments measuring the support deflection malfunctioned and there is thus no complete record of the beam support deflection. Thus, only the short-term portion of this deffection has been subtracted to obtain $d v$. The maximum measured $D i$, which was $0.14 \mathrm{in}$, is considerably less than the 0.93 in allowed by Criterion 4.4.4(a).

(b) The horizontal deffections, which were measured under vertical loads acting alone both with and without walls, were extremely small. In all cases they were less than 0.08 in under $1.3 D+1.7 \mathrm{~L}$ on the floor and columns. (See figs. 9.6 and 9.7.) This is considerably less than the 0.19 in permitted by Criterion 4.4.t (b)

(c) Figure 9.1 shows the residual deflection Dir to be approximately $0.005 \mathrm{in}$, which is considerably less than the residual deflection permitted by Criteria 4.4.4.(c) and 4.4.4(d), which is $0.03 \mathrm{in}$.

Criterion 4.4.4 was therefore satisfied.

9.2.2.3. Performance Criterion 4.4.5, Ultimate Strength

The structure or any portion thereof shall not fail at a load smaller than the following:

(a) $1.25(1.5 D+1.8 L)=w=145 \mathrm{psf}$.

The structure was capable of carrying a load of 370 psf without experiencing failure (fig. 9.2)

$$
\text { Criterion 4.4.5 (a) was thereforr sutisfied. }
$$

\subsection{Horizontal Forces}

Horizontal forces were applied to the structure in the form of the horizontal loads $H M$, $H s$ and $H s^{\prime}$ (see fig. 6.1 and tables 6.1 and 6.2). Racking tests were conducted in the north and the east direction with and without walls. The results of these tests are described and evaluated in the following sections.

\subsubsection{Horizontal Loads in the North Direction}

In the north direction racking of the structure is resisted by the firewalls.

\subsubsection{Racking Tests Wití Minimum Vertical Loads}

These racking tests were conducted with a superimposed column load of $0.9 \mathrm{D}$ acting alone. The results of the racking test in the north direction are illustrated in figure 9.8. This figure shows lateral deflection measured at the level of the second floor of the test structure. Loads were applied to simulate a wind pressure of 25 psf acting from the south. It may be noted from this figure that while overall deflection was small (0.091 in), recovery was also small. Figure 9.9 shows the results of a later racking test which was carried to an equivalent of $60 \mathrm{psf}$ wind load. These two tests are simultaneously plotted in figure $9.10^{\circ}$ and show good agreement.

Figure 9.11 shows a plot of south wind load versus diagonal compressive deformation measured on one of the fire walls. The diagonal shown in this figure was measured over a gage length of 147 in. The resultant unit strain at a wind load of $25 \mathrm{psf}$ is $0.000073 \mathrm{in} / \mathrm{in}$ and at a wind load of $60 \mathrm{psf}$ it is $0.000250 \mathrm{in} / \mathrm{in}$, which is extremely small. It is interesting to note from this figure that the recovery of the walls was good for all levels of load. No signs of distress were observed in the walls or other parts of the structure during Test 2 in which a wind load equivalent to $25 \mathrm{psf}$ was applied. However, at the upper limit of Test 10 at a wind load equivalent to $60 \mathrm{psf}$, some distress appeared in the form of bowing out (buckling) in compression areas near the corners of the wall panels. These signs of distress disappeared upon removal of the lateral load. After removal of the walls all connections between the walls and the frame were found to be in good condition, showing no dislocation of screws or anchorage devices. During Test 10 there was some opening up of the joints between the columns and the wall panels in regions which would normally be subjected to tension by the development of diaphragm action in the walls. These openings were all less than $1 / 8$ inch in width and tended to close partially upon removal of the load.

\subsubsection{Racking Tests at High Vertical Loads}

In Test 7 the columns and floor were loaded to $1.3 \mathrm{D}+1.7 \mathrm{~L}$ and a $15 \mathrm{psf}(0.8 H)$ south wind load was applied to the structure. The results

Only a portion of the test to 60 psf is shown here, since it exceeds the sitale of this figure. 
of this test are illustrated in figure 9.12. This test is also plotted in figure 9.13 along with Test 2 which had $0.9 \mathrm{D}$ and $25 \mathrm{psf}$ wind load. The agreement between these two tests is good. The structure experienced a considerably larger lateral drift under the application of the larger vertical load acting alone than it did under the smaller vertical load ( 0.024 in versus 0.007 in $)$. Under the subsequent wind-load application the structure with the larger vertical load exhibited greater stiffness than it did when more lightly loaded. At the point where the 15 psf wind load was reached, the two deflections were approximately equal ( $0.050 \mathrm{in})$.

\subsubsection{Frame Action Versus Wall Action}

The frame was racked after removal of the walls in Test No. 14. Results are illustrated in figure 9.14. This test is compared with an identical racking test performed before removal of the walls in figure 9.10. This comparison clearly indicates that a major portion of the lateral stiffness is provided by the walls rather than by the frame.

Figure 9.15 shows the results obtained in a later racking test (Test 18) on the structure with walls removed. This test was carried to the point where the frame no longer developed increasing resistance to load. In this test the structure had a vertical load on the columns of $0.9 \mathrm{D}$. In interpreting these results it must be remembered that the wind load reported here is in pounds per square foot of total vertical surface area of the structure. If none of the walls are present, then the surface area upon which the wind forces act is also not present. However, it is also conceivable that a situation could develop in which walls in one direction are present while walls in the opposite direction are absent. In such a case these results would have relevance. Figure 9.15 indicates that the frame acting alone in the north direction cannot be expected to withstand a wind force in excess of $10 \mathrm{psf}$ on the gross area of the structure. By the time this test was performed the structure had been carried through a number of earlier tests which might have somewhat weakened the frame. However, the structure at this point exhibited no obvious signs of distress attributable to earlier testing. It is recognized that the simulation of the column foundation which was used in the test structure was extremely conservative compared to that used in the real structure, particularly with respect to tests without walls. Thus the results of this test possibly fall well below the results which would be obtained from the test of a real structure.

\subsubsection{Horizontal Loads in the East Direction}

West wind forces in the test structure were resisted by one interior "structicore" rvall and one exterior wall. These walls would not normally be expected to be as strong as the fire walls; however, their rigidity in the lateral load tests appeared to be comparable to that of the fire walls. Both of the walls in this direction had openings; however, these walls also had a greater overall length resisting load.

\subsubsection{Racking Tests With Minimum Vertical Loads}

These racking tests were conducted in the same manner as in the south direction (sec. 9.3.1.1). Figure 9.16 illustrates Test 3 , which subjected the structure to $0.9 \mathrm{D}$ plus $25 \mathrm{psf}$ wind load from the west. In this test, measured deformations were extremely small (0.012 in). Recovery characteristics were similar to those observed for the fire walls. There appear to be two breaks in the load-deflection curve (fig. 9.16 ), one at $10 \mathrm{psf}$ and the other at $24 \mathrm{psf}$. Neither of these was accompanied by any visual signs of distress in either the concrete frame or in the gypsum walls. Figure 9.17 shows the results obtained from a racking test (Test 11) carried to a wind load in excess of $70 \mathrm{psf}$. A portion of this test, along with the results of Test 3 , is shown in figure 9.18. It is interesting to note that a definite break developed in the load-deflection curve of Test 11 at $6 \mathrm{psf}$; again, this break was not associated with any visual signs of distress. These breaks in the load deflection curve are not considered to be particularly significant since, for example in Test 11 , even at a wind load of 25 psf the lateral drift of the structure is still less than 0.04 in. Figure

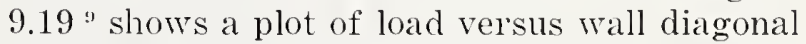
compressive deformation for a wall resisting west wind load during Test 11, which was carried to $74 \mathrm{psf}$. As was the case for the walls resisting south wind load (fig. 9.10) deformations and correspondingly average strains were extremely small and recovery was good. In this test, distress in the wall was not noted until the very upper range of the loading sequence was reached. At these loads distress was observed in the interior (north) wall in the form of shear cracks (fig. 9.20). However, no noticeable distress was observed in the wall-frame connections. Some progressive opening of the joint between the wall planels and the columms was observed at loads in excess of $35 \mathrm{psf}$ but the separation was not particularly pronounced and was similar to that discussed in section 9.3.1.1.

"The erratic behavior noted in the first unload-reload cycle was lue to a stuck instrument which was subsequently freed. 
9.3.2.2. Racking Test at High Vertical Loads

A racking test was performed in the east direction in Test 8 with $1.3 D+1.7 L$ and 15 psf wind load. The results of this test are illustrated in figure 9.21. It should be noted that the application of the vertical loads caused a horizontal deflection in the opposite direction to that in which the wind loads were subsequently applied. This deflection, resulting from the vertical loads, was only partially reversed by the application of the $15 \mathrm{psf}$ wind load. Test 8 $(1.3 D+1.7 L)$ is plotted along with Test 3 $(0.9 D)$ in figure 9.22. It can be seen that in either case the deformations due to lateral loads are so small as to make questionable any conclusions concerning the effect of the magnitude of vertical load on lateral stiffness.

\subsubsection{Frame Action Versus Wall Action}

Figure 9.16 (Test 3) shows the response of the structure with walls to racking in the east direction, while figure 9.23 (Test 15 ) shows the response of the structure after removal of the walls. Both of these curves are plotted together in figure $9.18^{10}$. As was the case in the north direction, it is evident that in the east direction the walls provide most of the stiffness against lateral loads.

In designing the test sequences to which the structure was subjected, it was felt that only one meaningful racking test could be carried through to the point at which the structure was approaching collapse. The north direction, which is the narrow direction for this system, was chosen for this test and its results were reported earlier (Test 18) in section 9.3.1.3. In the east direction the maximum load to which the frame without walls was subjecter was applied in Test 15, which is shown in figure 9.23. In this test the frame resisted a wind load in excess of $15 \mathrm{psf}$ without collapse, although some minor flexural cracks were observed in the columns at maximum load. This load level was substantially higher than that sustained in the racking test without walls in the north direction. The conservative nature of the foundation simulation in the test structure, which provided a hinge at the lower column connection, undoubtedly affected the results obtained in this test in an adverse manner.

\subsubsection{Compliance With Performance Criteria, Horizontal Loads}

9.3.3.1. Performance Criterion 4.4.1, Horizontal Deflection Under Dead and Wind Loads

At a load level of $0.9 D+1.1 H$ the horizontal deflection due to the superimposed load of $1.1 H$ shall not

\footnotetext{
${ }^{10}$ Only a portion of Test 15 is shown on this figure because of the scale.
}

exceed the following:

$D h \leq 0.002 \mathrm{~h}=0.002 \times 94$ in $=0.19 \mathrm{in}$

where:

$D h=$ horizontal gross deffection

h = height above grade.

In Test 2 (fig. 9.8) under $0.9 D$ and a wind load of 22 psf $(1.1 H)$ from the south, the maximum lateral drift was approximately $0.073 \mathrm{in}$, and in Test 3 (fig. 9.16) with a west wind load the maximum lateral drift was approximately $0.007 \mathrm{in}$, while the allowable drift under this criterion is $0.19 \mathrm{in}$.

\section{Criterion 4.4 .1 is therefore satisfied.}

\subsubsection{Performance Criterion 4.4.3, Horizontal Deflection Under Dead, Live, and Wind Load}

At a load level of $1.3 \mathrm{D}+1.7 \mathrm{~L}+0.8 \mathrm{H}$ the horizontal deflection due to the superimposed load of $0.3 D+$ $1.7 \mathrm{~L}+0.8 \mathrm{H}$ shall not exceed the following:

$$
D h \leq 0.002 h=0.19 \text { in }
$$

In Test 7 (fig. 9.24) under $1.3 D+1.7 L$ and a wind load of $15 \mathrm{psf}(0.8 H)$ from the south, the maximum lateral drift was 0.045 in and in Test 8 (fig. 9.20) with a west wind load the maximum lateral drift was $0.032 \mathrm{in}^{11}$, while the allowable drift under this criterion is $0.19 \mathrm{in}$.

$$
\text { Criterion 4.4.2 is therefore satisfied. }
$$

\subsubsection{Performance Criterion 4.4.5(b), Ultimate Strength}

The structure or any portion thereof shall not fail at a load smaller than the following:

(b) $0.9 D+1.4 H,(28$ psf wind load).

The structure was tested under these loading conditions in the north direction and in the east direction in Tests 10 and 11 respectively (see figs. 9.9 and 9.17). No distress was experienced in either test at that load level.

Criterion 4.4.4.(b) is therefore satisfied.

\subsection{Summary}

(1) All conclusions pertaining to the structural performance of the system in question are based on the structure as built in the laboratory and on the erection methods and materials used therein. Variations in materials and erection methods may influence performance.

(2) The building system satisfied the performance criteria which were set for its evaluation with substantial margin. As a system, it exhibited strength and stiffness in excess of service and ultimate load requirements.

\footnotetext{
11 In Test 8 the maximum drift was measured upon the application of the vertical load and took place in the opposite direction to the wind-induced deflection. If these two had been in the same direction rather than opposite, the maximum deflection would have been approximately 0.04 in.
} 
(3) The walls of the system behaved as an integral part of the structure. They provided most of the stiffness of the system with respect to lateral loads, and provided a significant portion of the stiffness against vertical loads.

(4) The building system with its walls removed had considerable reserve strength above the required vertical load bearing capacity; however, without the aid of its walls it was not capable of resisting the required service wind loads.

\section{Component Tests}

\subsection{Introduction}

Load tests were conducted on the three principal precast load-bearing components of the structure. The components tested were columns, main beams with an appropriate portion of the topping slab connected to them, and a floorchannel slab. These tests were performed to determine the behavior and ultimate strength of the components. Included were tests to determine the effects of creep on the columns and repeated loading on the beams.

\subsection{Column Tests}

The column specimens tested were typical "short"12 columns as shown in figure 5.6. Reinforcement was $60 \mathrm{ksi}$ steel. Actual outside dimensions and concrete cover of individual test specimens are shown in table 10.1. Values of concrete strength of the various specimens are reported in section 10.2.1.1. The tests consisted of the following:

(1) Short-term destructive loads were applied parallel to the column axis. Four columns were tested with an eccentric load on the major axis and three with an eccentric load on the minor axis.

(2) Two sustained-load tests were carried out: one with an eccentric load on the major axis, the other with an eccentric load on the minor axis.

The method of applying the eccentric loads to the columns is shown schematically in figures 10.1 and 10.2. The same method was used for both the short-term and the sustained-load tests.

${ }^{12}$ The term "short" column is applied in the plans to a column with end fixtures at both ends. This column in the structure has the same slenderness ratio as all other columns.

\subsubsection{Short-Term Destructive Tests}

\subsubsection{Specimens}

Seven columns were tested to destruction, three with a load eccentricity of 0.5 in on the minor axis $(e / t=0.1$ for columns 1,5 , and 8$)$, three with a load eccentricity of 2.0 in on the major axis $(e / t=0.33$ for columns 2,6 , and 7 ), and one with a load eccentricity of 1.5 in on the major axis (e/t $=0.25$ for column 9$)$.

Columns 1 and 2 were cast at the same time as the test structure components (April 16 and 17,1968 ) and from the same concrete, with concrete compressive strength $\left(f^{\prime} c\right)$ ranging from 4900 psi to 7200 psi (see table 11.1). These specimens were approximately 20 days old when tested. Columns 5, 6, 7, 8, and 9 were cast from similar concrete at a later date (May 15). Columns 5, 6, 7, and 8 were approximately 30 days old when tested and the concrete had a compressive strength of approximately 5400 psi. Column 9 was 60 days old when tested and the concrete compressive strength was $7000 \mathrm{psi}$.

The longitudinal reinforcing bars (No. 6 deformed bars) were approximately 3 in shorter than their full required length in Columns 1 and 2 , leaving a distance of about $11 / 2$ in between reinforcing bars and end fixtures, but in columns $5,6,7,8$, and 9 these bars were only $1 / 4$ in shorter.

\subsubsection{Loading}

The loads were applied continuously until failure, through a knife-edge loading plate (figs. 10.1 and 10.2 ) by a $600,000-1 b$ hydraulic testing machine at a rate of $8,000 \mathrm{lb}$ per minute. Deflections were measured with longthrow mechanical dial gages at mid-height. Figure 10.3 illustrates a typical test setup.

\subsubsection{Results}

Test results are shown in figures 10.4 through 10.10 as load-deflection curves. Ultimate loads are tabulated in table 10.2. The average maximum load for columns 1,5 , and 8 (minor axis bending, $e=0.5 \mathrm{in}$ ) was $78.9 \mathrm{kips}$. Figure 10.11 shows these columns after testing. Column 1 failed near its end connection, and its mode of failure appeared to be partially due to the short reinforcement used. Columns 5 and 8 (which had longer reinforcement) experienced compression failures in the concrete at mid-height at about 12 percent higher loads than did column 1.

The average maximum load for columns 2, 6 , and 7 (major axis bending, $e=2.0 \mathrm{in}$ ) was 51.2 kip. All three specimens failed in a similar manner, as illustrated in figure 10.12, with excessive bending of the channel-shaped, 
top-fixture and some spalling of the concrete near this fixture.

The maximum load for column 9 (major axis bending, $e=1.5 \mathrm{in}$ ) was $89.5 \mathrm{kips}$. This column failed by concrete compression at mid-height.

\subsubsection{Sustained Loading (Creep) Tests}

\subsubsection{Specimens}

Two columns (columns 3 and 4 ) were tested under a 25 kip sustained load. Both columns were cast with the test-structure components and were about 20 days old when placed under load. Concrete compressive strength ranged from 4900 psi to $7200 \mathrm{psi}$ (see table 11.1).

\subsubsection{Loading}

The loading frames used in these tests are shown in figures 10.13 and 10.14 . Column 3 had a load eccentricity of 0.5 in on the minor axis $(\rho / t=0.1)$, and column had a load eccentricity of 2.0 in $(e / t=0.33)$ on the major axis. A detail of the bottom of the column 4 loading frame is shown as figure 10.15. This figure also shows the heavy spring used to sustain the load on the specimen.

The 25 kip load $(1 D+1 L)$ was applied by means of a 30-ton hydraulic ram and a load cell inserted between the top two plates of the test frame. The ram load was applied through the column to the spring, causing the spring to compress. Once the required load was applied, nuts on the $: / 1$-in tie-bars were tightened against the top knife-edge plate. The deflection of the springs was about $11 / 2$ in at the $25 \mathrm{kip}$ load. The loads were checked and adjusted periodically.

Mid-height deflections were measured by means of a taut wire and a mirrored scale. The progression of the deflections with time was measured periodically.

\subsubsection{Results}

Results of a 170-day observation period are presented in figures 10.16 and 10.17 as timedeflection curves. The initial deflections are included in the total deflection for information and comparison purposes.

\subsubsection{Interpretation of Column Test Results}

10.2.3.1. Short-Term Destructive Tests

Figure 10.18 shows a plot of test results for columns with major axis load eccentricity, together with computed interaction curves for both the column cross section and the overall column slender'ness effects. This figure also shows interaction curves derived from performance criteria for lower-story columns.
Curve $C$ is the locus of extreme values of combined axial loads and end moments which the columns must be able to resist in the direction of their major axis. Critical loading conditions for columns were found to be $1.5 \mathrm{D}+$ $1.8 L$ and $1.25(D+L+H)$. The actual points plotted for these component requirements correspond to $1 / 0.8$ times the critical loading, where 0.8 represents an understrength factor. The requirement here is similar to that explained in the commentary to section 4.4 .5 of this report; namely, that in the absence of a laboratory sample of large size, individual columns are required to exhibit a strength in excess of their ultimate loading requirement. The ultimate moment imposed on the column by wind load was assumed to be $1 / 7$ of the computed ultimate moment imposed on the frame in the absence of walls. This assumption is based on the test results illustrated in figure 9.10, which compares horizontal wind deflections of the total system to these of the system with walls removed. Curve $A$ of figure 10.18 is a theoretical interaction diagram for crosssectional capacity, computed for the combinations of vertical load and moment which would cause failure in columns with a concrete compressive strength of $7,000 \mathrm{psi}$, which was the concrete compressive strength of column 9. Curve $B$ is a similar interaction curve for the specified concrete compressive strength of 4,500 psi.

The total maximum moment acting on a column is the end moment plus an additional moment which equals the product of the applied vertical load times the maximum deflection of the column. To determine the combination of maximum axial load and maximum end moment that can be imposed on a column at its supports, the maximum column moment in interaction curves $A$ and $B$, which represent the total cross-sectional capacity of the columns, must be reduced by the value of $P \times d h$, which is the product of axial load and maximum column net deflection at column failure. Curve $B^{\prime}$ has been plotted to account for this moment reduction at the specified concrete compressive strength of 4,500 psi. ${ }^{13}$ Curve $B^{\prime}$ is therefore the interaction curve of ultimate loads and ultimate end moments which a column, constructed in accordance with the plans and specifications for this system, should be theoretically expected to resist. It may be noted by comparing Curves $B^{\prime}$ and $C^{\prime}$ that the theoretical column capacity exceeds the required critical loading by a considerable margin.

1." Values of $\mathrm{P} \times$ dh were computed in accordance with "Proposials for Revision to Sections 915 and 916 of ACI 318-63" by MacGrexor, Breen, and Pfrang (unpublished). These computations ncounted for concrete cracking. 
The actual column tests for loads with major axis eccentricity are also plotted in figure 10.18. It will be noted that each specimen test is plotted twice. The triangular points represent a plot of the axial load at failure against the end moment caused by the axial load times its eccentricity.

The square points represent a plot of the axial load at failure against the maximum moment that actually existed in the specimen at failure. This actual maximum moment is the product of the axial load times the sum of its end eccentricity and the maximum center line deflection at failure. It should be noted that in a slender column such as the specimens tested the maximum center line deflection is relatively large (Refer to figures 10.4 through 10.10).

Only column 9 failed by compression at midheight. Column 9 had a concrete strength of $7,000 \mathrm{psi}$, and it can be seen that this column developed strength slightly in excess of the strength predicted by interaction curve $A$. Columns 2, 6, and 7 failed at their top fixture and therefore did not develop their theoretical ultimate strength. In column 2 the reinforcement was 3 in short. This was corrected in columns 6,7 , and 9 , without appreciable effect on columns 6 and 7 . To evaluate column strength in terms of component requirements the triangular plots of the test results should be compared with curve $C$. It may be noted that all the tested columns had considerable excess strength over the component requirements.

Results for columns tested with minor axis eccentricity are plotted in figure 10.19. Interaction curves $A, B$, and $B^{\prime}$ are plotted as in figure 10.18 , except that in this figure they represent relationships for loads with minor axis eccentricity, and curve $A$ was computed for a concrete compressive strength of 5,400 psi. Columns 5 and 8 experienced a compression failure at mid-height, and show strengths close to the theoretical strength predicted by interaction curve $A$, which was computed for 5,400 psi concrete (the actual strength of the concrete in these columns). Column 1 failed near its top fixture, and this mode of failure may have been caused by the fact that the reinforcement was 3 in short. In the case of minor axis eccentricity, no sizable end moments are expected to act on the columns, since the tie beams do not participate in the support of vertical loads to an appreciable extent. All columns tested at a minor axis eccentricity of 0.5 in were able to sustain vertical loads in excess of the 51 kip needed to satisfy the component requirements.

In summary, all the tested columns were able to withstand axial loads and moments in excess of required performance. Some of the columns did not develop their full theoretical ultimate strength because of weakness at the end fixture.
10.2.3.2. Sustained Lcading (Creep) Tests

Figures 10.16 and 10.17 show the results of creep tests conducted on columns 3 and 4 .

Column 4 was loaded with an axial load of 25 kip at an eccentricity of 2 in on its major axis. The test results are illustrated in figure 10.16. This figure also shows a computed value of instantaneous deflection. It should be noted that the vertical load is applied outside the kern of the section. The instantaneous deflection was therefore computed on the basis of a cracked section neglecting concrete tension. This will tend to overestimate the computed deflection, since not every section along the length of the column is cracked. In this case the computed instantaneous deflection is 0.32 in while the measured instantaneous deflection was only 0.22 in. However this measured value is low compared with values measured in tests on columns 2 , 6 , and 7 which were subjected to similar loading conditions. For the latter three tests the instantaneous deflection at a 25 kip load averaged 0.29 in (see figures 10.7, 10.8, and 10.9)

Figure 10.16 also shows an upper deflection limit for the given conditions, obtained by considering only the steel reinforcement and neglecting the concrete. This limit was computed by assuming that all the load is carried by the reinforcement. The deflection limit thus computed under the conditions of this test is 0.54 in and the steel stress at this deflection limit would be $38.2 \mathrm{ksi}$, which is well below the specified $60 \mathrm{ksi}$ yield stress of the column reinforcement. Creep buckling under the conditions of this test therefore cannot occur. All computed deflections referred to in this section accounted for an added moment equal to the axial load multiplied by the deflection at each point along the column.

Column 3 was loaded with an axial load of $25 \mathrm{kip}$ at an eccentricity of 0.5 in on the minor axis. This test is illustrated in figure 10.17, together with the computed instantaneous deflection of 0.106 in and the computed deflection limit assuming that no stress is carried by the concrete, which is $0.565 \mathrm{in}$. In this case the computed instantaneous deflection is based on an uncracked section and is in good agreement with the measured instantaneous deflection of 0.12 in as well as with instantaneous deflections measured in the tests of columns 1,5 , and 8 (figures 10.4, 10.5, and 10.6). The deflection limit under these loading conditions is 0.565 in and the computed steel stress at the deflection limit is $21 \mathrm{ksi}$, which precludes the possibility of creep buckling under the conditions of this test.

The creep tests on columns 4 and 3 respectively are also plotted in figures 10.20 and 10.21 . Curves $D$ in these figures are the interaction curves for maximum axial load and maximum 
total moment at which the steel carries the entire load without concrete participation. Curves $D^{\prime}$ show the same interaction curves for the reduced moments when deflections are taken into account. Thus the curves marked $D^{\prime}$ represent the combination of axial loads and applied end moments which can be supported by the column reinforcement without concrete participation as a limit condition. It is significant to note that curve $D^{\prime}$ in figure 10.20 when compared with curve $C$ indicates that creep buckling can not occur in this structure even under the assumed ultimate loading conditions. The creep tests of columns 3 and 5 simulate sustained loading of 1 live +1 dead load in the structure. It can be seen from the plot of these tests in figures 10.20 and 10.21 that there is a considerable margin of safety against creep buckling in the direction of both the major and the minor column axes.

\subsection{Channel Slab Test}

One of the channel slabs was picked at random and tested to destruction under centerpoint loading.

The slab was supported at each end and loaded through a 4-in-wide loading beam at midspan. Deflection of the slab was measured at midspan by two 2-in-throw mechanical dial gages.

The test results are shown in figure 10.22. The load at the yield point (2.5 kip) was higher than the predicted load at the yield point of the reinforcement ( $2.25 \mathrm{kip})$ using the nominal specified reinforcement yield strength, (40 ksi) and a $4.500 \mathrm{psi}$ concrete strength. The tests on the laboratory structure also indicated satisfactory performance of these components. No material specimens were tested to determine the actual steel and concrete strengths of the floor channels.

\subsection{Beam Tests-Repeated Loading}

\subsubsection{Test Specimens}

The test specimens were typical main beam components with a 22-in-wide and 2-in-thick topping slab cast on each beam. Results are presented for seven beams. Preliminary tests on three other beams are not reported because the test conditions (quarter-point loading) were found to be far too severe in relationship to service conditions.

Beams Nos. 6 through 11 were prepared with column stubs passing through the topping slab and with column connection fixtures in place simulating conditions in the structure except that tie beams were not attached and grouted to these connections (a block of wood was used as a spacer to fill the void caused by omission of the tie beams). The connections were not grouted. Beam No. 5 did not have the column stub or column fixtures.

In all of the beams tested, the top surface had not been roughened as required by the plans and specifications of the Neal Mitchell Housing System. All specimen preparation, including the placing of the topping slab, was performed by Neal Mitchell Associates. The top surfaces of these beams had been cast against steel forms and were very smooth.

Two types of shear connectors were used in the seven beams. These shear connectors are illustrated in figure 10.23. Beams Nos. 5, 7, and 9 used Star ${ }^{1 *}$ inserts spaced 19 in. on centers similar to the shear connectors used in the test structure. Beams Nos. 8 and 10 used Richmond (Kohler) ${ }^{14}$ inserts spaced 19 in. on centers. Beams Nos. 6 and 11 used the Richmond ${ }^{1+}$ inserts spaced $91 / 2$ in. on centers. All data on shear connector type and spacing in individual specimens are summarized in table 10.3.

\subsubsection{Beam Loading}

Figure 10.24 is a general view of the test setup. Two $10 \mathrm{kip}$ servo-controlled hydraulic rams applied the load by reacting against a frame bolted to the laboratory tie-down floor. Loading beams under the two rams distributed the test loads. All beams were tested by applying the loads in accordance with the sketch shown in Figure 10.25 and where simply supported by rollers on a clear span of $12.5 \mathrm{ft}$.

The beams were subjected to 1000 cycles of stress, alternating between intensities corresponding to $1 D$ and $1 D+1 L$, (for each ram $1 D=2.5 \mathrm{kip}$, and $1 L=2.5 \mathrm{kip}$; see Appendix C). Subsequently, the beams were tested to failure by 1000-cycle increments with the upper load level being increased at each increment by $0.5 L$ ( $1.25 \mathrm{kip})$.

The rate of cyclic loading was 1 cycle per second except for a few cycles at the beginning and end of each increment. During these periods when the rate was 0.01 cycle per second, mechanical dial gage readings were made. During these few cycles, center-span deflection measurements were made using a 5-in-throw mechanical dial gage. In addition, continuous center-span deflection measurements were recorded on a strip chart recorder by using a 3-in linear variable differential transducer (LVDT). Both measuring systems can be seen in figure

\footnotetext{
${ }^{14}$ Proprietary commercial product.
} 
10.24. In an effort to measure the relative horizontal slip between the beam and its topping slab, 0.001-in dial gages were mounted on the beam ends. One of these gages can also be seen in figure 10.24 .

\subsubsection{Test Results}

Graphs reproduced from strip-chart recordings of the midspan deflections are presented as figures 10.25 through 10.28 . Table 10.4 shows the midspan deflections measured at the beginning of each increment of loading for each of the beams. This table also indicates the point at which noticeable slippage between the topping slab and the beam occurred, as measured by the slip dial gages installed at the ends of the beam. After testing, the topping slab was removed from each beam, and spacing and condition of anchorage inserts were determined. The data relative to these tests are presented in table 10.5 .

\subsubsection{Interpretation of Results}

A study of table 10.5 and figures 10.25 through 10.28 indicates that all specimens tested showed a similar pattern of failure First a slip occurred between the precast beam and the topping slab. After this initial slip the beams no longer acted monolithically with the slab, and as a consequence the deflections caused by applied load increased. Deflections also increased moderately with the number of load cycles applied during the application of $1 D+$ $1 L, 1 D+1.5 L$ and $1 D+2 L$. During the repeated application of the load of $1 D+2.5 L$ deflections of all specimens tested increased rapidly and some of the specimens failed. All the remaining specimens failed during the first few cycles of application of the load of $1 D+$ $3 L$.

The initial slip that occurs between the precast beam and the topping slab is caused by horizontal shear. In the structure this shear is resisted by the shear connectors (inserts), the column-beam connection (the column base plate and part of the upper story column bear against the topping slab), and friction between the precast beam, the topping slab, and the floor channels. In the separate components that were tested not all these elements were present. Shear resisting devices were varied in the tests to determine their effectiveness in preventing slippage.

Beam 5, which had no column stub or columnbeam connection fixtures and had Star inserts at 19 inches on center, experienced slip between the beam and the topping slab during the first cycle of application of the $1 D+1 L$ load (figure 10.25). In terms of ultimate strength it performed considerably better, resisting 1000 cycles of $1 D+2.5 L$ without failure.

The results of the test on Beam 9 are shown in figure 10.26. This beam, which was similar to Beam 5 except that it did have a partial column-beam connection, performed approximately equal with Beam 5. Beam 9 exhibited signs of first slip during the first cycle of loading to $1 D+1 L$ and failed at the 820th cycle of $1 D+2.5 L$, while Beam 5 failed during the first cycle of $1 D+3 L$.

In comparison, Beam 7, the companion specimen to Beam 9, performed considerably better than either Beam 5 or Beam 9. Beam 7 was able to sustain 1000 cycles of $1 D+1 L$ without any signs of slip. First indications of slip for this beam were observed after the first few cycles of $1 D+1.5 \mathrm{~L}$. Failure occurred at approximately the same point as that of Beam 5 .

The results of the test on Beam 8 are shown in figure 10.27. Note that this beam, which had partial column-beam connections and Richmond inserts at 19 inches on center, had about the same initial slip behavior as did Beam 7 , which was similar except for type of insert. Beam 8 experienced ultimate failure somewhat earlier in the loading sequence than did Beam 7. Beam 10 (the companion to Beam 8) slipped at about the same point in the loading sequence as did Beam 8, but its ultimate failure took place during the first cycle of $1 D+3 L$.

The results of the test of Beam 6 are shown in figure 10.28. Beam 6 had a partial columnbeam connection and Richmond inserts spaced at $91 / 2$ in on center. This beam was able to sustain the full 1000 cycles of loading from $1 D$ to $1 D+1 L$ without slippage and went on to sustain about 500 cycles of loading from $1 D$ to $1 D+1.5 L$ before slip developed. Beam 6 was able to sustain 1000 cycles of $1 D$ to $1 D+$ $2.5 \mathrm{~L}$ without failure and finally failed during the seventeenth cycle of $1 D+3 L$. Its companion, Beam 11, showed first signs of slip at 300 cycles of $1 D$ to $2 L$ and ultimately failed at 1230 cycles of $1 D+3 L$.

When the repeated load tests were conceived, it was felt that from the standpoint of slip behavior, the beams should be capable of sustaining 1000 cycles of loading from $1 D$ to $1 D$ $+1 L$, and should be capable of sustaining a loading of at least $1 D$ to $1 D+2 L$ before ultimate failure. This component requirement was set for this particular test, even though it was realized that the performance of the main beam as a separate component does not necessarily simulate the behavior of the complete system. All of the beams tested which had partial column connections, except for Beam 9, satisfied this requirement. The reason that the presence 
of the partial connections had no effect on Beam 9 is not clear.

Beam strength was substantially improved at an insert spacing of $91 / 2$ in, as in Beams 6 and 11.

The beams tested as isolated components experienced considerably larger deflections at $1 D$ $+1 L$ than did the center main beam of the test structure (figure 9.2), indicating that the component test was conservative in comparison with the system test.

\section{Material Tests}

\subsection{Introduction}

Tests were conducted on the concretes used in the various parts of the structure as well as on the reinforcing steel used in the precast components. The objective of these tests was to determine the relationship between minimum specified properties of materials and the properties of the materials used in the test structure, and to determine material properties which might be useful in analyzing the tests on the main structure and structural components.

\subsection{Concrete Tests}

The concretes tested were: (1) concrete used in the precast components, except the channel slabs, (2) concrete used in the on-grade floor slab, and (3) concrete used for the topping slab. Concrete specimens were tested for the following: (1) compressive strength, (2) tensile splitting strength, (3) unit weight, (4) air content, and (5) modulus of elasticity.

\subsubsection{Precast Component Concrete}

The precast components were cast in two days (April 16 and 17, 1968) from five batches of lightweight aggregate concrete. This concrete was made from a $3 / 8$-in maximum size expanded shale aggregate, with preformed foam added at the time of mixing. A rather high cement content (about 9 U.S. bags per cubic yard) was used, and water was added to produce a workable mix. The amount of the preformed foam used was adjusted to provide a concrete with a fresh weight of about $96 \mathrm{lb} / \mathrm{ft}^{3}$ at the mixer. The slump was judged to be about 2 in although it was not measured. The workability of the concrete was excellent with no indication of either segregation or bleeding.

Test specimens $(6 \times 12$ in cylinders $)$ were cast in cardboard molds from four of the five batches. These specimens were shipped in the molds to the test site with the structural com- ponents and were removed from the molds when about 8 days old. They were then stored in the laboratory air until tested.

The components were cast under commercial conditions and no records were available which would permit the association of individual components with particular batches of concrete.

\subsubsection{Floor and Topping Slab Concrete}

The on-grade floor slab was cast from a 1-in maximum size crushed-stone concrete delivered by a ready-mix truck. The mix proportions and slump are not known. The compressive test specimens were molded in $6 \times 12$ in cast iron molds which were removed when the concrete was 3 days old. The specimens were then airdried until tested.

The topping slab was cast from a standard 6-bag, 3000 psi lightweight mix delivered by a ready-mix truck in two batches. The first batch was placed in the west section of the topping slab. The coarse aggregate was a $3 / 4$-in maximum size expanded shale and the fine aggregate was a natural sand. The compressive test specimens were molded in $6 \times 12$ in cast iron molds which were removed at 2 days of age. The specimens were then air-dried until tested.

\subsubsection{Concrete Test Results}

The results from the strength tests are shown in table 11.1. The unit weight and air-content determinations are presented in table 11.2. Aircontent determinations were made by ASTM Method C-457[12]. The values of the modulus of elasticity are shown in table 11.3. By way of comparison, values for an average lightweight aggregate concrete are included in these tables. These values are averages from a total of 46 batches of concrete made from 21 different expanded shale, lightweight aggregates[13]. The average cement content for these concretes was $6.5 \mathrm{bags} / \mathrm{yd}$ and the average wet density was $100.3 \mathrm{lb} / \mathrm{ft}^{3}$.

The results indicate that: (1) the compressive strength of the lightweight concrete used in the precast components was well above the design strength of 3500 psi; (2) there was considerable variation in the strengths from batch to batch of the lightweight concrete; (3) there was considerable variation in the unit weights from batch to batch of the lightweight concrete; and (4) there was an apparent increase in the unit weight of the concrete as placed in the precast components when compared to the fresh unit weight at the mixer (about $96 \mathrm{lb} / \mathrm{ft}^{3}$ ).

These indications justify three conclusions:

(1) The concrete strengths in the test structure were significantly higher than the 
strengths called for in the plans and specifications of the Neal Mitchell System.

(2) Handling and placing techniques of the fresh concrete can affect the unit weight (and therefore the strength) of the concrete. This is especially true in the case of the high-aircontent concrete used in the precast components. The unit weight of the concrete at the mixer may not necessarily be equal to the unit weight of the concrete in the form.

(3) When working with lightweight concretes, quality control tests on the fresh concrete should be made at the point of placing in such a manner that handling and placing effects can be evaluated.

\subsection{Reinforcing Steel}

Specimens of the reinforcing steel used in the precast components were tested to determine their yield and ultimate strengths. The results are presented in table 11.4.

\section{Summary and Conclusions}

\subsection{Summary}

A full-scale, first-story portion of a building system was tested in the laboratory in a manner that simulated the structural behavior of a three-story building under both service and potential ultimate loading conditions. Additional tests were carried out on components of this building system to determine their behavior and capacity and to provide data needed for the evaluation of the system. Performance criteria for the evaluation of the structural safety and adequacy of certain building systems were developed.

\subsection{Conclusions}

This series of tests demonstrated that it is feasible and practical to use structural performance tests as a basis for the evaluation of innovative building systems.

All conclusions pertaining to the structural performance of the system in question are based on the test structure as built in the laboratory and on the erection methods and materials used therein. Variation in materials and erection methods may influence performance.

The following significant deviations of the test structure from the plans and specifications of the Neal Mitchell System have been determined:
(1) The test structure had higher than specified concrete strength.

(2) Topping slab thickness exceeded that shown in the plans.

(3) Floor channel reinforcement size was increased.

(4) Gypsum wallboard thickness was less than that shown in the plans.

(5) Greater than ordinary variations in concrete strength and in the dimensions of precast members were observed.

The following conclusions relative to the performance of the building system have been reached:

(1) The building system satisfied the performance criteria which were set for its evaluation with substantial margins. As a system it exhibited strength and stiffness in excess of service- and ultimate load requirements.

(2) The walls of the system behaved as an integral part of the structure. They provided most of the stiffness of the system with respect to lateral loads, and provided a significant portion of the stiffness against vertical loads.

(3) The building system with its walls removed had considerable reserve strength above the required ultimate vertical load bearing capacity; however, without the aid of its walls it was not capable of resisting the required service wind loads.

(4) All columns tested as separate components satisfied component requirements. Column creep tests indicate that the application of service loads over a long period of time is not likely to result in creep-buckling of columns.

(5) Five of six subassemblages consisting of a precast main beam, a section of the topping slab and a partial column-beam connection were able to resist 1000 cycles of repeated loading from dead to dead-plus-live load without exhibiting signs of deterioration. Two such subassemblages with reduced shear connector spacing satisfied this performance requirement by a considerable margin. The column-beam connections appeared to play a major role in shear transfer between the precast beam and the cast-in-place topping slab.

\section{Acknowledgment}

The contribution of the following persons is acknowledged:

Frank A. RANKIN and JAMEs W. RAInes, Engineering Technicians, were respectively in charge of erection and electronic instrumentation of the test structure. 
EARle F. CARPENTER was the Research Engineer in charge of electronic data processing and participated in the preparation of this report.

Thomas W. ReICHaRd, Research Physicist, was in charge of specimen and material testing and participated in the preparation of Chapters 10 and 11 of the report.

Robert G. MAtheY, Assistant Chief of the Structures Section, supervised and coordinated the testing effort.

JoHn E. Breen, Professor of Civil Engineering at the University of Texas critically reviewed the report and made many helpful suggestions.

The team effort of these persons made the successful completion of this project possible.

\section{References}

[1] Ackleston, A. Y., "Load Tests on a 3 Story Reinforced Concrete Building in Johannisburg, South Africa," Structural Engr. 33, 304-322

[2] American Concrete Institute, Committee 318, Proposed Revision to (ACI 318-63) Building Code Requirements for Reinforced Concrete (Unpublished, Oct. 1955).

[3] State of New York, Building Codes Bureau, State Building Construction Code (Dec. 1964).

[4] Federal Housing Administration Research Paper No. 30 (1954).

[5] American Society for Testing Materials, Philadelphia, Pennsylvania. ASTM Designation: A61-66 "Deformed Rail Steel Bars for Concrete Reinforcement with 60,000 psi Minimum Field Strength" (1966).

[6] American Society for Testing Materials, Philadelphia, Pennsylvania. ASTM Designation: A15-66 "Billet-Steel Bars for Concrete Reinforcement" (1966).

[7] American Society for Testing Materials, Philadelphia, Pennsylvania. ASTM Designation: A185-64 "Welded Steel Fabric for Concrete Reinforcement" (1964).

[8] American Society for Testing Materials, Philadelphia, Pennsylvania. ASTM Designation: C442-67 "Specifications for Gypsum Wallboard" (1967).

[9] American Society for Testing Materials, Philadelphia, Pennsylvania. ASTM Designation: (36-67) "Specifications for Gypsum Wallboard" (1967).

[10] American Society of Testing Materials, Philadelphia, Pennsylvania. ASTM Designation: C39-66 "Test for Compressive Strength of Molded Concrete Cylinders" (1966).

[11] American Standards Association Minimum Design Loads in Buildings and Other Structures (Sept. 1955).

[12] American Society for Testing Materials, Philadelphia, Pelunsylvania. ASTM Designation C457-67T, "Recommended Practice for Microscopic Determination of Void Content, Specific Surface, and Spacing Factor of the Air-Void System in Hardened Concrete "Tentative)" (1967).
[13] Reichard, T. W., Creep and Drying Shrinkage of Lightweight and Normal Weight Concrete. NBS Monograph 74, National Bureau of Standards, Washington, D.C. (March 1964).

\section{Tables}

TABLE 6.1. Simulated Loads (symbols and magnitude)

(For computations, refer to Appendix C) Symbols for Loading:
$D=$ Service dead load
$L=$ Service live load
$H=$ Service wind load

Simulated load

Magnitude

Second story column

W-E wind

S-N wind (point opposite firewall)

$\mathrm{S}-\mathrm{N}$ wind (point between firewalls)

Major floor load:

(equivalent distributed load between columns (center strip))

Minor floor load:

(Equivalent distributed load between north end of structure and northern row of columns (cantilever strip))

" $w$ and $w^{\prime}$ were increased to allow for incomplete area coverage by the air bags (see fig. 6.1).

b $46 \mathrm{psf}$ is the dead load weight of the floor of the test structure.

c $9.3 \mathrm{psf}$ is the additional dead load which would be acting on the real structure but which is not present on the test structure.

\section{TABLE 6.2. Simulated loads in load schedule} (For computations, refer to Appendix C)

\begin{tabular}{l|c|c|c|c|c|c}
\hline \multicolumn{1}{c}{ Loading } & $P$ & $H w$ & $H s$ & $H s^{\prime}$ & $w$ & $w^{\prime}$ \\
\hline & $($ kip $)$ & $($ kip $)$ & $($ kip $)$ & $($ kip $)$ & $(p s f)$ & $(p s f)$ \\
& 17 & & & & 52 & 52 \\
$1 D+1 L$ & 9 & 2.3 & 4.5 & 1.0 & & \\
$0.9 D+1.1 H$ & 25 & & & & 100 & 100 \\
$1.3 D+1.7 L$ & 25 & 1.6 & 3 & 0.7 & 100 & 100 \\
$1.3 D+1.7 L+0.8 H$ & 25 & & & \\
$1.25(1.5 D+1.8 L)$ & 35 & & & & 144 & 144 \\
$0.9 D+1.4 \mathrm{H}$ & 9 & 2.9 & 5.7 & 1.3 & & \\
& & & & & & \\
\hline
\end{tabular}


TABLE 10.1. Column tests (actual dimensions and reinforcement cover of the columns)

\begin{tabular}{|c|c|c|c|c|c|c|c|c|c|c|}
\hline \multirow[t]{2}{*}{ Column No. } & \multicolumn{2}{|c|}{$\begin{array}{l}\text { Outside dimensions } \\
\text { in inches }\end{array}$} & \multicolumn{8}{|c|}{ Cover Measurements in inches } \\
\hline & $" X "$ & $" Y "$ & A & $\mathrm{B}$ & $\mathrm{C}$ & $\mathrm{D}$ & $\mathrm{E}$ & $\mathrm{F}$ & G & $\mathrm{H}$ \\
\hline $\begin{array}{l}1 \\
2 \\
3 \\
4 \\
5 \\
6 \\
7 \\
8 \\
9\end{array}$ & $\begin{array}{l}4.76 \\
4.77 \\
4.76 \\
4.76 \\
4.79 \\
4.81 \\
4.78 \\
4.74 \\
4.75\end{array}$ & $\begin{array}{l}6.05 \\
6.07 \\
6.05 \\
6.15 \\
6.16 \\
6.06 \\
6.05 \\
6.15 \\
6.20\end{array}$ & $\begin{array}{cc} & 11 / 16 \\
1 & 1 / 8 \\
1 & 1 / 4 \\
1 & 1 / 8 \\
1 & 1 / 4 \\
1 & 1 / 4 \\
1 & 1 / 8\end{array}$ & $\begin{array}{cc}1^{3} & 3 / 4 \\
1 & 1 / 4 \\
1 & 1 / 16 \\
1 & 316 \\
1 & 1 / 8 \\
1 & 1 / 8\end{array}$ & $\begin{array}{r}11 / 16 \\
1 \quad 1 / 66 \\
13 / 16 \\
11 / 8 \\
7 / 8 \\
1516 \\
7 / 8\end{array}$ & $\begin{array}{ll}1 & 1 / 4 \\
1 & 1 / 16 \\
1 & \\
1 & \\
& 7 / 8\end{array}$ & $1^{11 / 16}$ & $\begin{array}{ll}1 & 1 \\
1 & 16 \\
1 & 1 / 8 \\
1 & 1 / 4 \\
1 & 1 / 8\end{array}$ & $\begin{array}{cc} & 3 / 4 \\
1 & 1 / 16 \\
1 & 1 / 8 \\
1 & 3 / 8 \\
1 & 3 / 4 \\
1 & 1 / 8\end{array}$ & 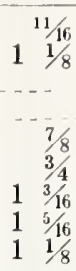 \\
\hline $\begin{array}{c}\text { Average } \\
\text { specified (fig. 5.13) }\end{array}$ & $\begin{array}{l}4.77 \\
4.75\end{array}$ & $\begin{array}{l}6.10 \\
6.00\end{array}$ & $\begin{array}{l}1.12 \\
1.00\end{array}$ & $\begin{array}{l}1.07 \\
1.00\end{array}$ & $\begin{array}{l}0.96 \\
1.00\end{array}$ & $\begin{array}{l}0.98 \\
1.00\end{array}$ & $\begin{array}{l}0.92 \\
1.00\end{array}$ & $\begin{array}{l}1.08 \\
1.00\end{array}$ & $\begin{array}{l}1.03 \\
1.00\end{array}$ & $\begin{array}{l}1.01 \\
1.00\end{array}$ \\
\hline
\end{tabular}

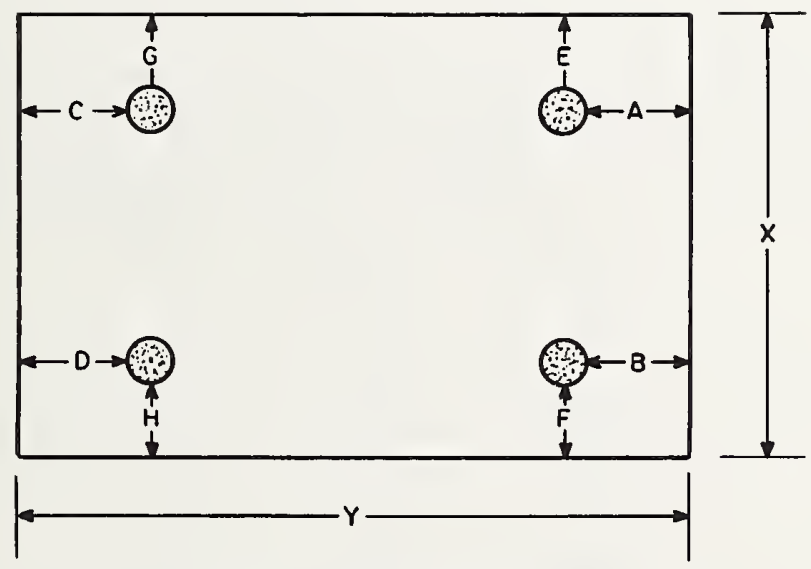

TABLE 10.1. Illustrative figures 
TABLE 10.2. Column tests

(ultimate loads and failure modes)

\begin{tabular}{|c|c|c|c|c|}
\hline $\begin{array}{l}\text { Column } \\
\text { No. }\end{array}$ & $\begin{array}{l}\text { Major } \\
\text { axis } \\
\text { eccen- } \\
\text { tricity }\end{array}$ & $\begin{array}{l}\text { Minor } \\
\text { axis } \\
\text { eccen- } \\
\text { tricity }\end{array}$ & $\begin{array}{l}\text { Ultimate } \\
\text { load }\end{array}$ & $\begin{array}{l}\text { Type of } \\
\text { failure }\end{array}$ \\
\hline 1 & $\begin{array}{l}\text { (in) } \\
0.0\end{array}$ & $\begin{array}{l}(\text { in }) \\
0.5\end{array}$ & ${ }^{(k i p)}{ }_{73.0}$ & Botto \\
\hline 5 & 0.0 & 0.5 & 82.0 & Concrete \\
\hline 8 & 0.0 & 0.5 & 81.8 & $\begin{array}{c}\text { Concrete } \\
\text { mid-ht. }\end{array}$ \\
\hline & & & Avg. $=78.9$ & \\
\hline $\begin{array}{l}2 \\
6\end{array}$ & $\begin{array}{l}2.0 \\
2.0\end{array}$ & $\begin{array}{l}0.0 \\
0.0\end{array}$ & $\begin{array}{l}56.6 \\
51.0\end{array}$ & $\begin{array}{l}\text { Top fixture } \\
\text { Top fixture }\end{array}$ \\
\hline 7 & 2.0 & 0.0 & 45.9 & Top fixture \\
\hline 9 & 1.5 & 0.0 & $\begin{aligned} \text { Avg. }= & 51.2 \\
& 89.5\end{aligned}$ & $\begin{array}{c}\text { Concrete } \\
\text { mid-ht. }\end{array}$ \\
\hline
\end{tabular}

TABLE 10.3. Beam tests (insert spacing and concrete strength of specimens)

\begin{tabular}{|c|c|c|c|c|c|c|}
\hline \multirow{2}{*}{$\begin{array}{l}\text { Beam } \\
\text { No. }\end{array}$} & \multirow{2}{*}{ Inserts } & \multicolumn{2}{|c|}{ Date cast } & \multirow{2}{*}{$\begin{array}{l}\text { Date beam } \\
\text { tested }\end{array}$} & \multicolumn{2}{|c|}{ Concrete strength, psi" } \\
\hline & & Beam & Topping & & Beam & Topping \\
\hline 5 & $\mathrm{Star}^{\mathrm{c}}$ at $19 \mathrm{in}$ & $4 / 17$ & $5 / 10$ & $5 / 20$ & 7000 & 3400 \\
\hline 7 & Star at 19 in & $5 / 15$ & $6 / 7$ & $6 / 13$ & 6740 & 4100 \\
\hline 9 & Star at 19 in & $5 / 15$ & $6 / 7$ & $6 / 15$ & 6740 & 4100 \\
\hline 8 & Richmond at 19 in & $6 / 5$ & $6 / 7$ & $6 / 14$ & 6400 & 4100 \\
\hline 10 & Richmond at 19 in & $6 / 5$ & $6 / 7$ & $6 / 17$ & 6400 & 4100 \\
\hline 6 & Richmond $d^{d}$ at $91 / 2$ in & $6 / 5$ & $6 / 7$ & $6 / 12$ & 6400 & 4100 \\
\hline 11 & Richmond at $91 / 2$ in & $6 / 5$ & $6 / 7$ & $6 / 18$ & 6400 & 4100 \\
\hline
\end{tabular}

"Approximate strength when beam was tested. All concretes were made from expanded shale and were similar to concretes used in the test structure.

b Column stubs cast $6 / 5$ from concrete used in beams cast on that date.

c All beams with 19 in insert spacing between supports had one insert outside each support at 18 in from the centerline of the support.

d All beams with $9 \frac{1}{2}$ in insert spacing between supports had three inserts outside each support at 6,18 and 30 in from the centerline of the support.

NOTES ON INSERTS:

1. Star inserts were $3_{8}$ in zinc base, die-casting alloy.

2. Richmond inserts were $3 / 8$ in grey cast-iron "Kohler".

3. Jam nuts were used with Star inserts.

4. Cross-bars on shear-studs were 8 in long when inserts were spaced at $91 / 2$ in between columns. 
TABLE 10.4. Beam tests (repeated load test results)

\begin{tabular}{|c|c|c|c|c|c|c|c|c|c|c|c|c|c|}
\hline \multirow{3}{*}{$\begin{array}{l}\text { Beam } \\
\text { No. }\end{array}$} & \multirow{3}{*}{$\begin{array}{l}\text { Inserts } \\
\text { used }\end{array}$} & \multicolumn{10}{|c|}{ Beam mid-span deflections, inch" } & \multicolumn{2}{|c|}{ Results } \\
\hline & & \multicolumn{2}{|c|}{ Increment 1} & \multicolumn{2}{|c|}{ Increment 2} & \multicolumn{2}{|c|}{ Increment 3} & \multicolumn{2}{|c|}{ Increment 4} & \multicolumn{2}{|c|}{ Inerement 5} & \multirow{2}{*}{$\begin{array}{l}\text { Slippage } \\
\text { observed }\end{array}$} & \multirow{2}{*}{$\begin{array}{l}\text { Collapse } \\
\text { occurred }\end{array}$} \\
\hline & & $D$ & $D+L$ & $D$ & $D+1.5 L$ & $D$ & $D+2 L$ & $D$ & $D+2.5 L$ & $D$ & $D+3 L$ & & \\
\hline 5 & $\begin{array}{l}\text { Star } \\
\text { at } 19 \text { in }\end{array}$ & 0.32 & 0.72 & 0.68 & 1.31 & 0.82 & 1.80 & 0.92 & 2.45 & 1.01 & & $\begin{array}{l}1 \text { eycle } \\
\text { of } 1 L\end{array}$ & $\begin{array}{l}1 \text { cycle } \\
\text { of } 3 L\end{array}$ \\
\hline 7 & $\begin{array}{l}\text { Starb } \\
\text { at } 19 \text { in }\end{array}$ & 0.20 & 0.68 & 0.56 & 0.97 & 0.78 & 1.48 & 0.99 & 1.89 & -..... & - & $\begin{array}{c}\text { Few eycles } \\
\text { of } 1.5 \mathrm{~L}\end{array}$ & $\begin{array}{l}3 \text { cycles } \\
\text { of } 3 L \\
\end{array}$ \\
\hline 9 & $\begin{array}{l}\text { Starb } \\
\text { at } 19 \text { in }\end{array}$ & 0.17 & 0.76 & 0.61 & 1.07 & 0.81 & 1.43 & 0.96 & 2.06 & $\ldots$ & & $\begin{array}{l}1 \text { cycle } \\
\text { of } 1 L\end{array}$ & $\begin{array}{r}820 \text { cycles } \\
\text { of } 2.5 \mathrm{~L}\end{array}$ \\
\hline 8 & $\begin{array}{l}\text { Richmond } \\
\text { at } 19 \text { in }\end{array}$ & 0.18 & 0.48 & 0.30 & 0.65 & 0.80 & 1.36 & 1.00 & 2.23 & -... & 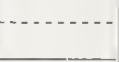 & $\begin{array}{c}\text { Few cycles } \\
\text { of } 1.5 \mathrm{~L}\end{array}$ & $\begin{array}{l}4 \text { eycles } \\
\text { of } 2.5 L\end{array}$ \\
\hline 10 & $\begin{array}{l}\text { Richmond } \\
\text { at } 19 \text { in }\end{array}$ & 0.15 & 0.50 & 0.38 & 0.74 & 0.46 & 1.07 & 0.72 & 1.45 & 0.86 & - . & $\begin{array}{c}100 \text { cycles } \\
\text { of } 1.5 \mathrm{~L}\end{array}$ & $\begin{array}{l}1 \text { cycle } \\
\text { of } 3 L \\
\end{array}$ \\
\hline 6 & $\begin{array}{l}\text { Richmond } \\
\text { at } 91 / 2 \text { in }\end{array}$ & 0.17 & 0.54 & 0.42 & 0.82 & 0.70 & 1.28 & 0.82 & 1.63 & 1.28 & 3.05 & $\begin{array}{c}500 \text { cycles } \\
\text { of } 1.5 L\end{array}$ & $\begin{array}{l}17 \text { cycles } \\
\text { of } 3 L\end{array}$ \\
\hline 11 & $\begin{array}{l}\text { Richmond } \\
\text { at } 91 / 2 \text { in }\end{array}$ & 0.21 & 0.55 & 0.40 & 0.79 & 0.50 & 1.02 & 0.59 & 1.21 & 0.70 & 1.52 & $\begin{array}{c}300 \text { cycles } \\
\text { of } 2 L\end{array}$ & $\begin{array}{l}1230 \text { cycles } \\
\text { of } 3 L\end{array}$ \\
\hline
\end{tabular}

a Deflections reported were measured at beginning of each increment and are based on initial zero-load condition. b These beams had partial column connections.

TABLE 10.5. Beam tests (modes of insert failures)

\begin{tabular}{|c|c|c|}
\hline $\begin{array}{l}\text { Beam } \\
\text { No. }\end{array}$ & Inserts & Mode of Insert Failure \\
\hline 5 & $\begin{array}{l}\text { Star at } \\
19 \text { in }\end{array}$ & $\begin{array}{l}\text { Inserts broken } 1 \text { in below interface } \\
\text { and pulled out }\end{array}$ \\
\hline 7 & $\begin{array}{l}\text { Star at } \\
19 \text { in }\end{array}$ & $\begin{array}{l}\text { Inserts broken } 1 \text { in below interface } \\
\text { and pulled out }\end{array}$ \\
\hline 9 & $\begin{array}{l}\text { Star at } \\
19 \text { in }\end{array}$ & Bolts broken just above jam nuts \\
\hline 8 & $\begin{array}{l}\text { Richmond } \\
\text { at } 19 \text { in }\end{array}$ & $\begin{array}{l}\text { Bolts sheared off at slab-beam inter- } \\
\text { face }\end{array}$ \\
\hline 10 & $\begin{array}{l}\text { Richmond } \\
\text { at } 19 \text { in }\end{array}$ & $\begin{array}{l}\text { Bolts sheared off at slab-beam inter- } \\
\text { face }\end{array}$ \\
\hline 6 & $\begin{array}{l}\text { Richmond } \\
\text { at } 91 / 2 \text { in }\end{array}$ & $\begin{array}{l}\text { Bolts sheared off at slab-beam inter- } \\
\text { face }\end{array}$ \\
\hline 11 & $\begin{array}{l}\text { Richmond } \\
\text { at } 91 / 2 \text { in }\end{array}$ & $\begin{array}{l}\text { Bolts sheared off at slab-beam inter- } \\
\text { face }\end{array}$ \\
\hline
\end{tabular}


TABLE 11.1. Concrete tests

\begin{tabular}{|c|c|c|c|c|c|c|}
\hline \multirow{2}{*}{ Concrete } & \multirow{2}{*}{ Batch } & \multirow{2}{*}{ Date tested } & \multirow{2}{*}{$\begin{array}{l}\text { Age at } \\
\text { test }\end{array}$} & \multicolumn{2}{|c|}{ Compressive strength } & \multirow{2}{*}{$\begin{array}{l}\text { Splitting } \\
\text { strength }\end{array}$} \\
\hline & & & & Specified & Actual & \\
\hline $\begin{array}{l}\text { Precast component } \\
\text { Precast component }^{\text {b }} \\
\text { Precast component } \\
\text { Precast component } \\
\text { Floor slab } \\
\text { Topping slab } \\
\text { Topping slab }\end{array}$ & $\begin{array}{c}4 / 16-\mathrm{B} \\
4 / 16-\mathrm{C} \\
4 / 17-\mathrm{A} \\
4 / 17-\mathrm{B} \\
\mathrm{A} \\
\mathrm{B}\end{array}$ & $\begin{array}{l}\text { May } 10 \\
\text { May } 10 \\
\text { May } 10 \\
\text { May } 10 \\
\text { May } 10 \\
\text { May } 21 \\
\text { May } 21\end{array}$ & $\begin{array}{c}\text { Days } \\
\\
24 \\
24 \\
23 \\
23 \\
17 \\
26 \\
26\end{array}$ & $\begin{array}{l}p s i \\
\\
3500 \\
3500 \\
3500 \\
3500 \\
2000 \\
3000 \\
3000\end{array}$ & $\begin{array}{l}p s i \\
5100 \\
4930 \\
7160 \\
7090 \\
5600 \\
3840 \\
2560\end{array}$ & $\begin{array}{r}p s i \\
\text { с346 } \\
\text { с287 } \\
\text { ‘369 } \\
\end{array}$ \\
\hline $\begin{array}{l}\text { Avg. value for typical } \\
\text { lightweight aggregate } \\
\text { concrete }^{\mathrm{d}}\end{array}$ & & & 28 & & 5800 & \\
\hline
\end{tabular}

"The tests on the laboratory structure were carried out during the period of May 10-22. See Appendix C for actual dates of each test.

b Concrete for the long columns (first story) was specified to be $4500 \mathrm{psi}$ strength.

c Tested May 22 at an age of 36 days after 25 days air drying.

d Derived from NBS Monograph 74, March, 1964.

TABLE 11.2. Concrete tests (unit weights and air contents of concrete)

\begin{tabular}{|c|c|c|c|c|c|c|}
\hline Concrete & Batch & Date tested & Age & $\begin{array}{l}\text { Air drying } \\
\text { period }\end{array}$ & $\begin{array}{c}\text { Unit } \\
\text { weight }\end{array}$ & Air content \\
\hline $\begin{array}{l}\text { Precast component } \\
\text { Precast component } \\
\text { Precast component } \\
\text { Precast component } \\
\text { Floor slab } \\
\text { Topping slab } \\
\text { Topping slab }\end{array}$ & $\begin{array}{c}4 / 16-\mathrm{B} \\
4 / 16-\mathrm{C} \\
4 / 17-\mathrm{A} \\
4 / 17-\mathrm{B} \\
\mathrm{A} \\
\mathrm{B}\end{array}$ & $\begin{array}{l}\text { May } 16 \\
\text { May } 16 \\
\text { May } 16 \\
\text { May } 16 \\
\text { May } 14 \\
\text { May } 16 \\
\text { May } 16\end{array}$ & $\begin{array}{c}\text { Days } \\
30 \\
30 \\
29 \\
29 \\
21 \\
21 \\
21\end{array}$ & $\begin{array}{c}\text { Days } \\
21 \\
21 \\
21 \\
21 \\
20 \\
20 \\
20\end{array}$ & $\begin{array}{r}l b / f t^{3} \\
98.5 \\
96.4 \\
103.7 \\
103.4 \\
147.7 \\
117.7 \\
108.3\end{array}$ & $\begin{array}{c}\% \\
11.3 \\
8.2 \\
\end{array}$ \\
\hline $\begin{array}{l}\text { Average values for typi- } \\
\text { cal lightweight aggre- } \\
\text { gate concrete }\end{array}$ & & & 28 & 27 & 97.0 & 4.7 \\
\hline
\end{tabular}

a Derived from NBS Monograph 74, March, 1964. 
TABLE 11.3. Concrete tests (modulus of elasticity of precast component concrete

\begin{tabular}{c|c|c|c|c}
\hline Batch & $\begin{array}{c}\text { Age } \\
\text { at } \\
\text { test }\end{array}$ & $\begin{array}{c}\text { Date } \\
\text { tested }\end{array}$ & $\begin{array}{c}\text { Compressive } \\
\text { strength }\left(f^{\prime} c\right)\end{array}$ & $\begin{array}{c}\text { Secant } \\
\text { modulus }\end{array}$ \\
\hline & days & & $p s i$ & $10^{6} p s i$ \\
$\begin{array}{c}4 / 16-B \\
4 / 16-C\end{array}$ & 41 & May 27 & 6400 & 2.1 \\
$4 / 17-B$ & 40 & May 27 & 6030 & 2.2 \\
\cline { 1 - 2 } $\begin{array}{c}\text { Avg. value } \\
\text { for light- } \\
\text { weight ag- } \\
\text { gregate } \\
\text { concrete }\end{array}$ & 28 & & 7380 & 2.4 \\
\hline
\end{tabular}

"Secant Modulus at $0.4 f^{\prime} c$ after prior loading to $0.5 f^{\prime} c$ several times.

bDerived from NBS Monograph 74, March 1964.

TABLE 11.4. Reinforcing steel test results

\begin{tabular}{|c|c|c|c|c|}
\hline \multirow{2}{*}{ Specimen } & \multirow{2}{*}{ Where used } & \multicolumn{2}{|c|}{ Yield strength } & \multirow{2}{*}{ Ultimate strength } \\
\hline & & Specified & Actual & \\
\hline $\begin{array}{l}\text { No. } 5 \text { deformed bar } \\
\text { No. } 4 \text { deformed bar } \\
\text { No. } 2 \text { plain bar }\end{array}$ & $\begin{array}{l}\text { Beams } \\
\text { Cantilever beams } \\
\text { Tie bars in columns }\end{array}$ & $\begin{array}{c}p s i \\
60,000 \\
60,000 \\
40,000\end{array}$ & $\begin{array}{c}p s i \\
65,000 \\
73,000 \\
47,000\end{array}$ & $\begin{array}{c}p s i \\
96,000 \\
117,000 \\
77,000\end{array}$ \\
\hline
\end{tabular}




\section{Figures}

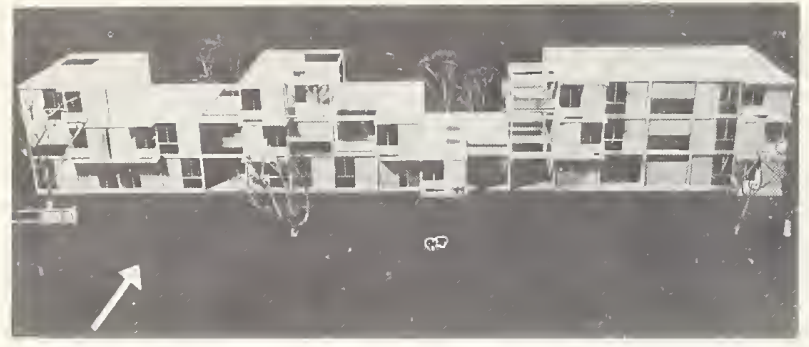

Figure 5.1. Typical complete structure.

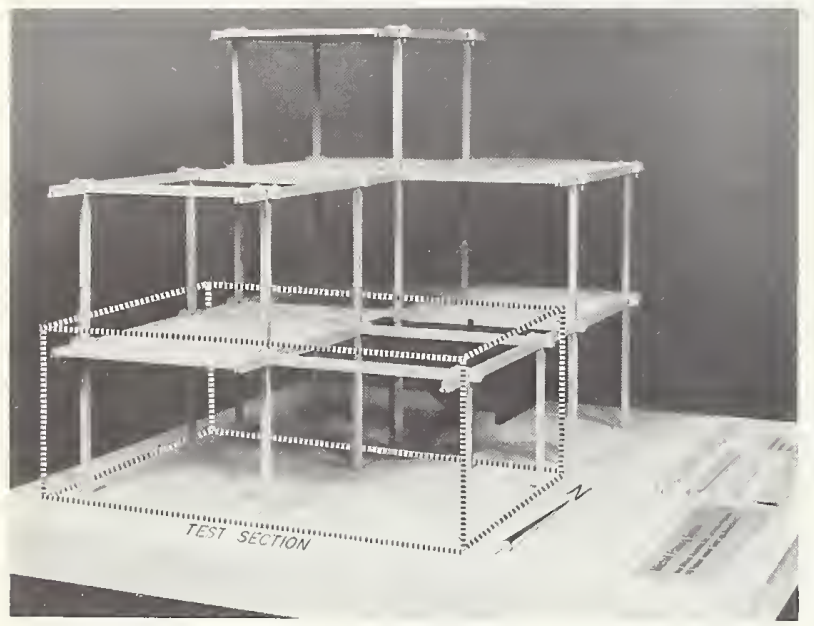

FIGURE 5.2. Structural system model.

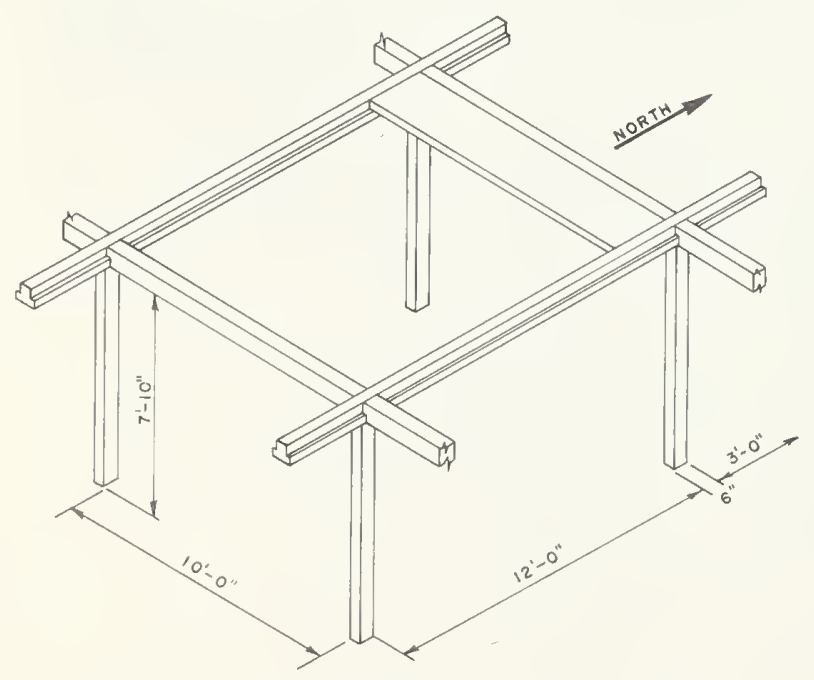

FIGURE 5.3. Typical bay of two-bay frame test.
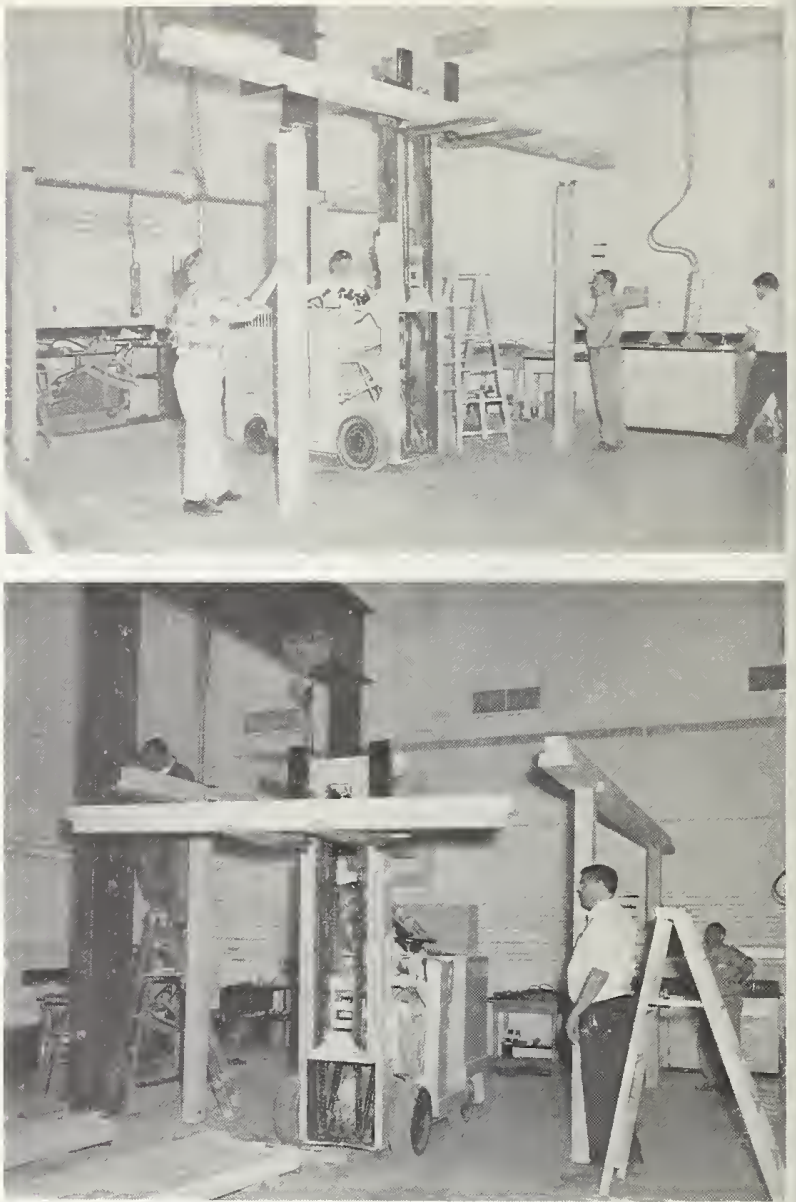

FIGURE 5.4. Assembling structural frame.

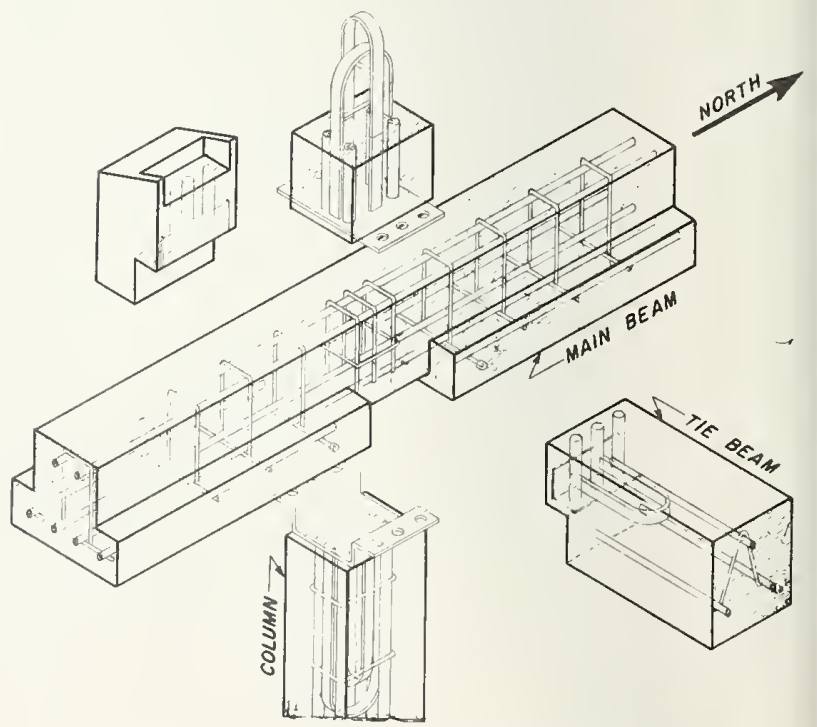

FIGURE 5.5 Berm and column reinforcement. 


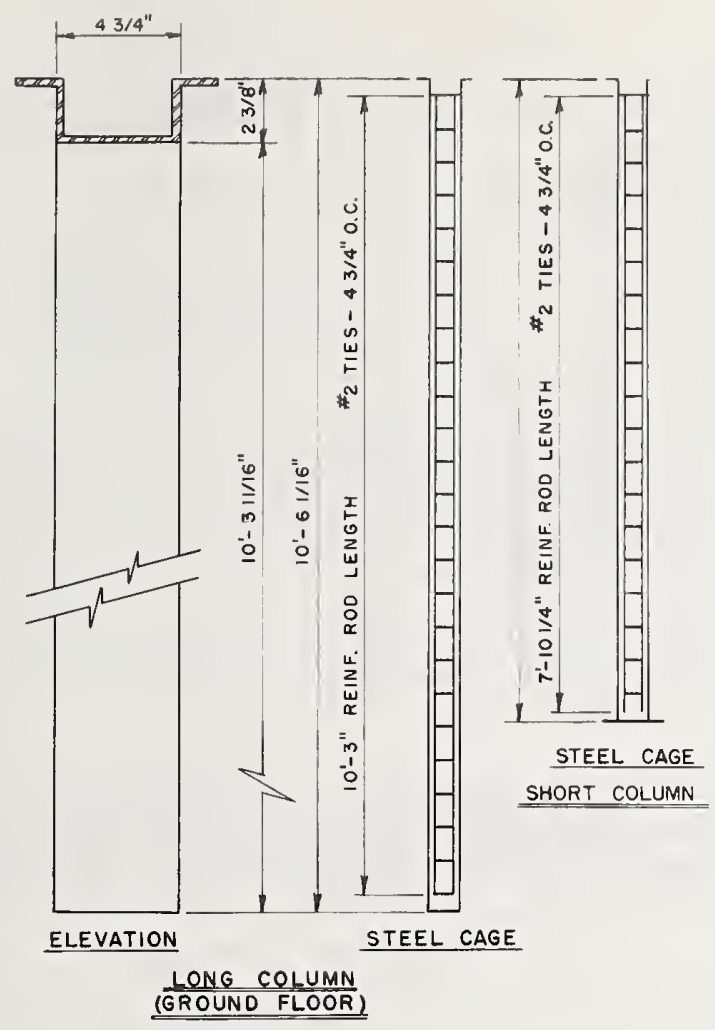

FIGURE 5.6. Elevation of column reinforcement.
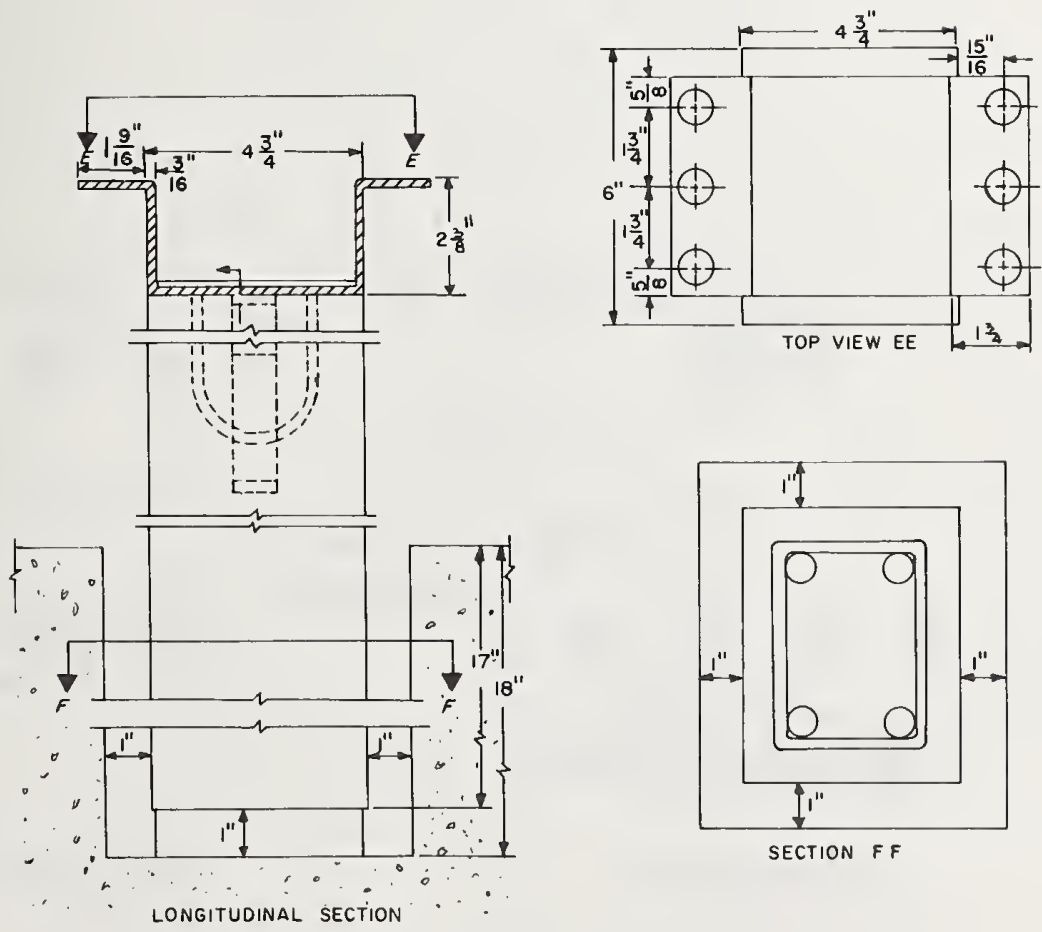

FigURE 5.7. Long column details. 


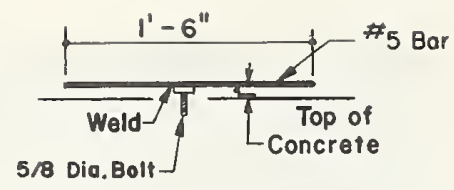

SHEAR STUD DETAIL

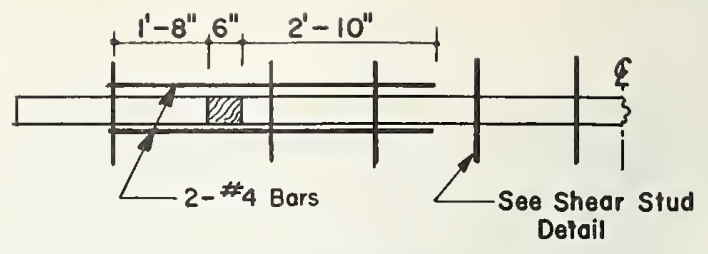

SLAB REINFORCEMENT ABOVE MAIN BEAM

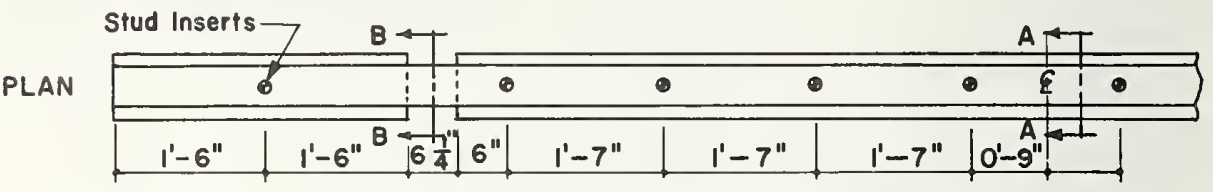

ELEV.

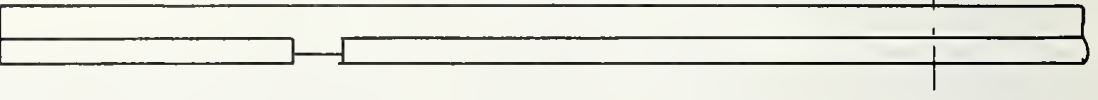

STEEL

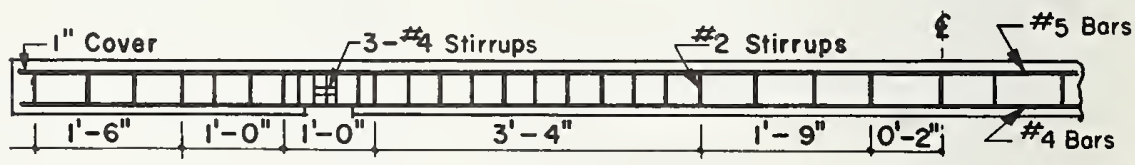

Figure 5.8. Main beam reinforcement.
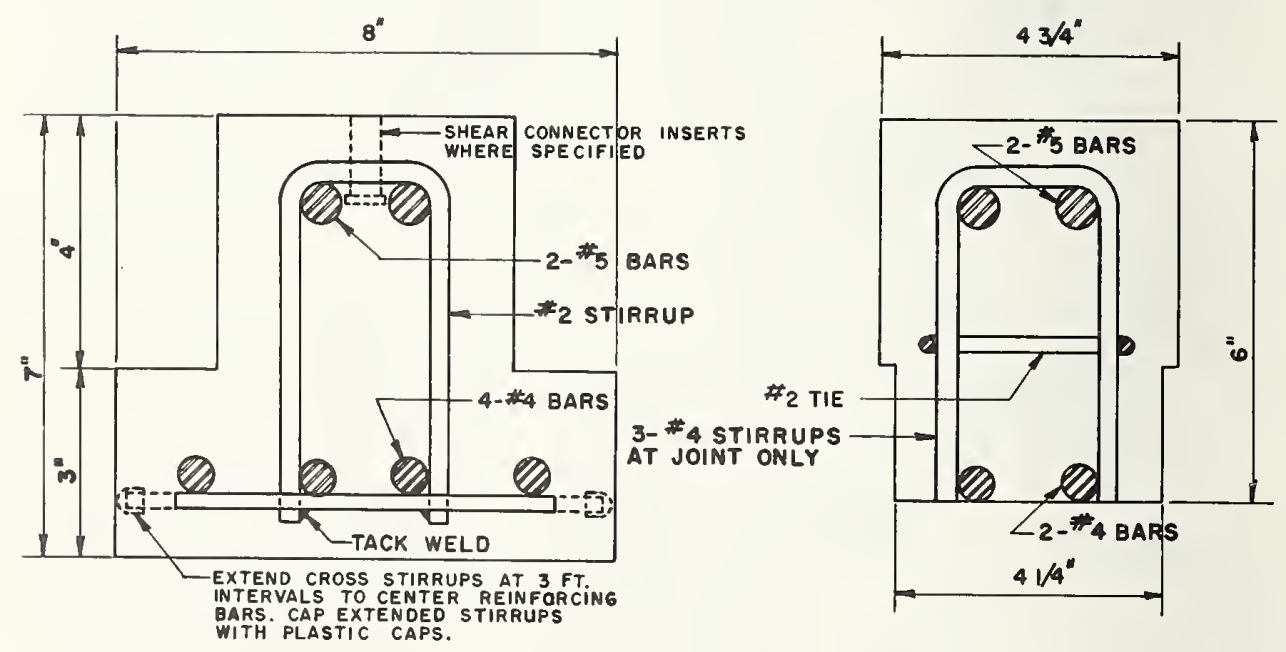

$\frac{\text { SECTION "A-A" }}{\text { (SEE FIG. 5.8) }}$

Figure 5.9. Main beam sections. 


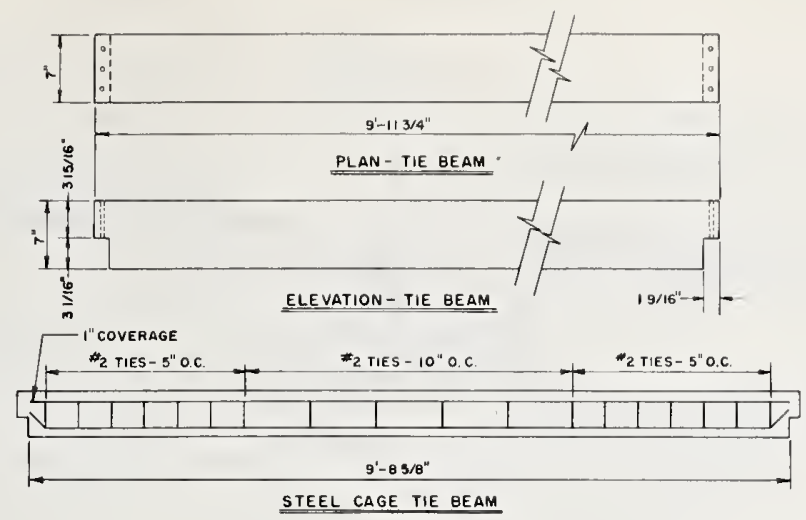

Figure 5.10. Tie-beam plan and elevation.

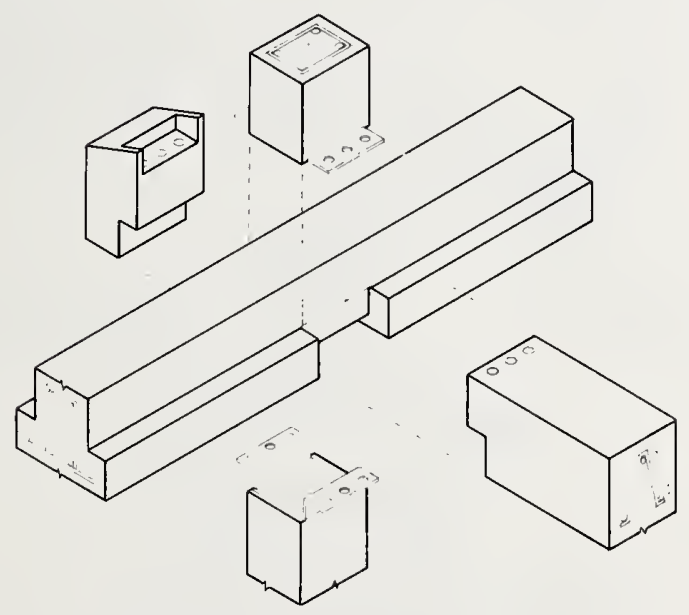

FIGURE 5.11. Beam and column connection. 

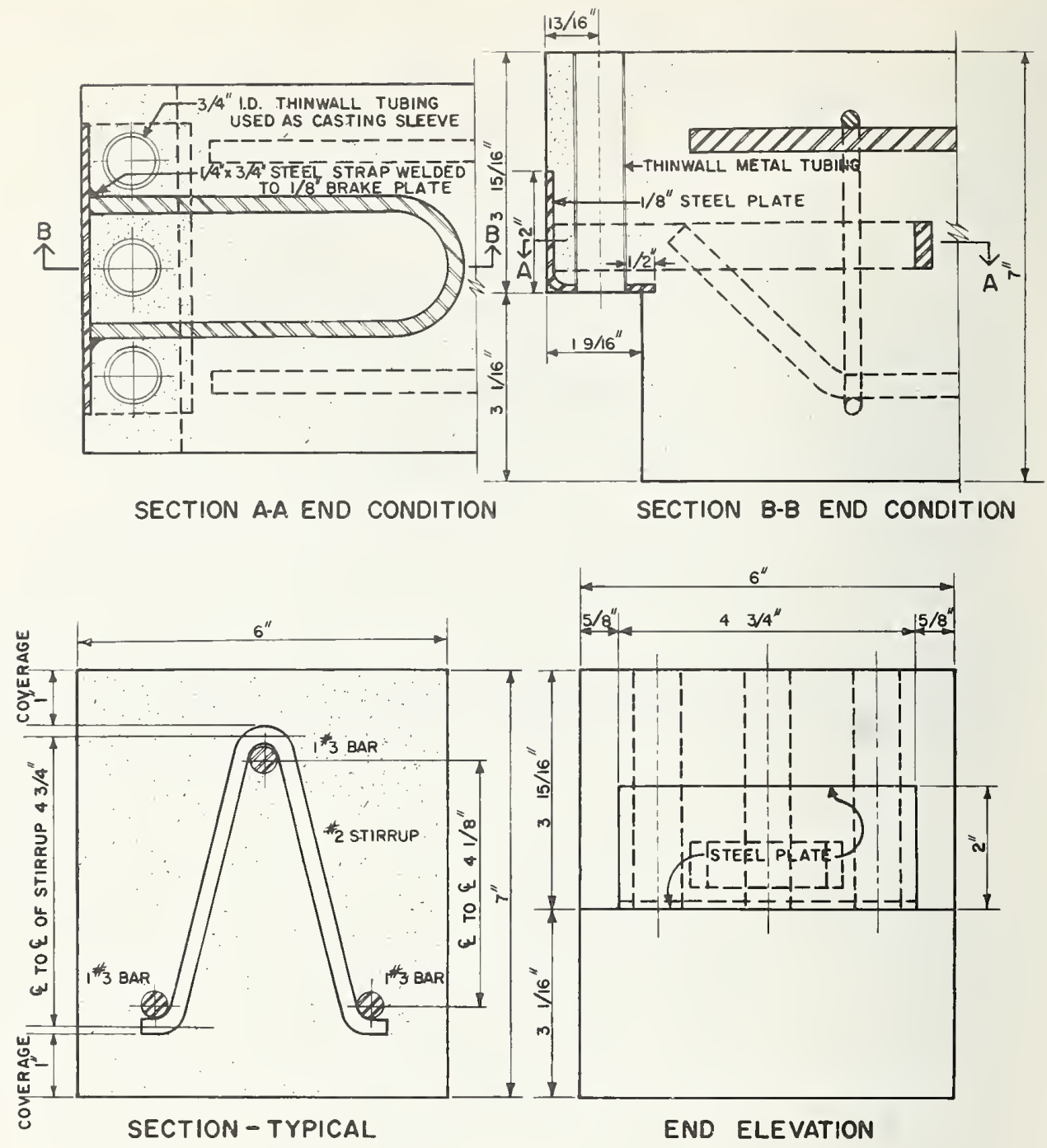

FIgURE 5.12. Tie-beam end details. 

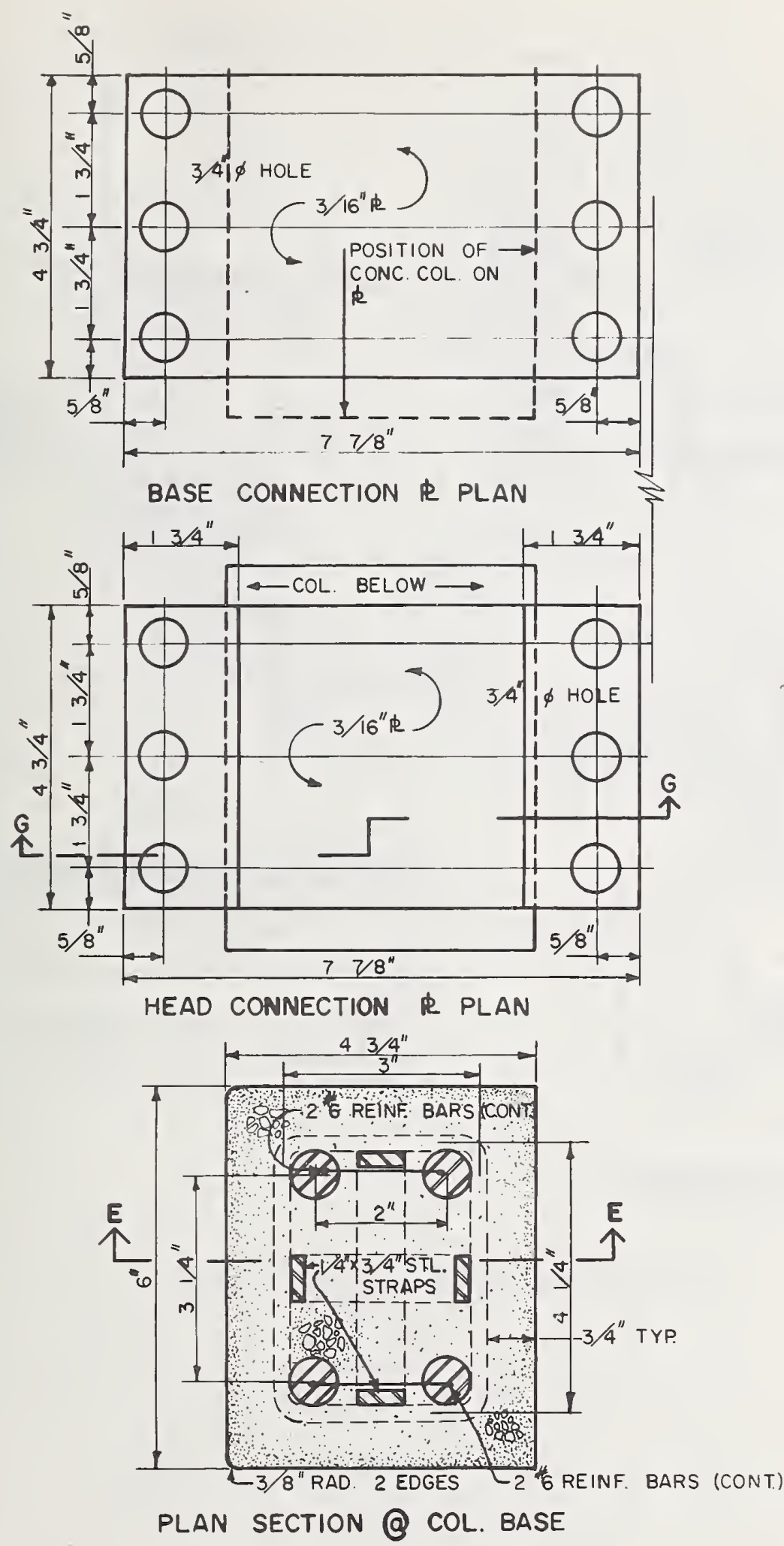

Figure 5.13. Plan sections of column connections. 

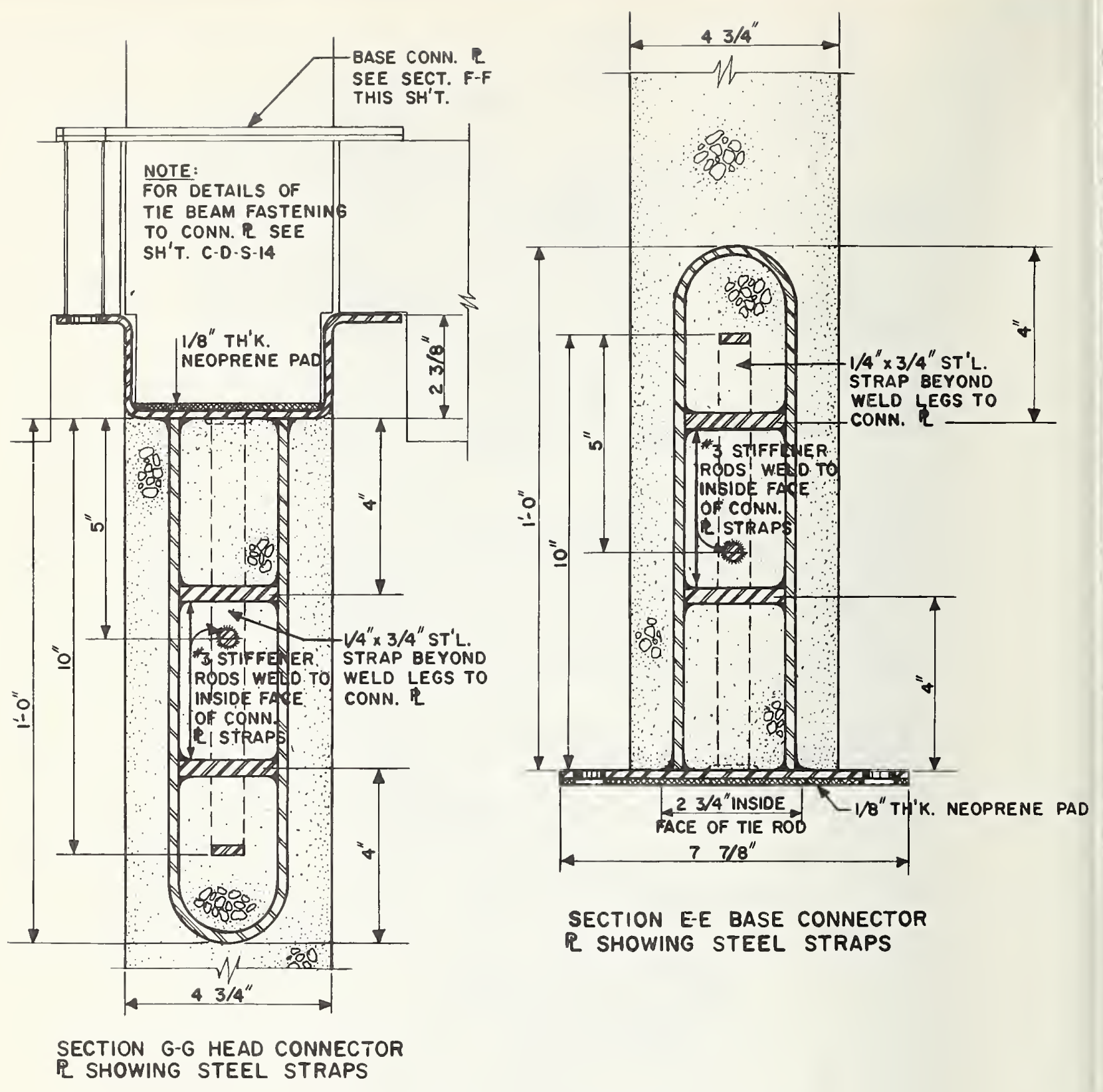

FIGURE 5.14. Elevation sections of column connections. 


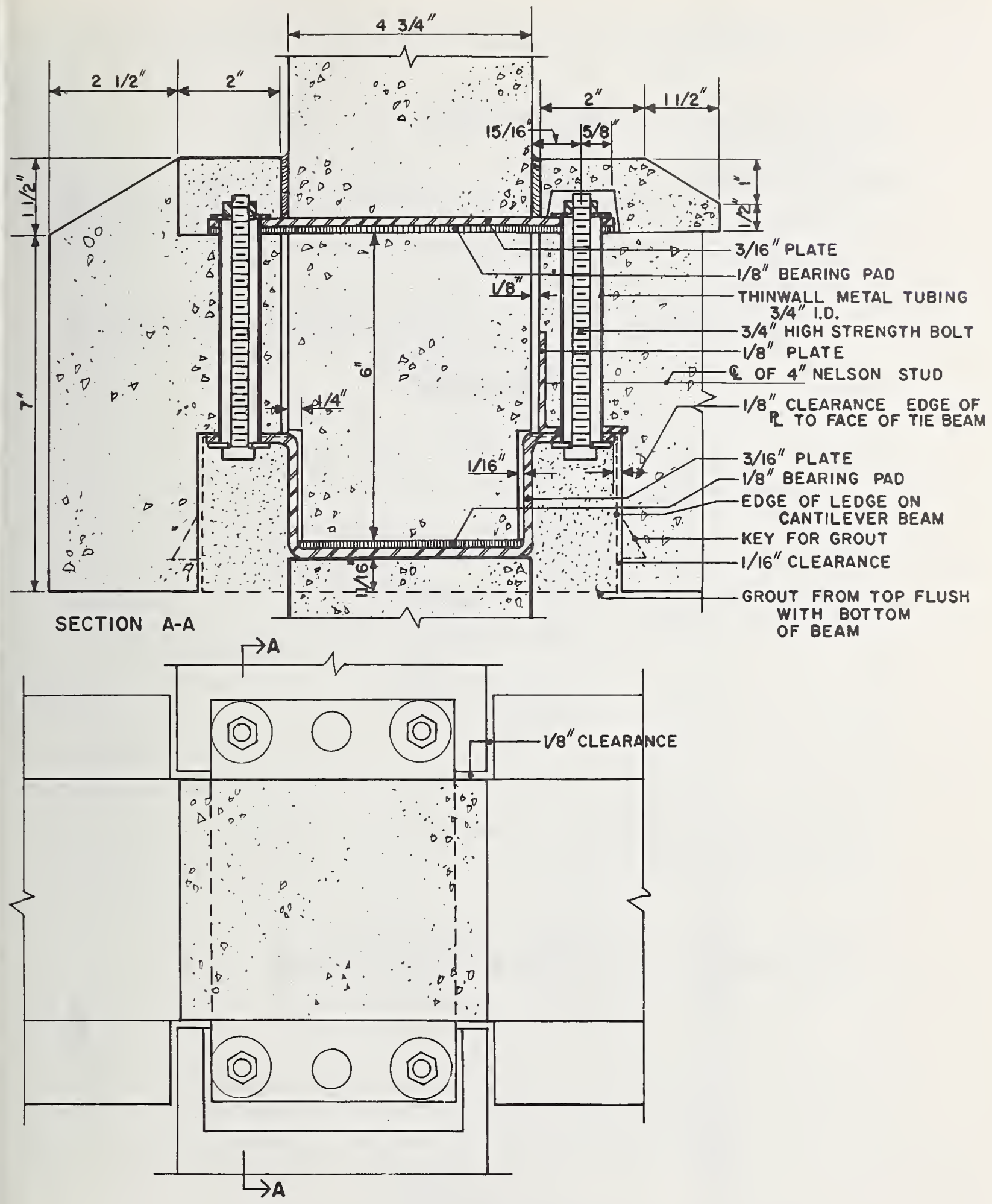

FIGURE 5.15. Connection detail. 


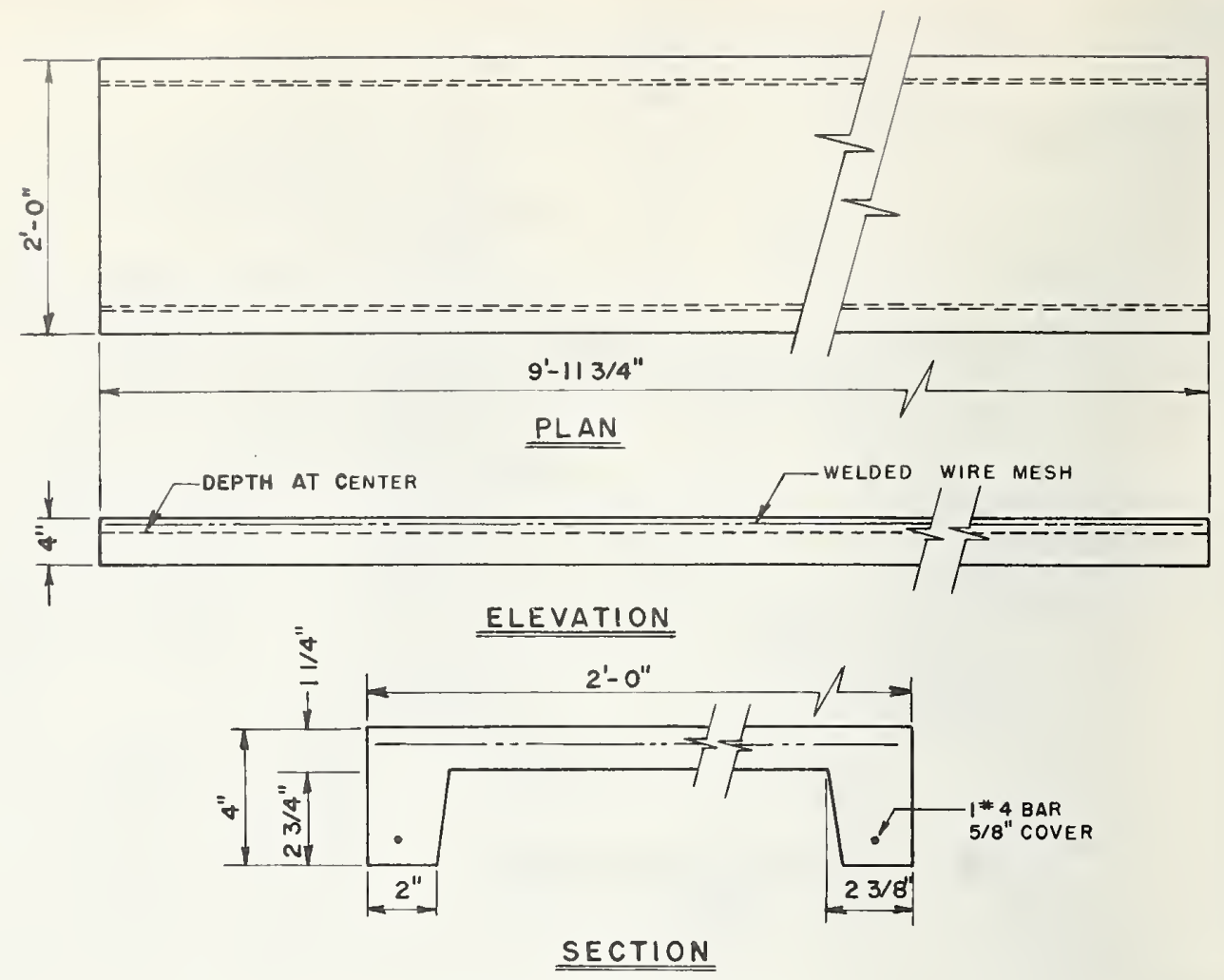

Figure 5.16. Floor channels.

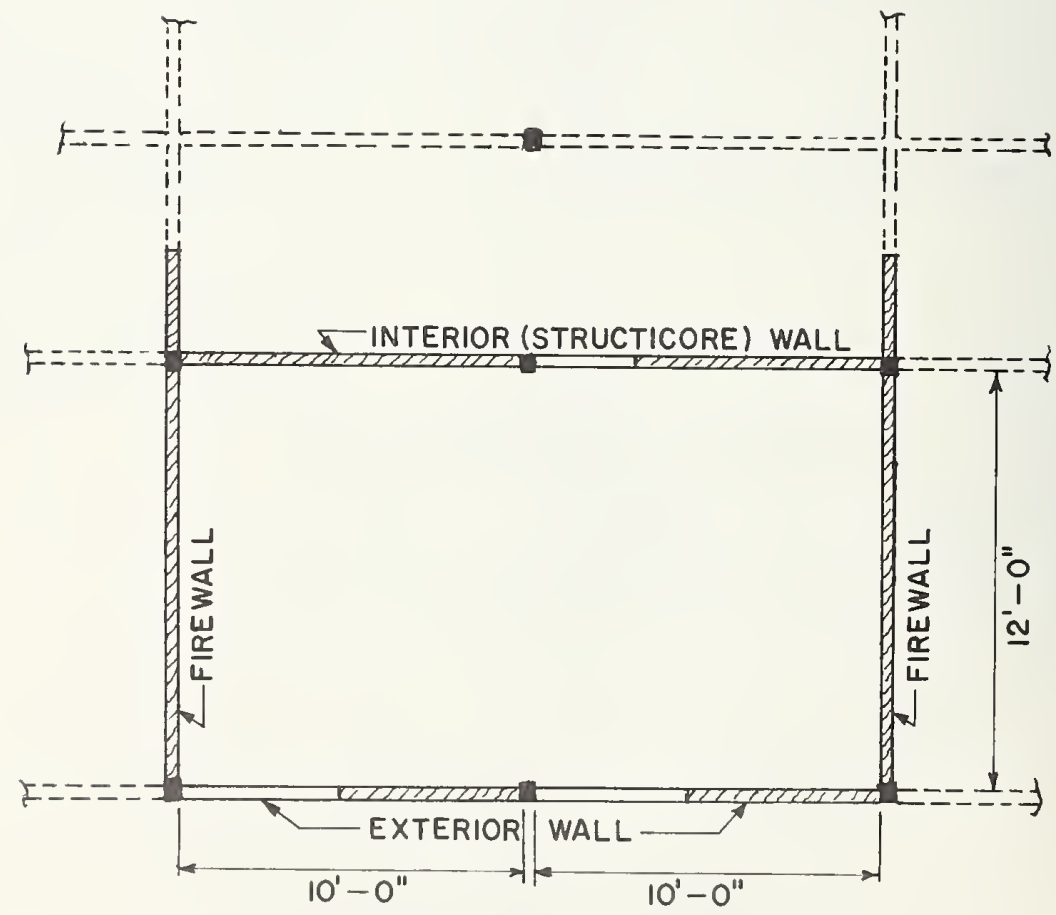

Figure 5.17. Plan section through walls. 
25 GAUGE GALV CHANNEL

RUNNER (2 V/2") NOTE:

DO NOT FASTEN VERTICAL

STUDS TO THE RUNNER

THEY RIDE UP 8 DOWN

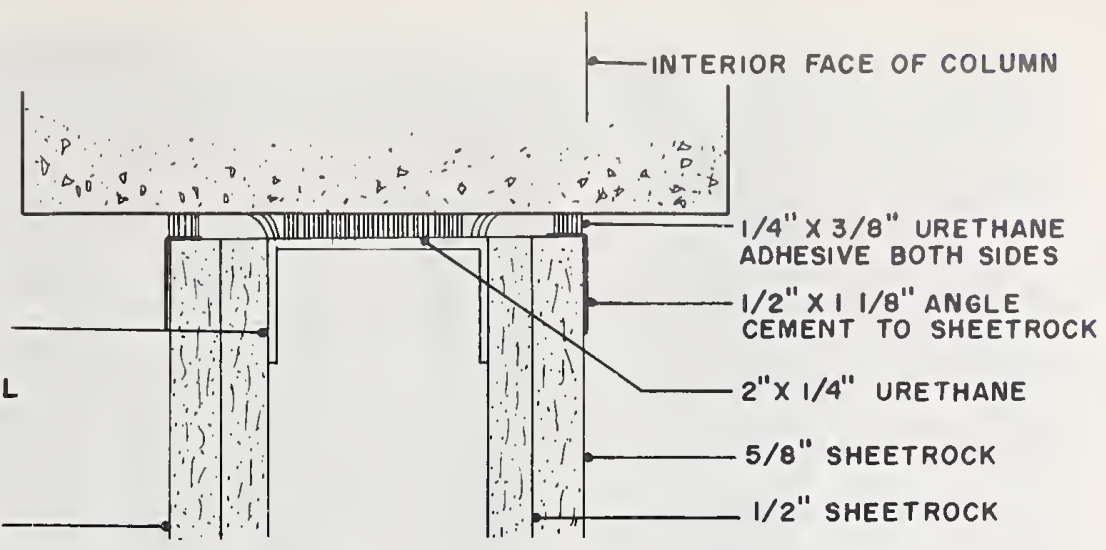

COLUMN FACE

SECTION

DETAIL AT HEAD

2 HOUR RATING

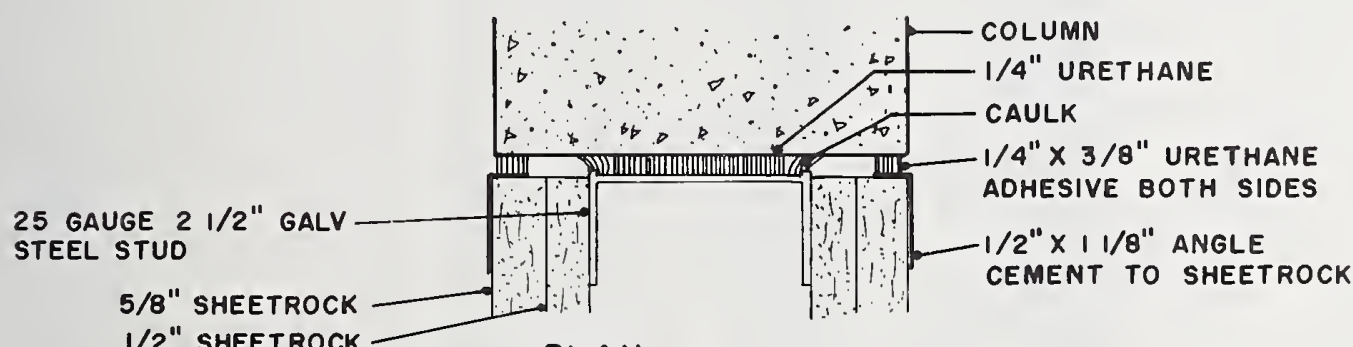

PLAN

DETAIL AT COLUMN

2 HOUR RATING

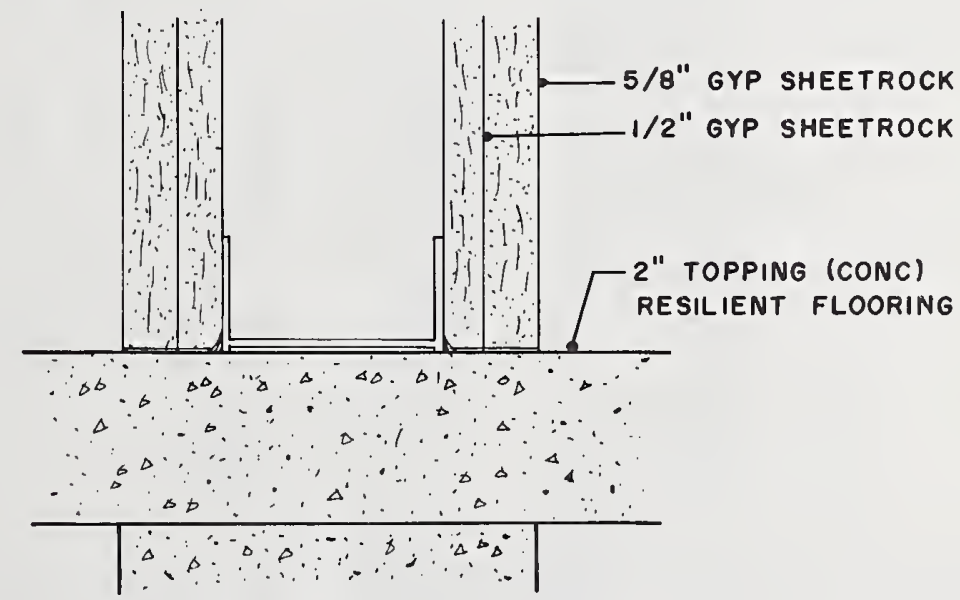

SECTION

DETAIL@SILL

2 HOUR RATING

Figure 5.18. Fire wall. 


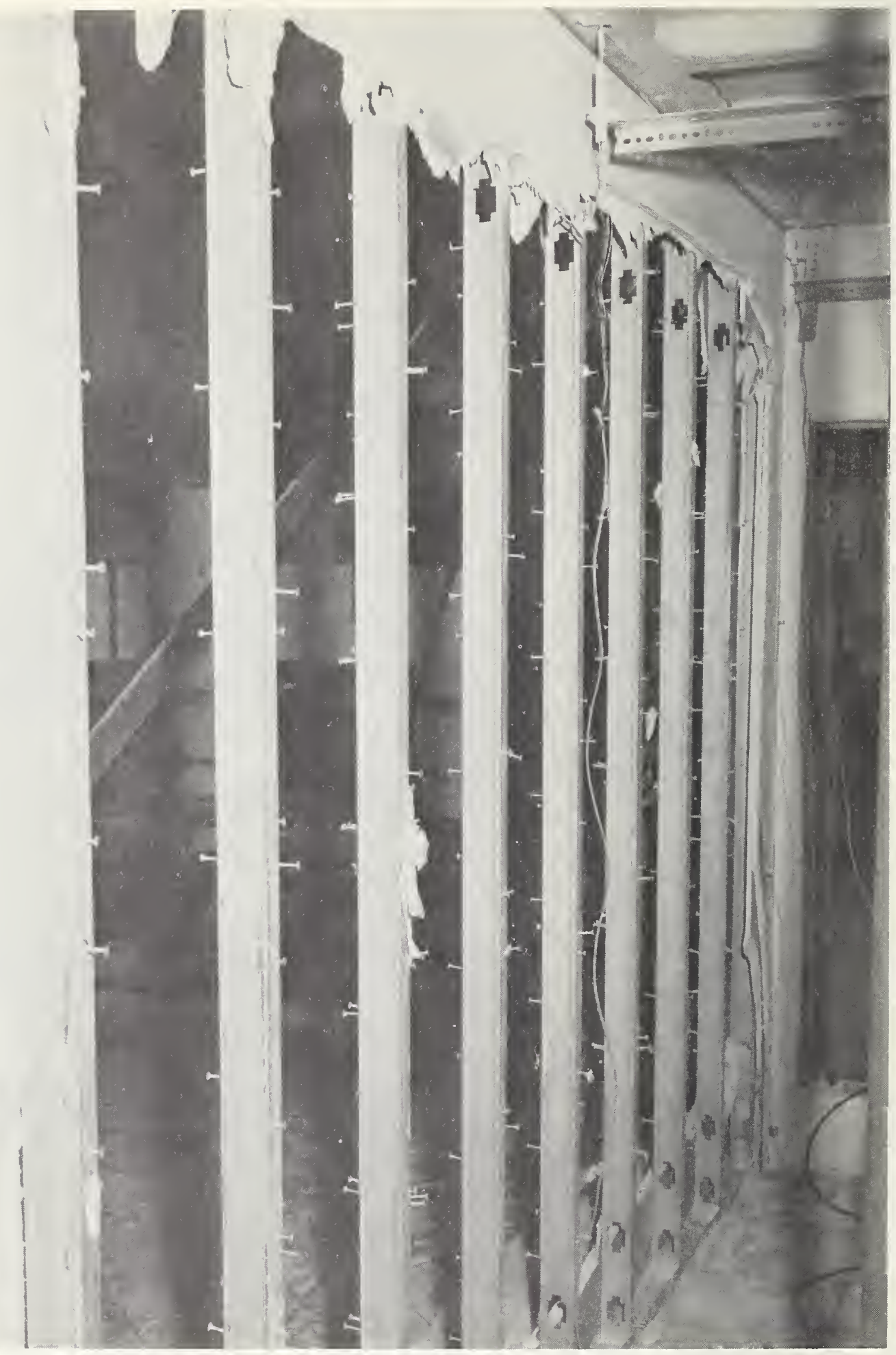

Figure 5.19. Fire wall (partially dismantled). 


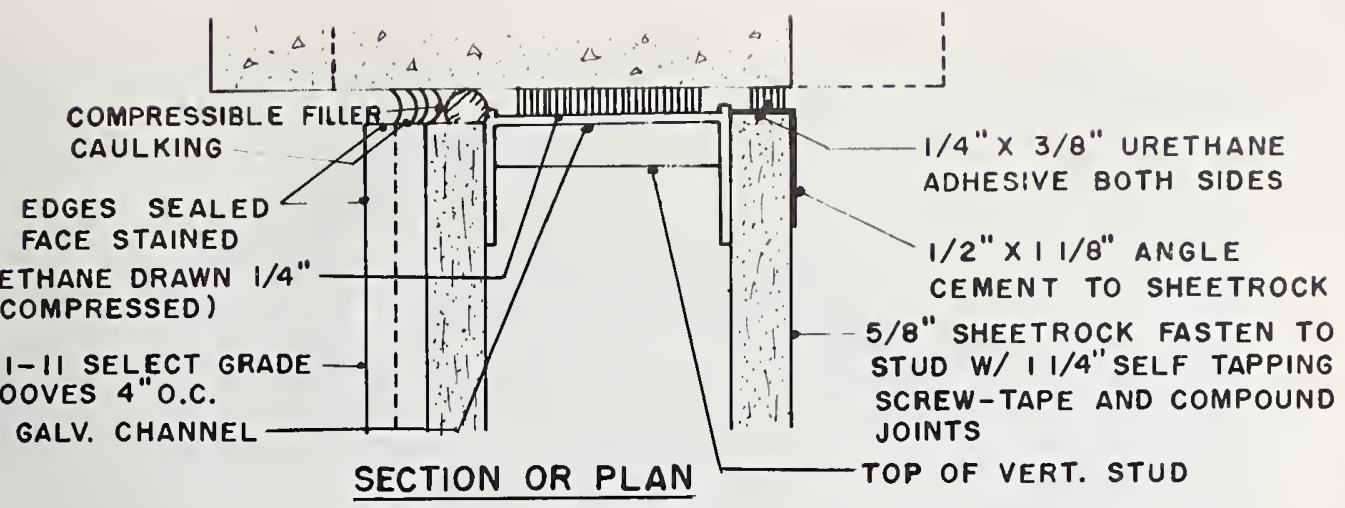

DETAIL AT HEAD

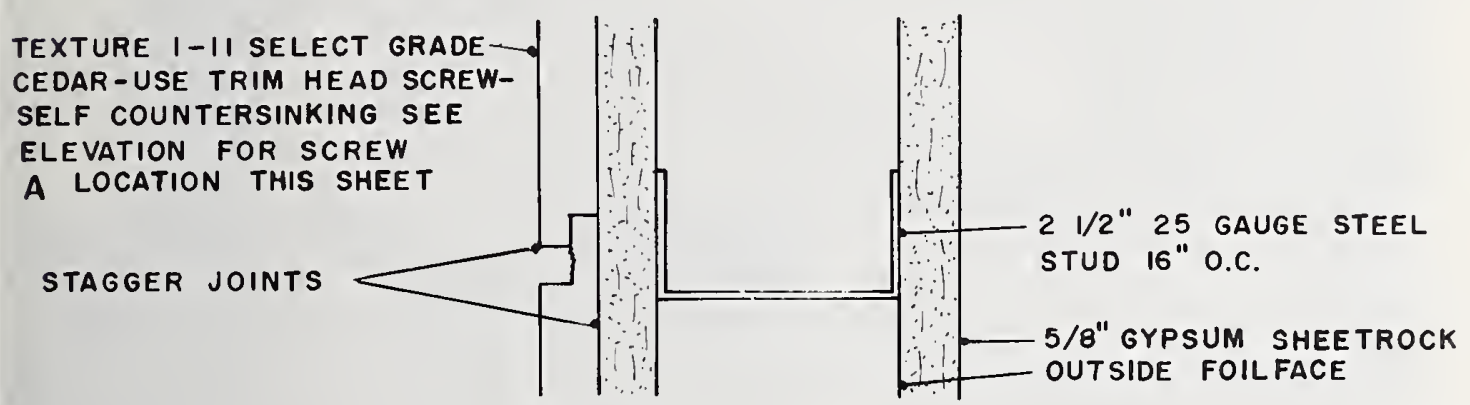

PLAN

SECTION

DETAIL AT SILL

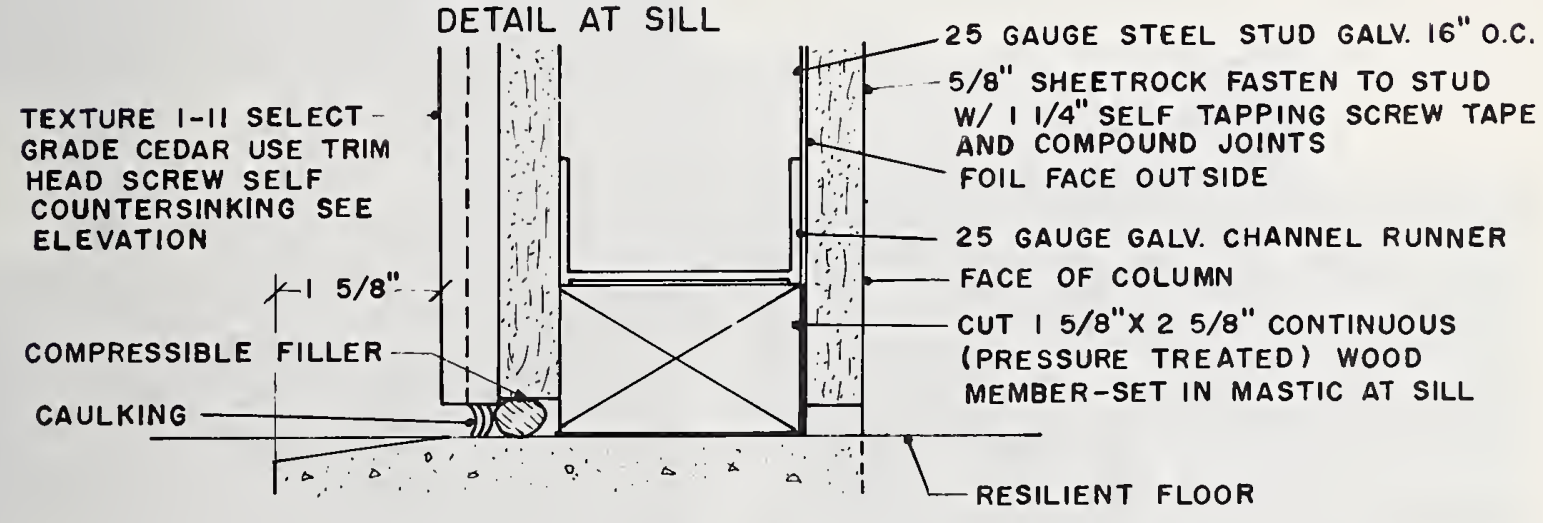

Figure 5.20. Exterior wall details. 


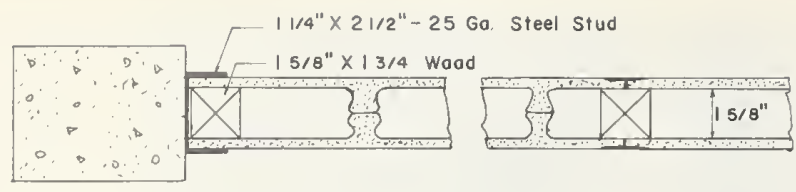

PLAN
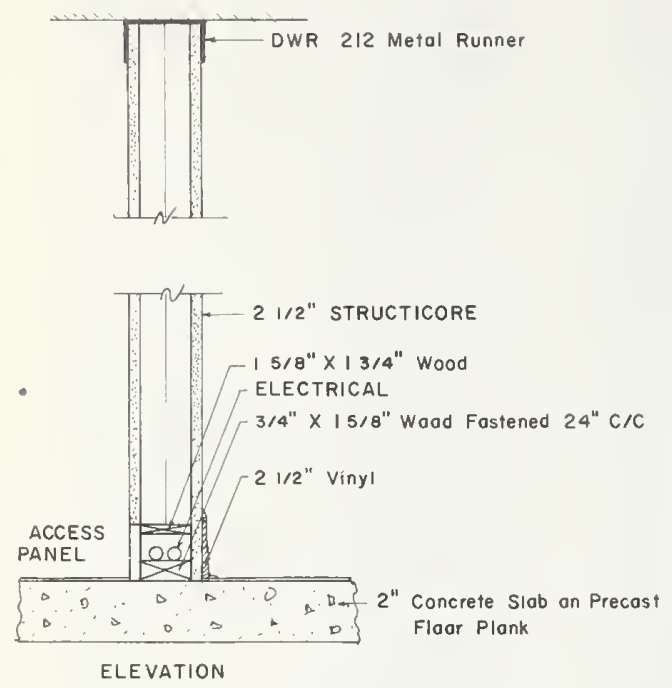

FIgURE 5.21. Interior uall sections.

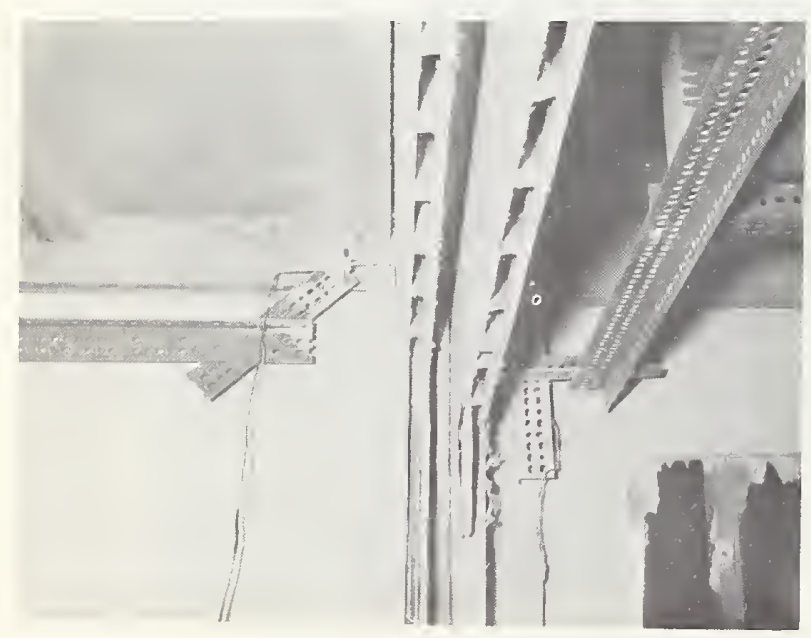

H'IGURE 5.22. Ireterior wall (partially dismantled)

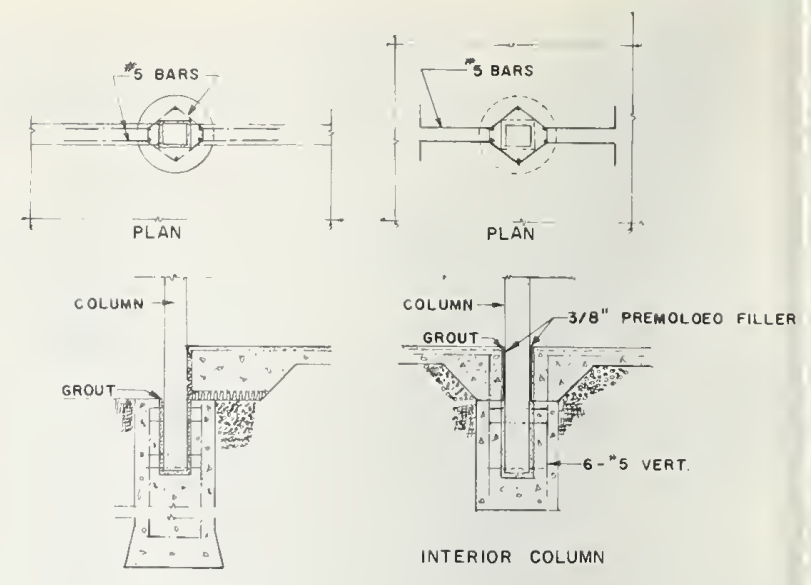

FIGURE 5.23. Foundation detail.

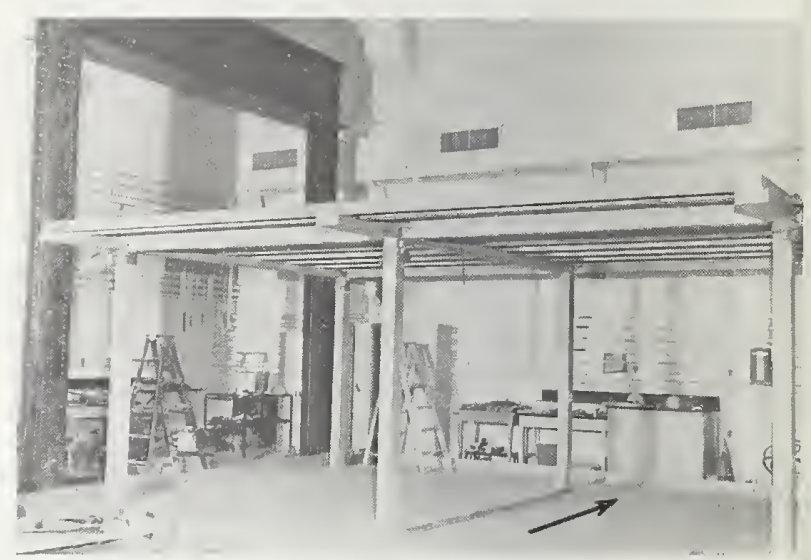

FIgURE 5.24. Test structure before the installation of walls.

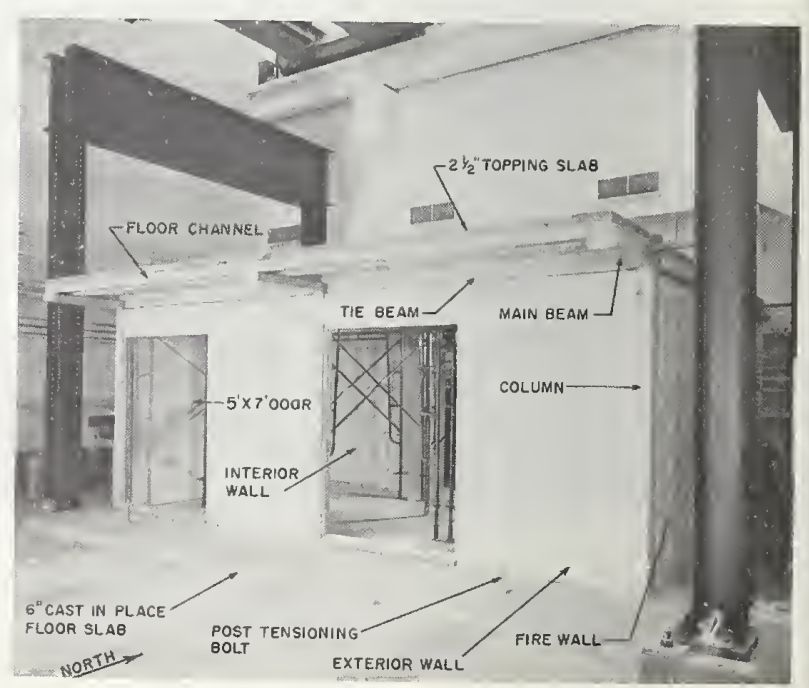

FIGURE 5.25. Test structure after the installation of walls. 


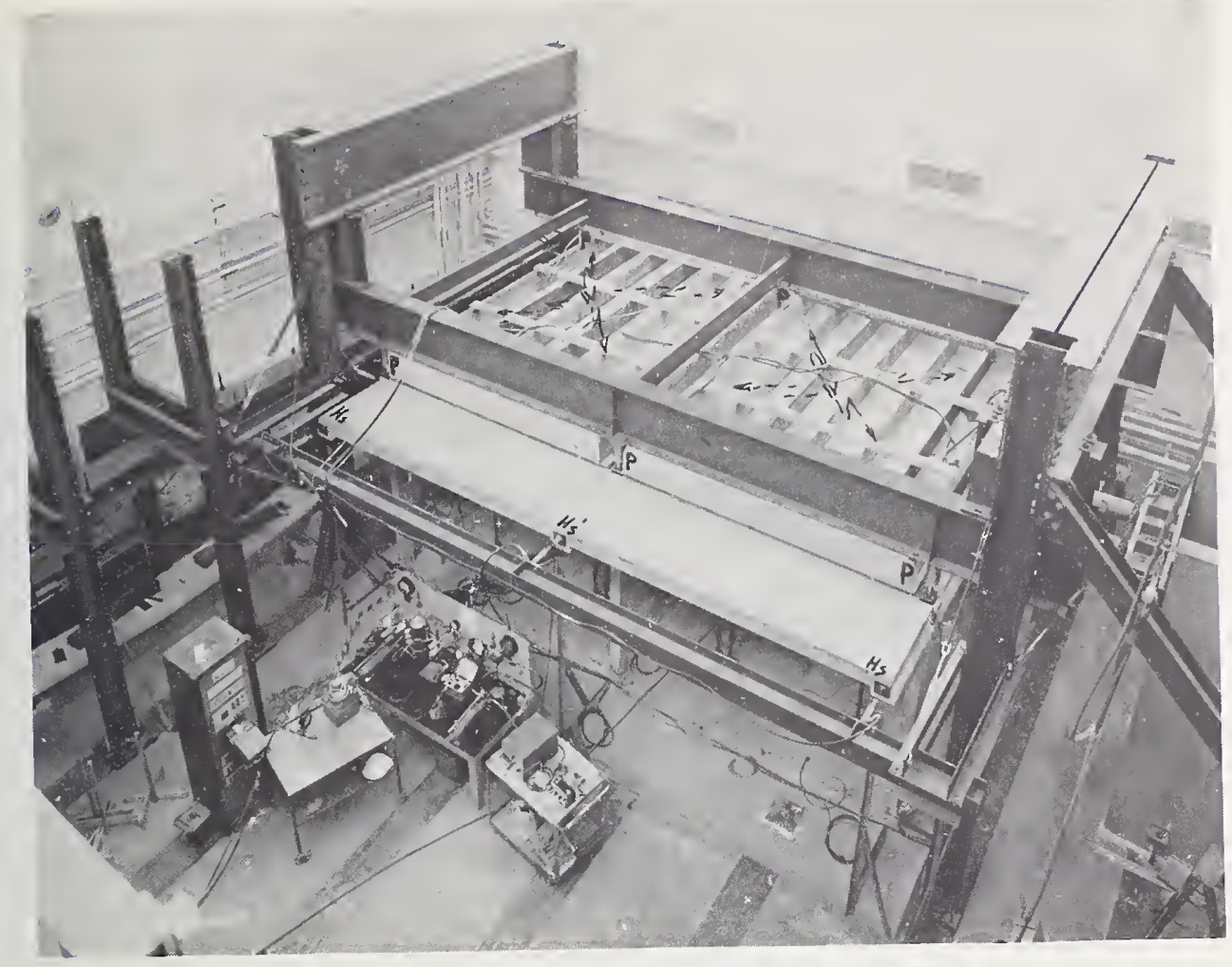

Figure 5.26. Test structure with testing equipment installed (top view).

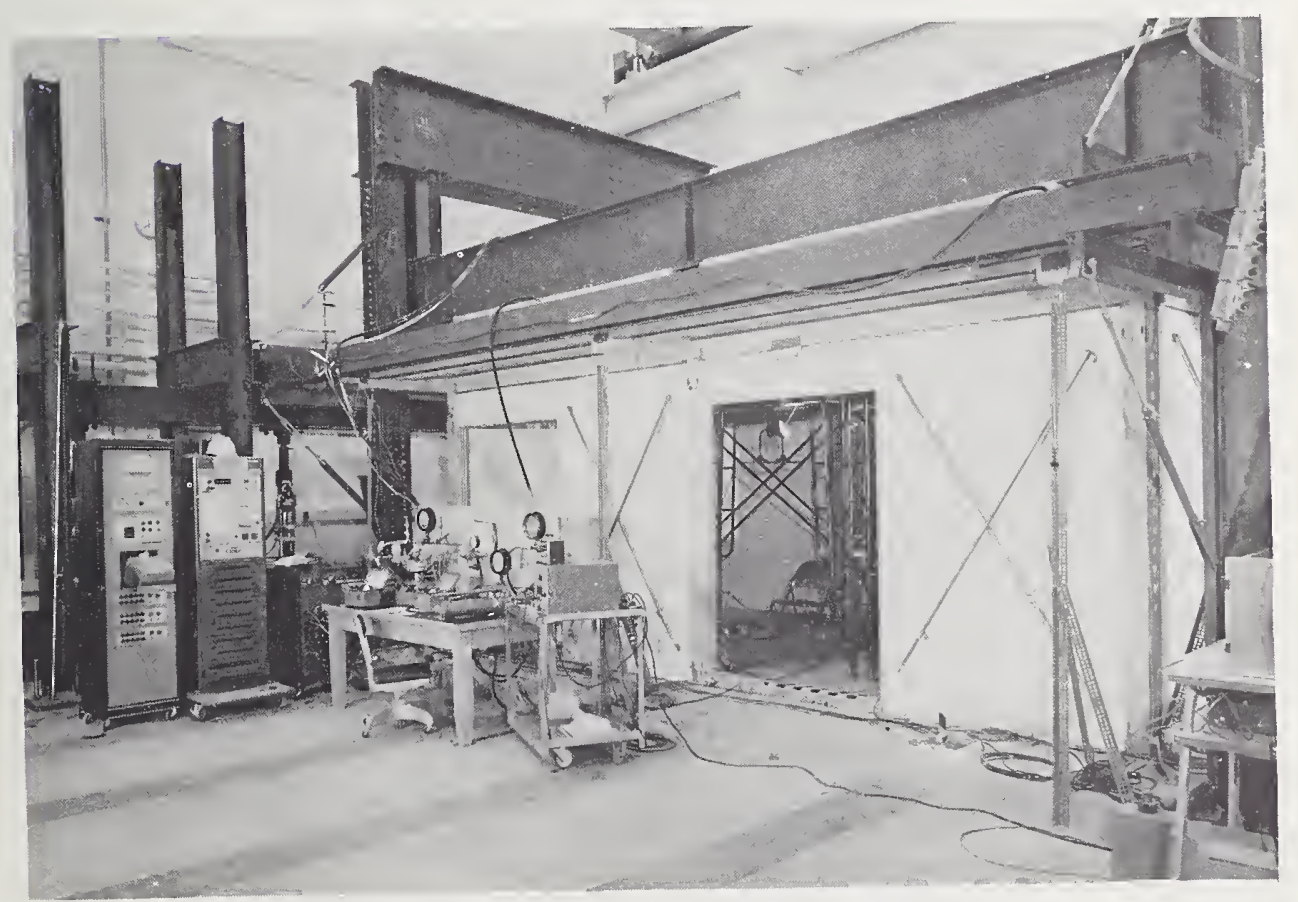

FIGURE 5.27. Test structure with testing equipment installed (front vicw). 


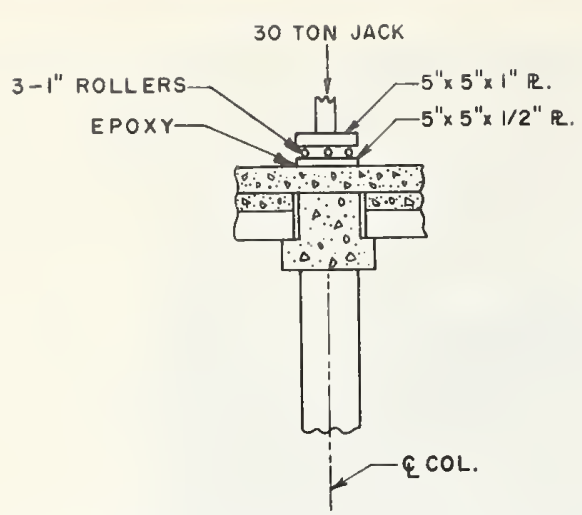

Figure 5.28. Column load equipment connection.

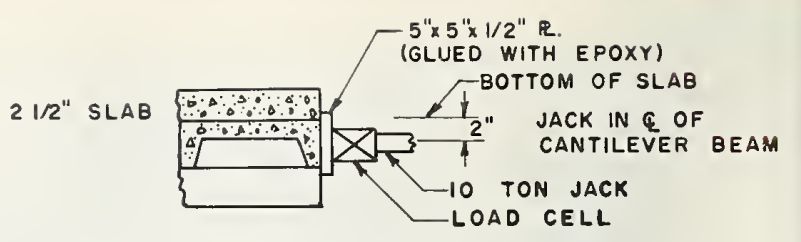

$N \rightarrow S$ RACKING LOAD

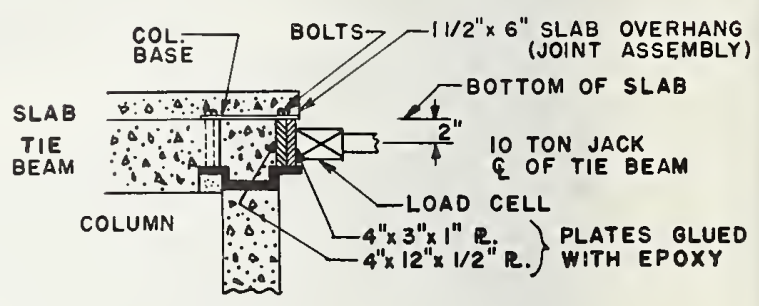

W-E RACKING LOAD
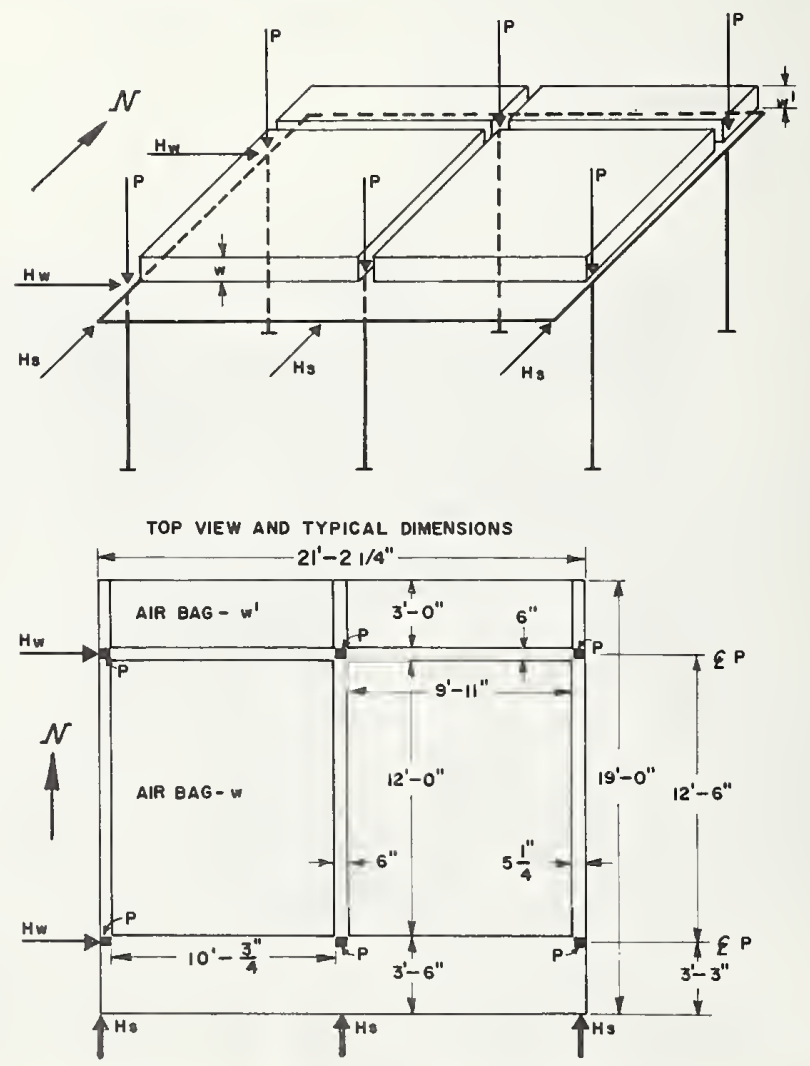

FIGURE 6.1. Loading of test structure. 


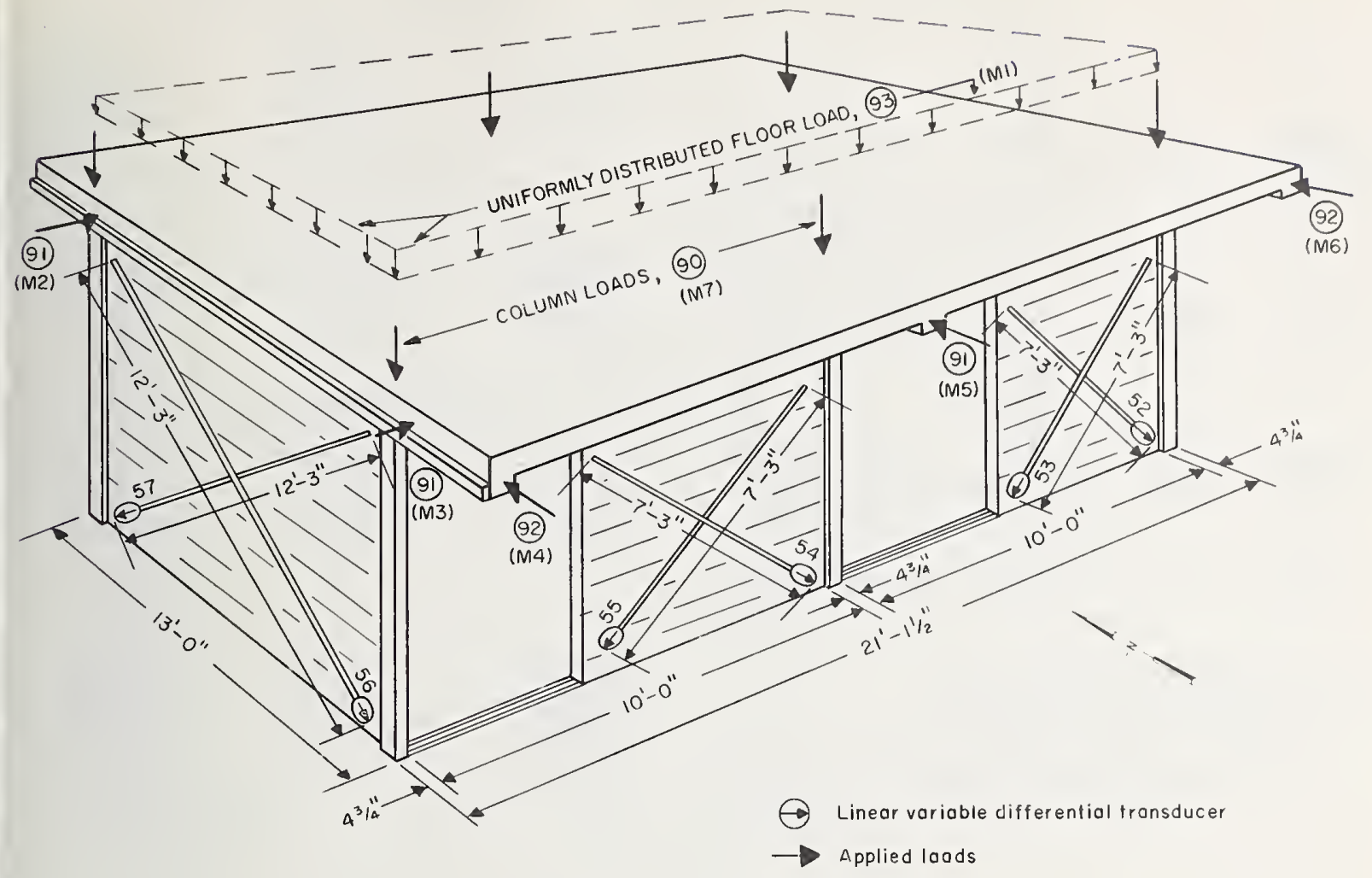

Figure 7.1. Instrumentation location. Northeast schematic.

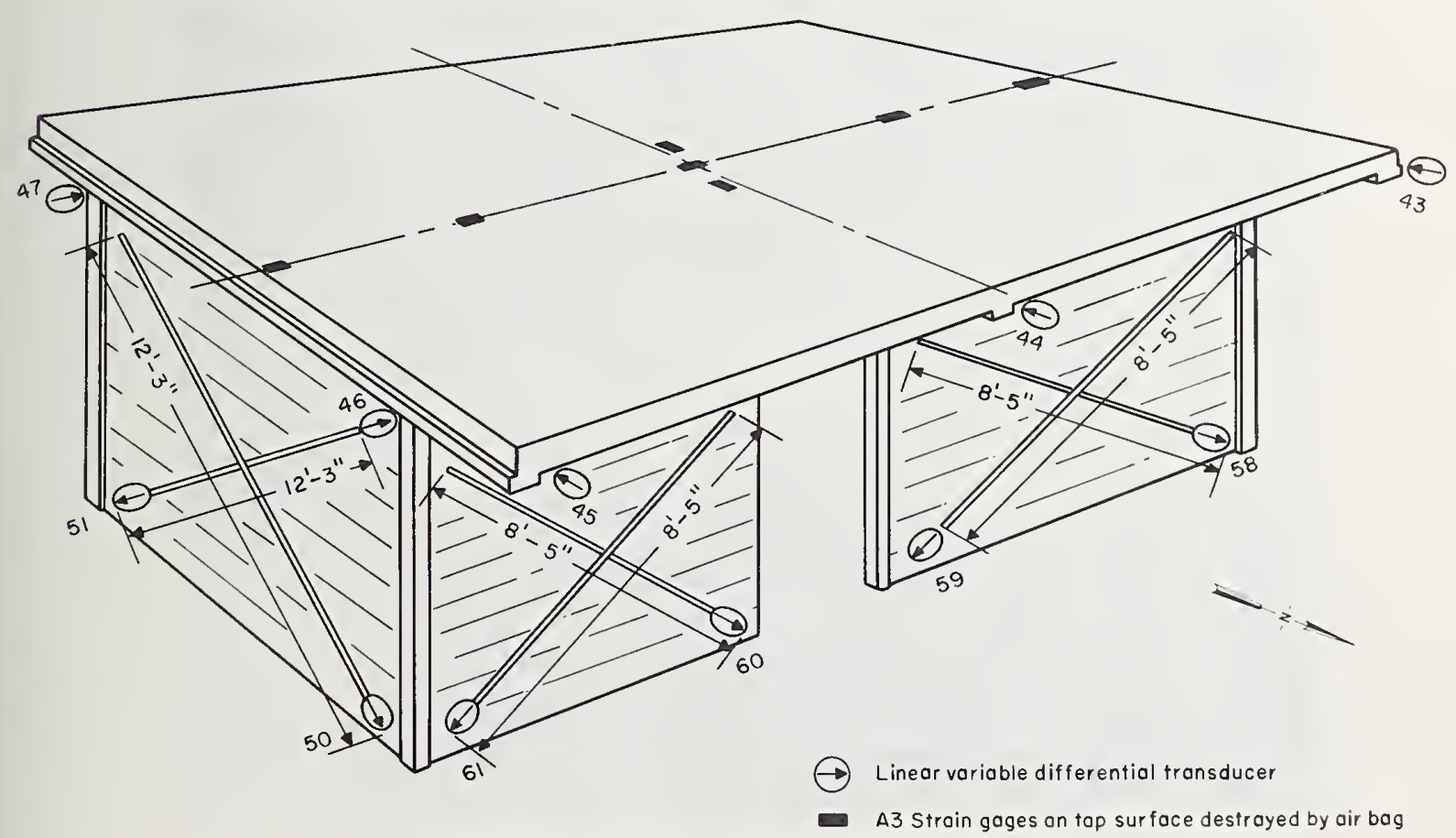

FIGURE 7.2. Instrumentation location. Southwest schematic. 


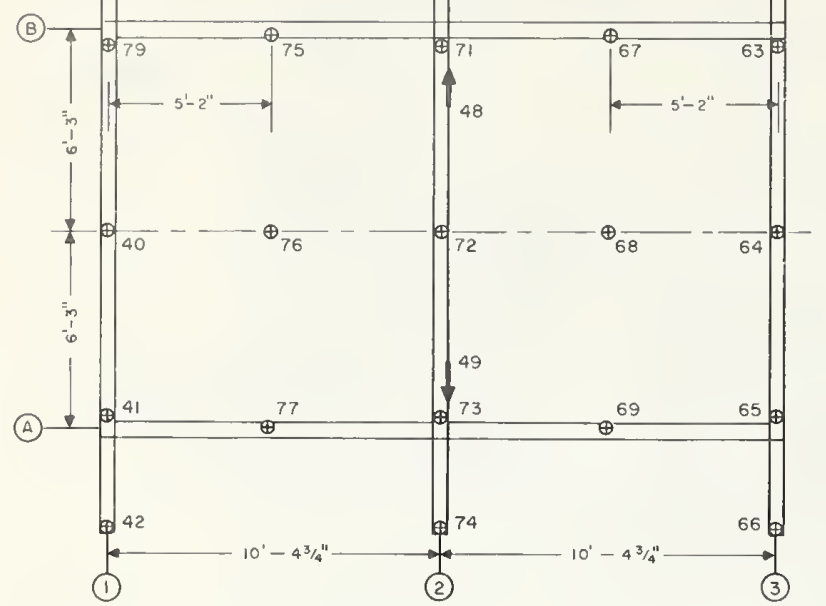

$\oplus \quad$ Linear variable differential transducer-vertical

$\rightarrow$ Linear variable differential iransducer - harizantal slip Numbers define channel lacotion digital recarder tope

Figure 7.3. Vertical deflection gages.

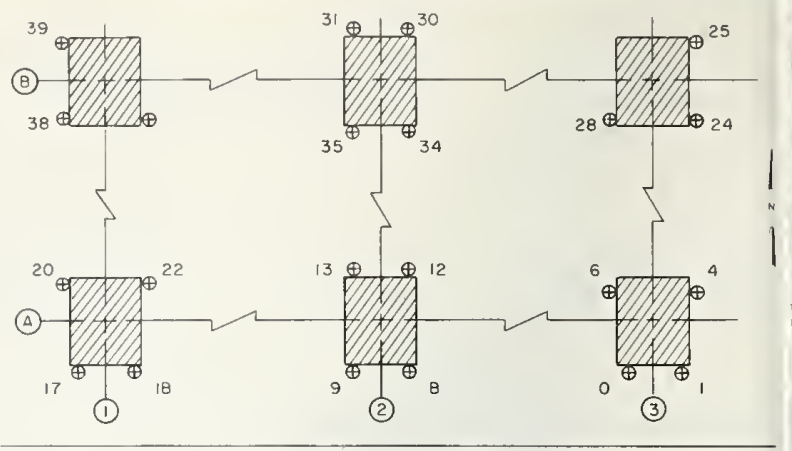

PLAN SECTION 6" ABOVE FLOOR

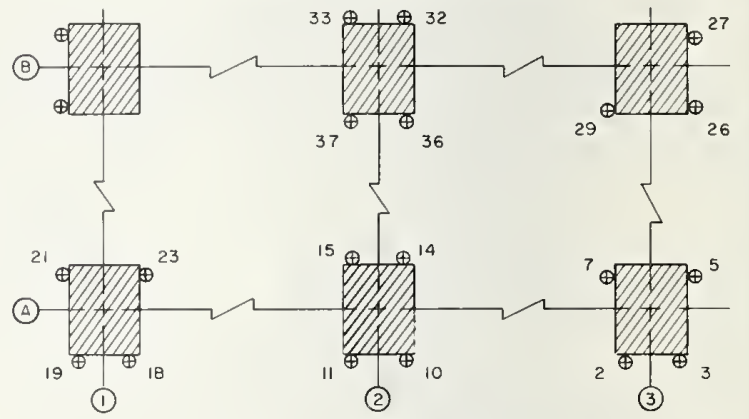

(4ype A-3 stroin gage locoted $1 / 2$ fram carner of calumn

Figure 7.4. Column strain gage location.

CHANNELS 72 AND 73, SEE FIGURES A-11 AND A-16

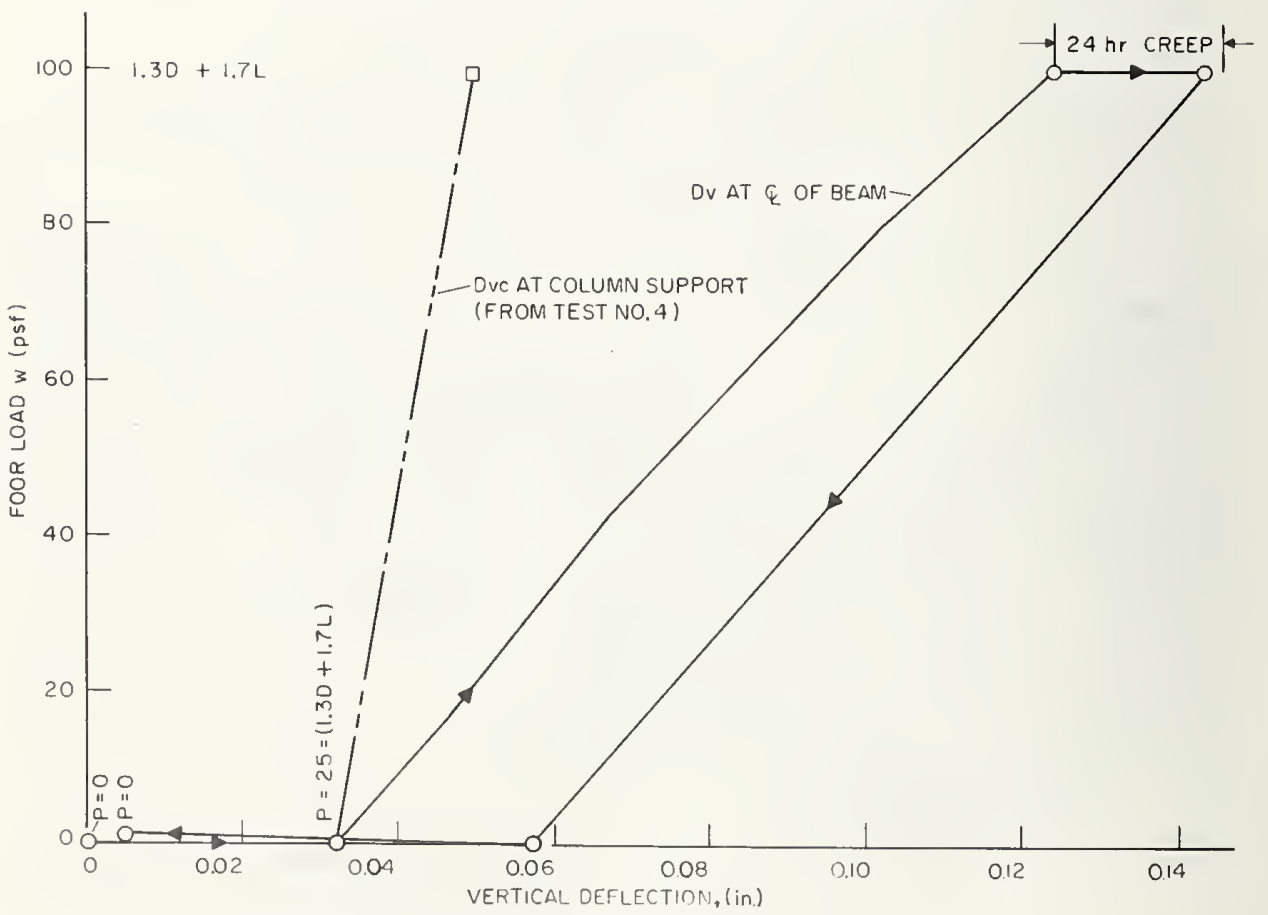

FIGURE 9.1. Test No.5, sustained vertical load versus midspan deflection of center main beam. 


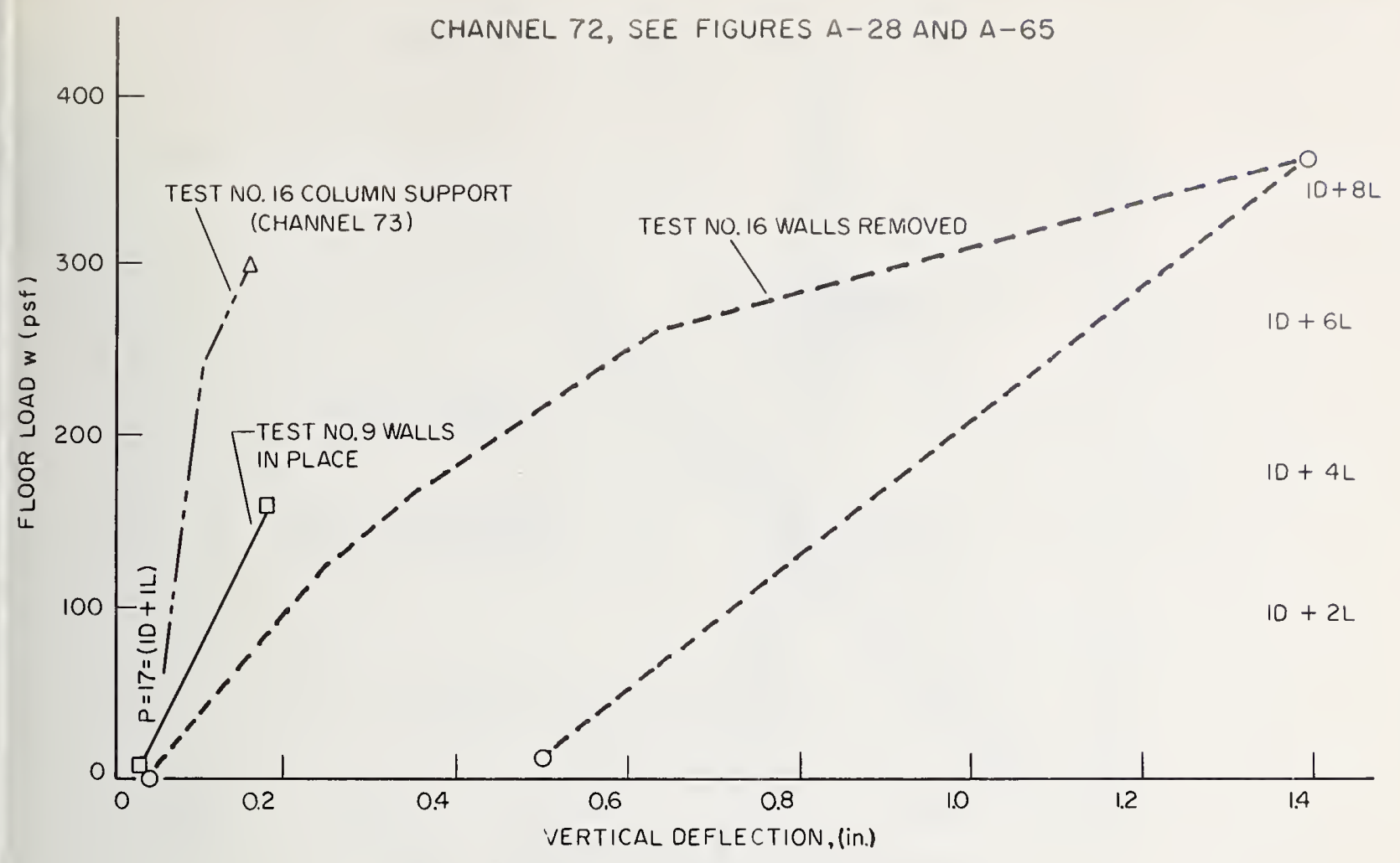

Figure 9.2. Test No. 16, major floor load (w) versus midspan deflection of center main beam.

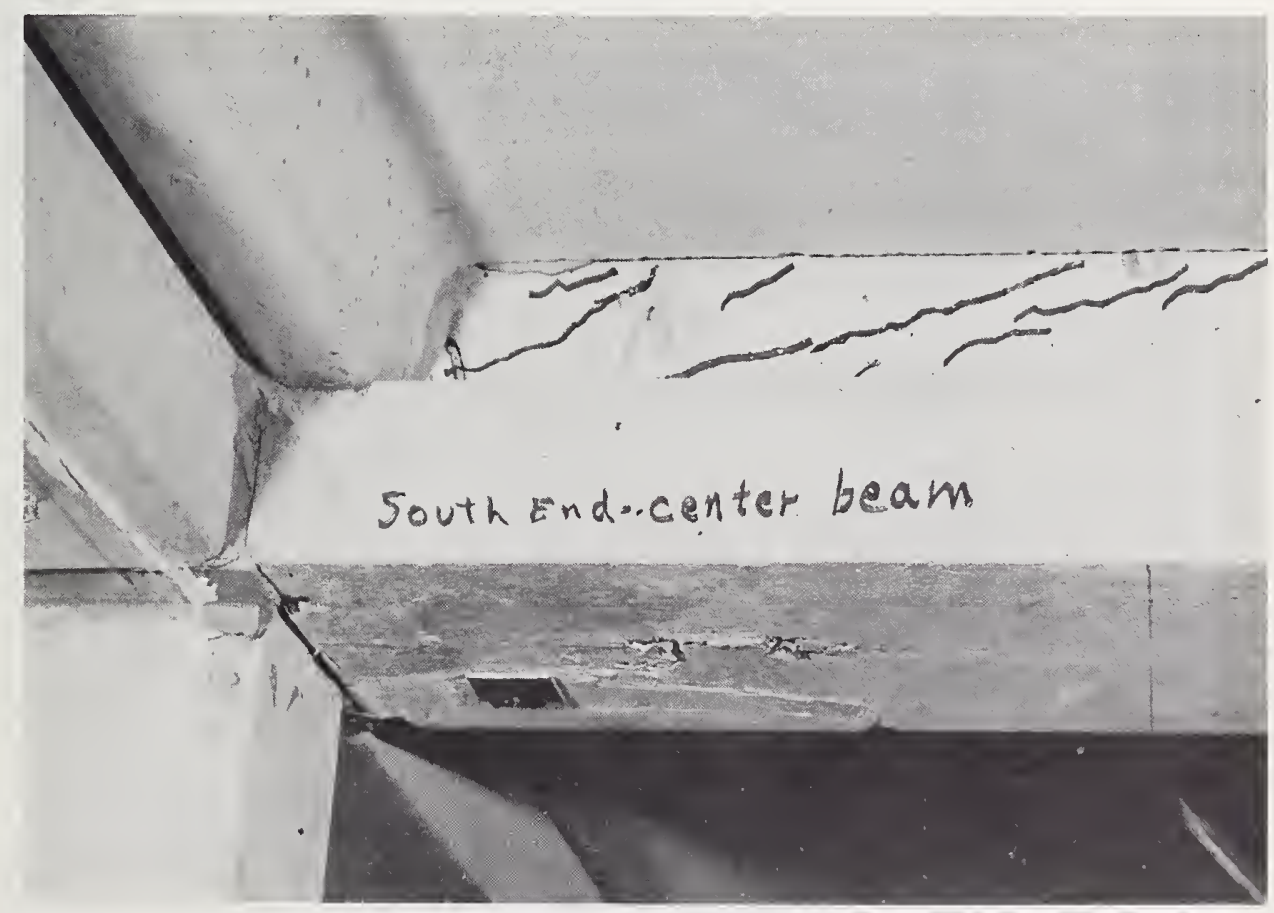

Figure 9.3. Diagonal tension cracking at $\mathrm{w}=2 r 0 \mathrm{psf}$ (Test No, 16). 


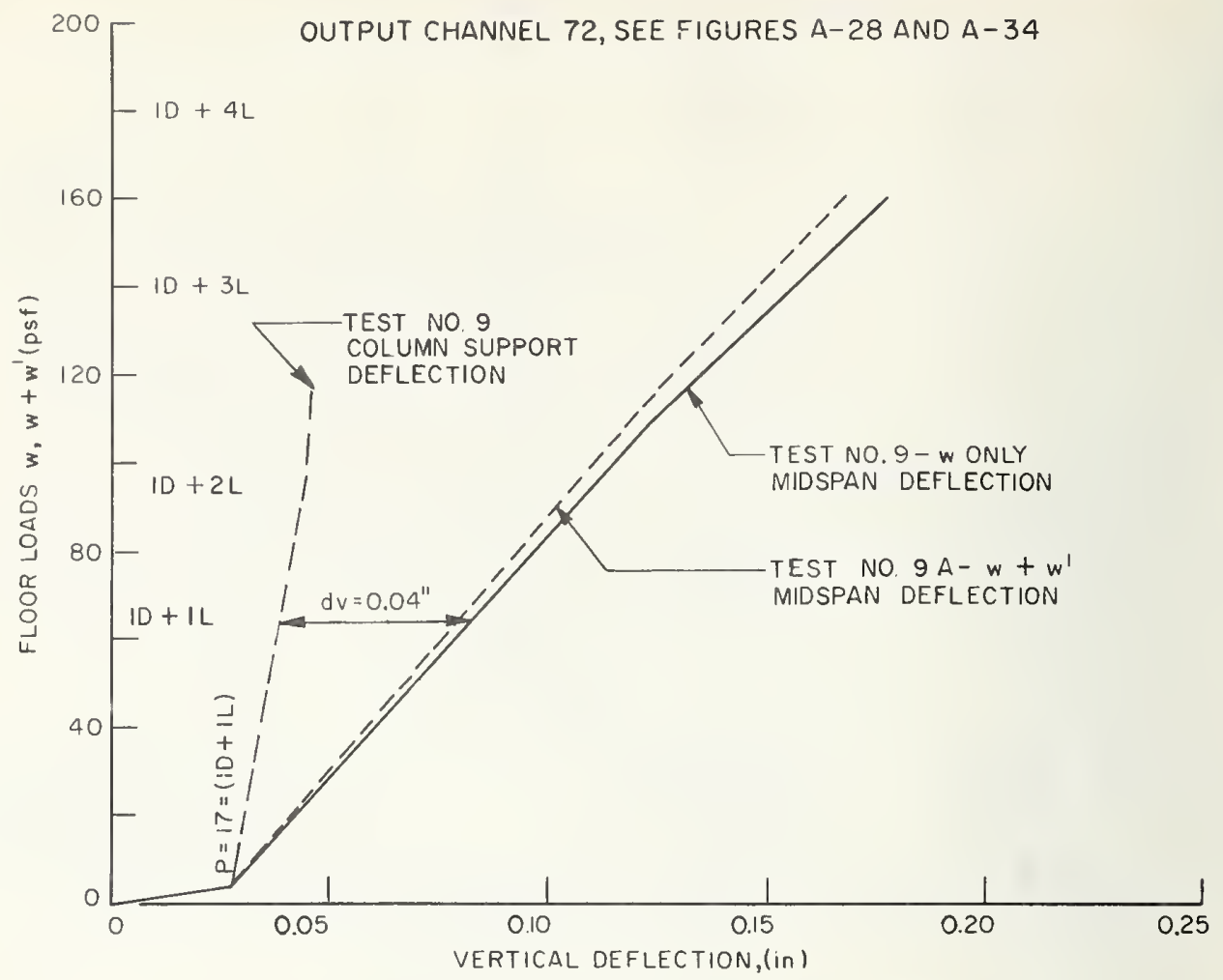

FIGURE 9.4. Interior floor load (w) and total floor load $\left(\mathrm{w}+\mathrm{w}^{\prime}\right)$ versus midspan and column support deflection of center main beam.

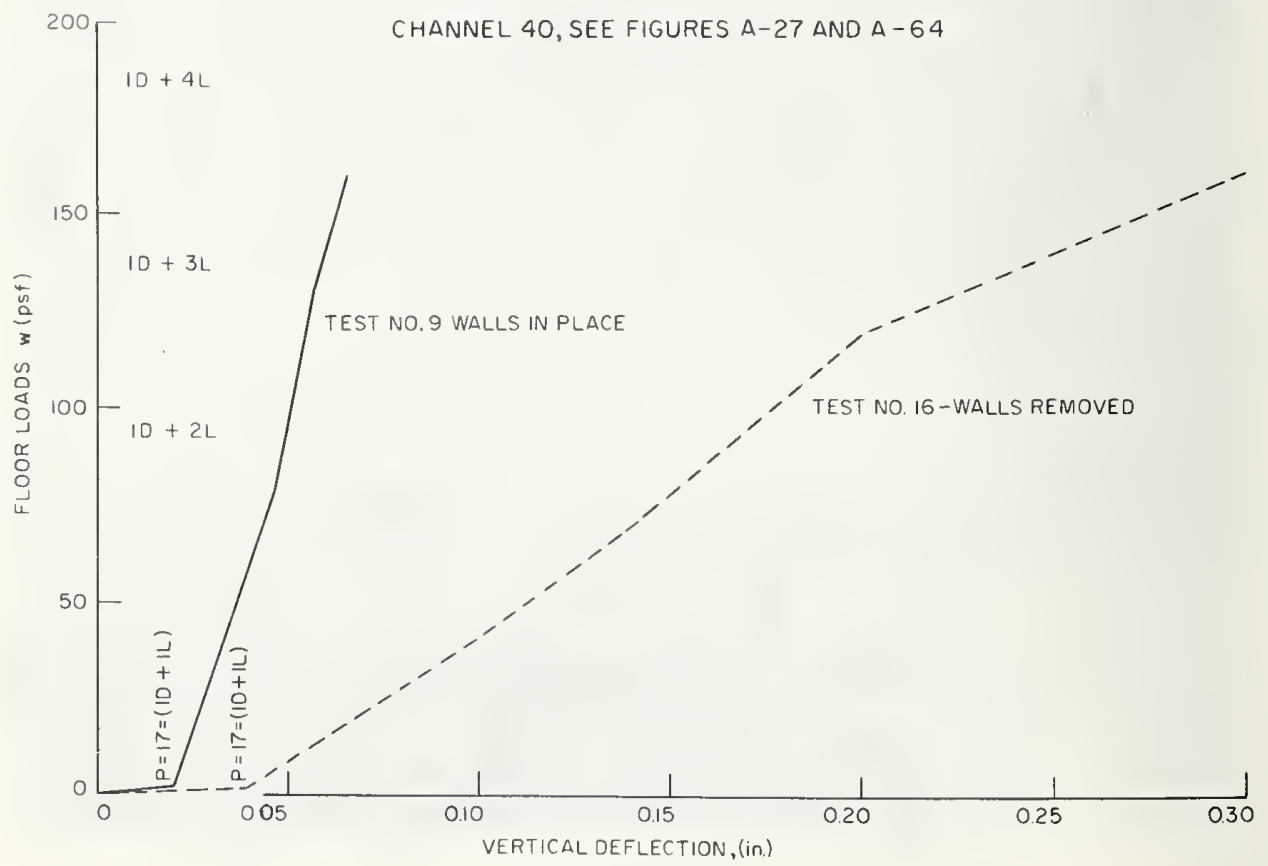

FIGURE 9.5. Midspan deflection of west main beam with and without walls. 


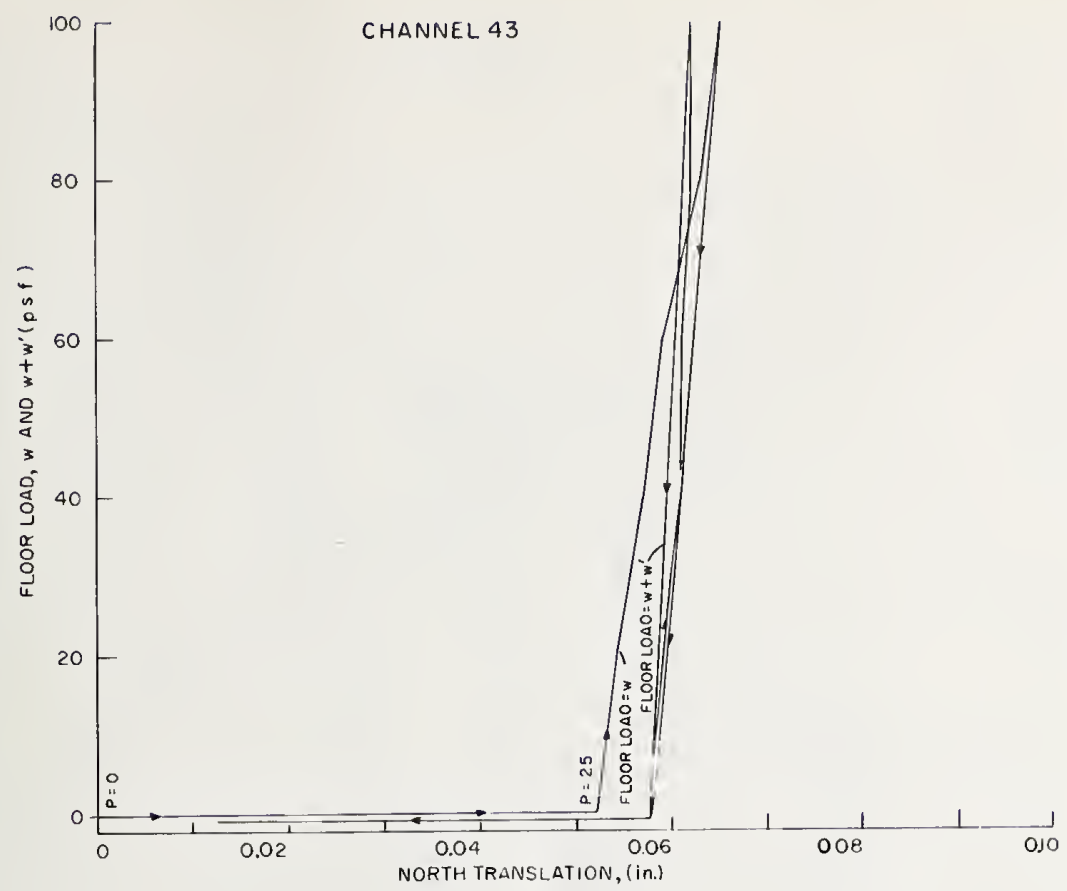

FIGURE 9.6. Tests No. $12 A$ and $13 A$, vertical load versus north translation.

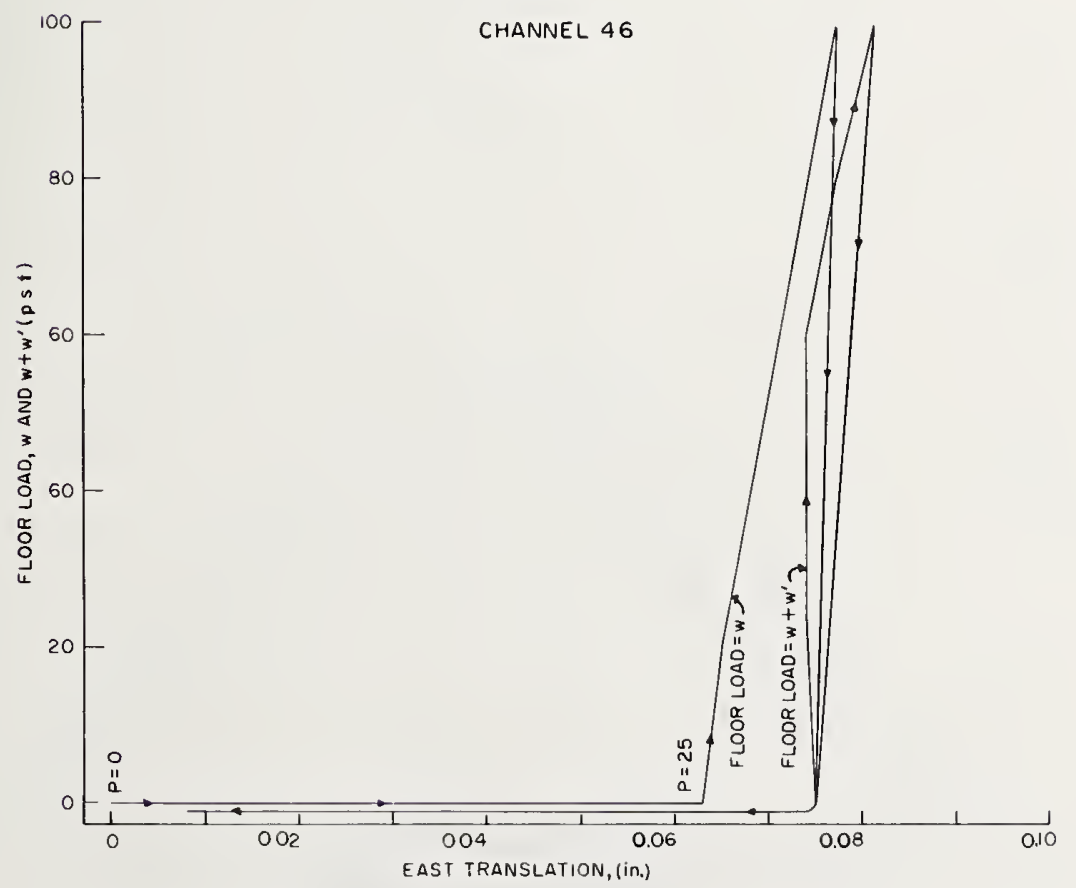

FigUGE 9.7. Tests No. 12 and 13, vertical load versus east translation. 


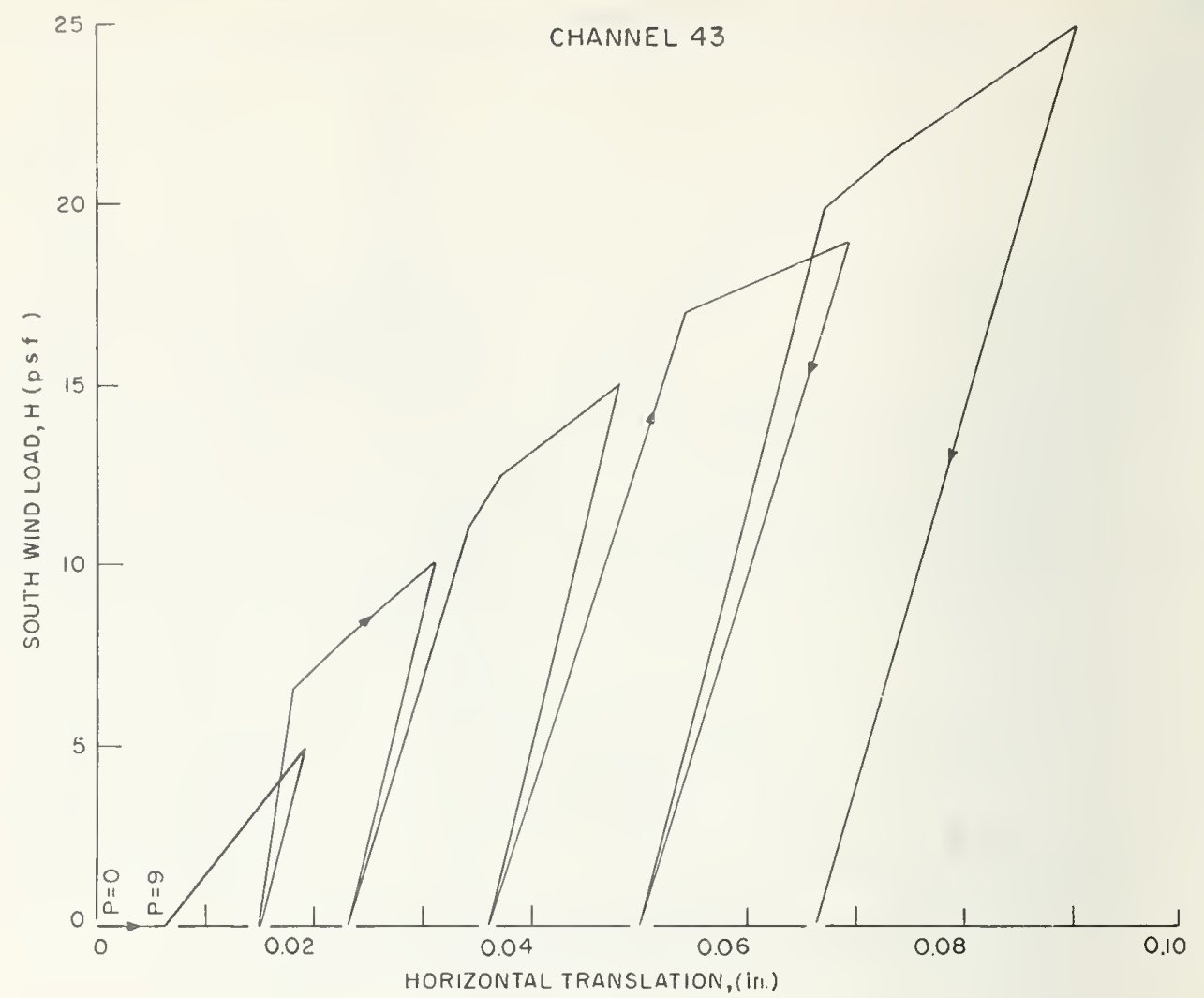

Figure 9.8. Test No.2, south wind load versus translation.

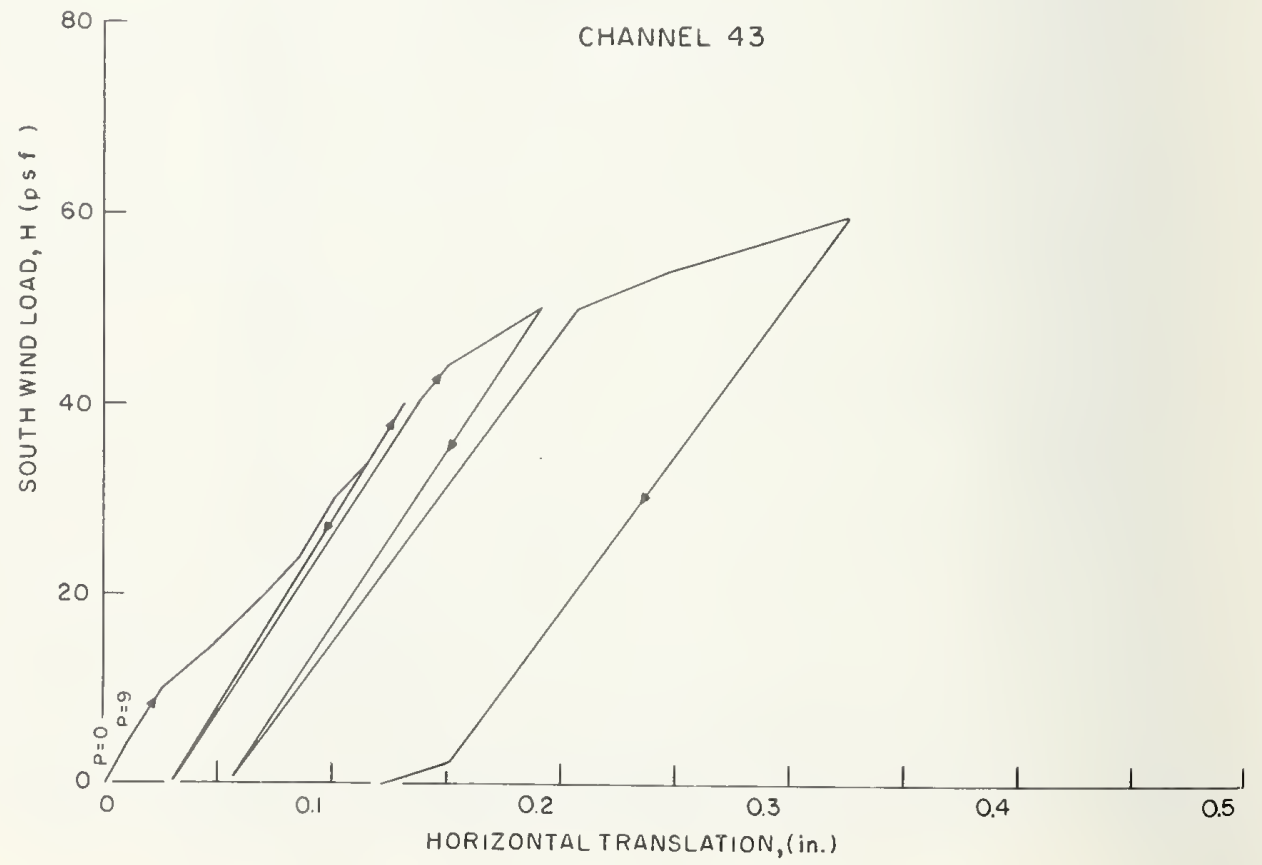

FIGURE 9.9. Test No. 10, south wind load versus translation. 


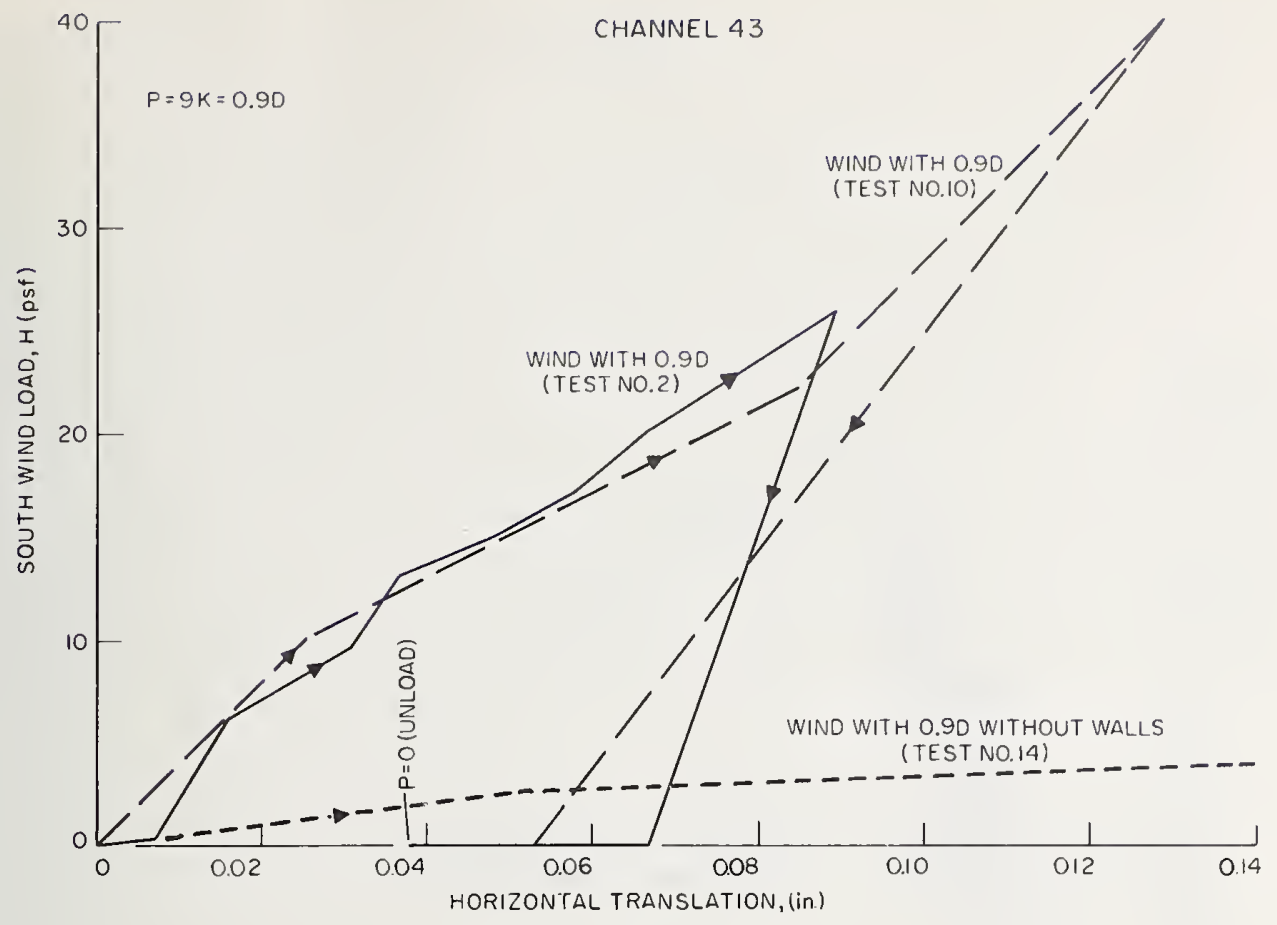

Figure 9.10. North-south horizontal translation of structure with and without walls.

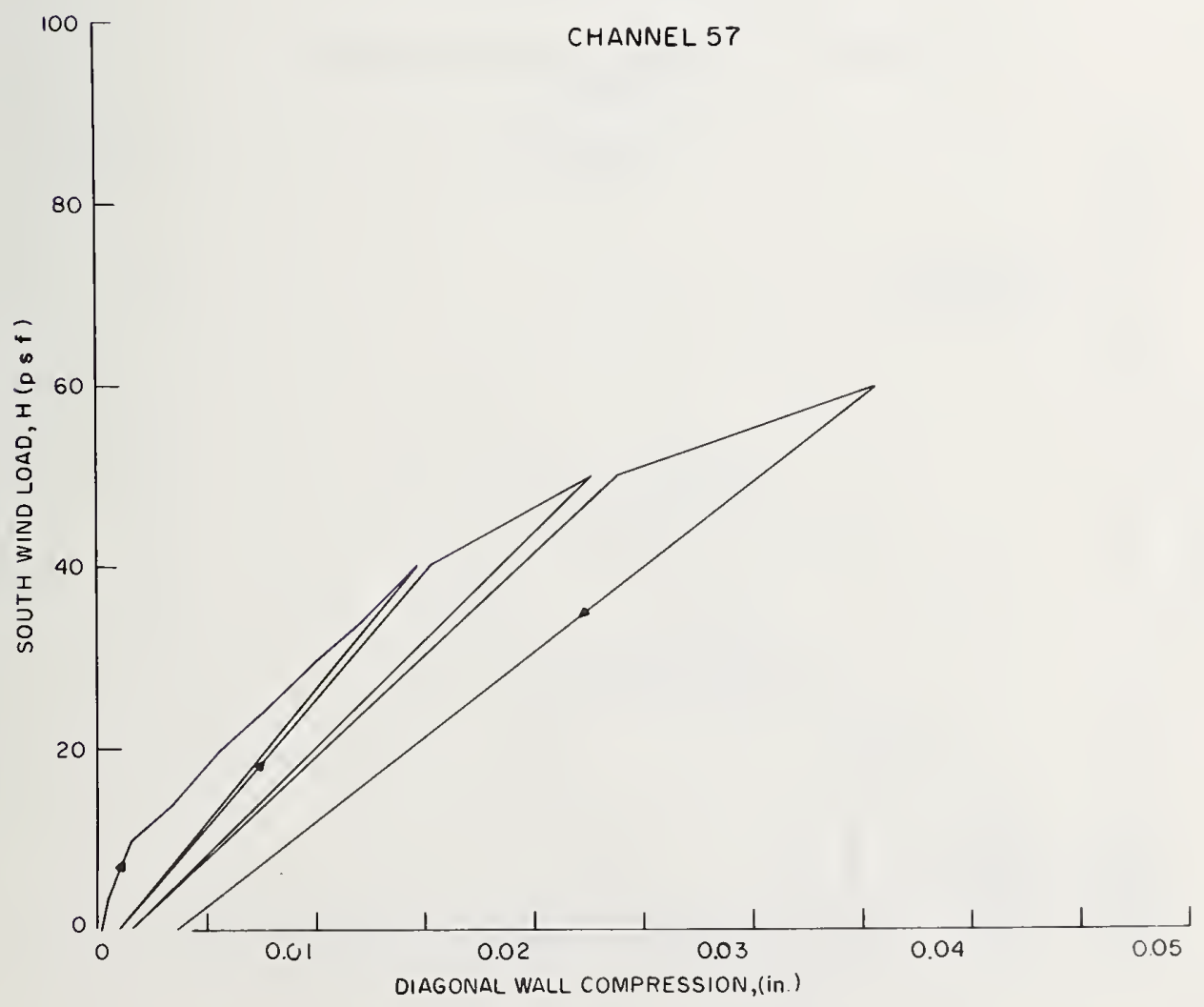

FIGURE 9.11. Test No. 11. south wind load versus wall compression. 


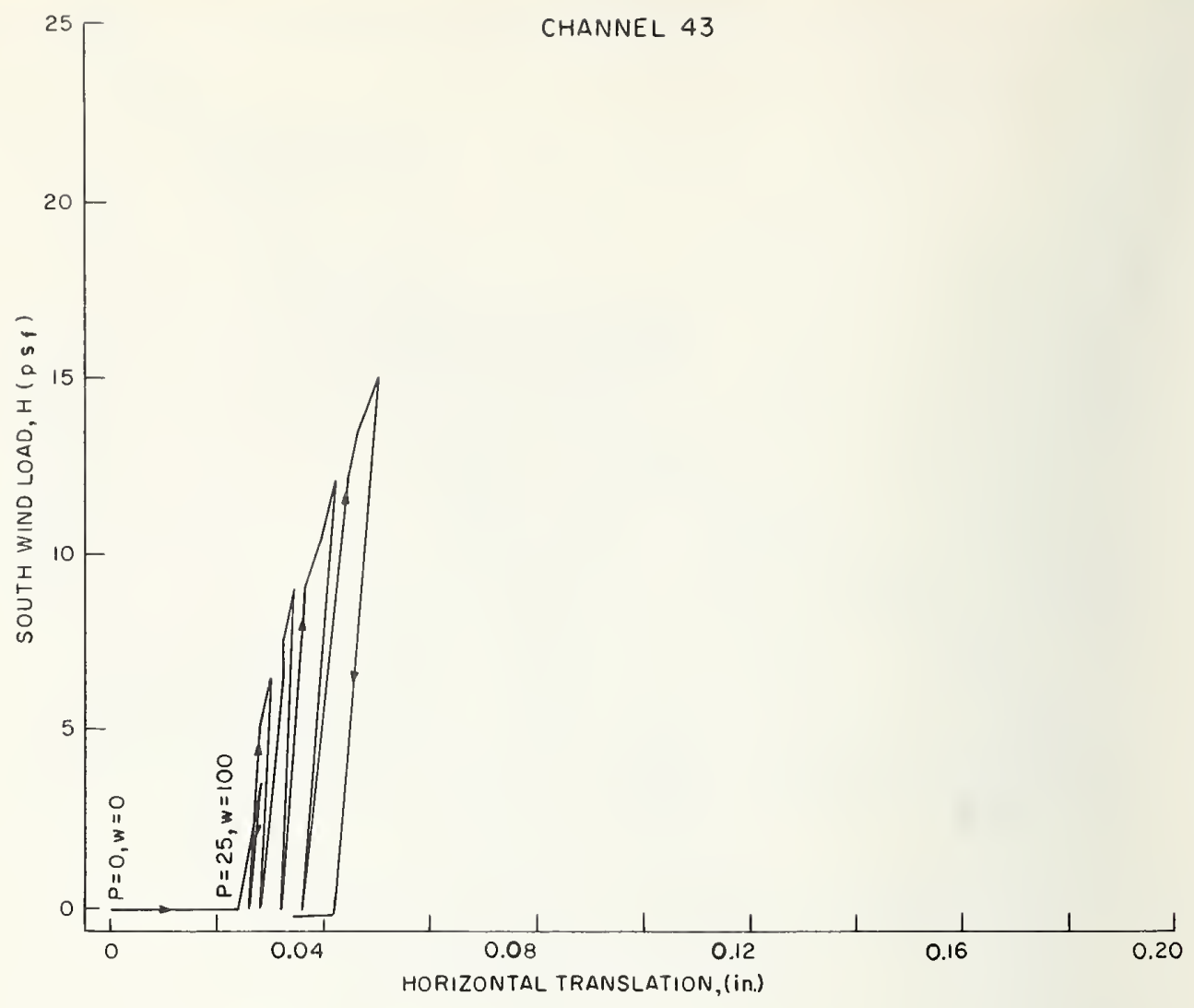

Figure 9.12. Test No. 7 , south wind load versus translation.

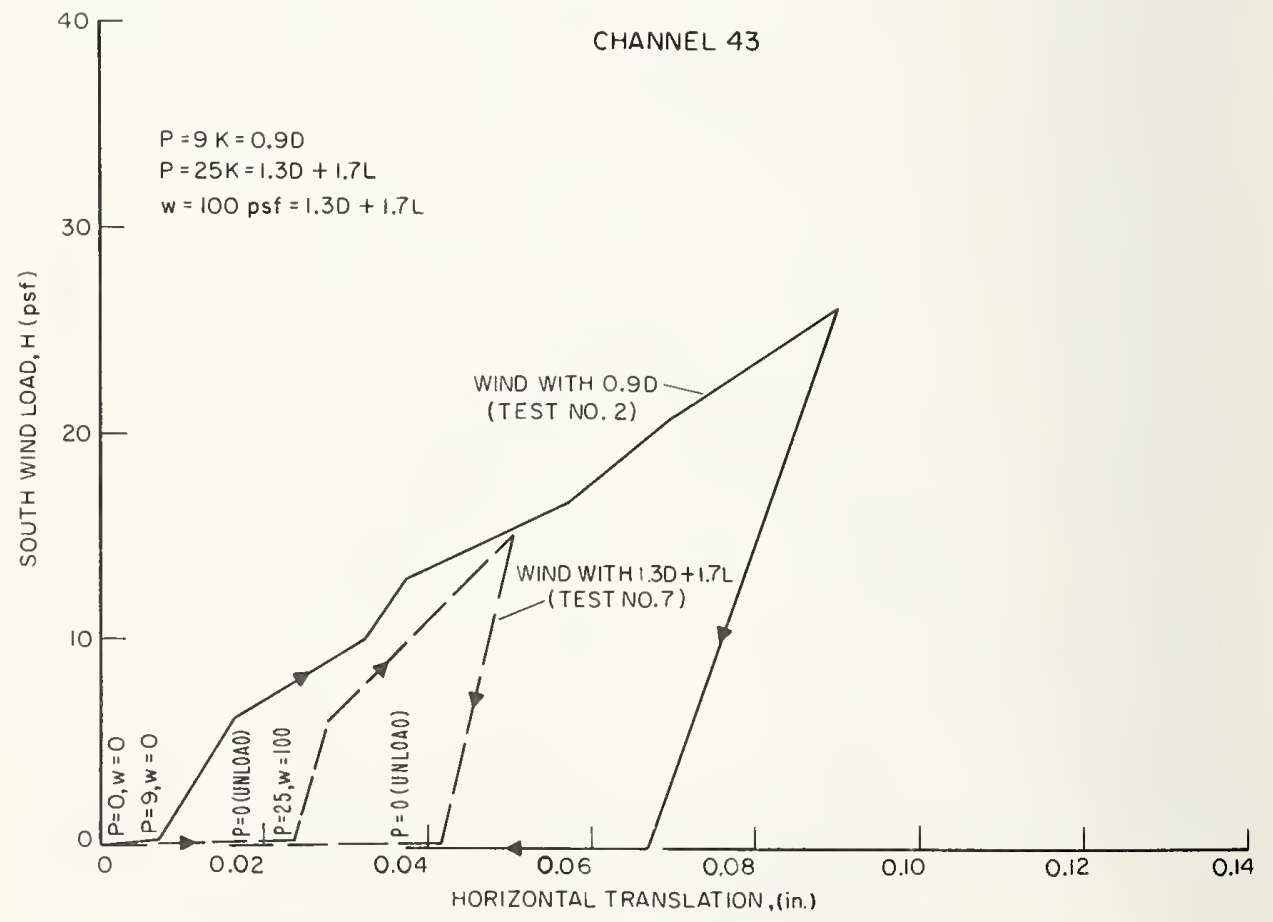

FIGURE 9.13. Effect of vertical loads on north-south horizontal translation. 


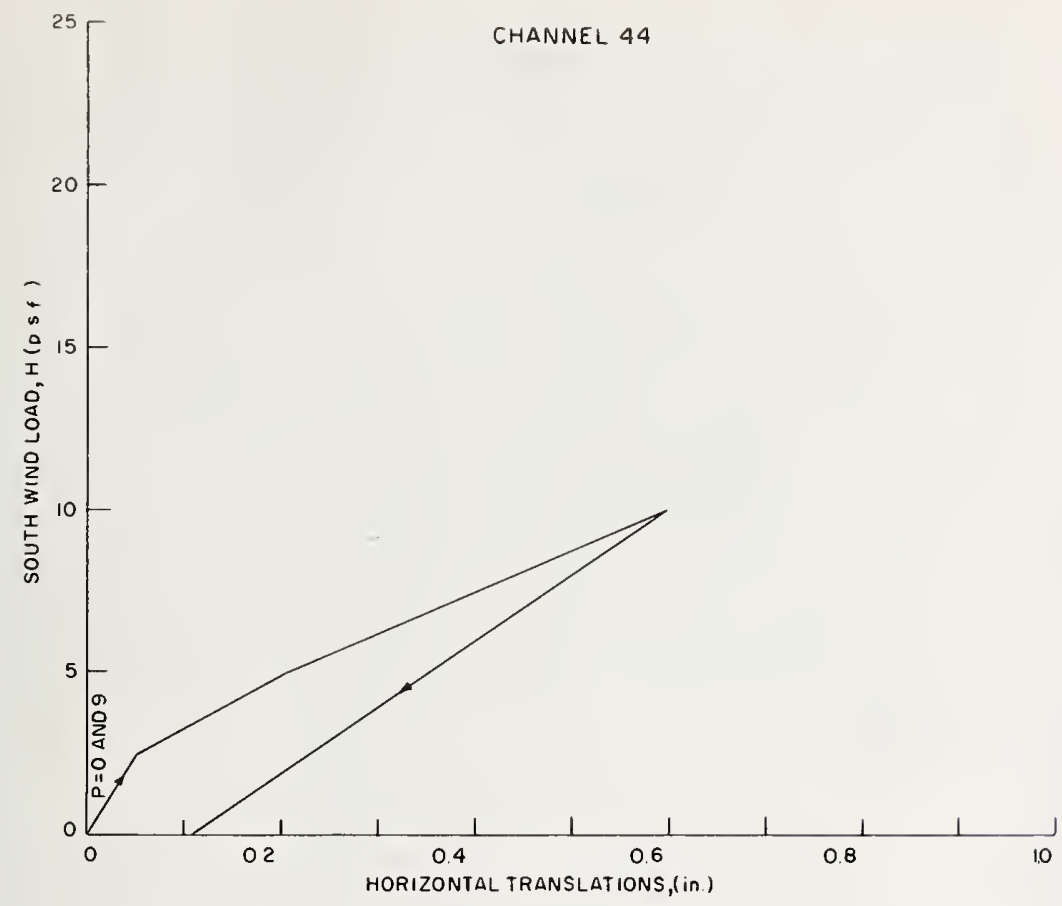

Figure 9.14. Test No. 14, south wind load versus translation.

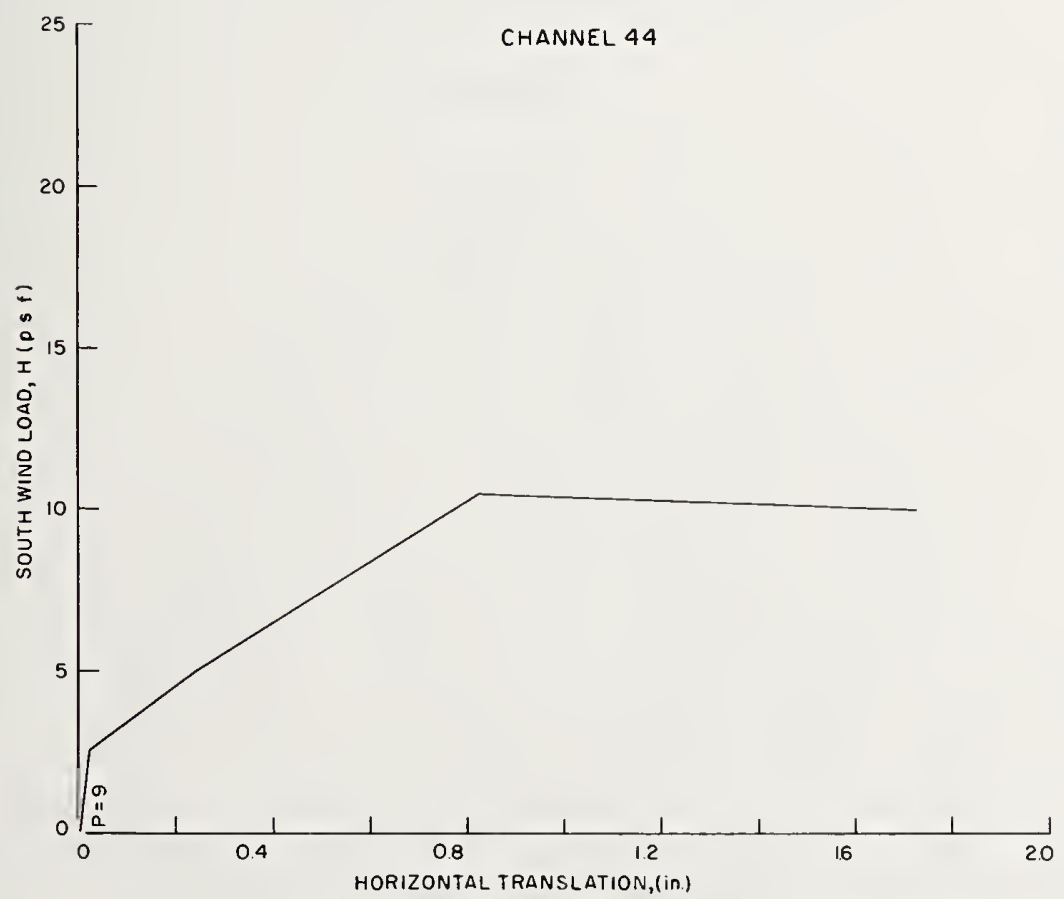

FIGURE 9.15. Test No. 18, south wind load versus translation. 


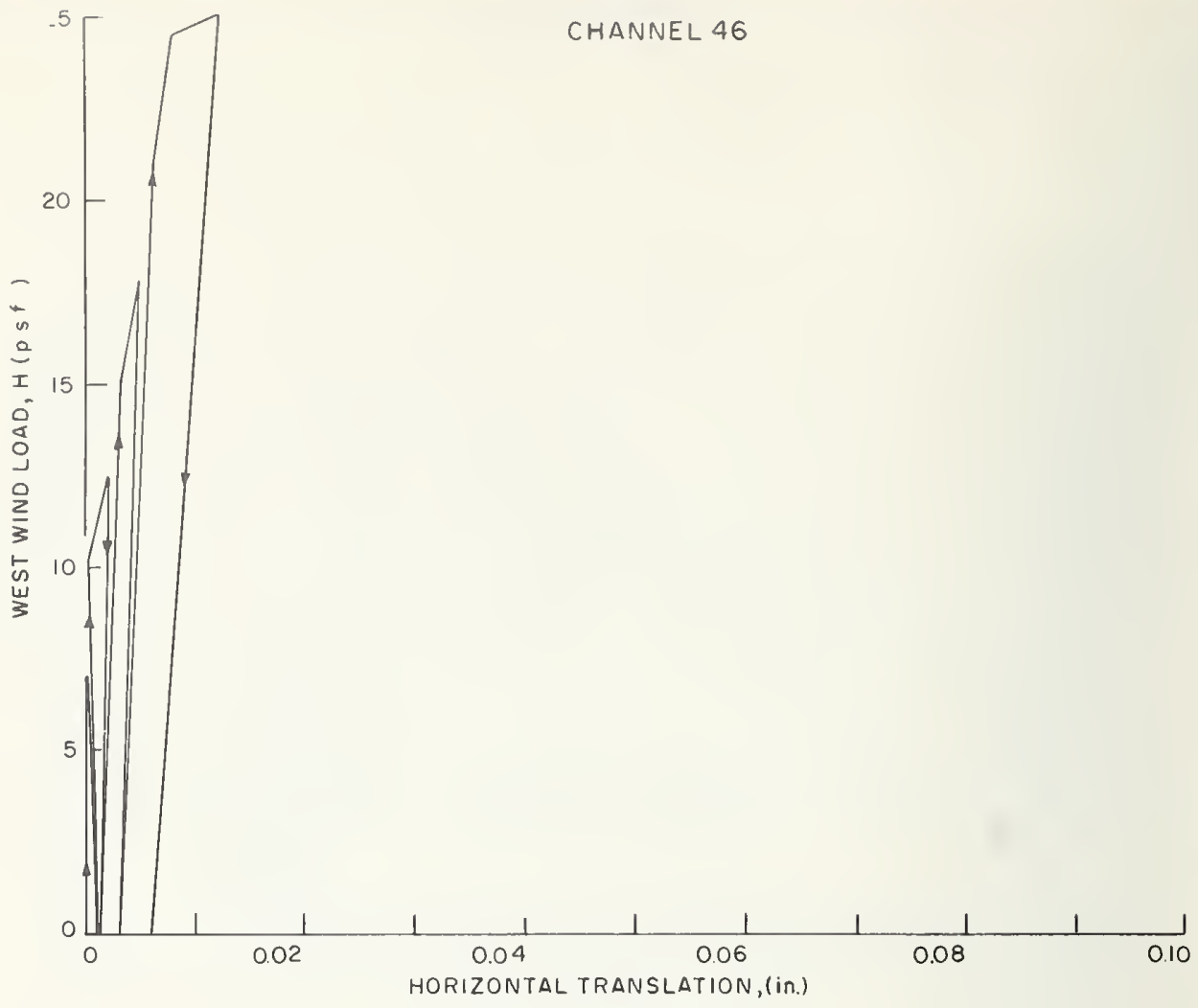

Frgure 9.16. Test No.3, west wind load versus translation.

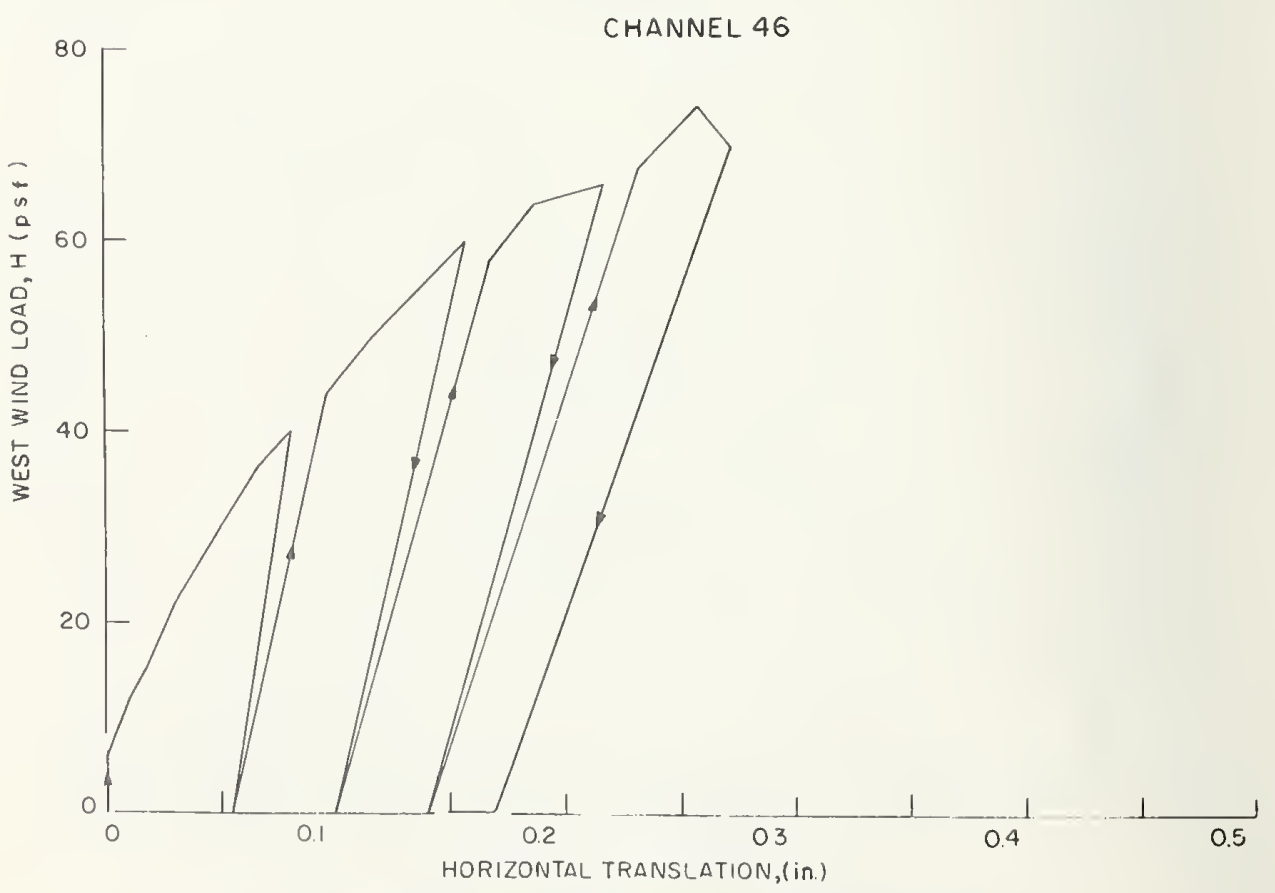

Frgure 9.17. Test No. 11, west wind load versus translation. 


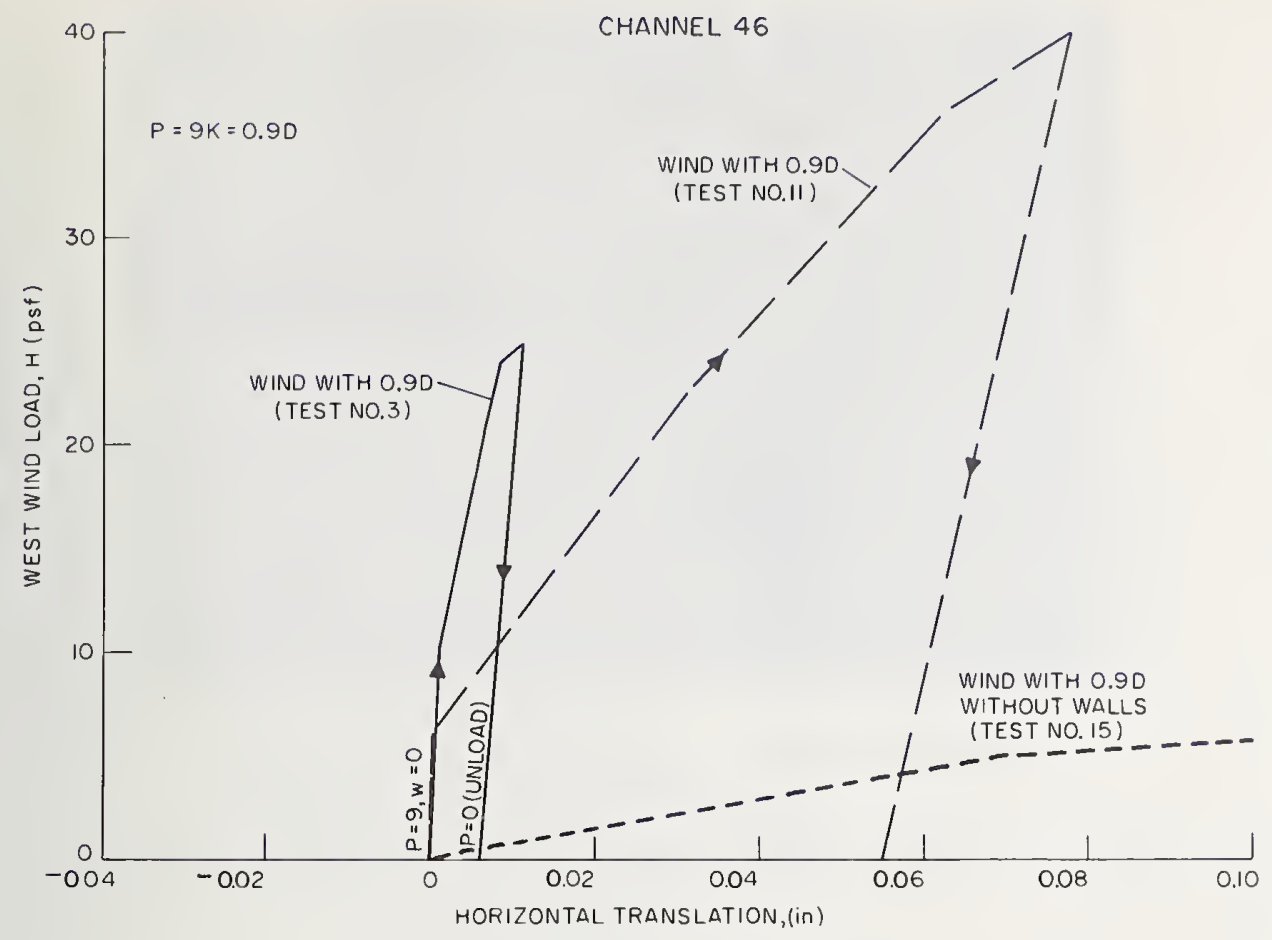

FIGURE 9.18. East-west horizontal translation of structure with and without walls.

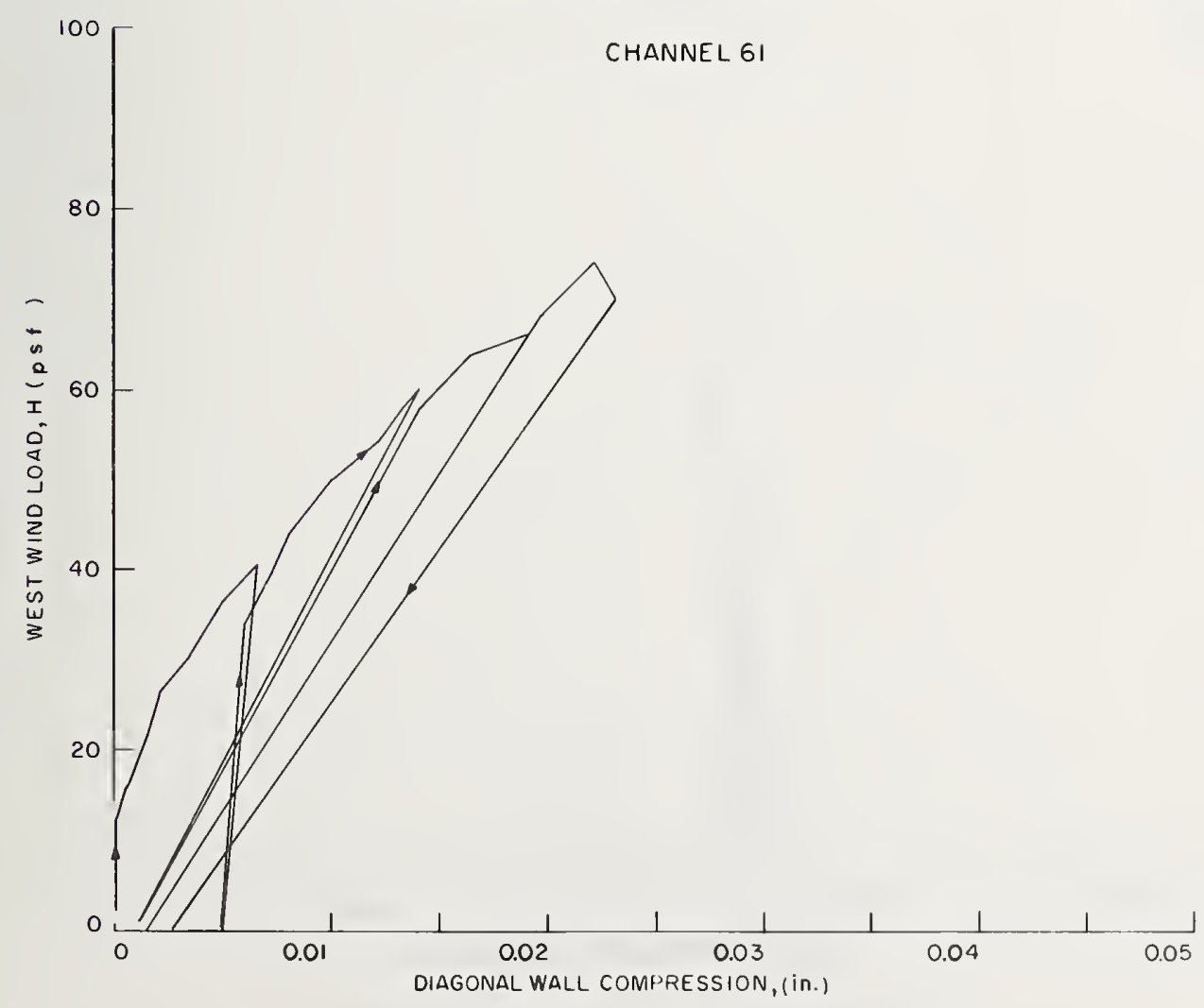

FIGURE 9.19. Test No. 11, west wind load versus wall compression. 


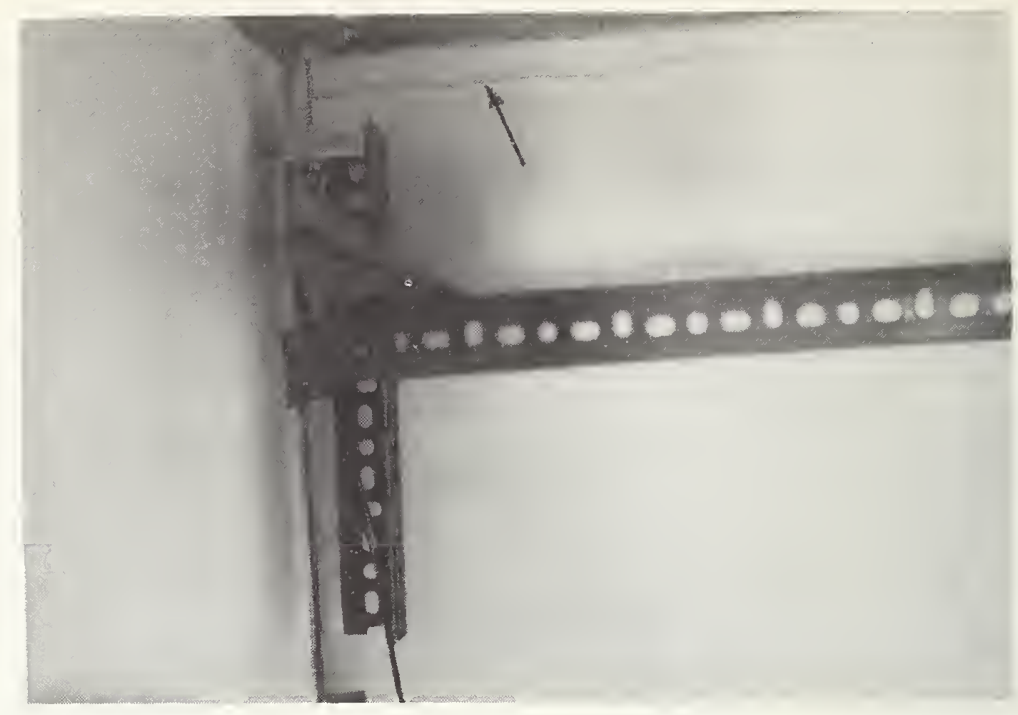

H'IGURE 9.20. Urywall crack near ceiling on interior side of each wall.

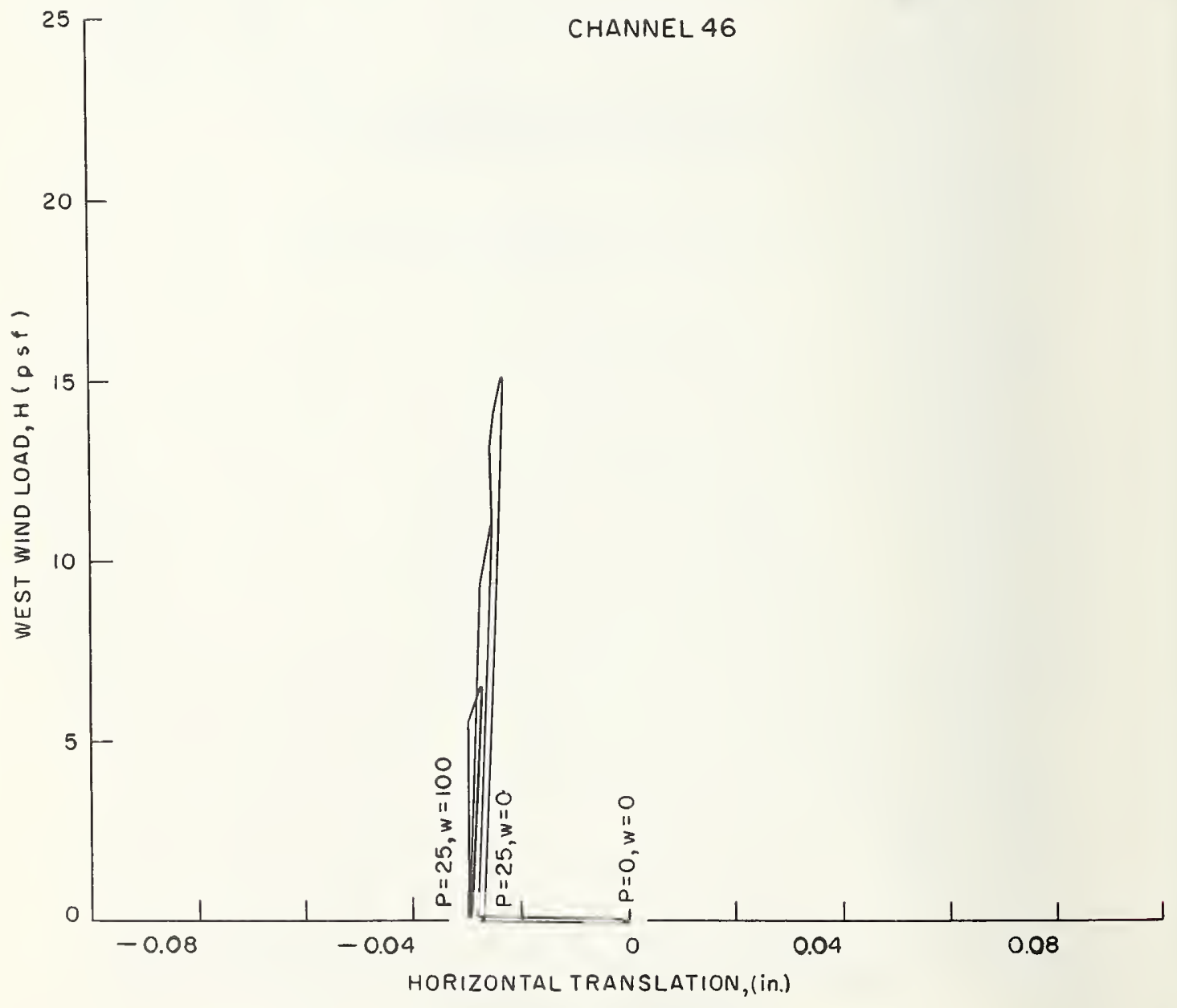

Figure 9.21. Test No. 8, west wind load versus translation. 


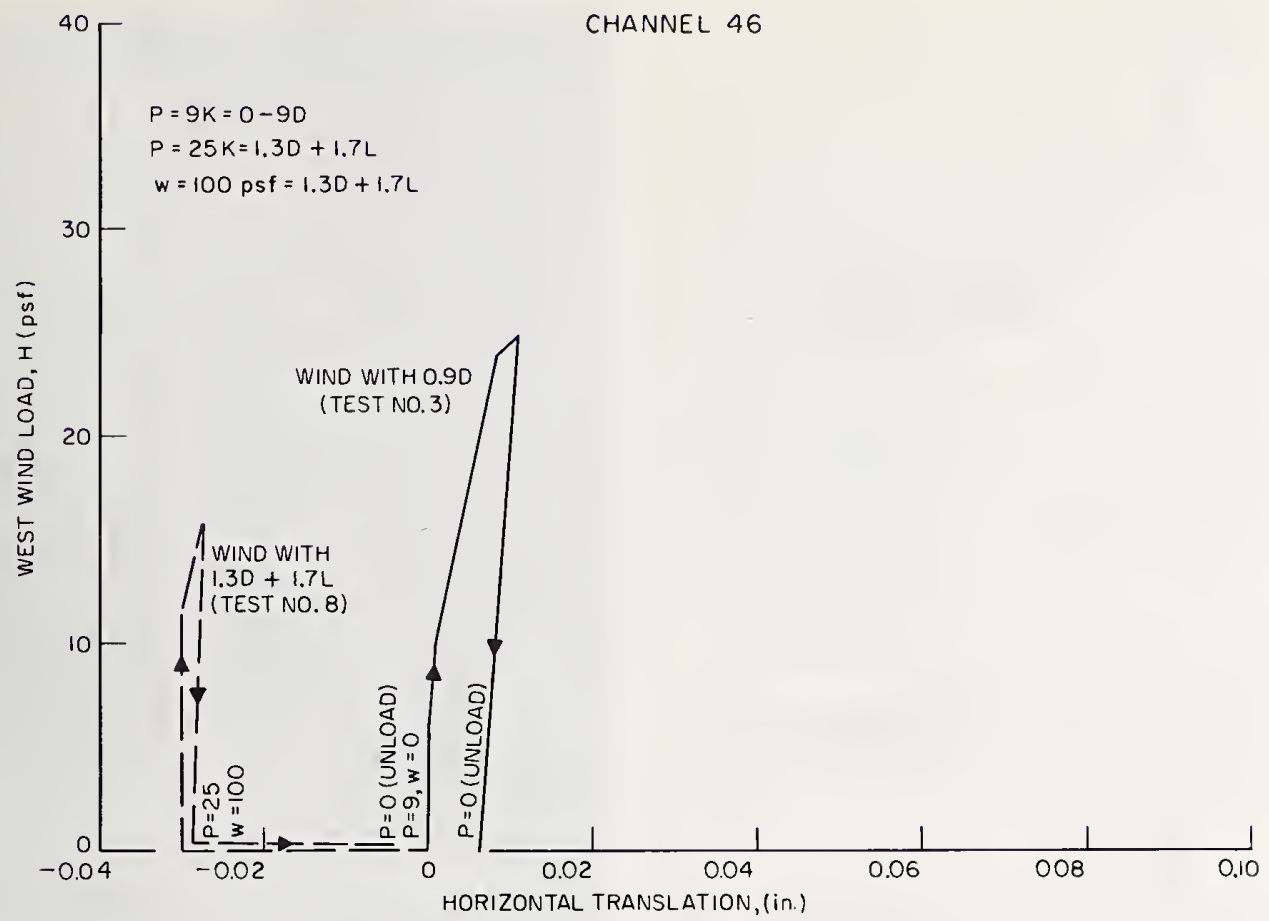

FIGURE 9.22. Effect of vertical loads on east-west horizontal translation.

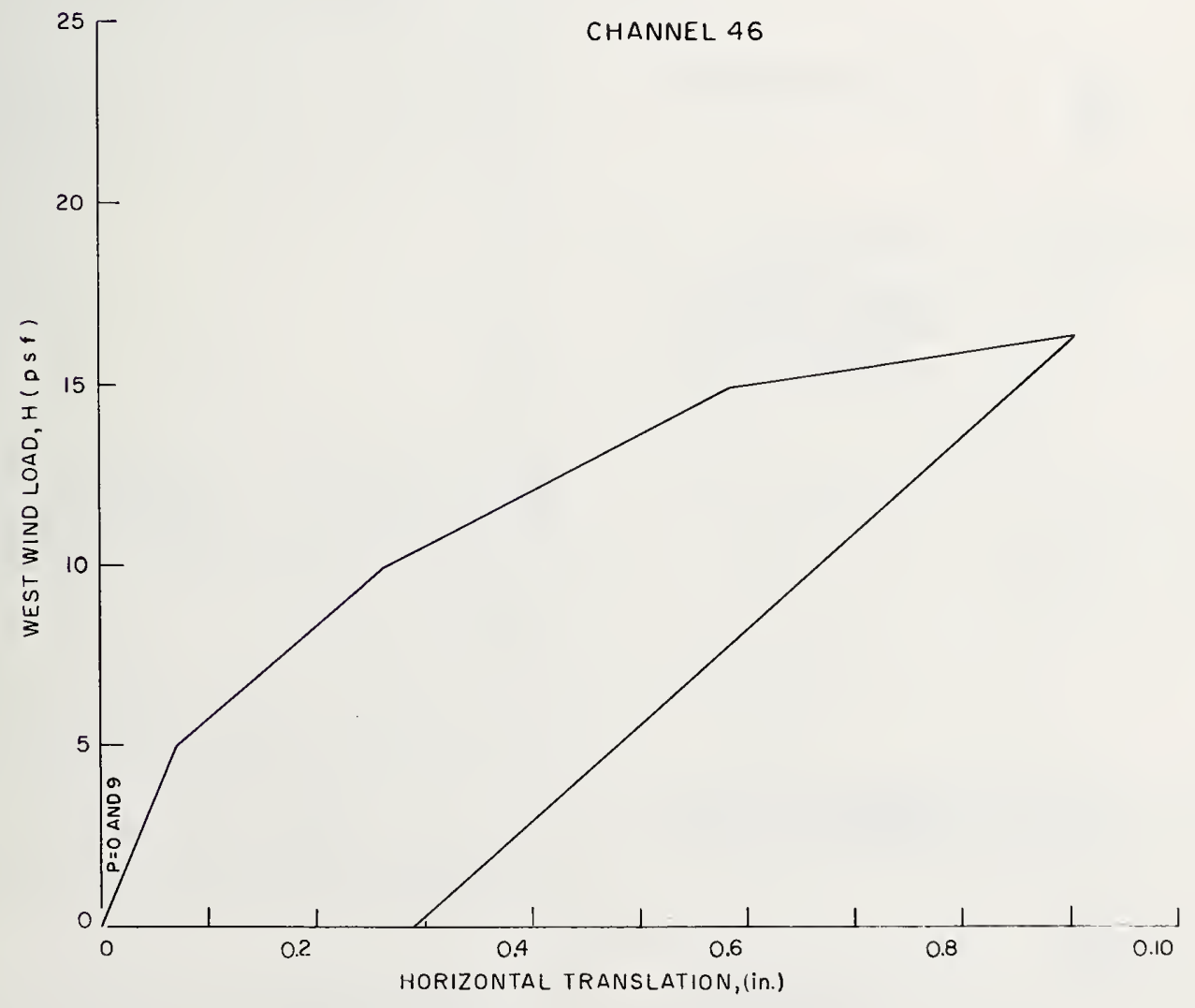

Figure 9.23. Test No. 15, west wind load versus translation. 


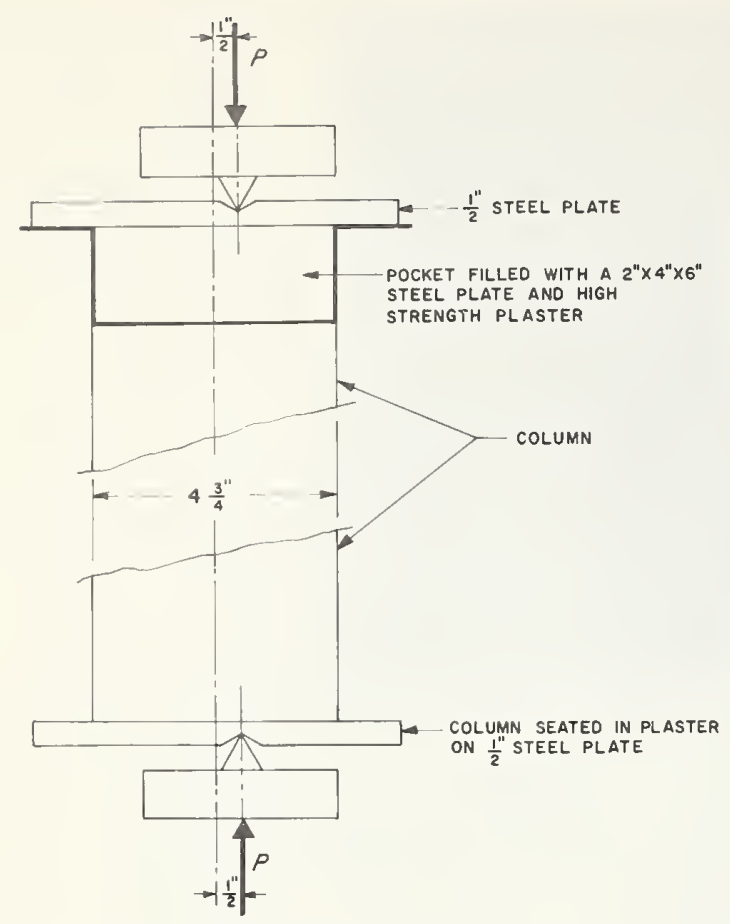

Figure 10.1. Test method for column tests (minor axis).

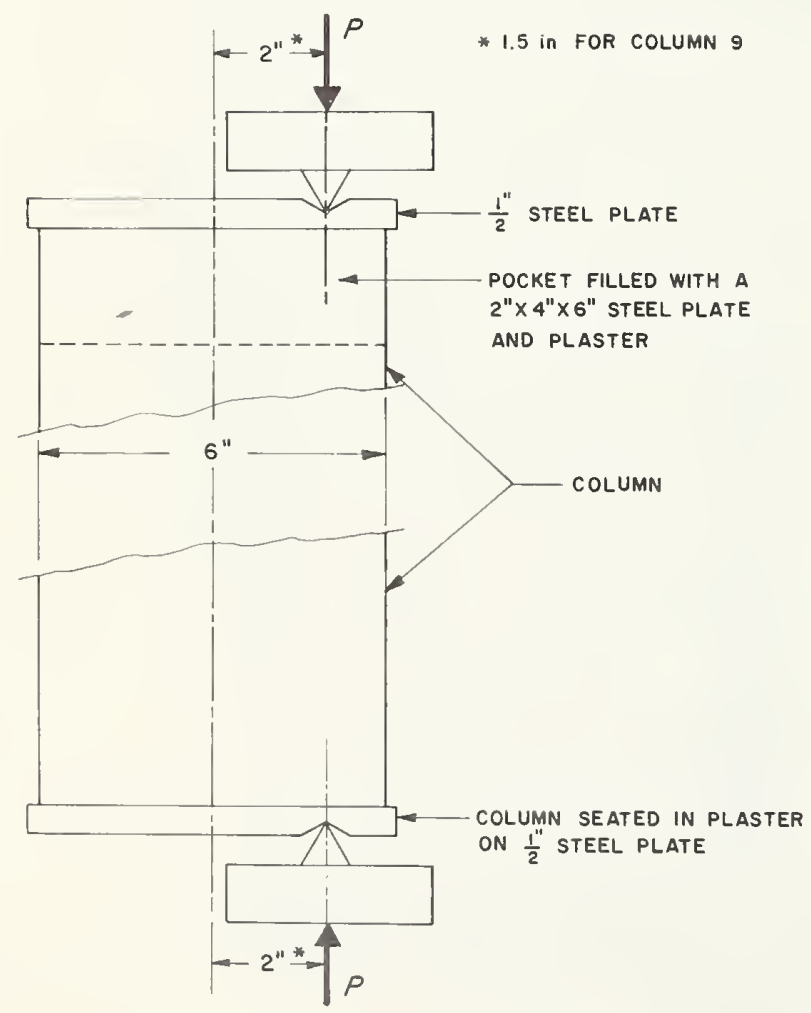

FiguRE 10.2. Test method for column tests (major axis).

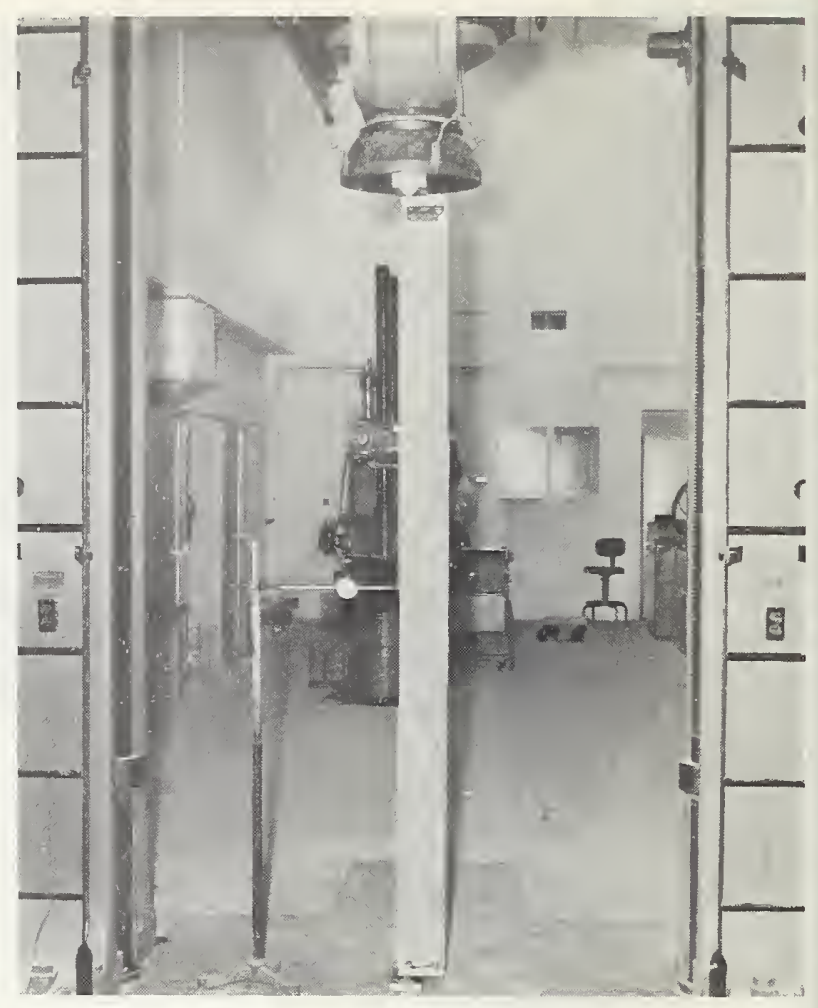

Figure 10.3. Column under test.

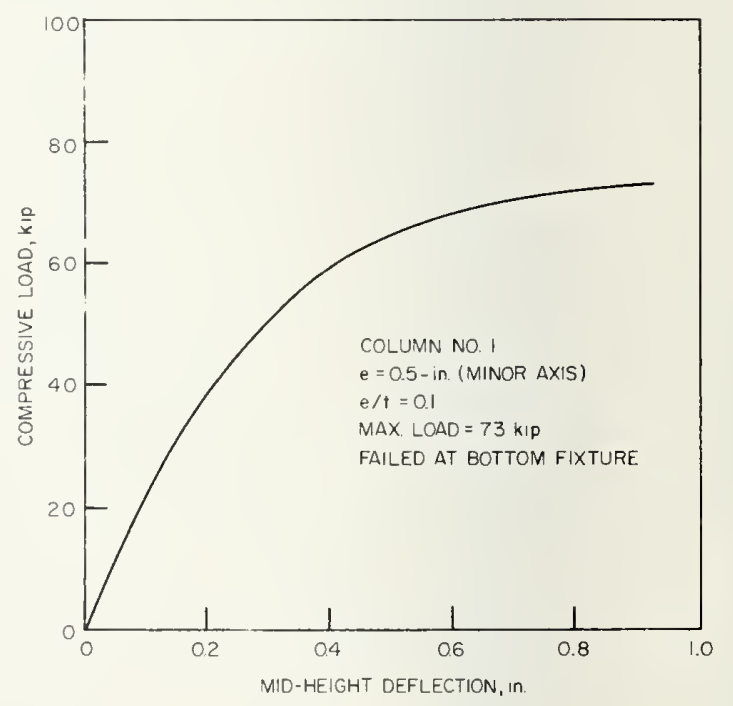

Figure 10.4. Short-term test on column No. 1. 

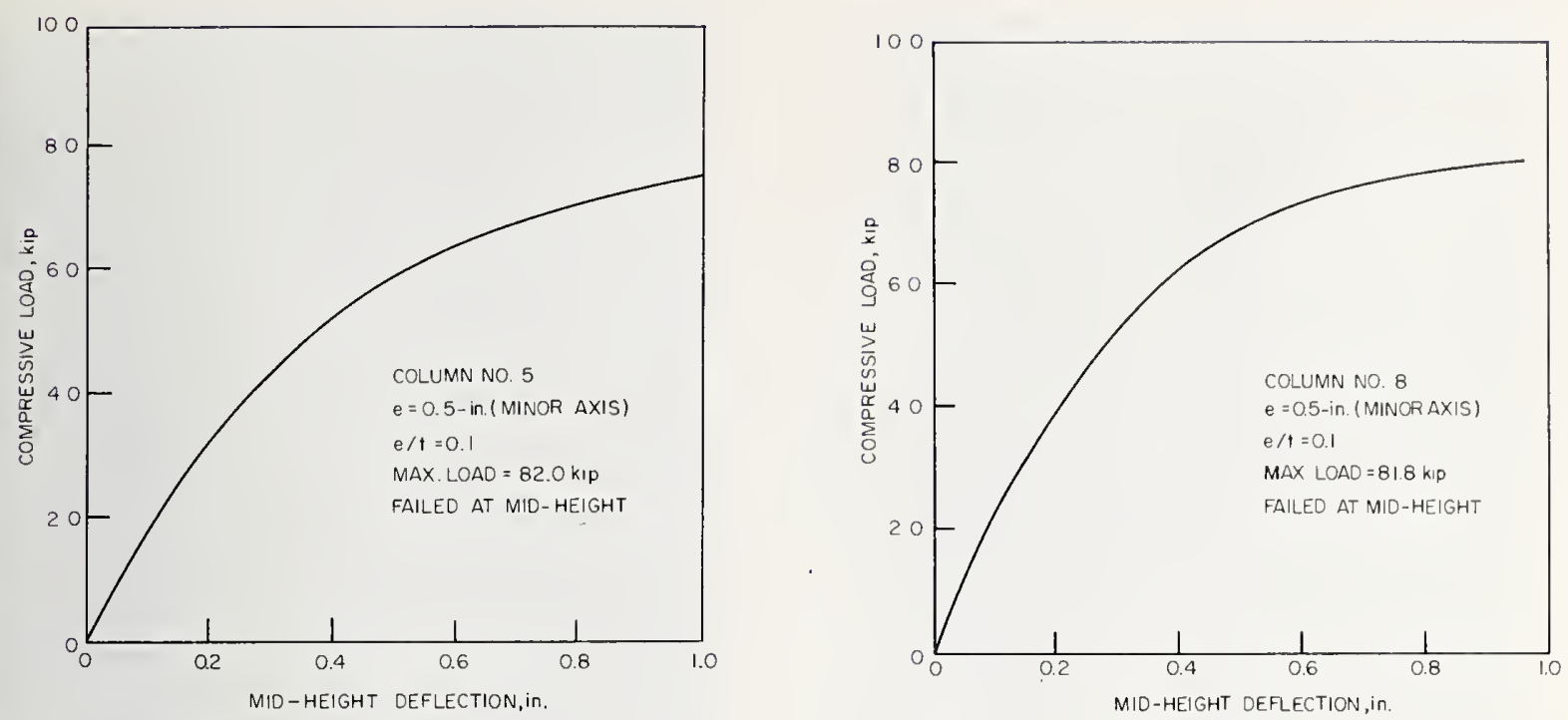

Figure 10.5. Short-term test on column No. 5 .

Figure 10.6. Shirt-term test on column No. 8.
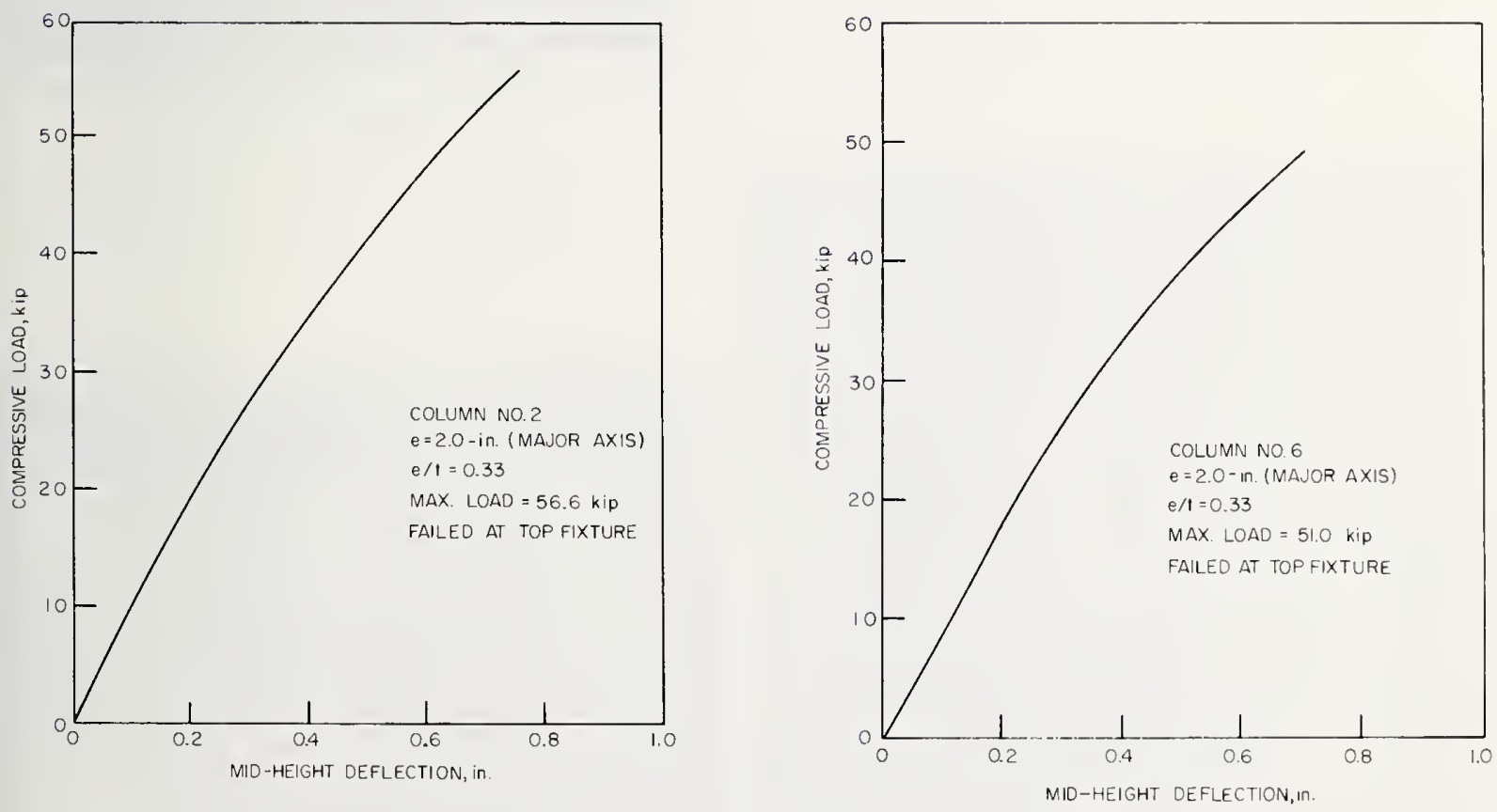

Figure 10.7. Short-term test on column No.2.

FIgURE 10.8. Short-term test on column No. 6 . 


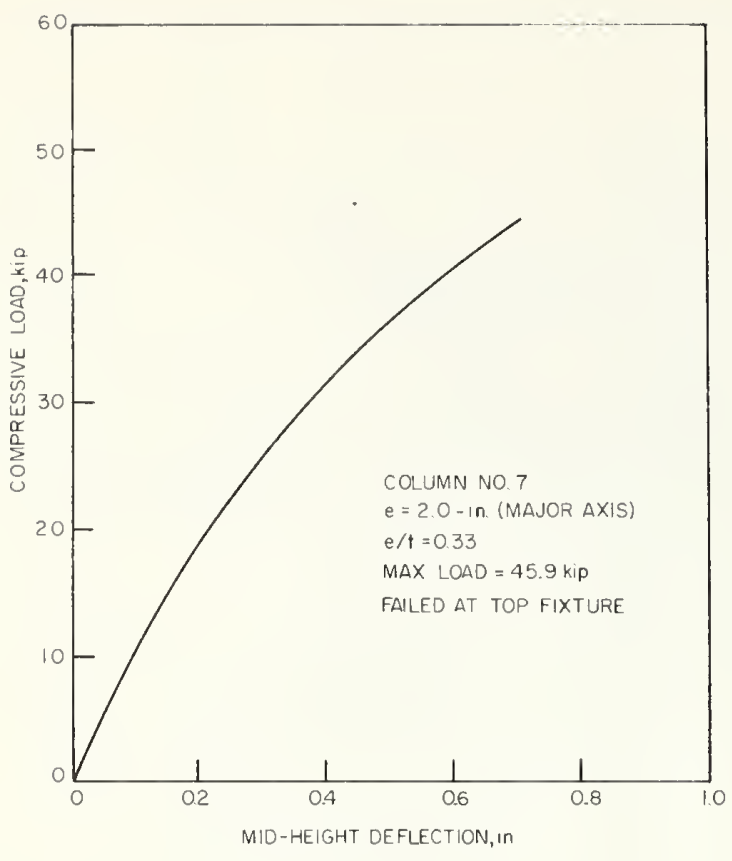

FigUre 10.9. Short-term test on column No. $\%$.

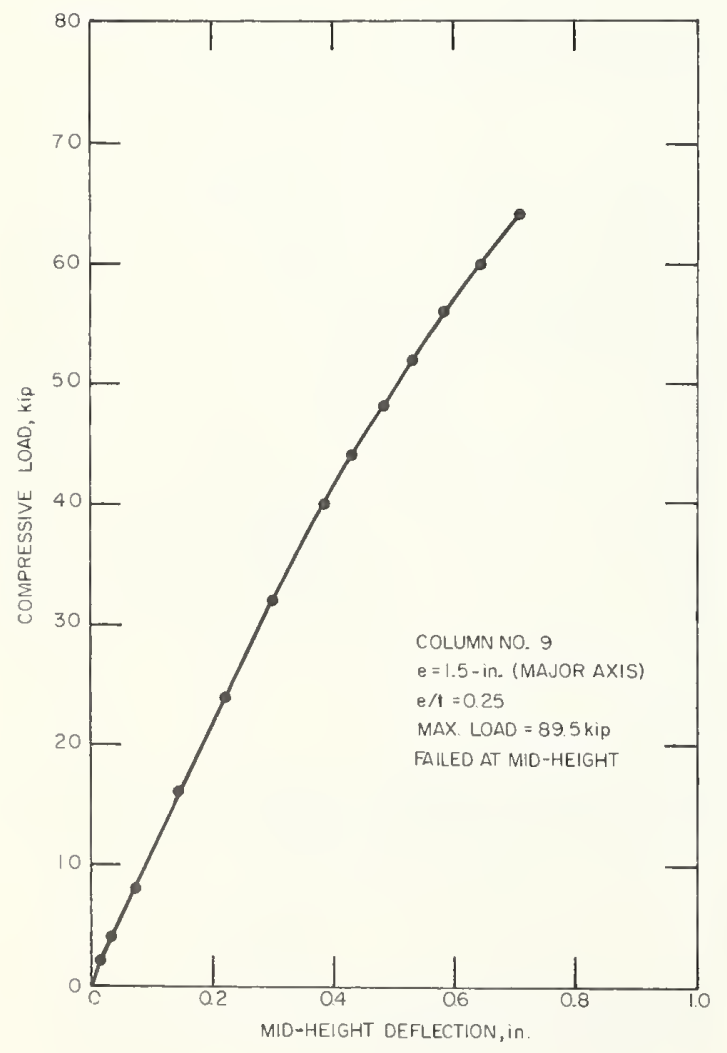

Figure 10.10. Short-term test on column No. 9.

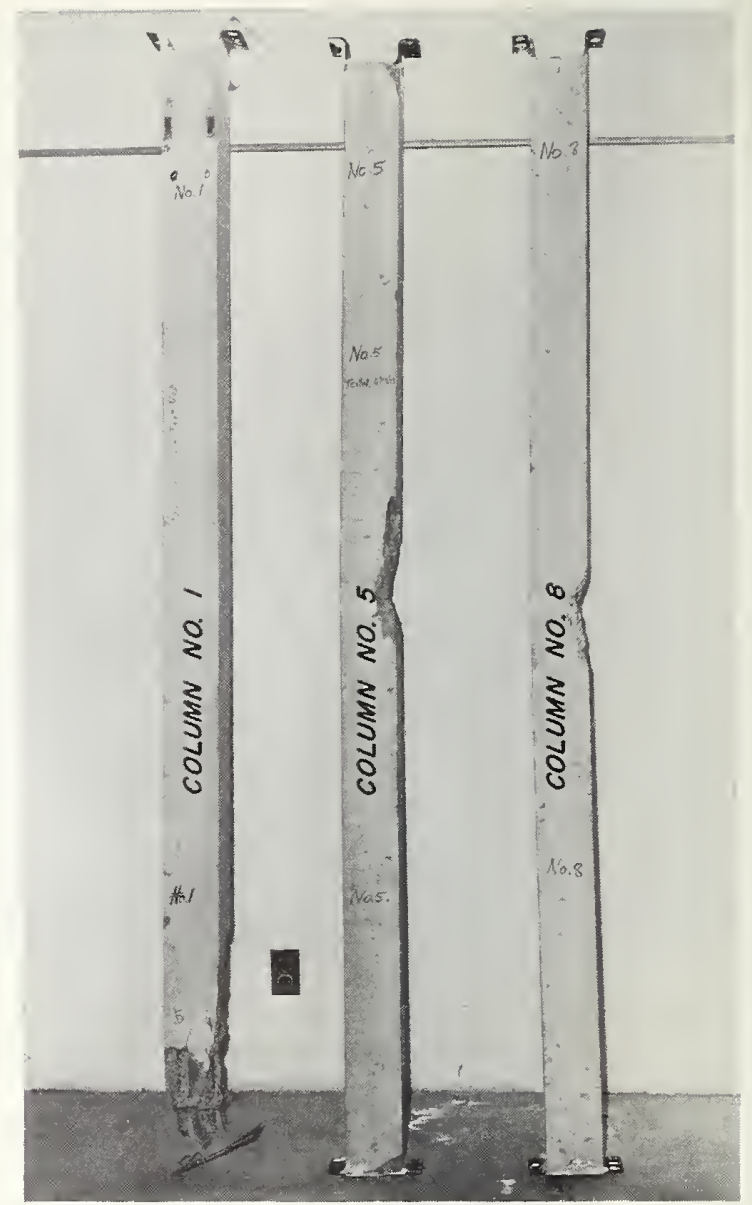

FIGURE 10.11. Columns after testing.

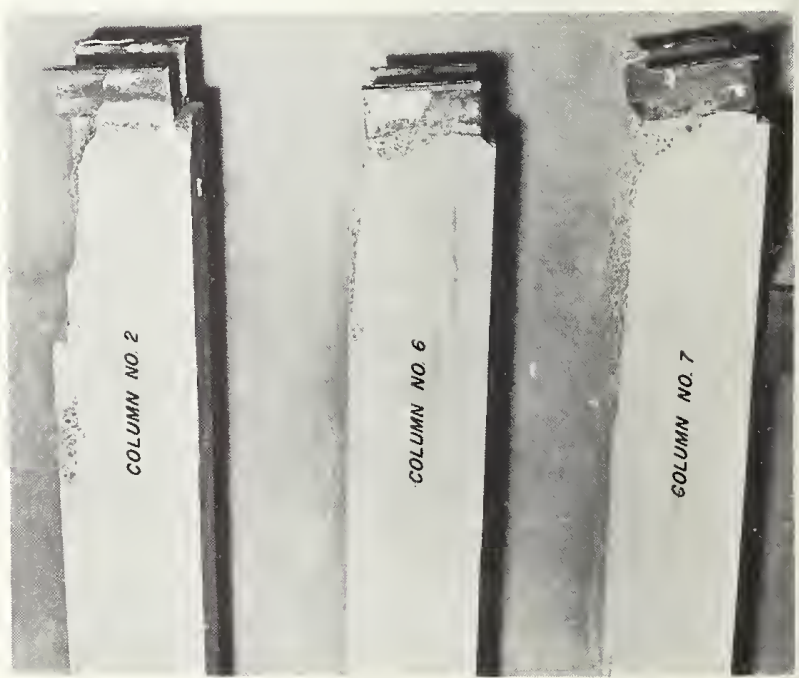

FigURe 10.12. Column ends after testing. 


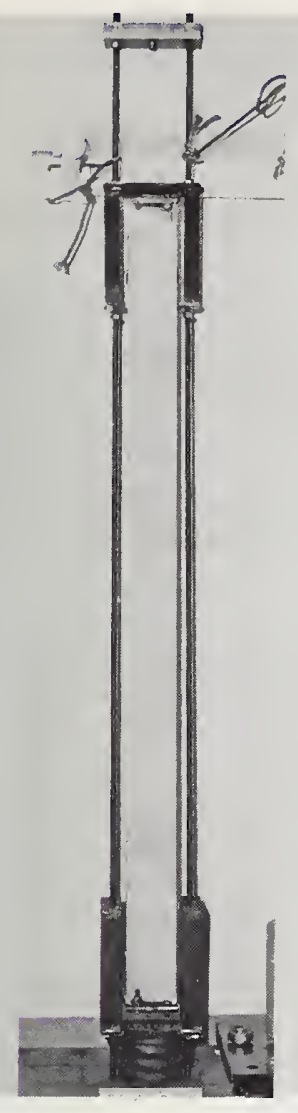

Figure 10.13. Creep loading fame for column No. 3 minor axis bending.

Figure 10.15. Detail of base for column No. 4 creep frame.

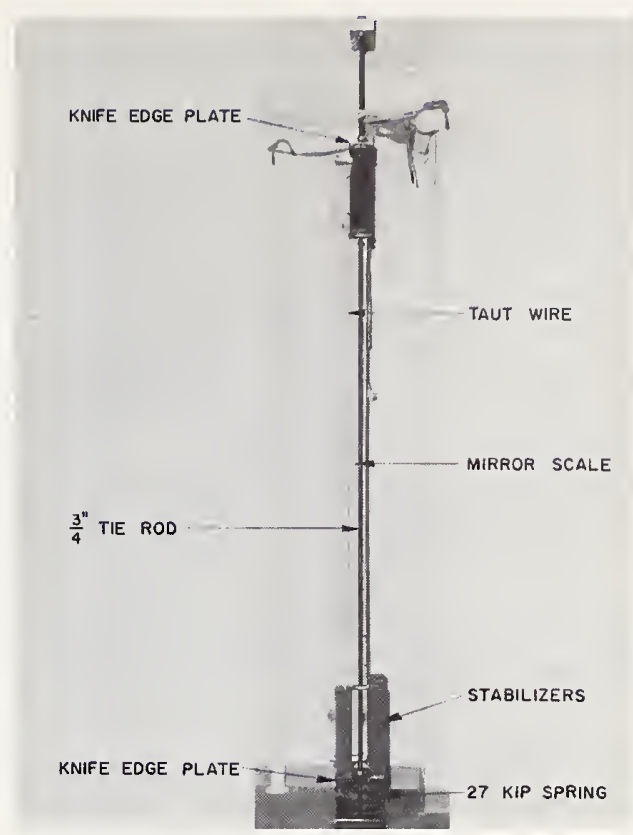

Figure 10.14. Creep loading frame for column No. 4 major axis bending.

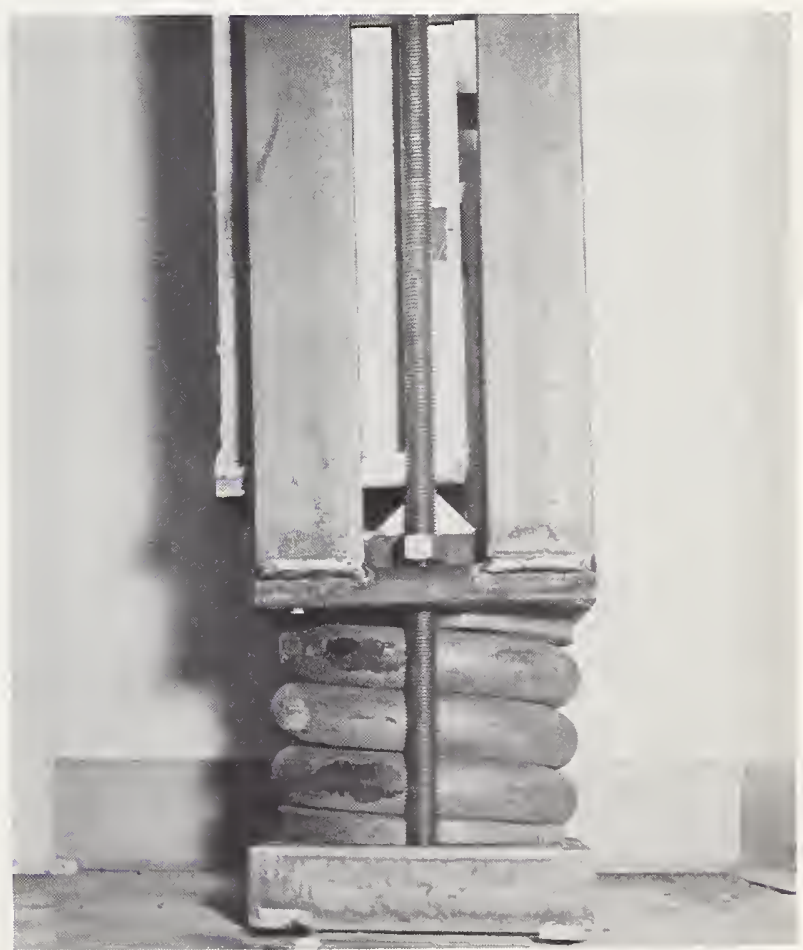




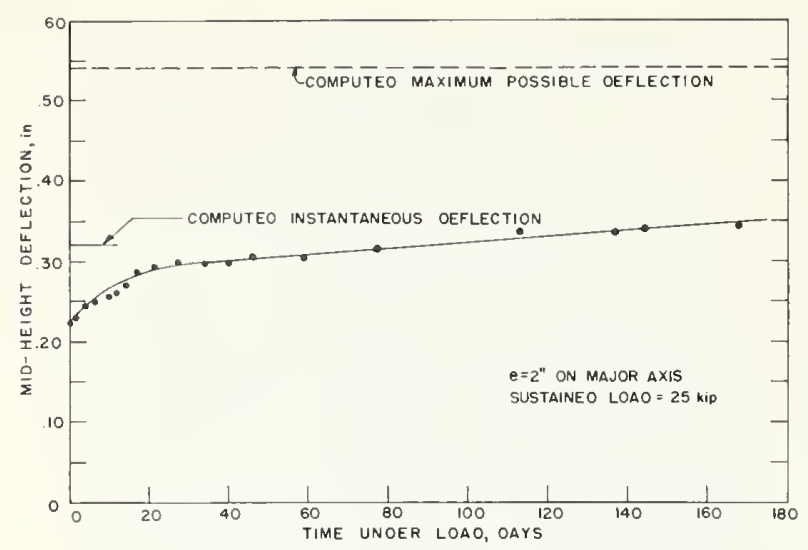

Figure 10.16. Sustained load test, column No. 4.

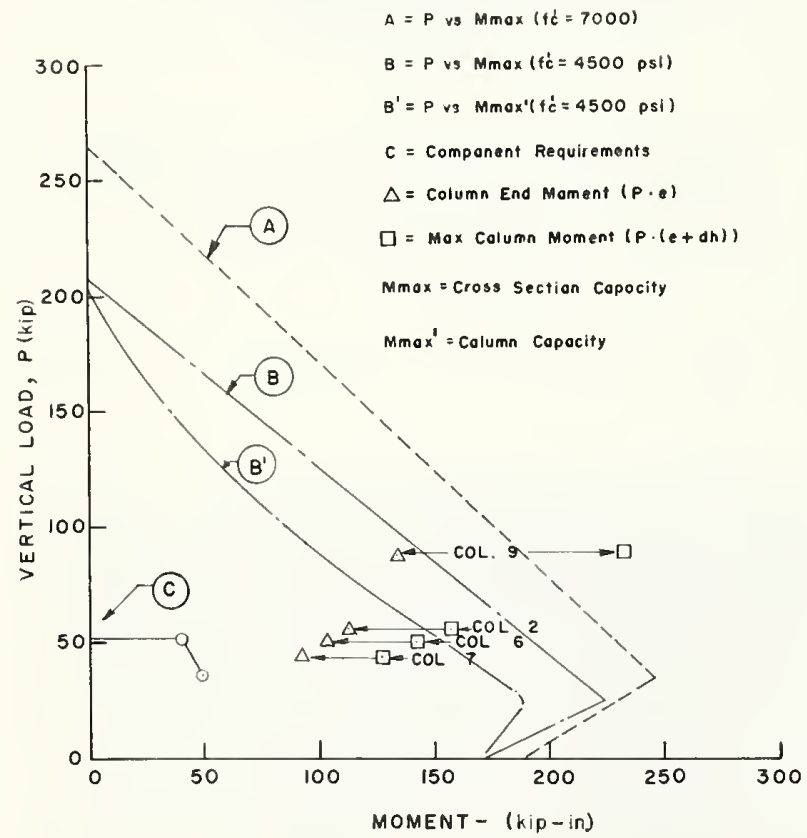

Figure 10.18. Columns with major axis eccentricity.

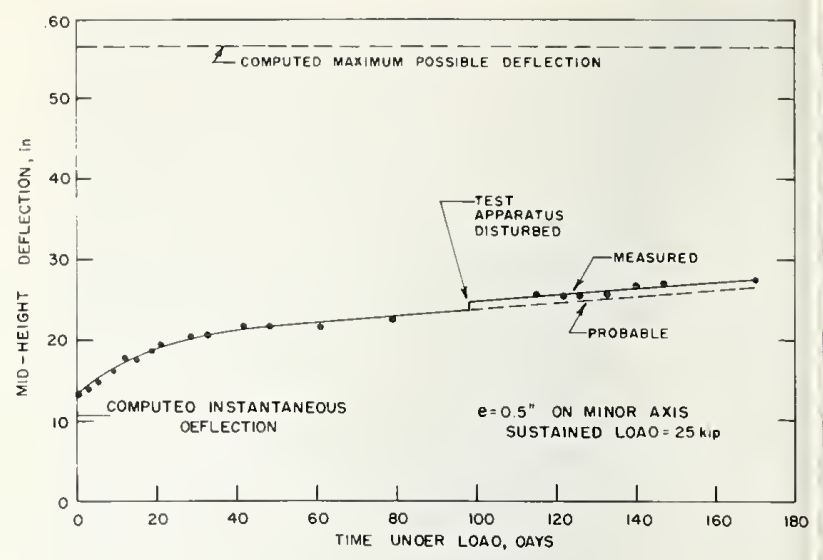

Frgure 10.17. Sustaincd load test, column No.3.

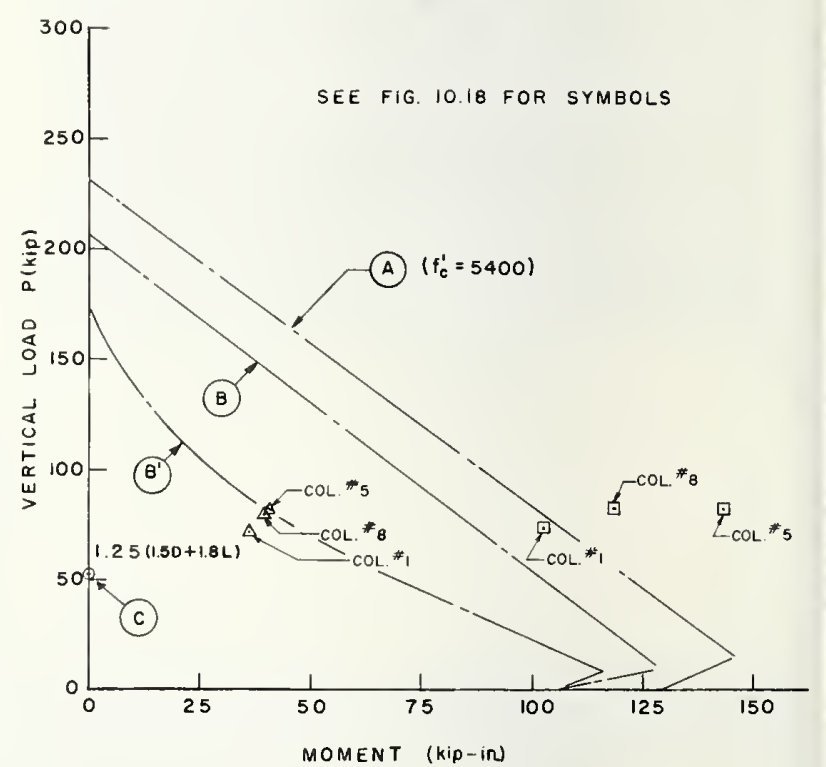

Figure 10.19. Columns with minor axis eccentricity. 


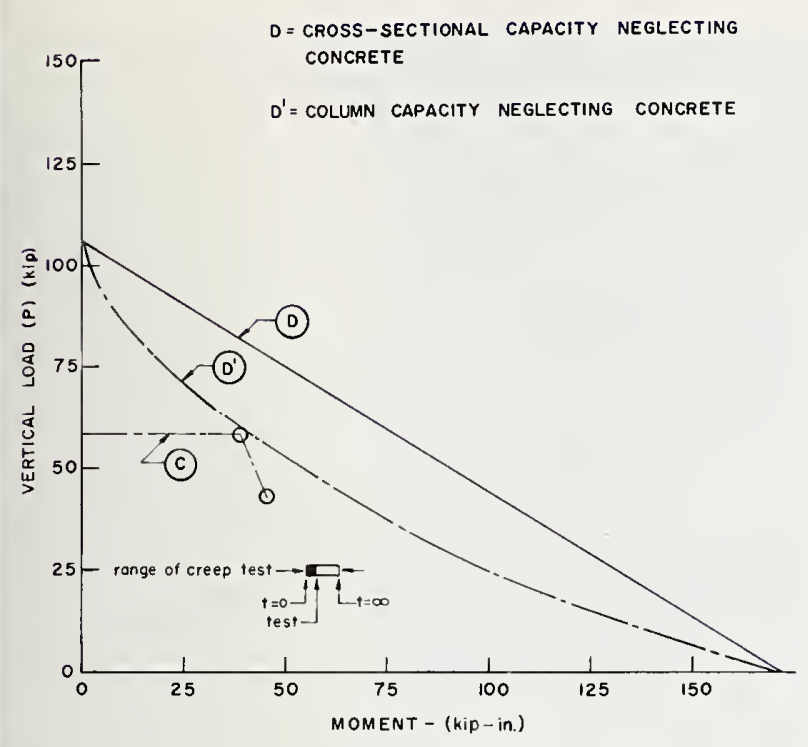

FIGURE 10.20. Column creep with major axis eccentricity.

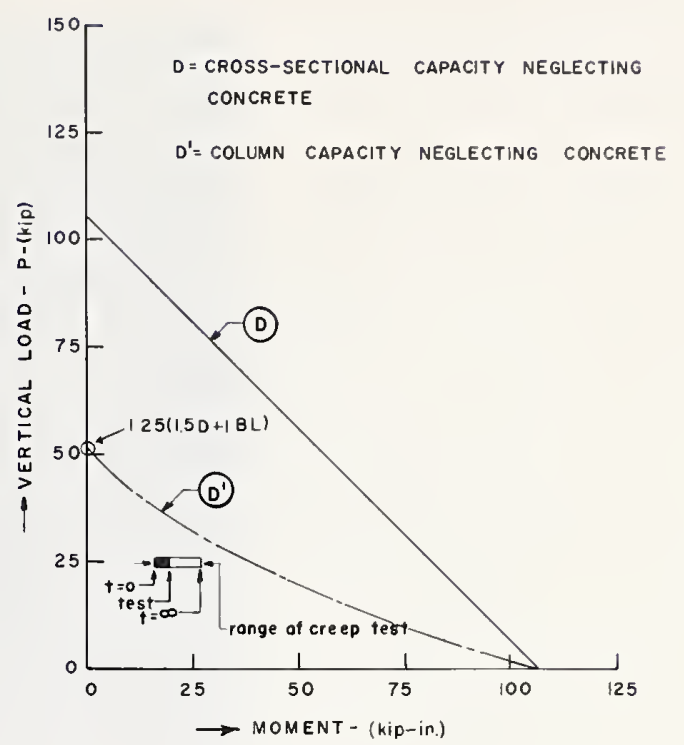

FIgURe 10.21. Column creep with minor axis eccentricity.

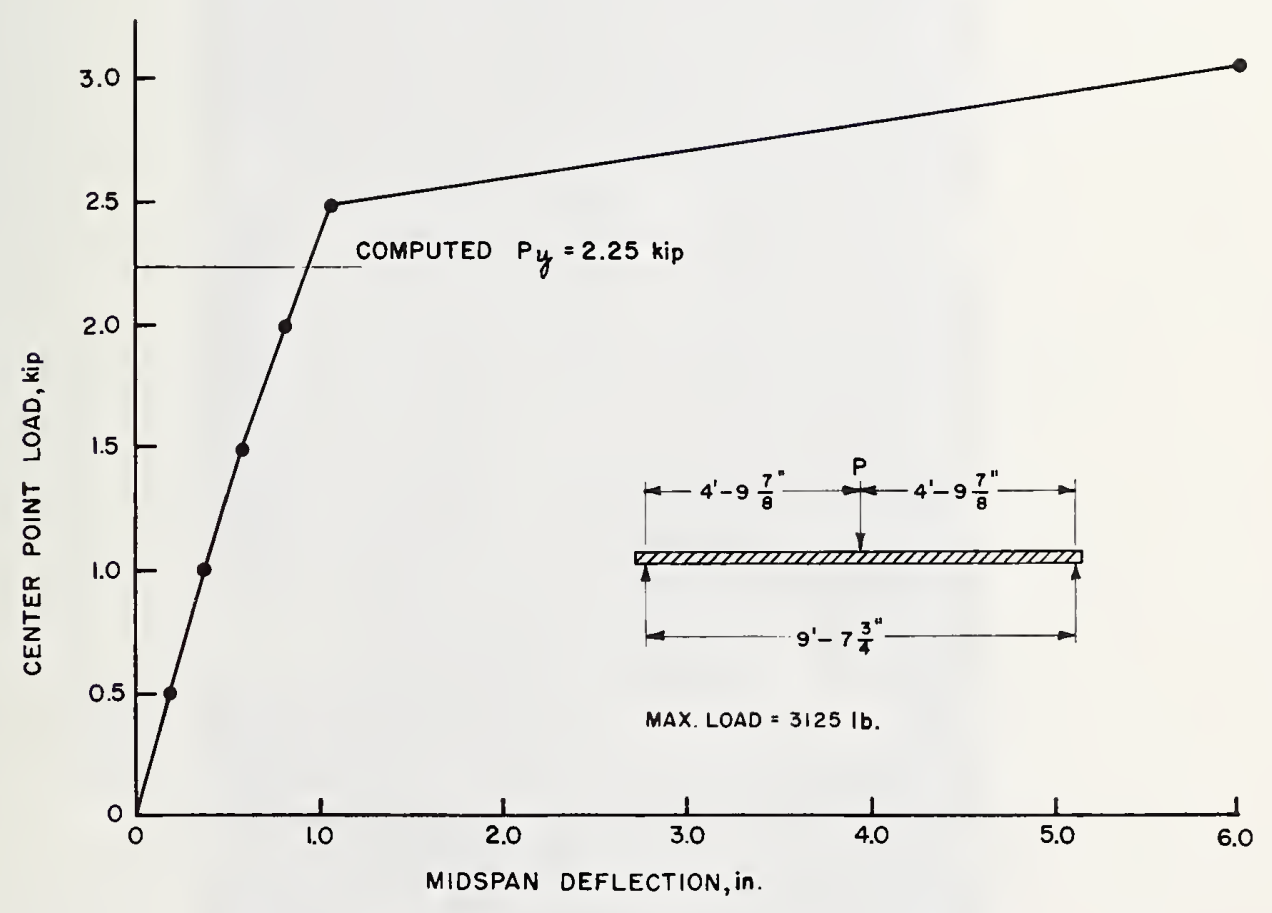

Figure 10.22. Channel roof slab test. 


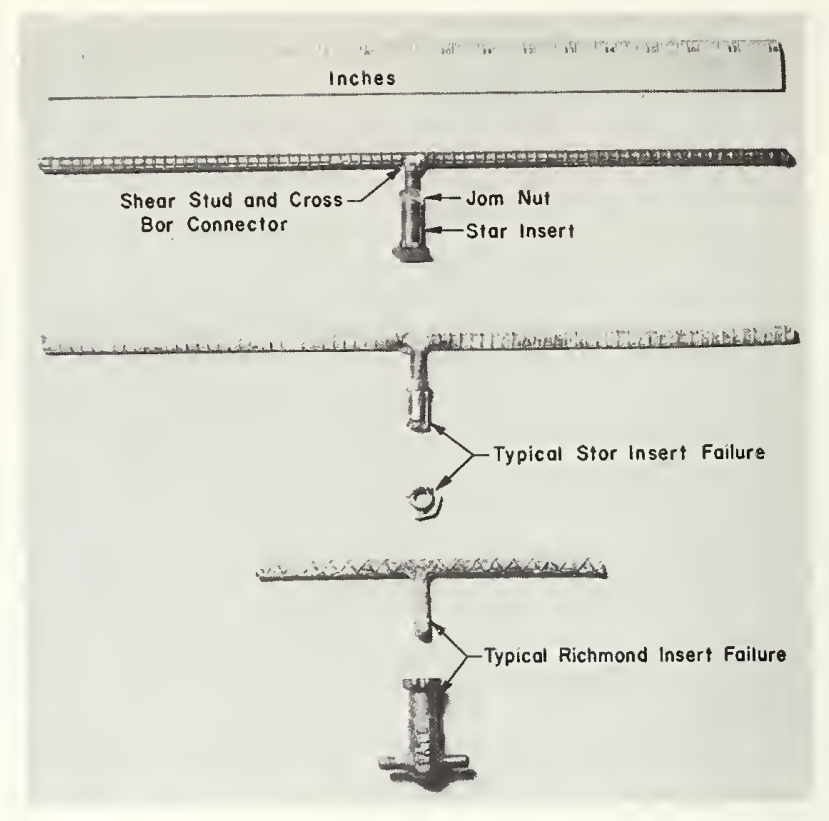

Figure 10.23. Bcam to slab shear connectors.

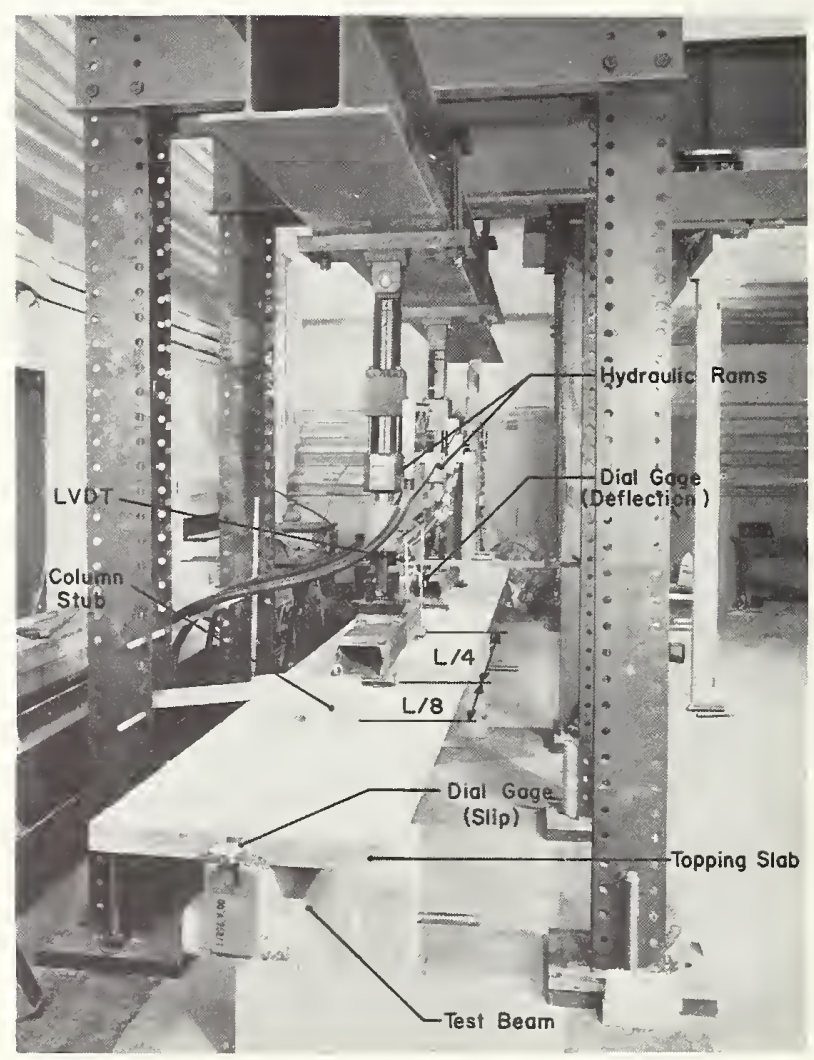

FIGURE 10.24. Fatigue test on main beam. 
BEAM NO. 5

STAR INSERTS AT 19"

NO COLUMN CONNECTIONS

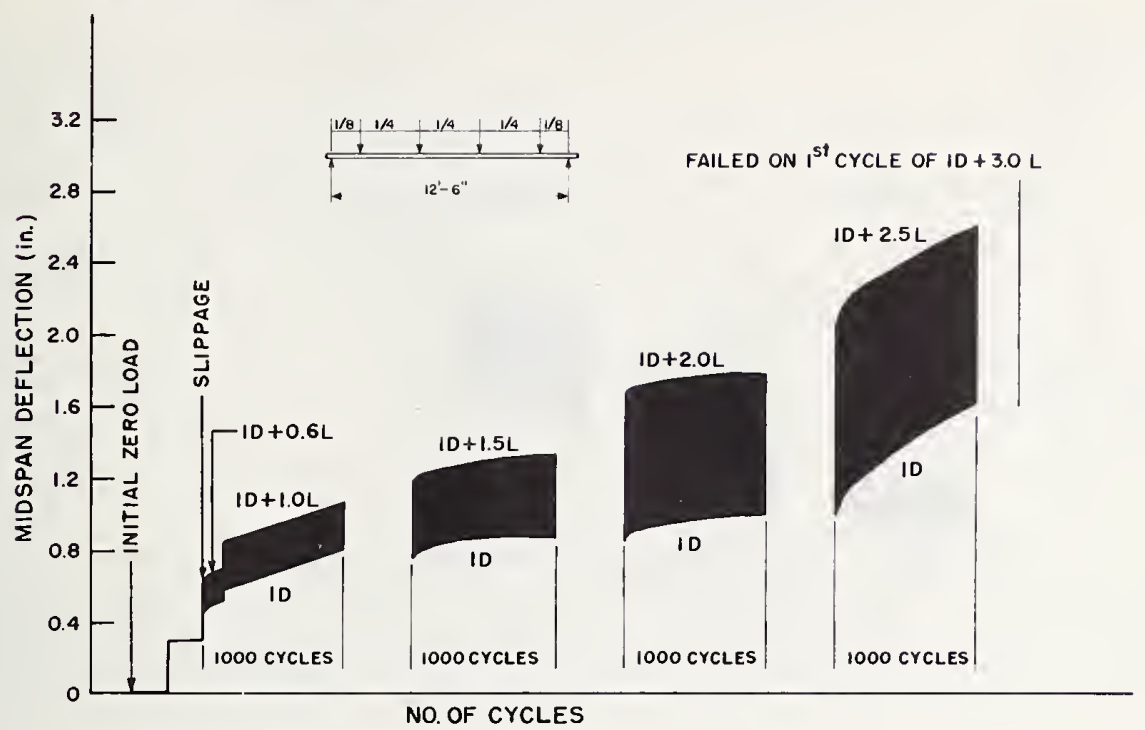

Figure 10.25. Fatigue loading, beam No. 5.

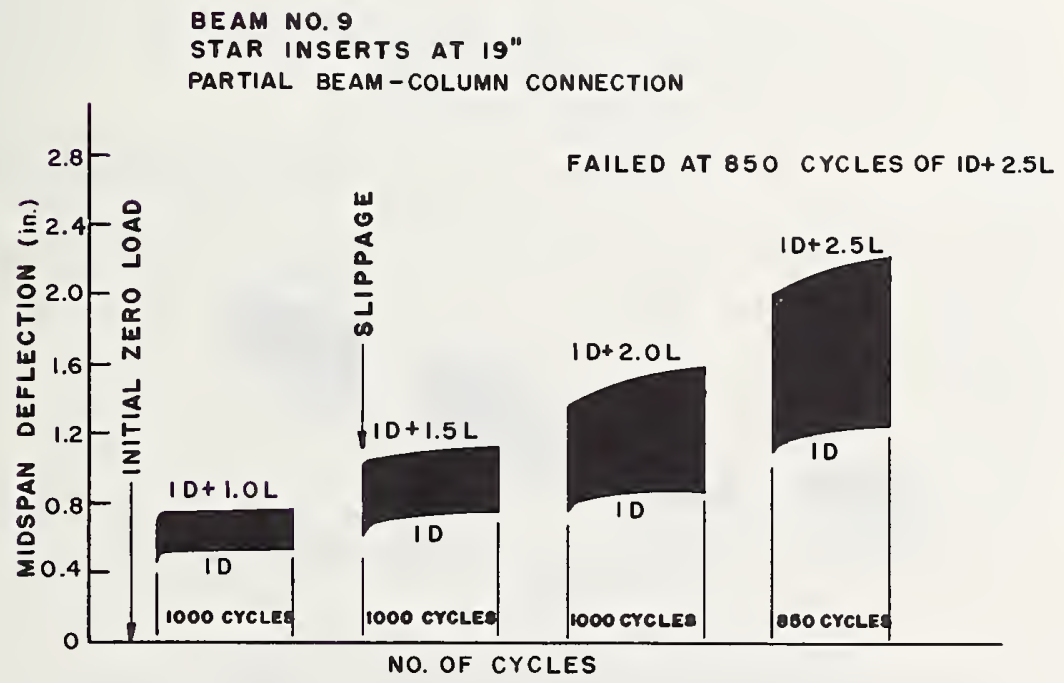

Figure 10.26. Fatigue loading, beam No. 9. 


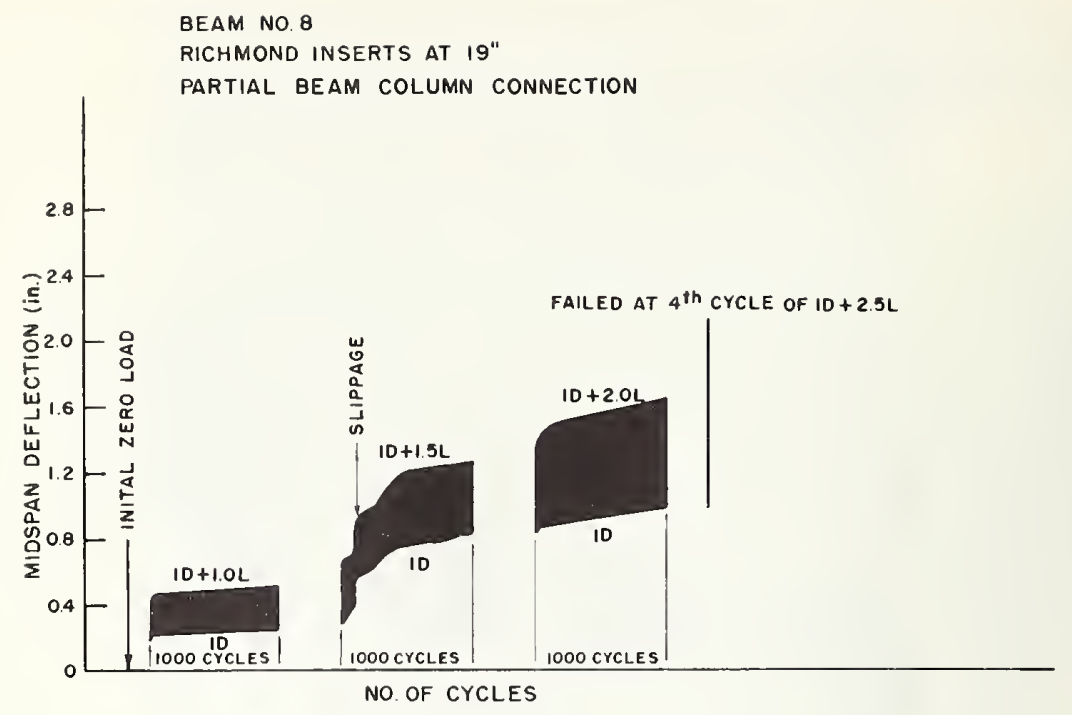

Figure 10.27. Fatigue loading, beam No. 8 .

BEAM NO. 6

RICHMOND INSERTS AT $9 \frac{1}{2}$ "

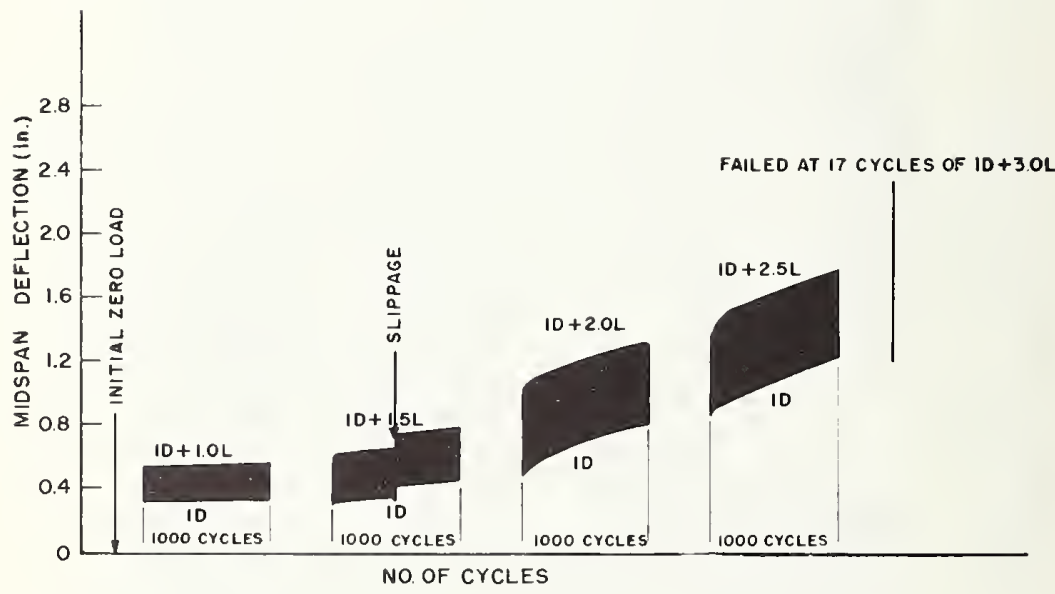

Figure 10.28. Fatigue loading, beam No. 6. 


\begin{tabular}{|l|l|l|}
\hline $\begin{array}{l}\text { LABORA TORY NUMEER } \\
\text { N- } 5592\end{array}$ & $\begin{array}{l}\text { NAME } \\
\text { Mr TOM Reichard }\end{array}$ & $\begin{array}{c}\text { DATE REPORTED } \\
5 / 29 / 68\end{array}$ \\
\hline $\begin{array}{l}\text { IDENTIFICATION MARKS } \\
\text { NBS B4-16 No. 4 }\end{array}$ & $\begin{array}{l}\text { SUBMITTED BY } \\
\text { National Bureau of Standards }\end{array}$ \\
\hline DATE SAMPLED & $\begin{array}{l}\text { DATE RECEIVED } 5 \mathrm{p} . \mathrm{m} . \\
5 / 24 / 68\end{array}$ & SAMPLED FROM \\
\hline QUANTITY REPRESENTED & $\begin{array}{l}\text { SOURCE OF MATERIAL } \\
\text { National Bureau of Standards }\end{array}$ \\
\hline LOCATION USED OR TO BE USED & & $\begin{array}{l}\text { EXAMINED FOR Air (void) content } \\
\text { by Linear Traverse (Rosiwal Method) }\end{array}$ \\
\hline
\end{tabular}

\section{TEST RESULTS}

The concrete specimen, a $6 \times 12$-inch cylinder, NBS B4-16 No. 4, was received 5/24/68. An inch thick slice was diamond sawed through the vertical axis of the cylinder. One side was ground and lapped for 30 minutes (on a Lapmaster "24" with No. 1950 Lapmaster Lapping Compound). The prepared surface was examined under Il2X magnification and tested by the Linear Traverse (Rosiwal) Method (ASTM Designation C 457-66 T).

The data recorded were:

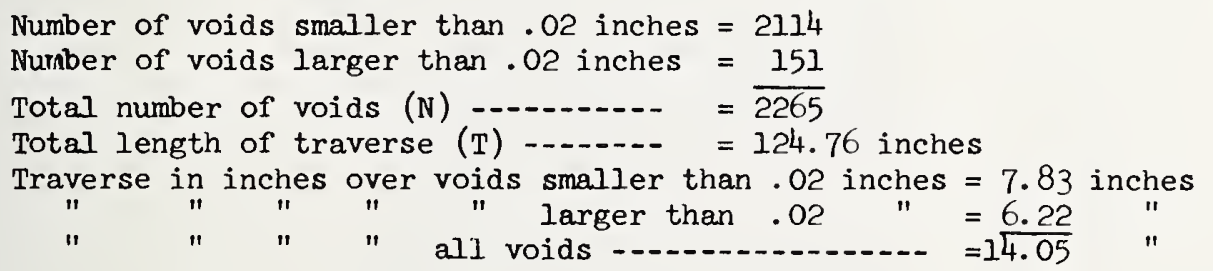

Calculated values:

Air void content (voids smaller than .02 inches) $=6.3$ percent

" " $" \begin{array}{rl}\text { larger than } .02 \text { inches })=5.0 & " \\ \text { Total air void content } & =\overline{11.3} "\end{array}$

Voids in porous aggregate were not counted.

Note information phoned to Mr. Reichard 4 p.m. 5/29/68

M. C. Gleason 


\title{
Appendix A. Plotted Test Results
}

\author{
List of Figures
}

A. 1. Test

A. 2. Test

A. 3. Test

A. 4. Test

A. 5. Test

A. 6. Test

A. 7. Test

A. 8. Test

A. 9. Test

A. 10. 'Test

A. 11. Test

A. 12. 'Test

A. 13. Test

A. 14. Test

A. 15. Test

A. 16. Test

A. 17. Test

A. 18. Test

A. 19. Test

A. 20. Test

A. 21. Test

A. 22. Test

A. 23. Test

A. 24. Test

A. 25. Test

A. 26. Test

A. 27. 'Test

A. 28. Test

A. 29. Test

A. 30. Test

A. 31. Test

A. 32. Test

A. 33. Test

A. 34. 'Test

A. 35. Test

A. 36. Test

A. 37. Test

A. 38. 'Test

A. 39. 'Test

A. 40. Test

A. 41. Test

A. 42. Test

A. 43 . Test

A. 44. Test

A. 45. 'Test

A. 46. Test

A. 47. Test

A. 48. Test

A. 49. Test

A. 50. Test

A. 51. Test

A. 52. Test

A. 53. Test

A. 54. Test

A. 55. Tests

A. 56. Tests No. 12A

A. 57. Tests

A. 58. Tests

A. 59. Test

A. 60. Test

A. 61. Test

A. 62. Test

A. 63. Test

No. 1,

No. 2 ,

No. 2 ,

No. 3,

No. 3 ,

No. 4,

No. 4,

No. 4,

No. 4

No. 4,

No. 5 ,

No. 5 ,

No. 7

No. 7 ,

No. 8 ,

No, 8 ,

No. 8,

No. 9,

No. 9 ,

No. 9

No. 10 ,

No. 10 ,

No. 11,

No. 11,

No. 11 ,

No. 11,

No. 11 ,

No. 11,

No. 11,

No. 11,

No. 11,

No. 11,

No. 11,

No. 12

No. 14,

No. 14,

No. 14 ,

No. 15 ,

No. 15 ,
No. 2,

No. 2,

No. 3,

No. 4,

No. 5 ,

No. 5,

No. 7 ,

No. 9,

major floor load versus beam deflection

No. 9A, floor loads versus beam deflection

No. 9A, floor loads versus column shortening _._.

No, 9A, floor load versus slab deflection

No. 9A, floor load versus beam deflection

No. 10 , south wind load versus translation

No. 10, south wind load versus translation

No. 10, south wind load versus wall compression

No. $12 \mathrm{~A}$ south wind load versus wall compression

south wind load versus beam deflection

west wind load versus translation

west wind load versus translation

west wind load versus wall compression

west wind load versus wall compression -

west wind load versus wall compression $\ldots \ldots \ldots$

west wind load versus wall compression

west wind load versus wall compression $\ldots \ldots$

west wind load versus wall compression

west wind load versus wall compression _______-__-_-_ 97

west wind load versus wall compression

west wind load versus beam deflection

and 13, vertical load versus east translation

and 13, vertical load versus east translation

and $13 \mathrm{~A}$, vertical load versus north translation $\ldots$

and $13 \mathrm{~A}$, vertical load versus north translation

and $13 \mathrm{~A}$, vertical load versus north translation

south wind load versus translation 101

south wind load versus translation

south wind load versus translation _.______________-__-_ 102

west wind load versus translation

west wind load versus translation _._. 
A. 64. Test

A. 65 . Test

A. 66. Test

A. 67 . Test

A. 68 . Test

A. 69 . Test

A. 70. Test

A. 71 . Test

A. 72. Test

A. 73. Test

A. 74 . Test

A. 75 . Test

A. 76 . Test

A. 77 . Test
No. 16, major floor load versus beam deflection

No. 16, major floor load versus beam deflection

No. 16, major floor load versus column shortening _-_____-_-_-_-_ 104

No. 16, major floor load versus slab deflection

No. 16, major floor load versus slab deflection _____________ 105

No. 16A, floor loads versus beam deflection

No. 16A, floor loads versus beam deflection _- 106

No. $16 \mathrm{~A}$, floor loads versus beam deflection

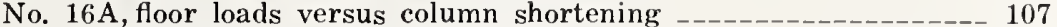

No. $16 \mathrm{~A}$, floor loads versus slab deflection

No. $16 \mathrm{~A}$, floor loads versus beam deflection

No. 18, south wind load versus translation

No. 18, south wind load versus translation

No. 18, south wind load versus translation 


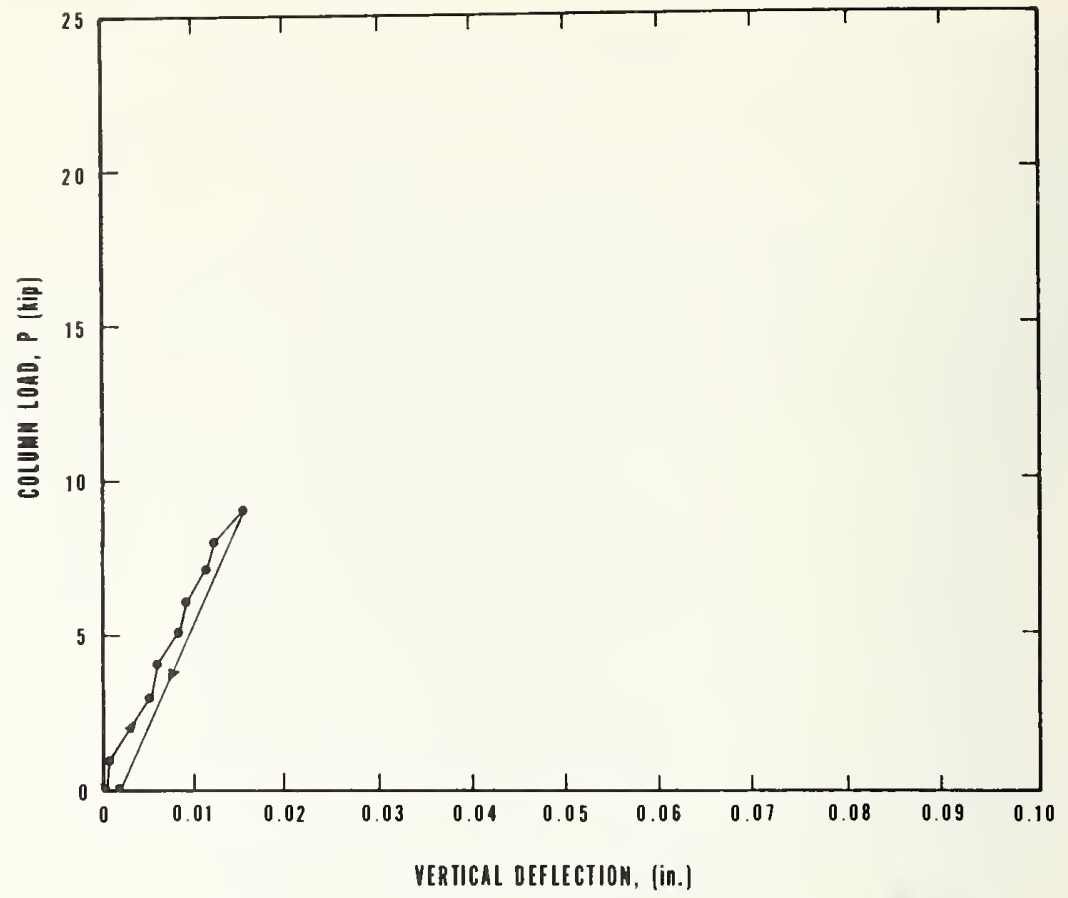

Figure A. 1. Test No. 1, eolumn load versus beam deflection. (Output Channel 72)

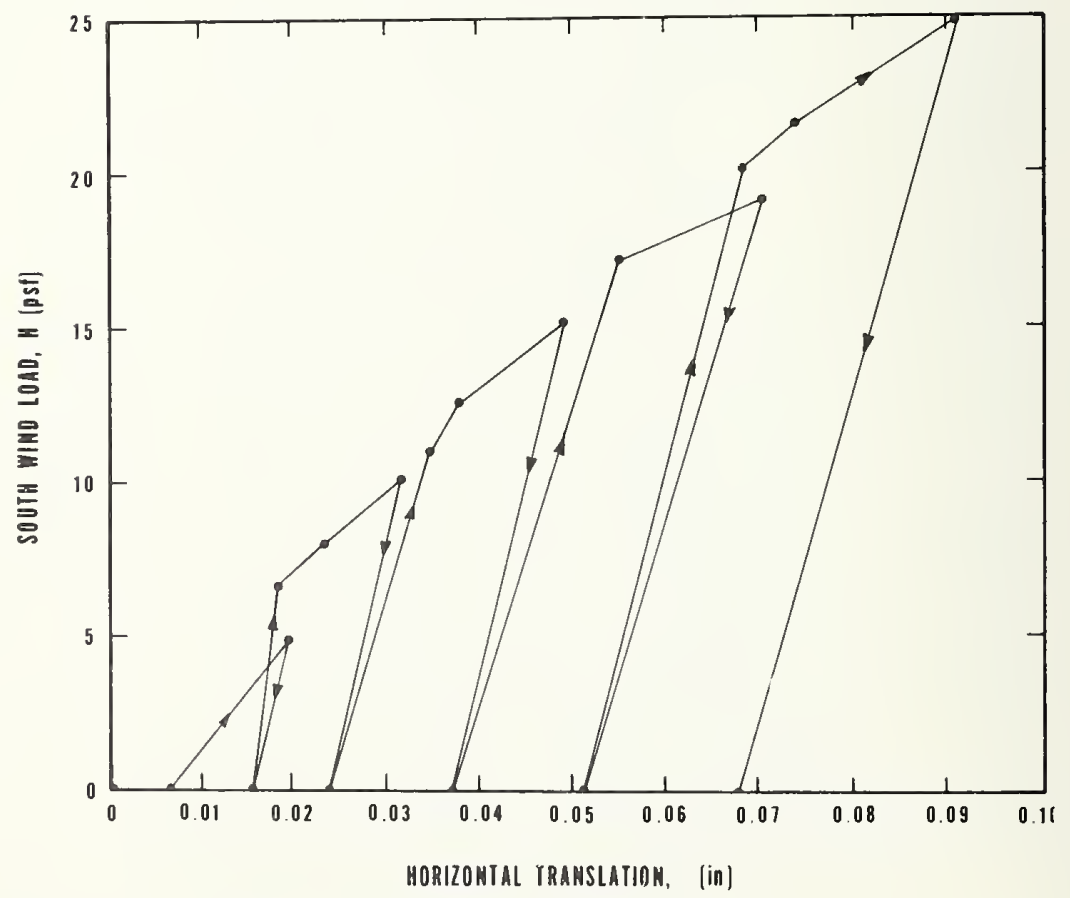

Figure A. 2. Test No. 2, south wind load versus translation. (Output Channel 43) 


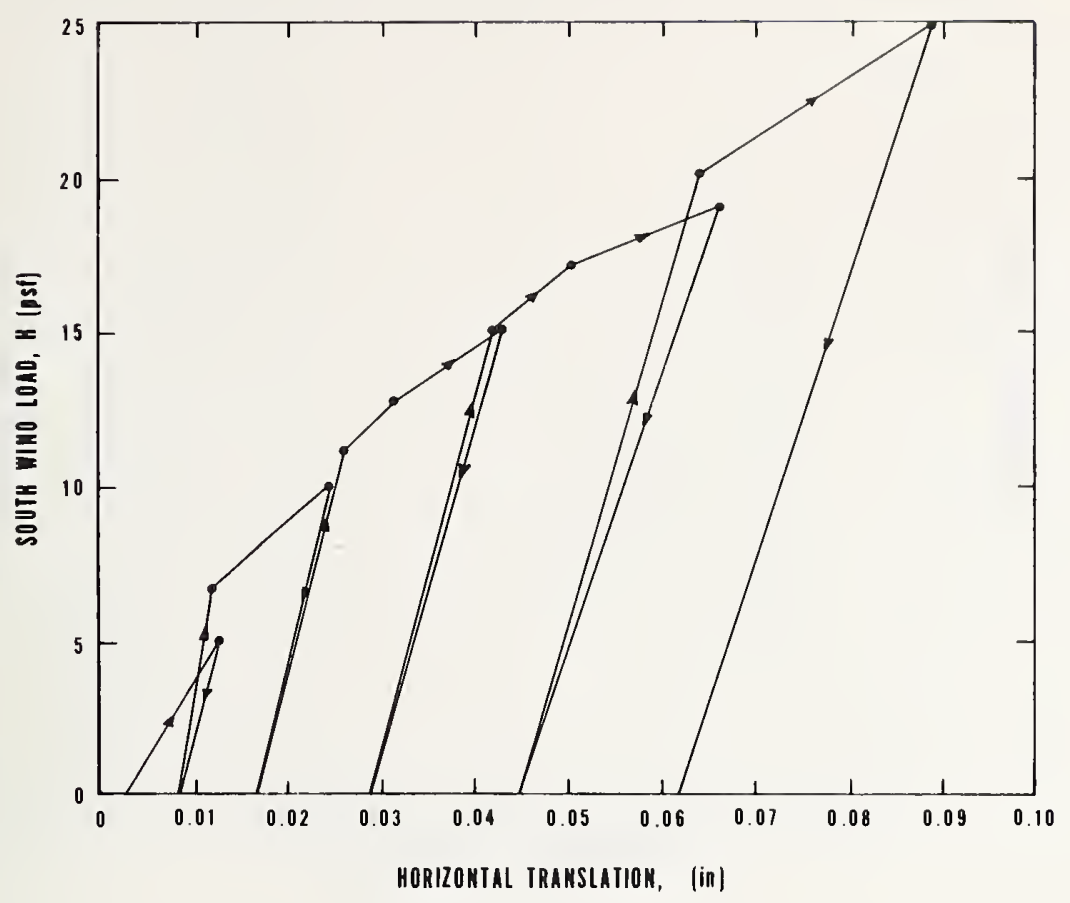

Figure A. 3. Test No. 2, south wind load versus translation. (Output Channel 44)

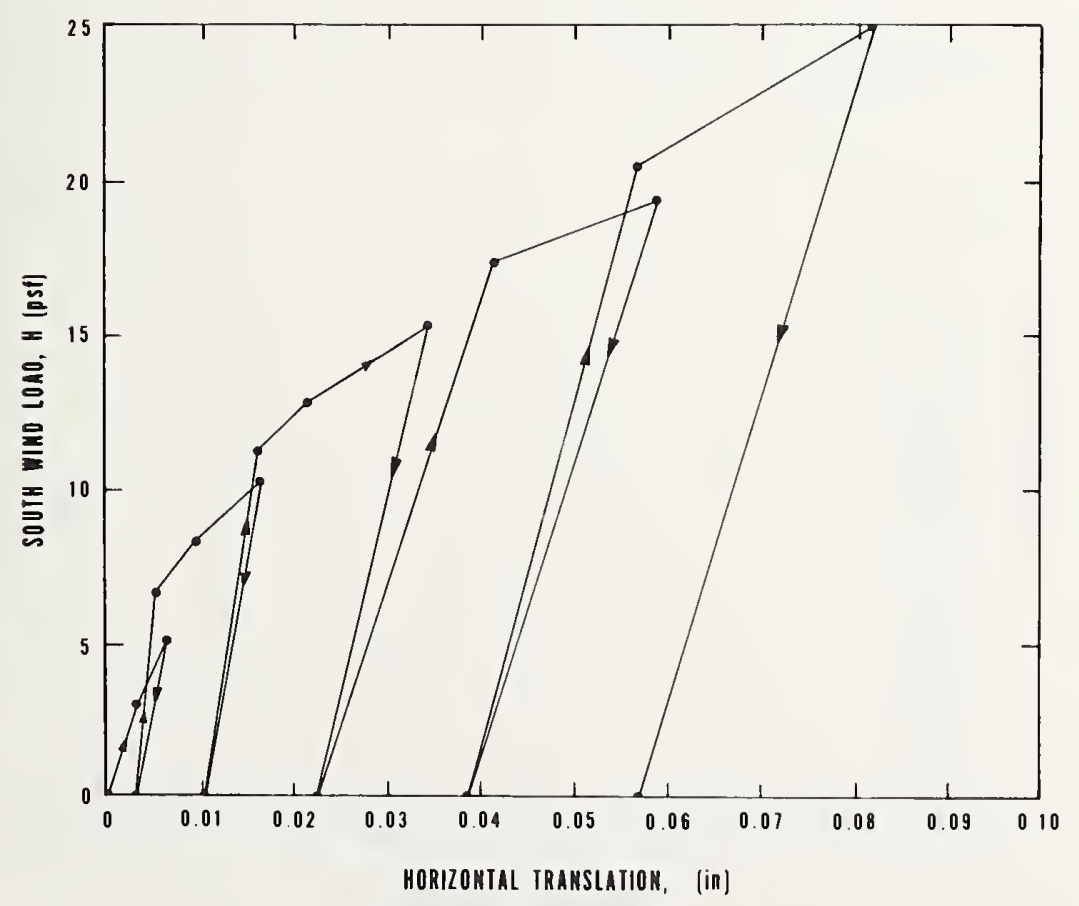

Figure A. 4. Test No. 2, south wind load versus translation. (Output Channel 45) 


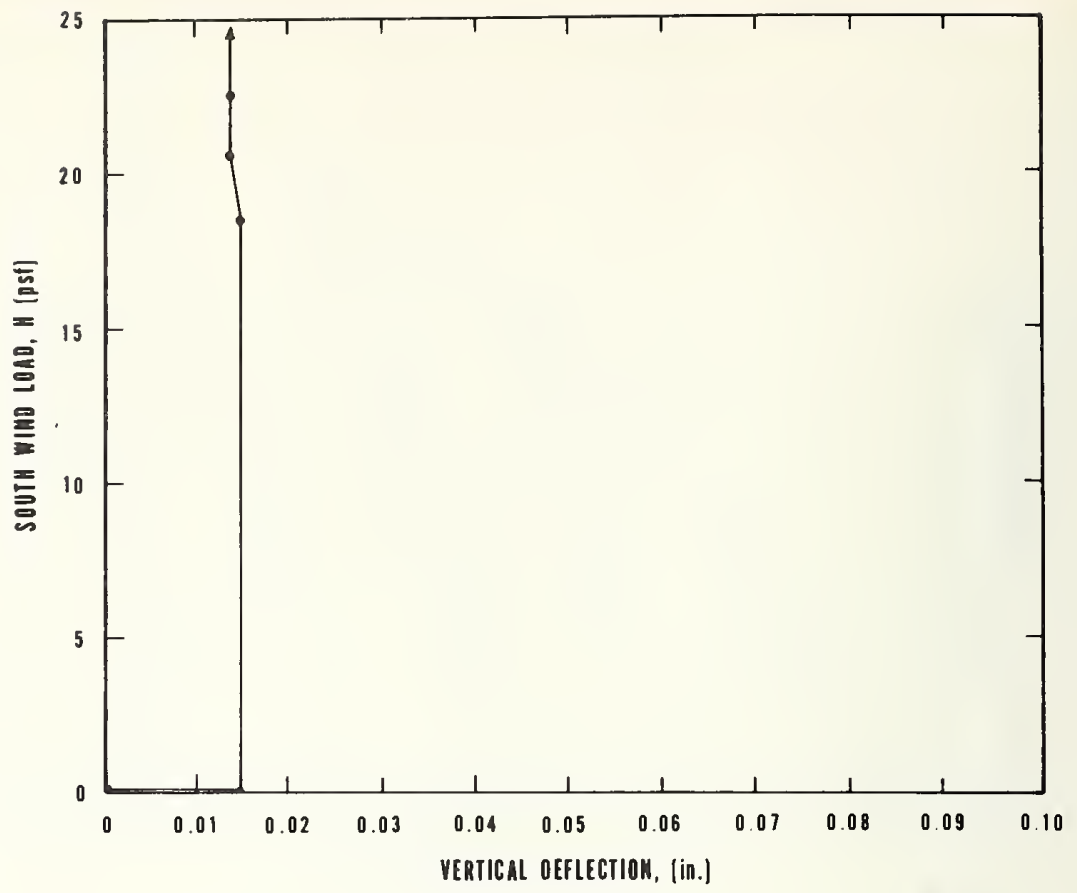

Figure A. 5. Test No. 2, south wind load versus beam deflection. (Output Channel 72)

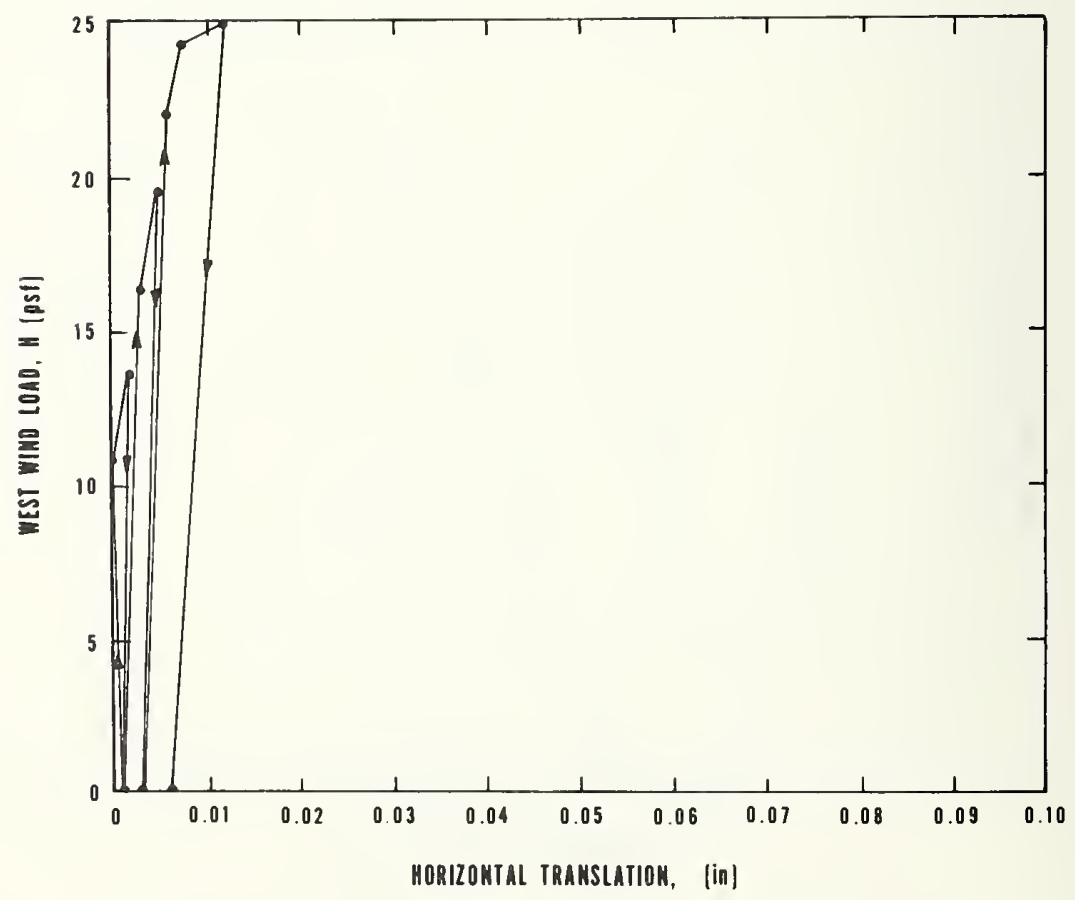

Figure A. 6. Test No. 3, west wind load versus translation. (Output Channel 46) 


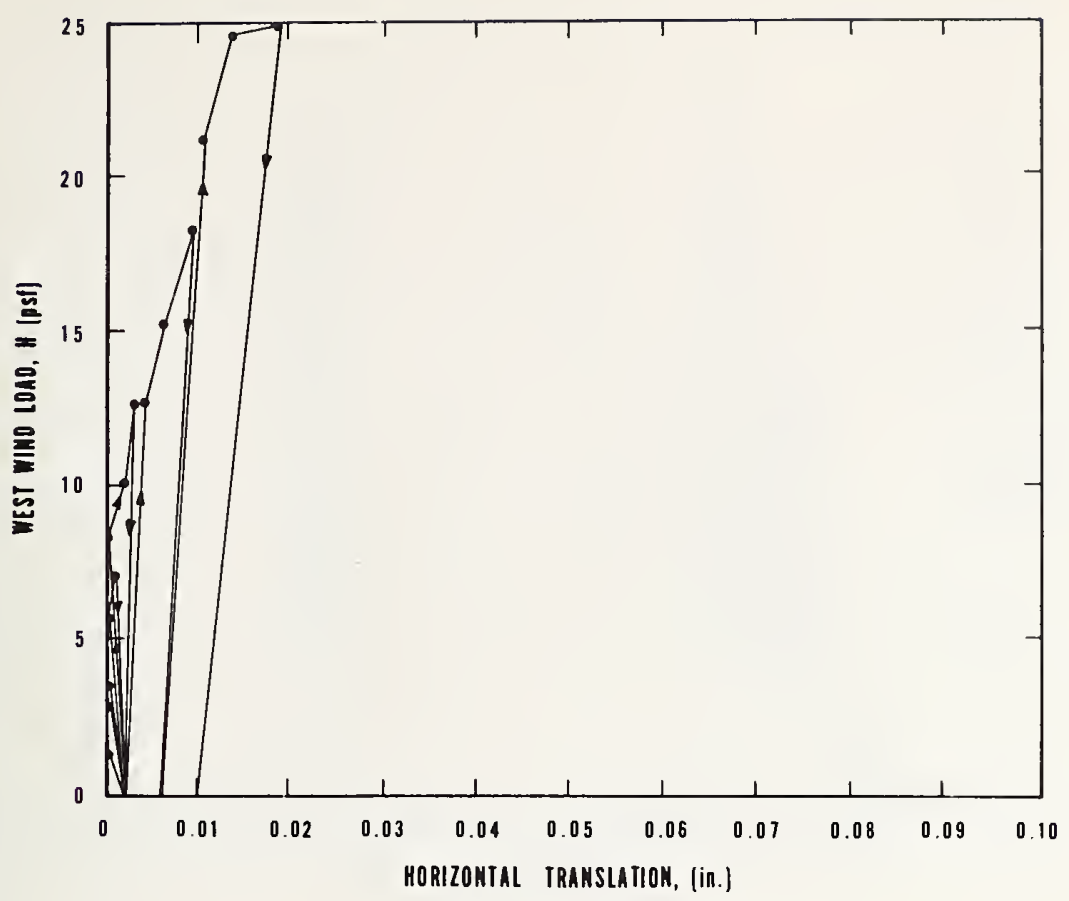

Figure A. 7. Test No. 3, west wind load versus translation. (Output Channel 47)

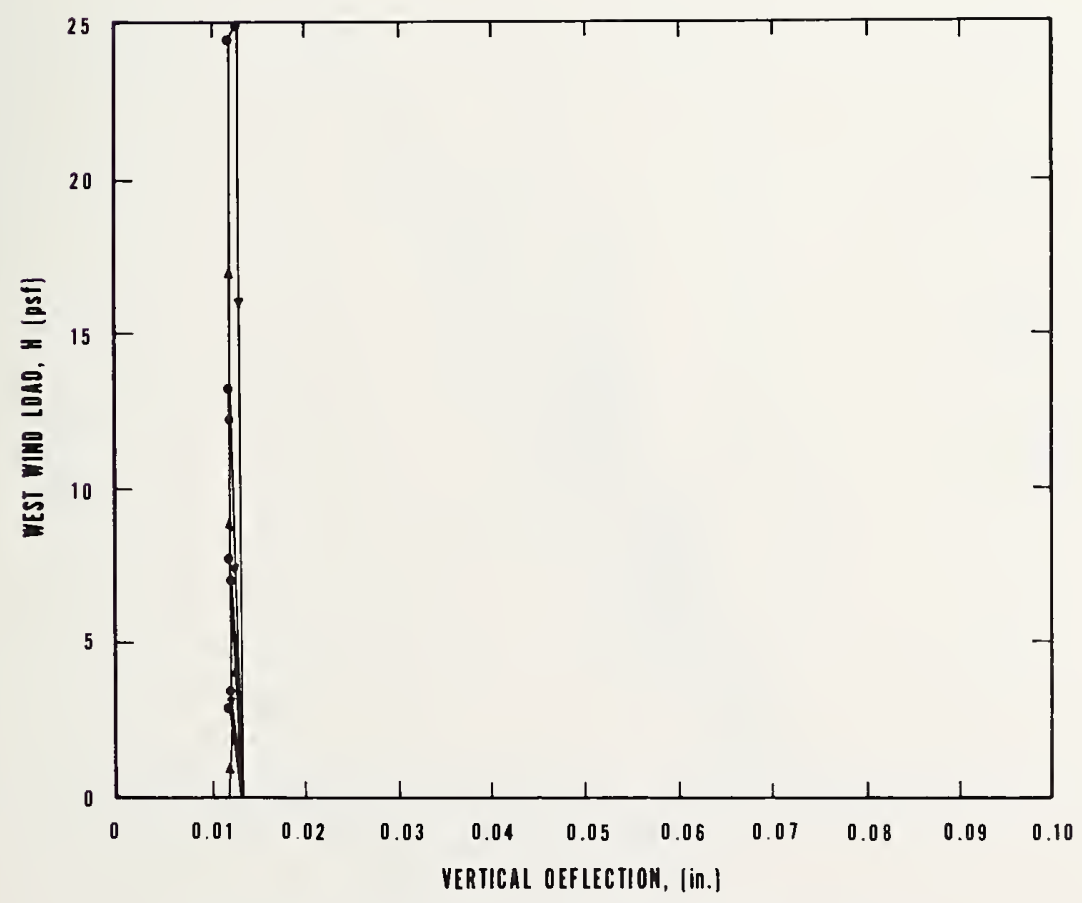

Figure A. 8. Test No. 3, west wind load versus beam deflection. (Output Channel 72) 


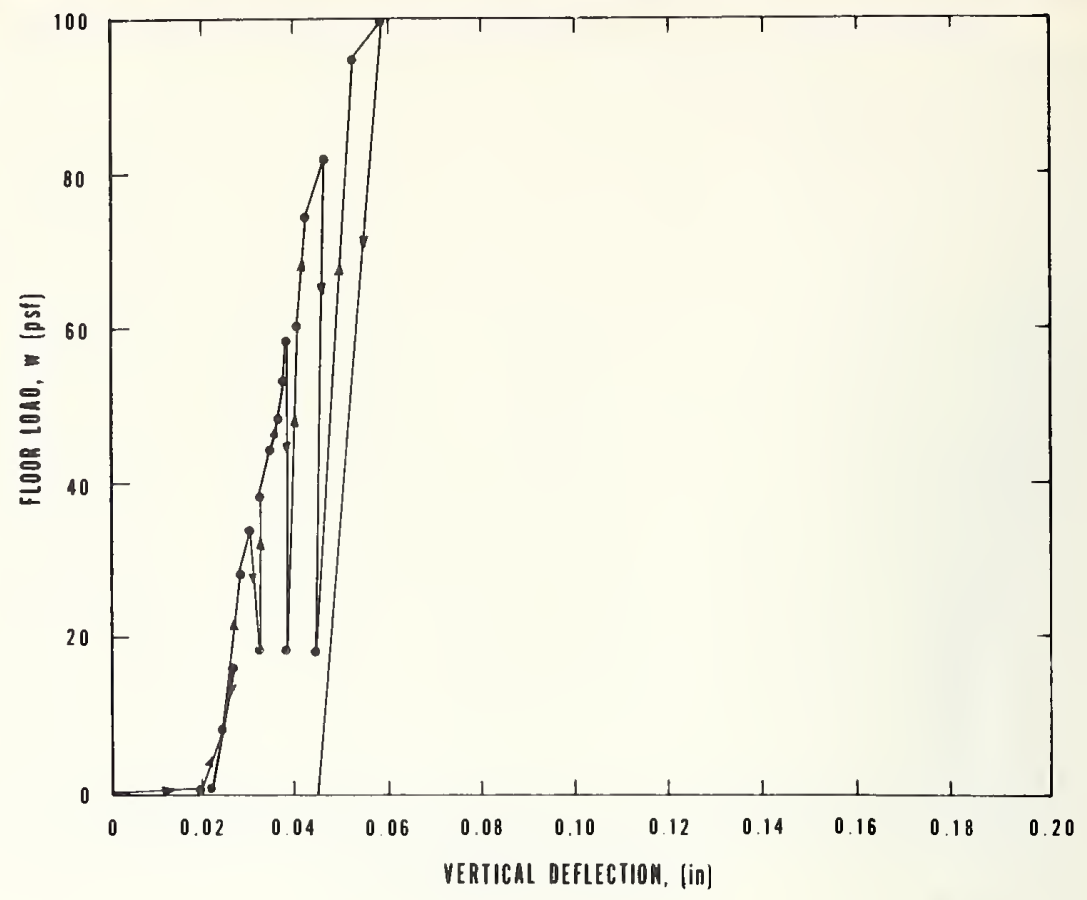

Figure A. 9. Test No.4, floor load versus beam deflection. (Output Channel 40)

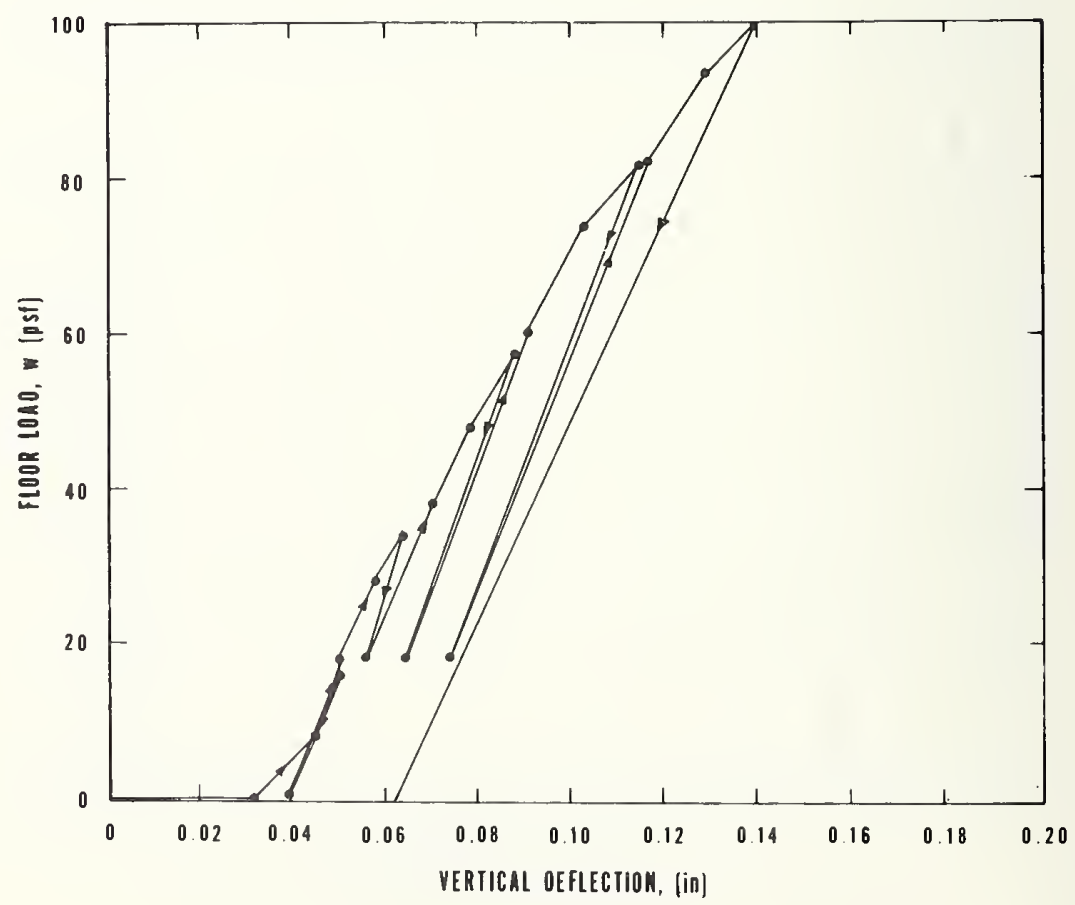

Figure A. 10. Test No. 4, floor load versus beam deflection. (Output Channel 72) 


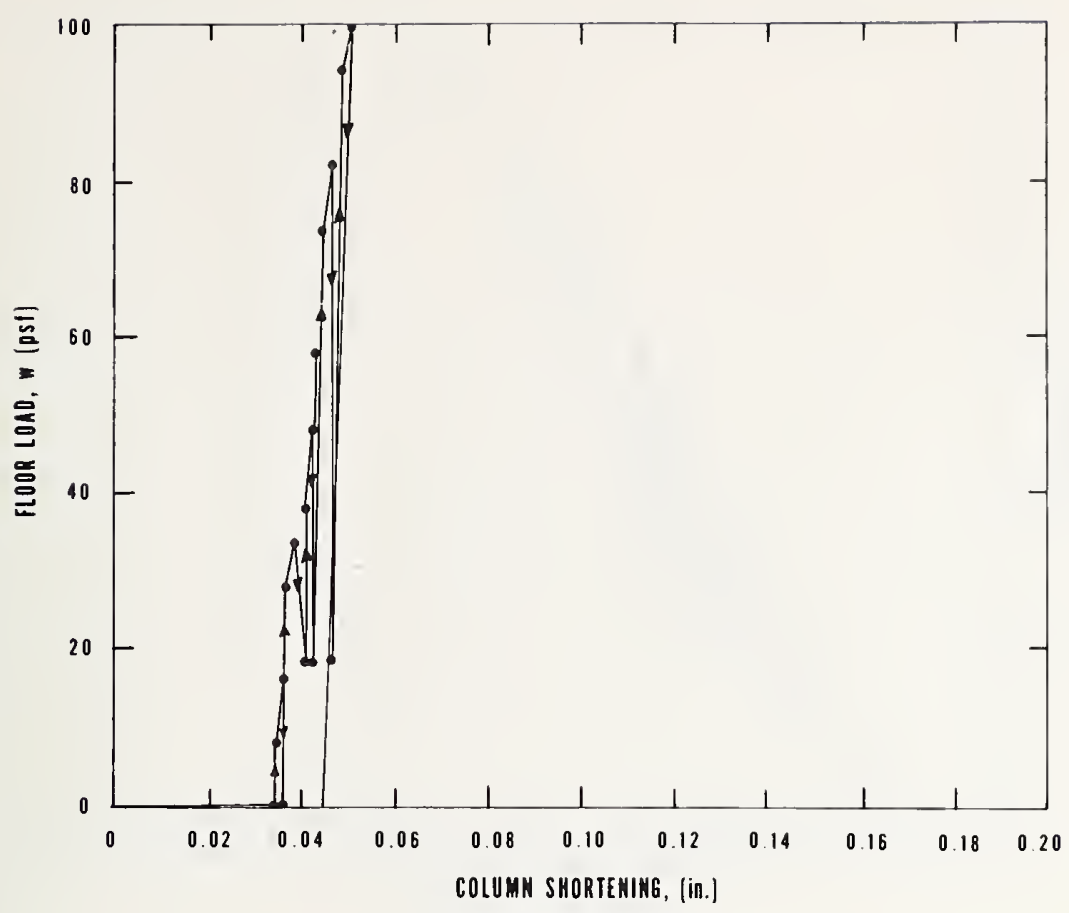

Figure A. 11. Test No. 4, floor load versus column shortening. (Output Channel 73)

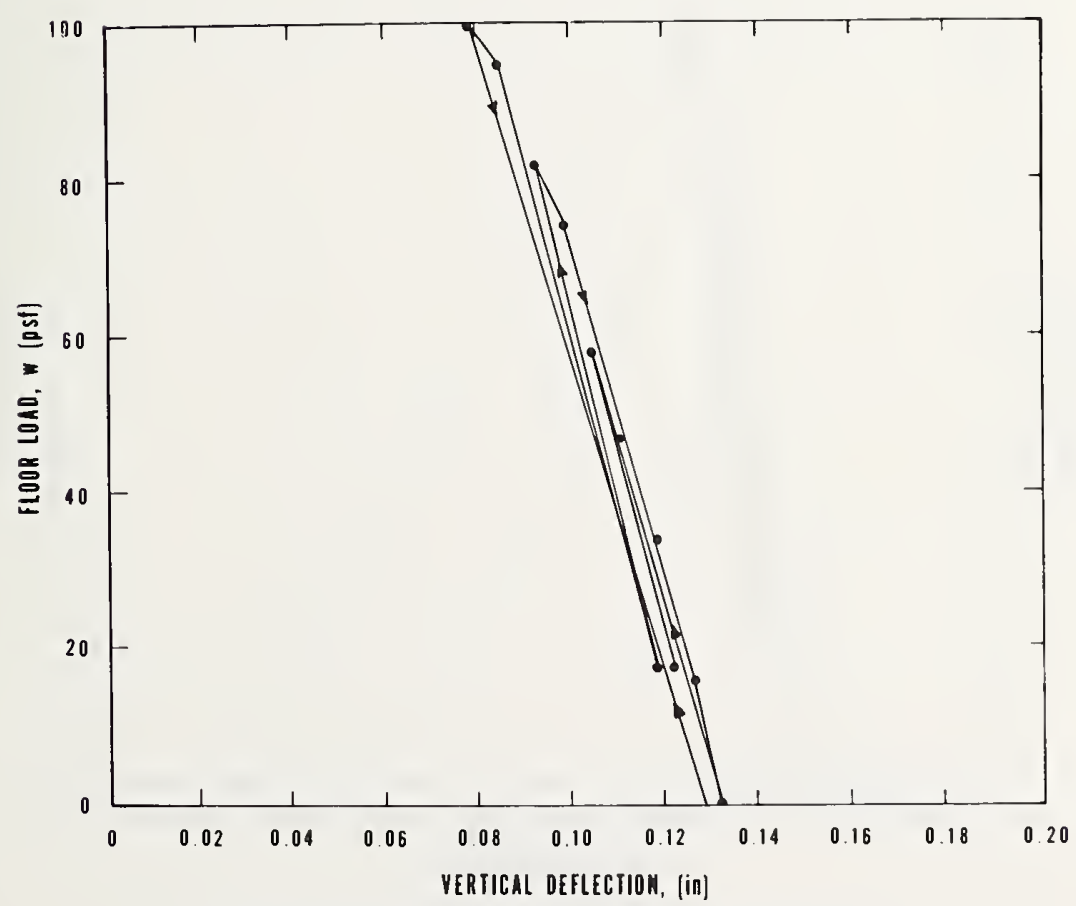

Figure A. 12. Test No. 4, floor load versus beam deflection. (Output Channel $\gamma_{4}$ ) 


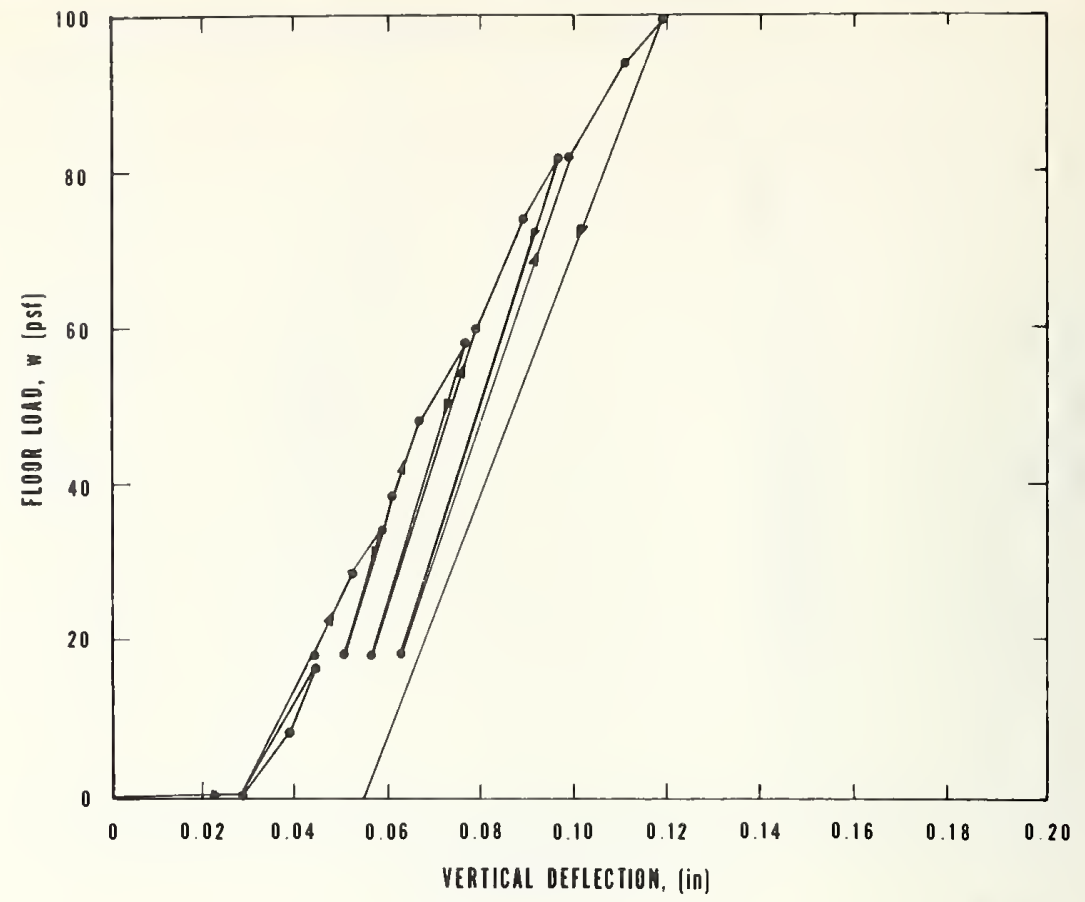

Figure A. 13. Test No. 4, floor load versus slab deflection. (Output Channel 76 )

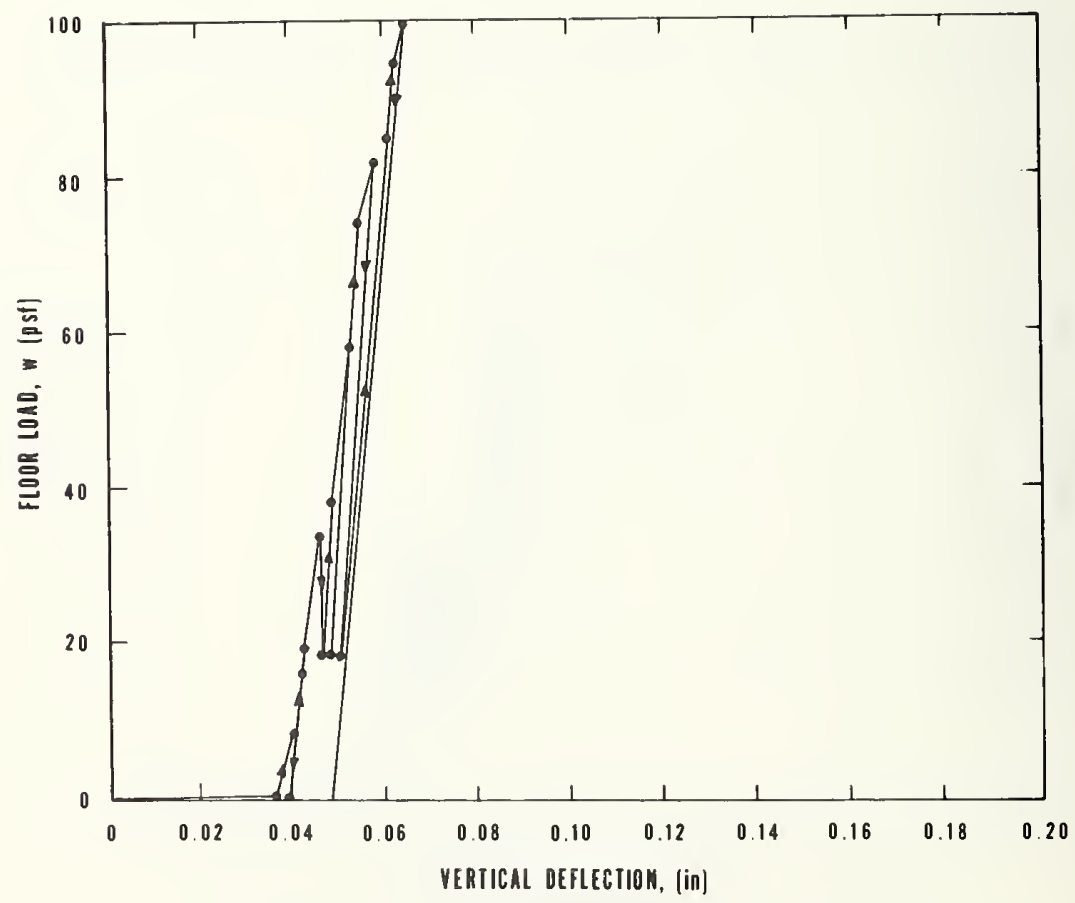

Figure A. 14. Test No. 4, floor load versus beam deflection. (Output Channel 77) 


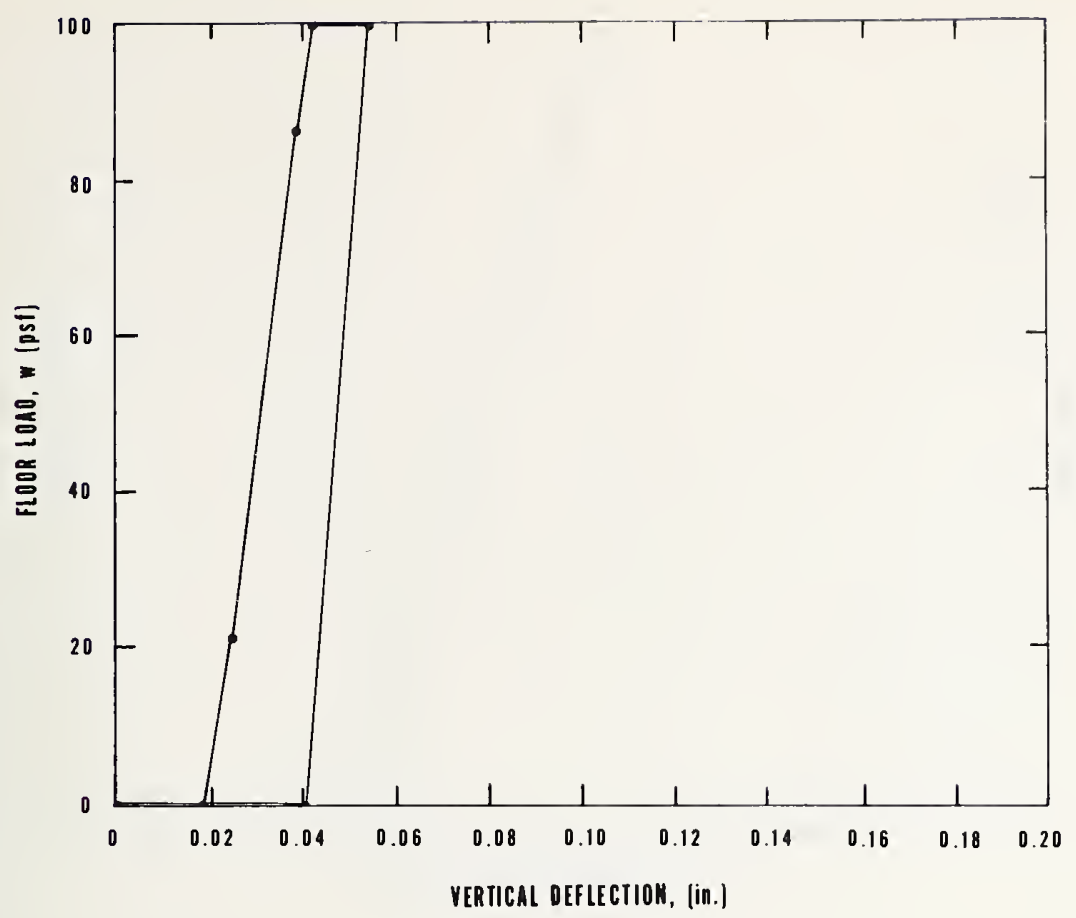

Figure A. 15. Test No. 5, sustained floor load versus beam deflection. (Output Channel 40)

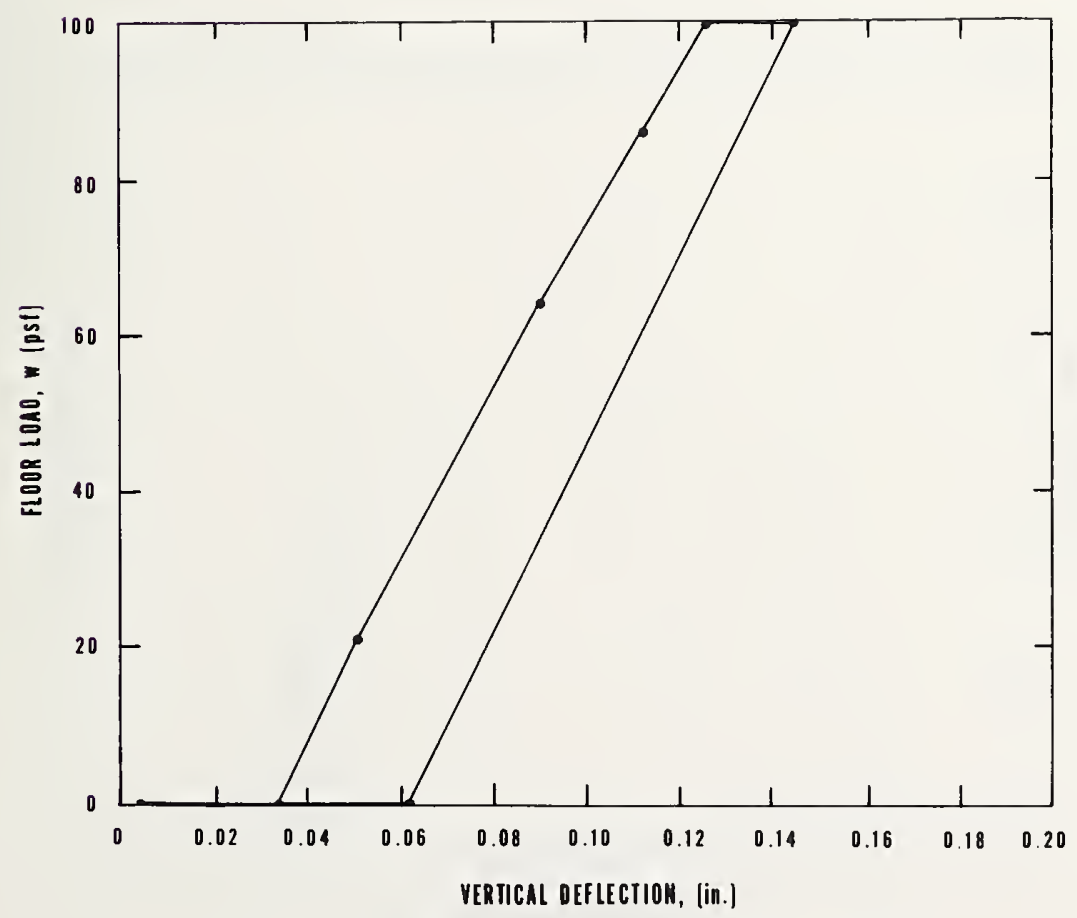

Figure A. 16. Test No. 5, sustained floor load versus deflection. (Output Channel 72) 


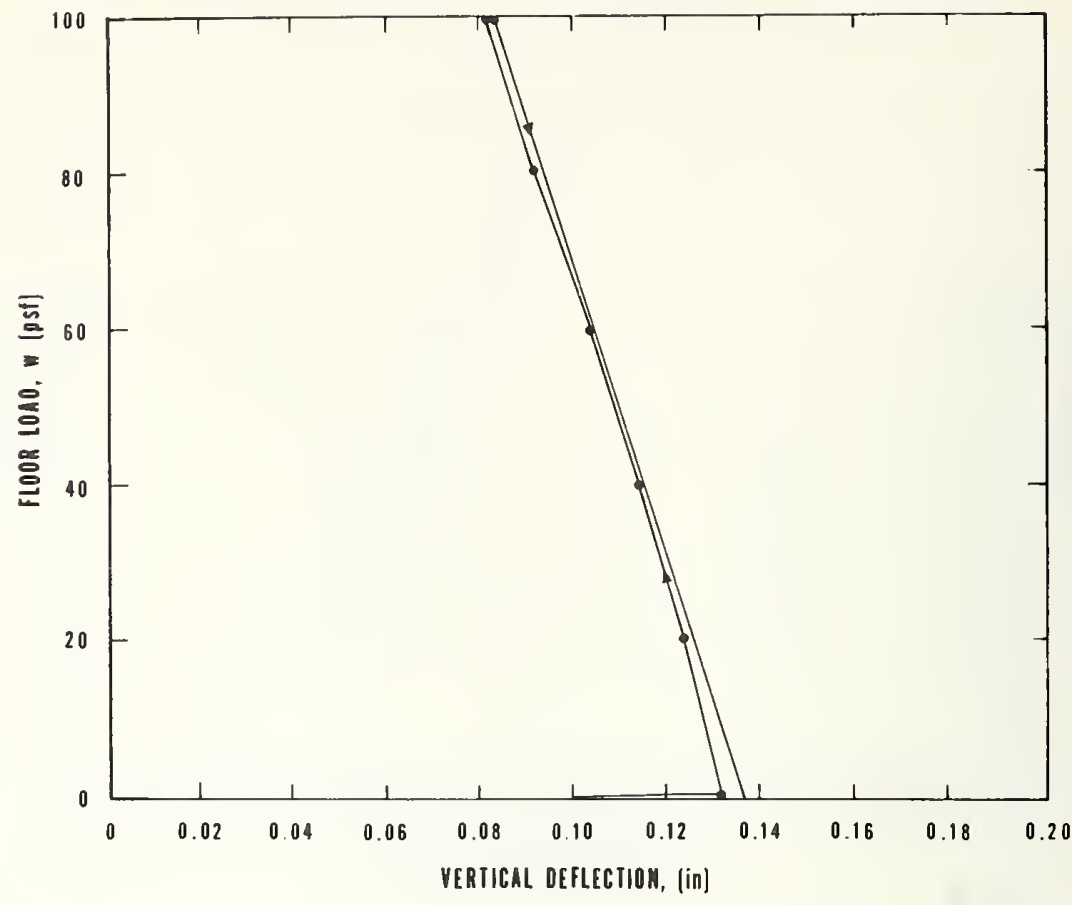

Figure A. 17. Test No. 5, sustained floor load versus beam deflection. (Output Channel 74)

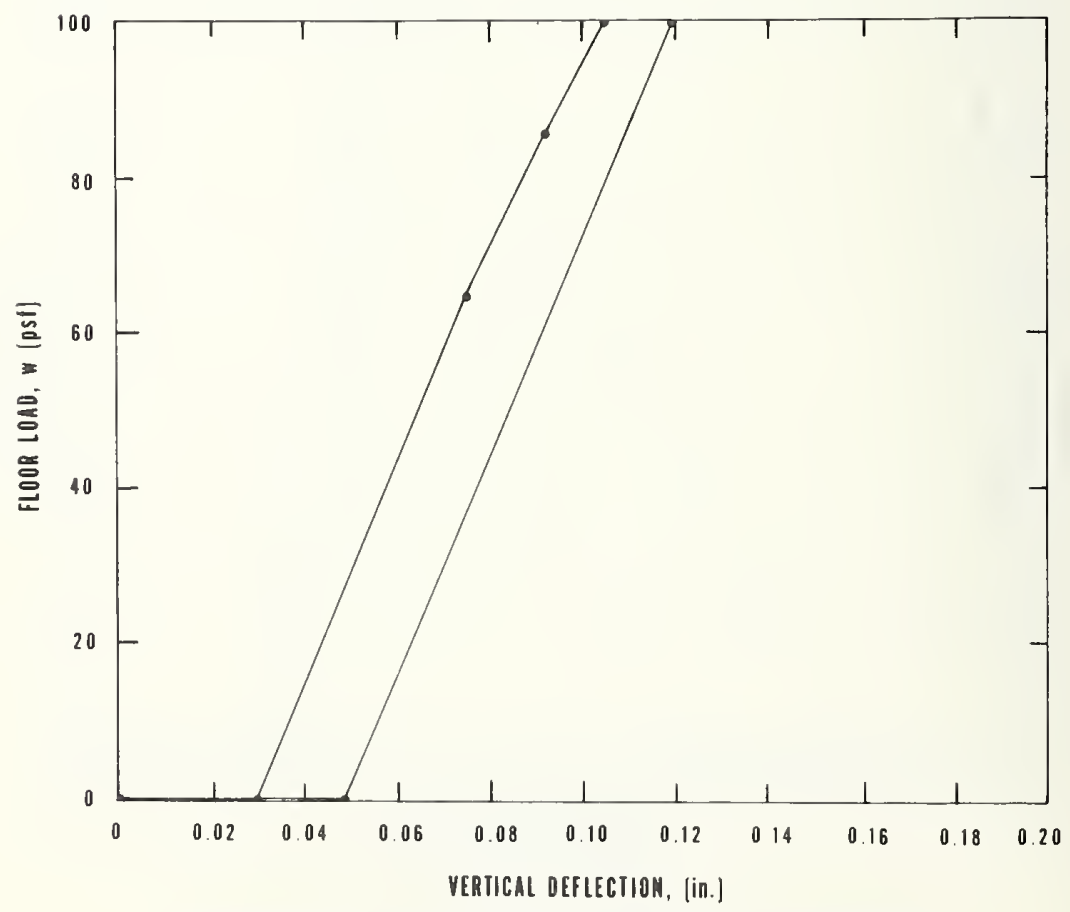

Figure A. 18. Test No. 5, sustained floor load versus slab deflection. (Output Channel 76) 


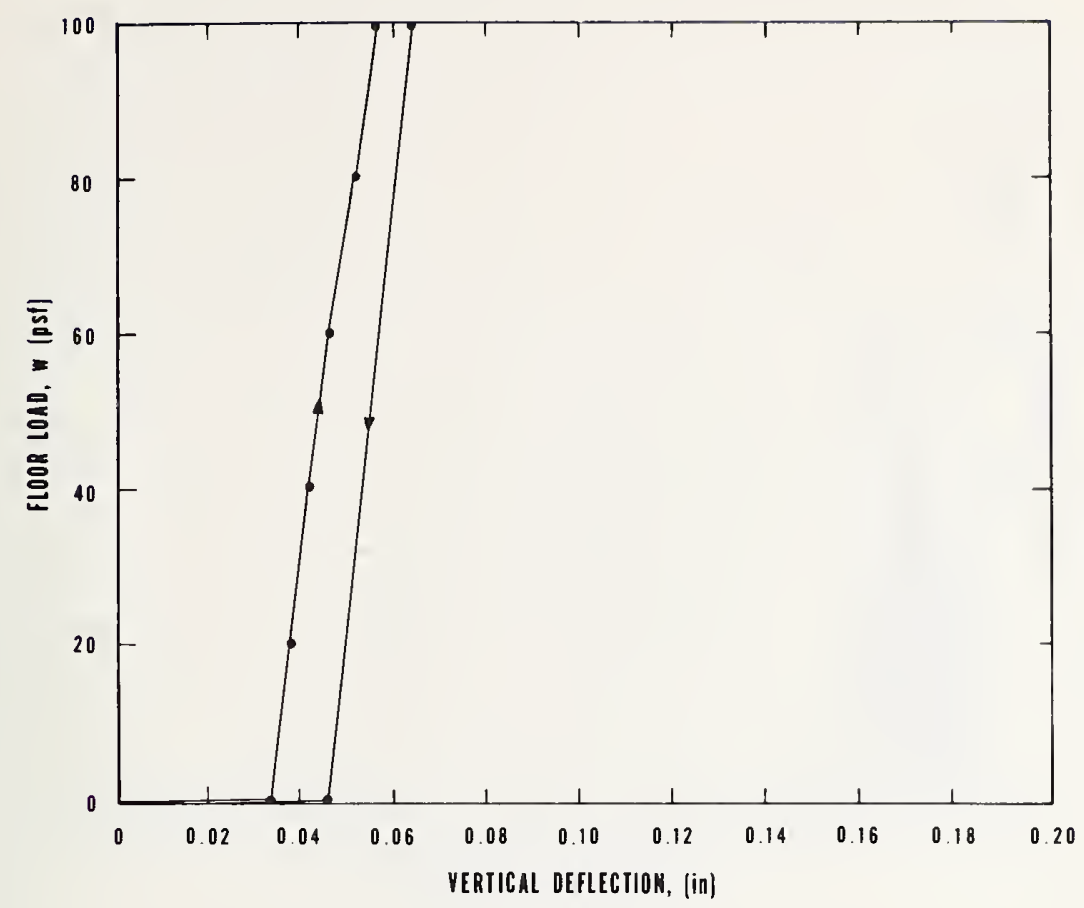

Figure A. 19. Test No. 5, sustained floor load versus beam deflection. (Output Channel 77)

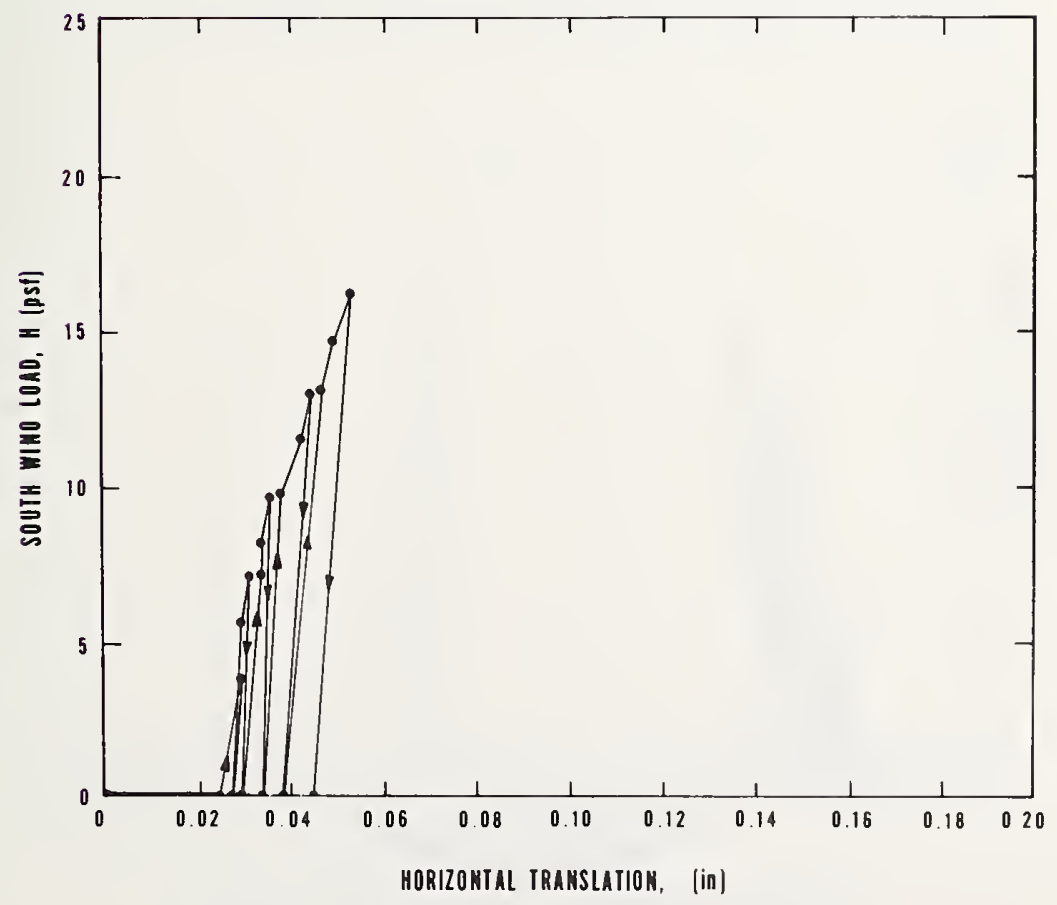

Figure A. 20. Test No. 7, south wind load versus translation. (Output Channel 43) 


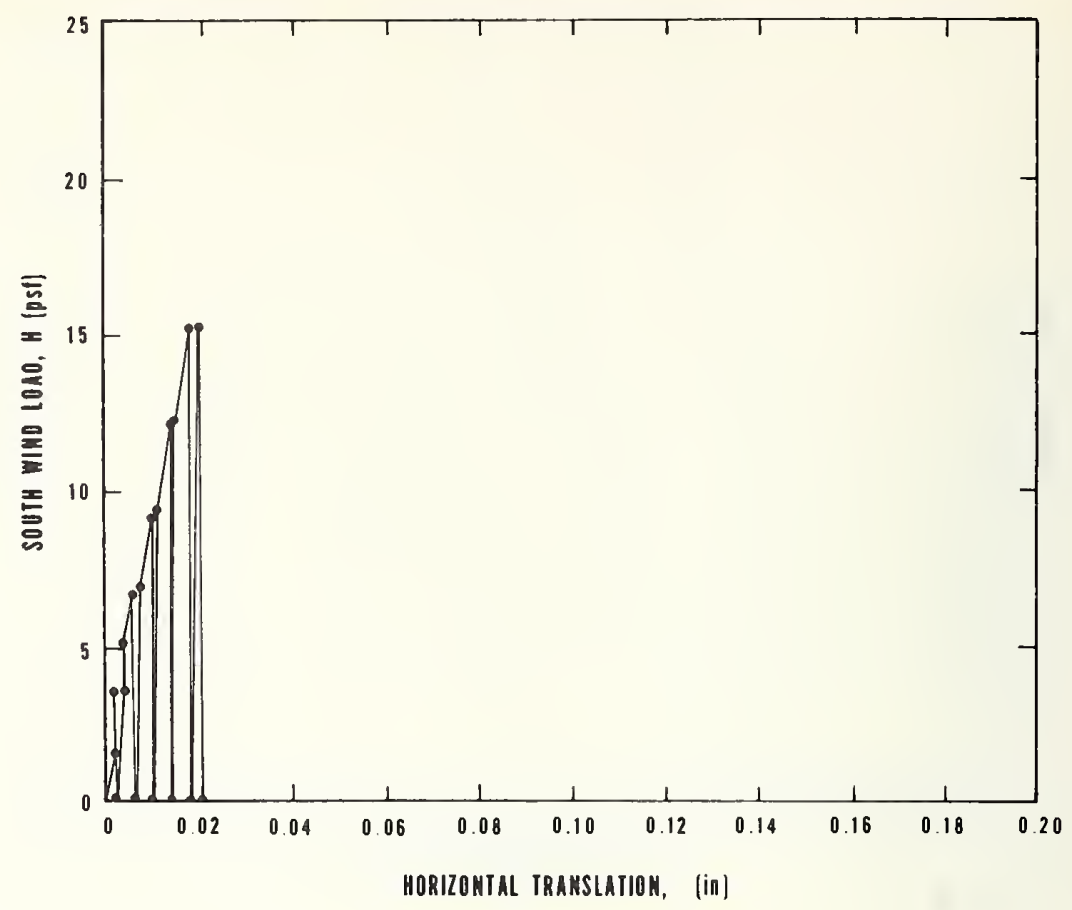

Figure A. 21. Test No. 7, south wind load versus translation. (Output Channel 44)

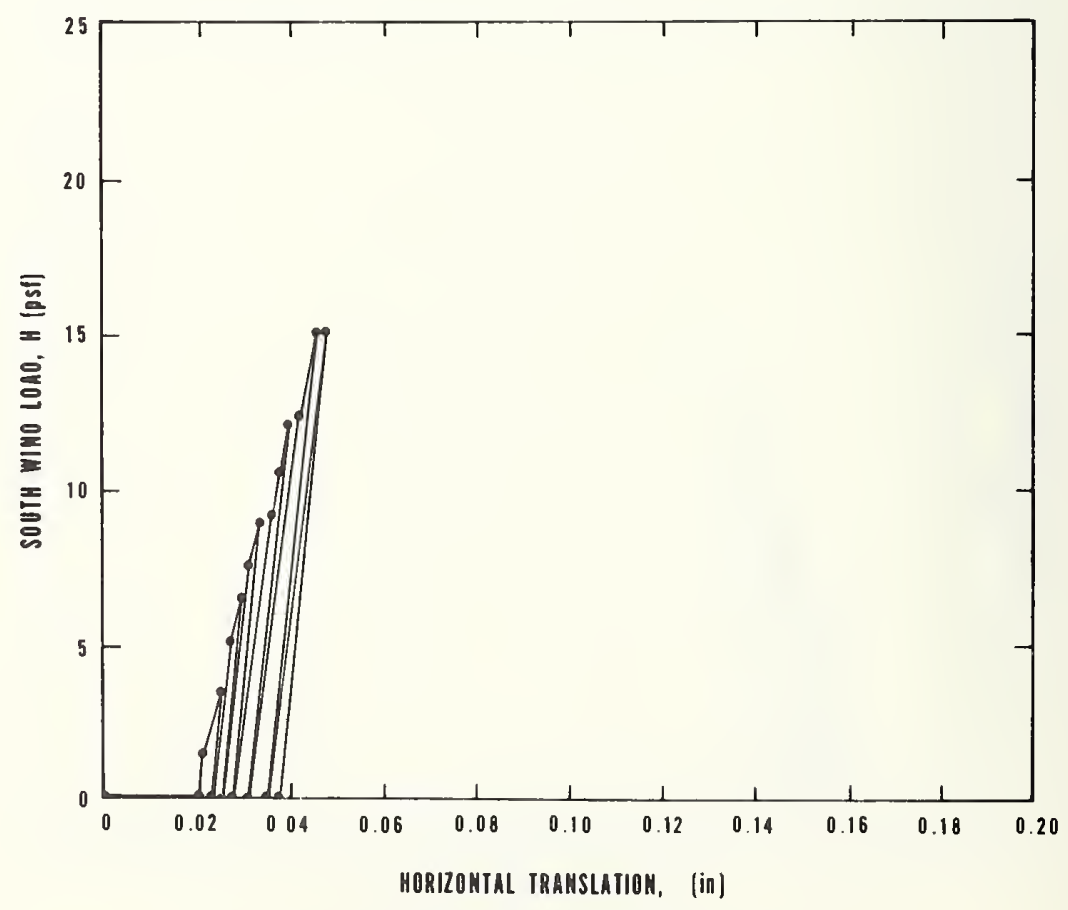

FigURE A. 22. Test No. 7, south wind load versus translation. (Output Channel 45) 


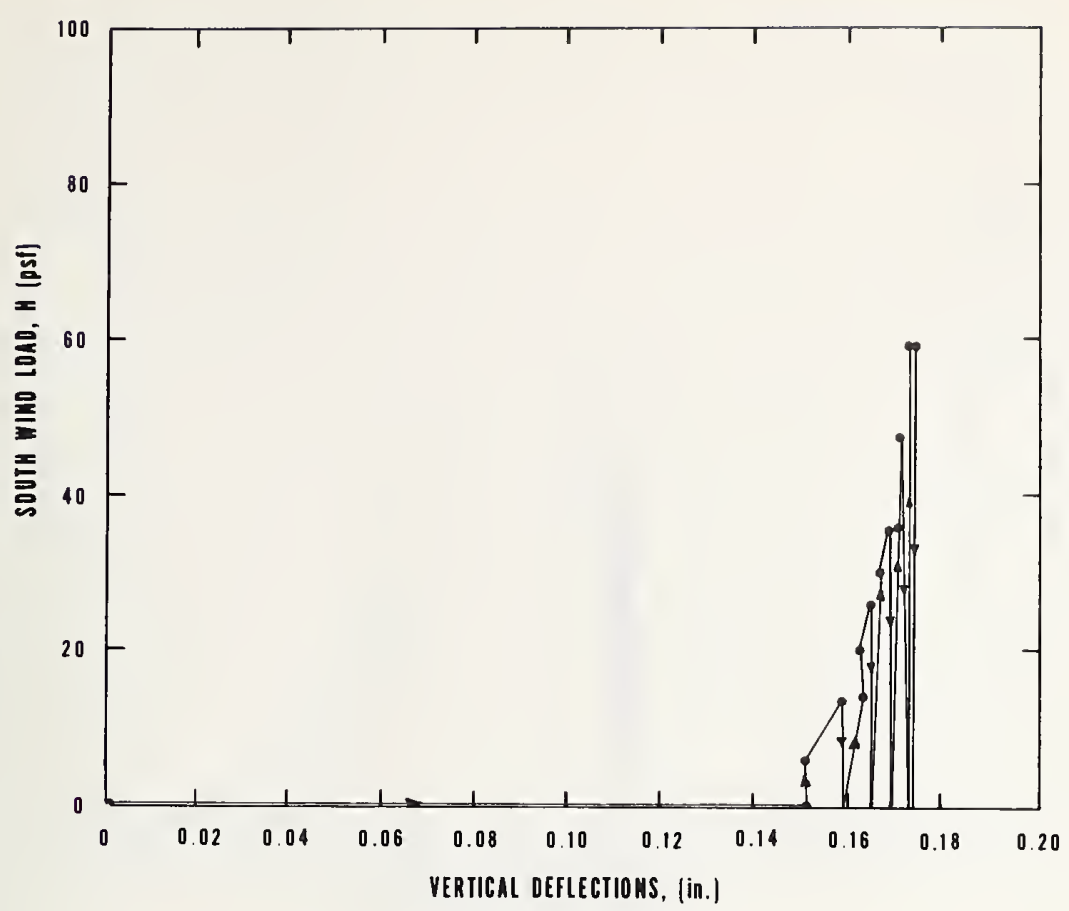

Figure A. 23. Test No. 7, south wind load versus beam deflection. (Output Channel 72)

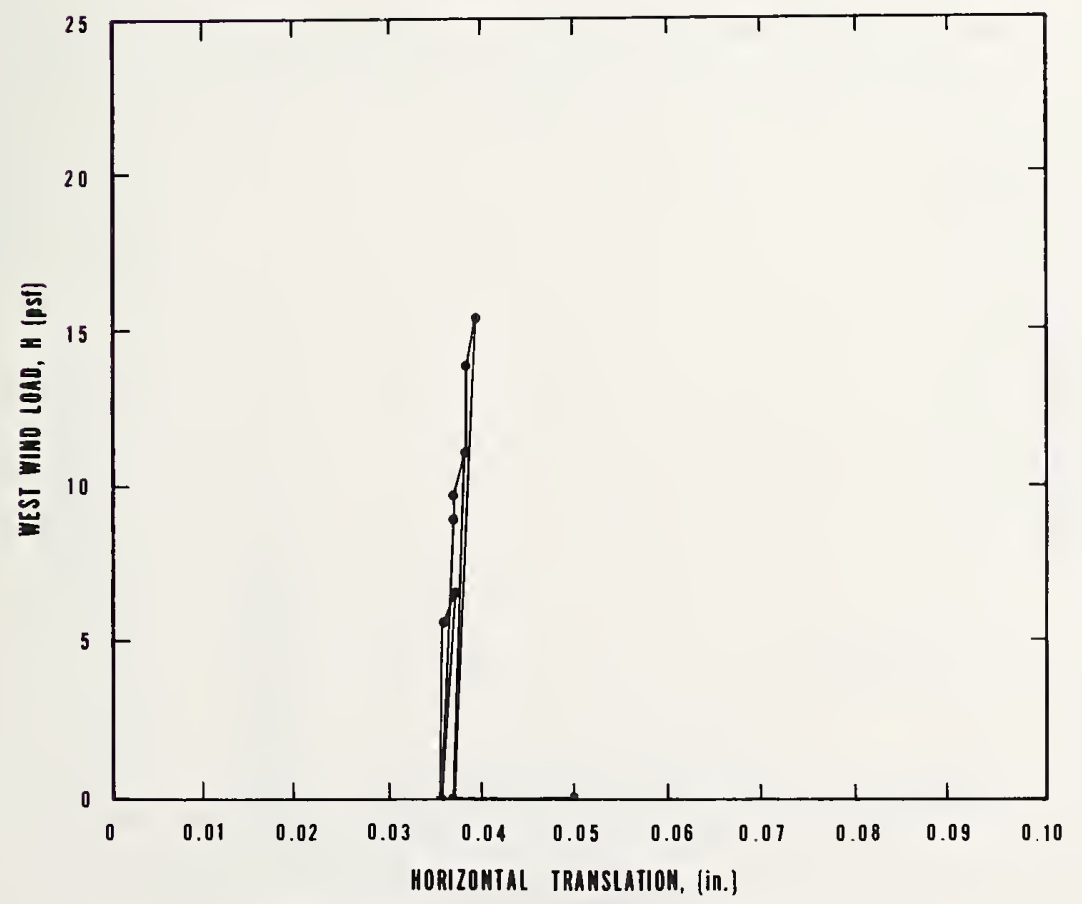

Figure A. 24. Test No. 8, west wind load versus translation. (Output Channel 46) 


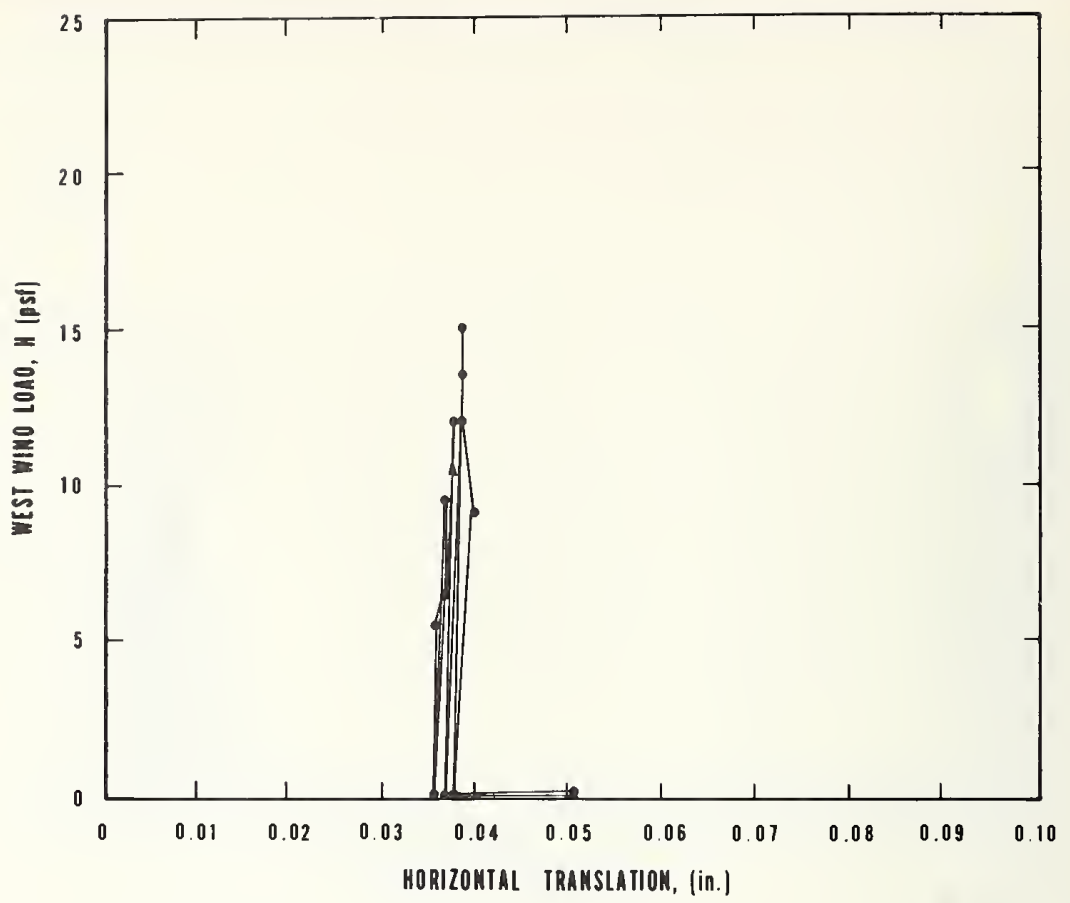

Figure A. 25. Test No. 8, west wind load versus translation. (Output Channel 47)

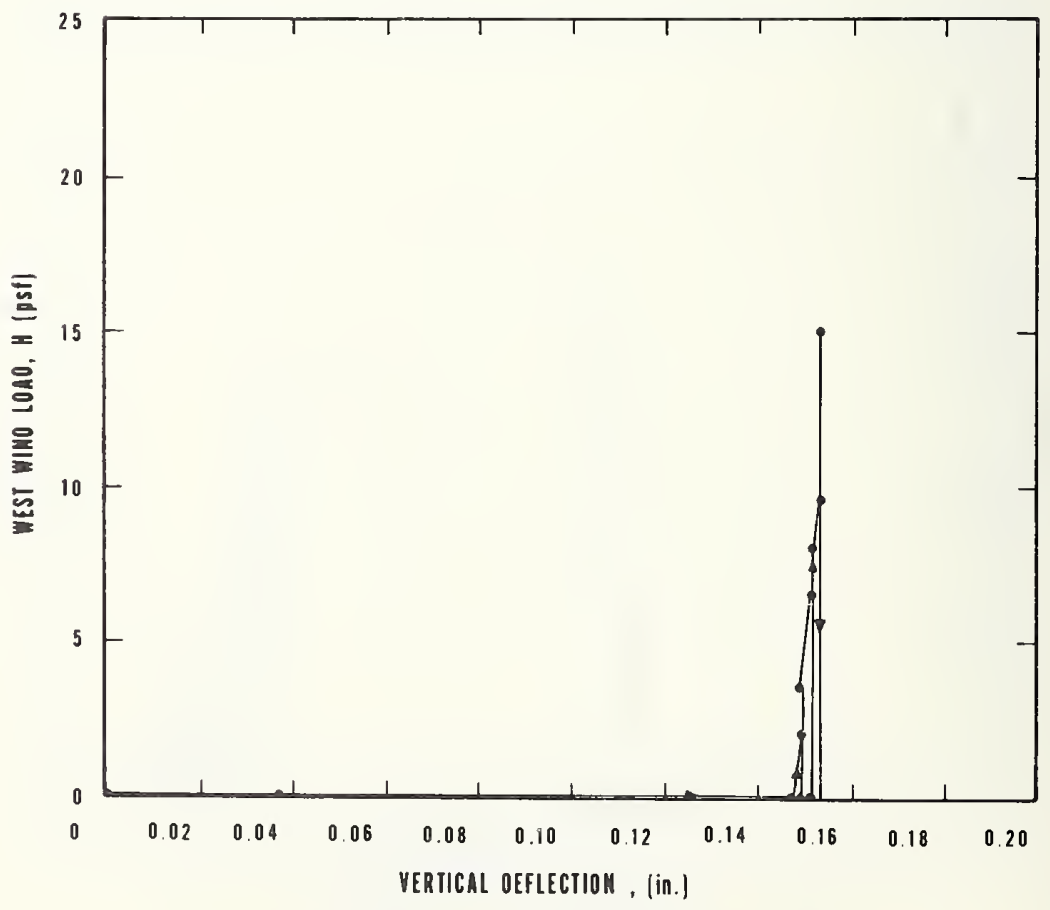

Figure A. 26. Test No. 8, west wind load versus beam deflection. (Output Channel \%2) $^{2}$ 


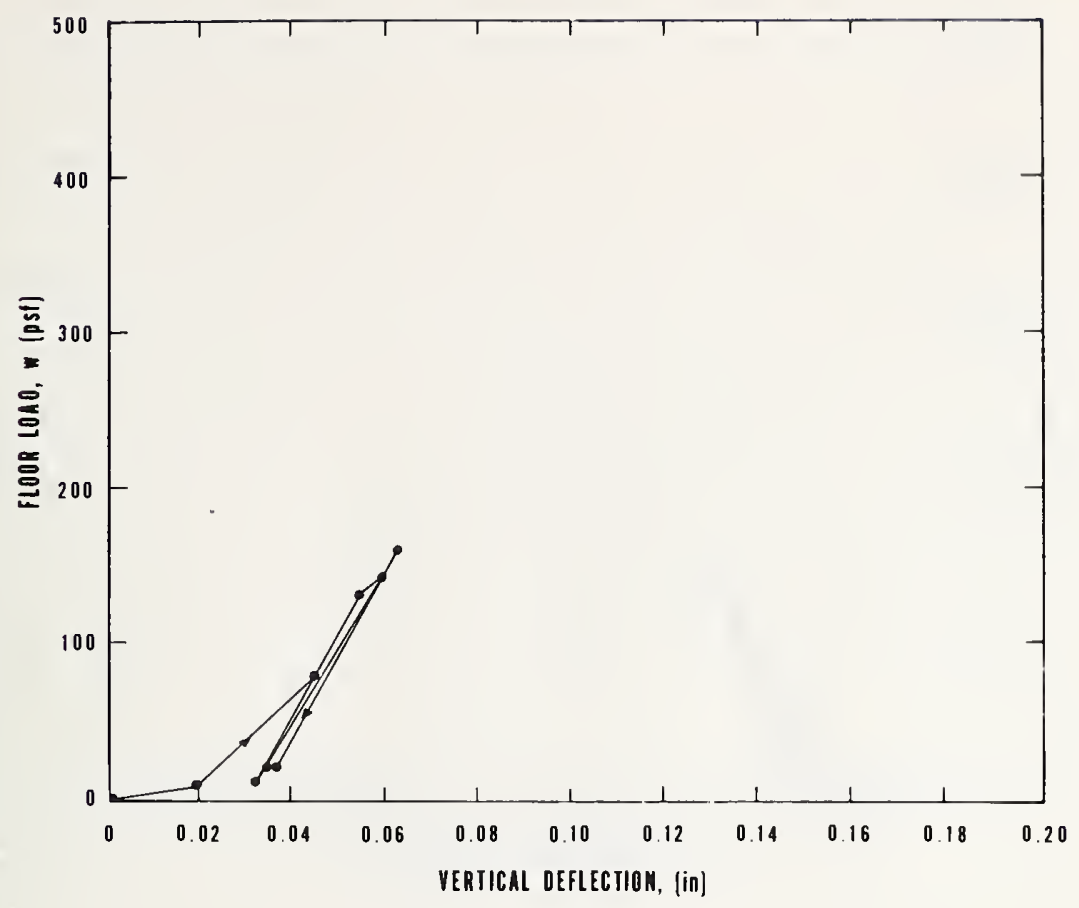

Figure A. 27. Test No. 9, major floor load versus beam deflection. (Output Channel 40)

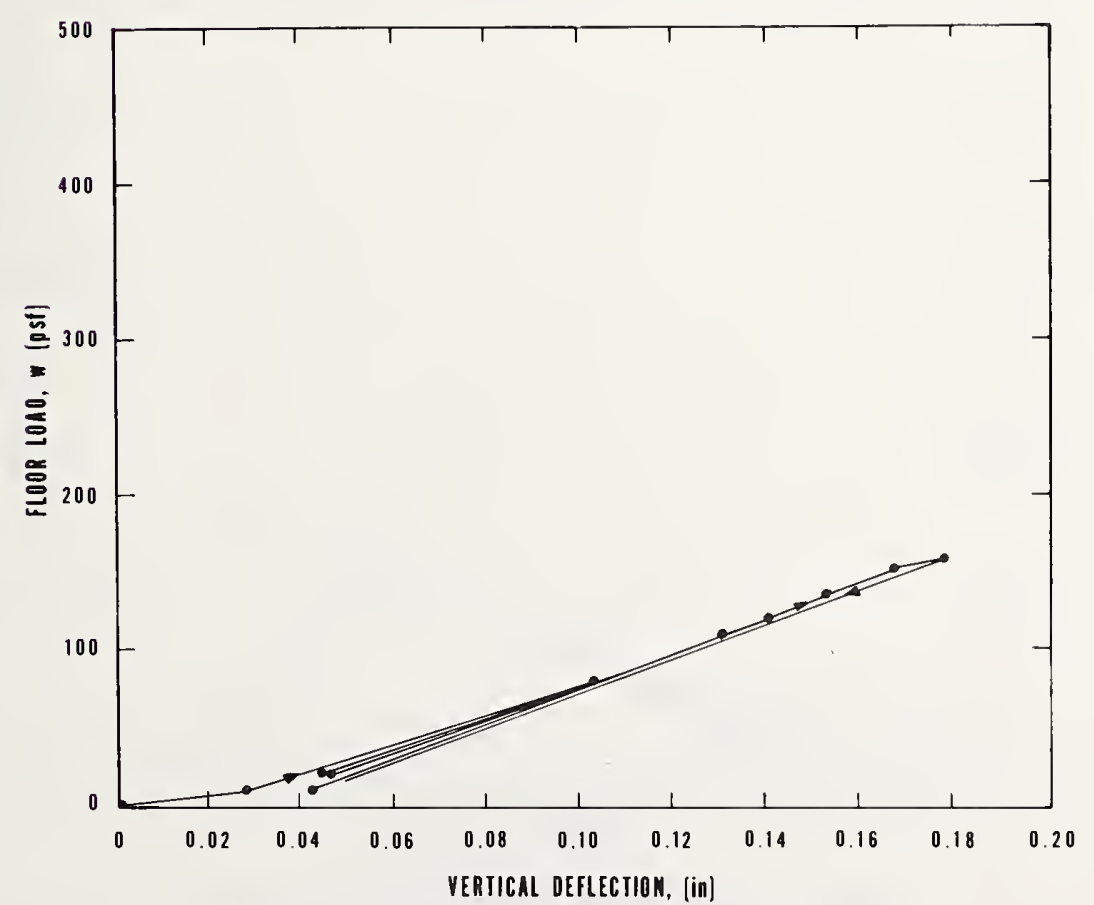

Figure A. 28. Test No. 9, major floor load versus beam deflection. (Output Channel \%2) $^{2}$ 


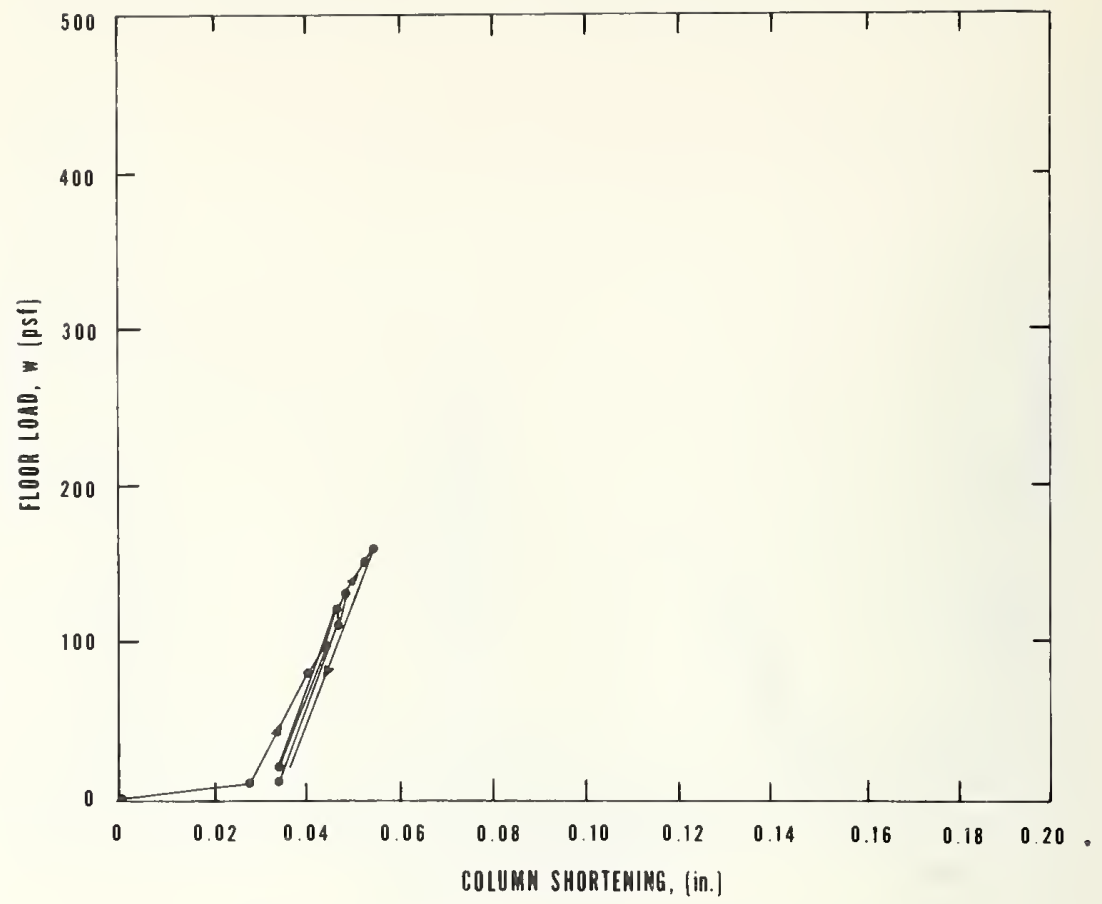

Figure A. 29. Test No. 9, major floor load versus columns shortening. (Output Channel 73)

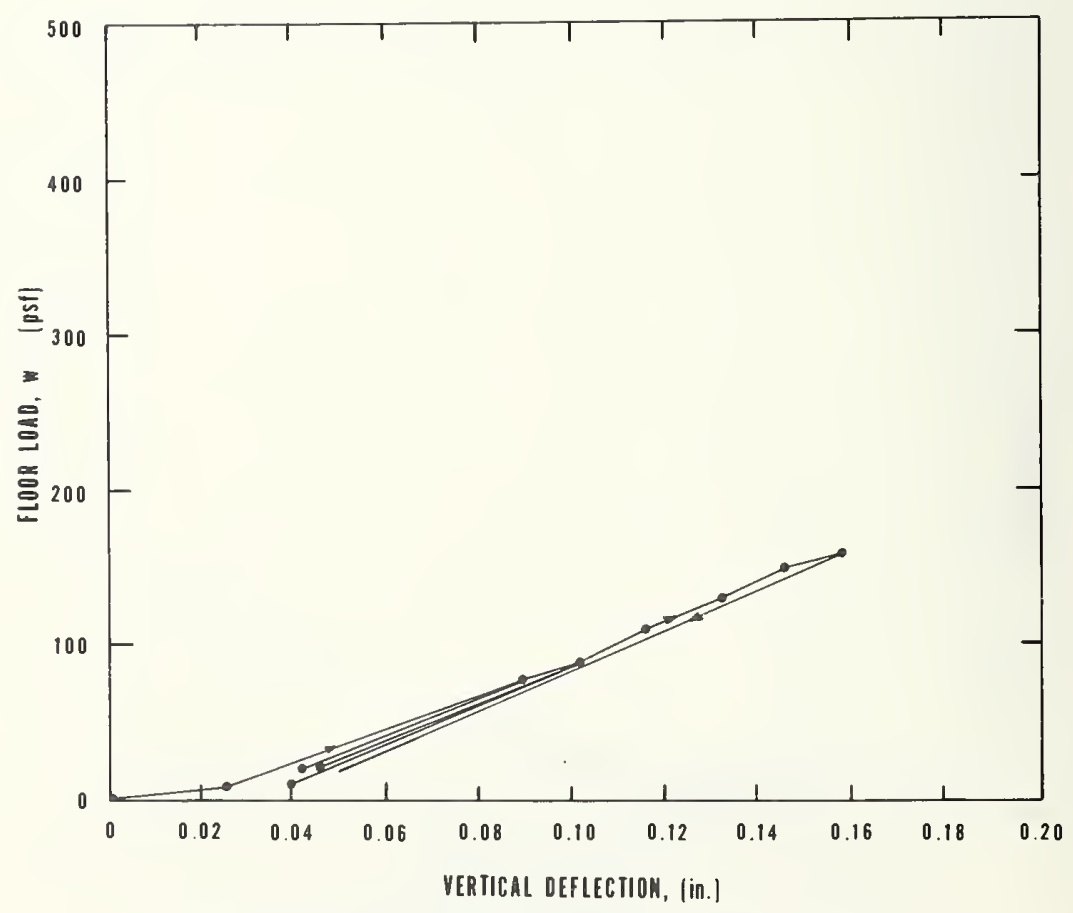

Figure A. 30. Test No. 9, major floor load versus slab deflection. (Output Channel 76) 


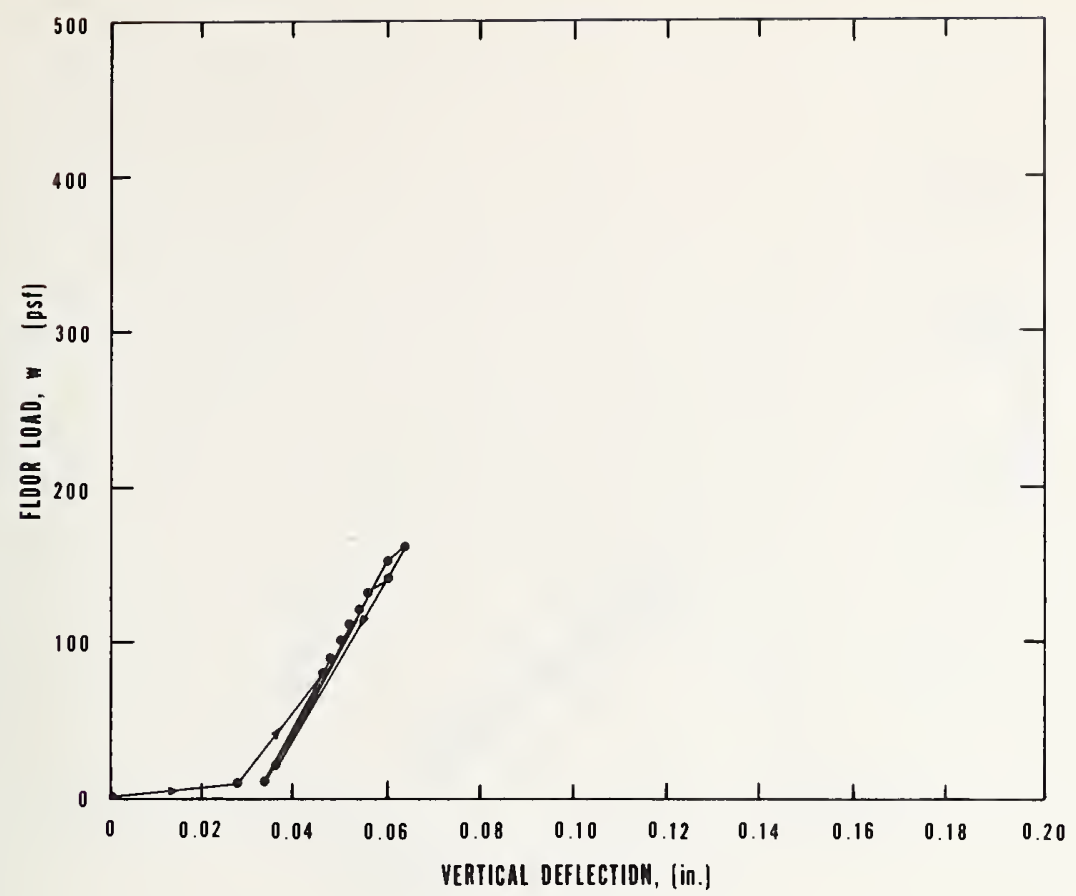

Figure A. 31. Test No. 9, major floor load versus beam deflection. (Output Channel 77)

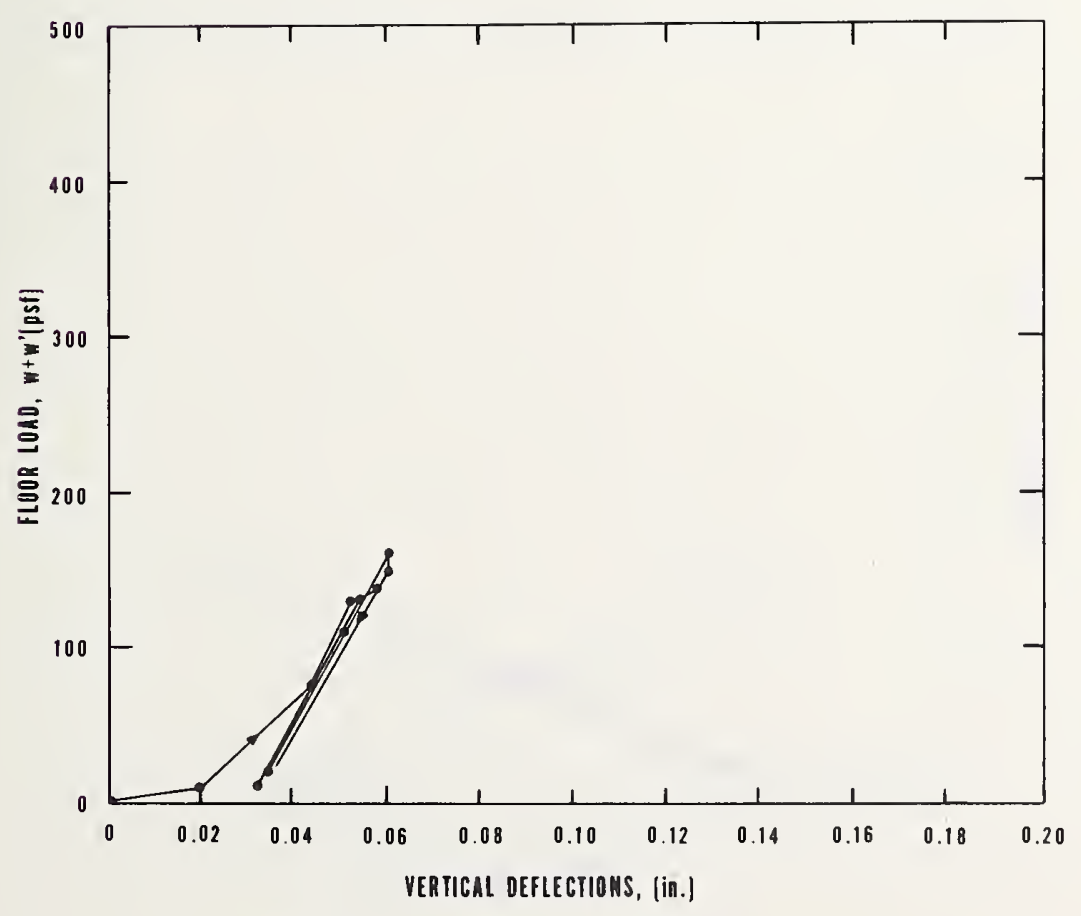

Figure A. 32. Test No. 9A, floor loads versus beam deflection. (Output Channel 40) 


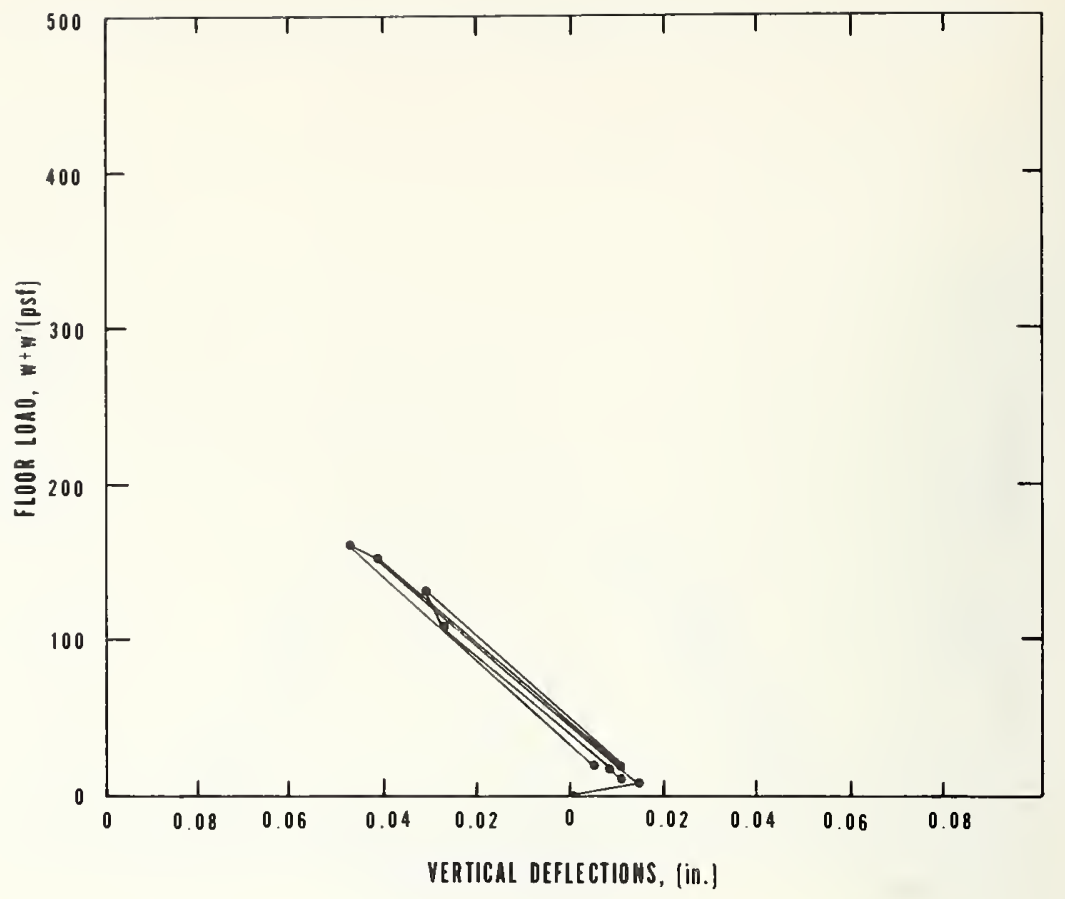

Figure A. 33. Test No. 9 A, floor loads versus beam deflection. (Output Channel ro)

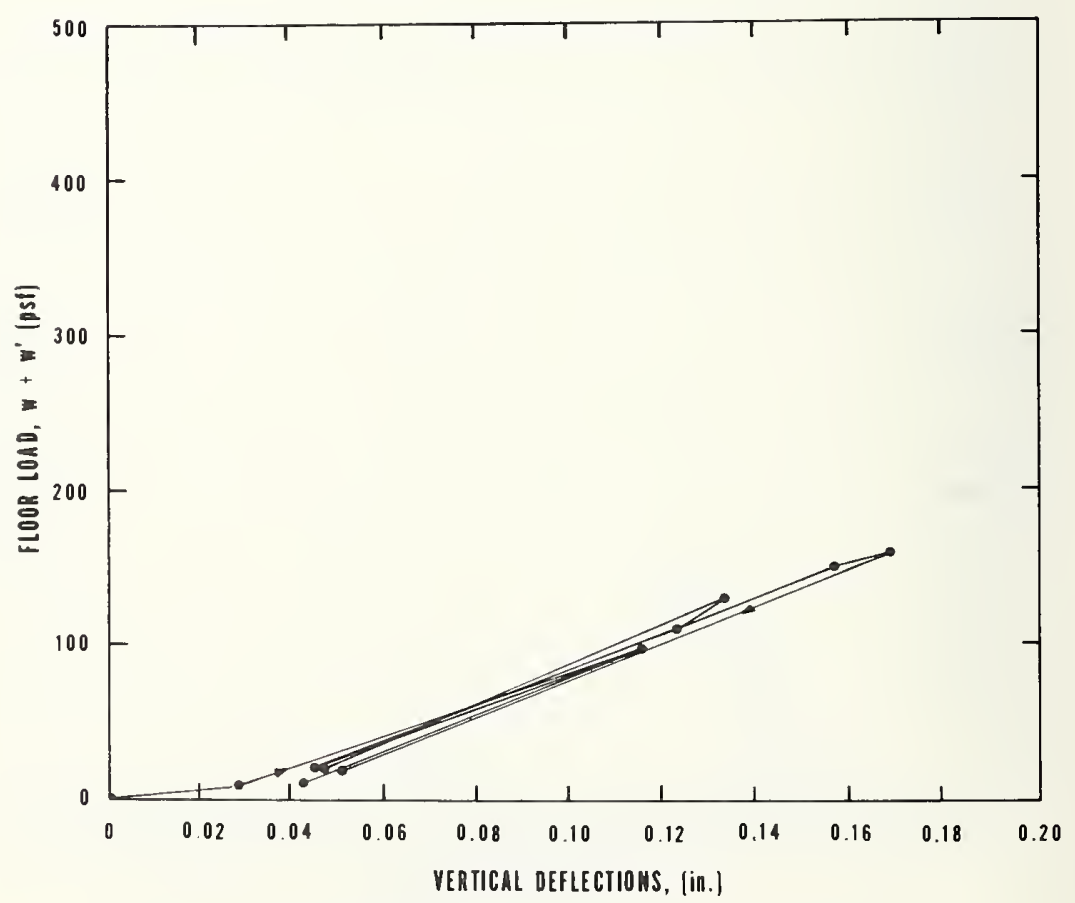

Frgure A. 34. Test No. 9A, floor loads versus beam deflection. (Output Channel 72) 


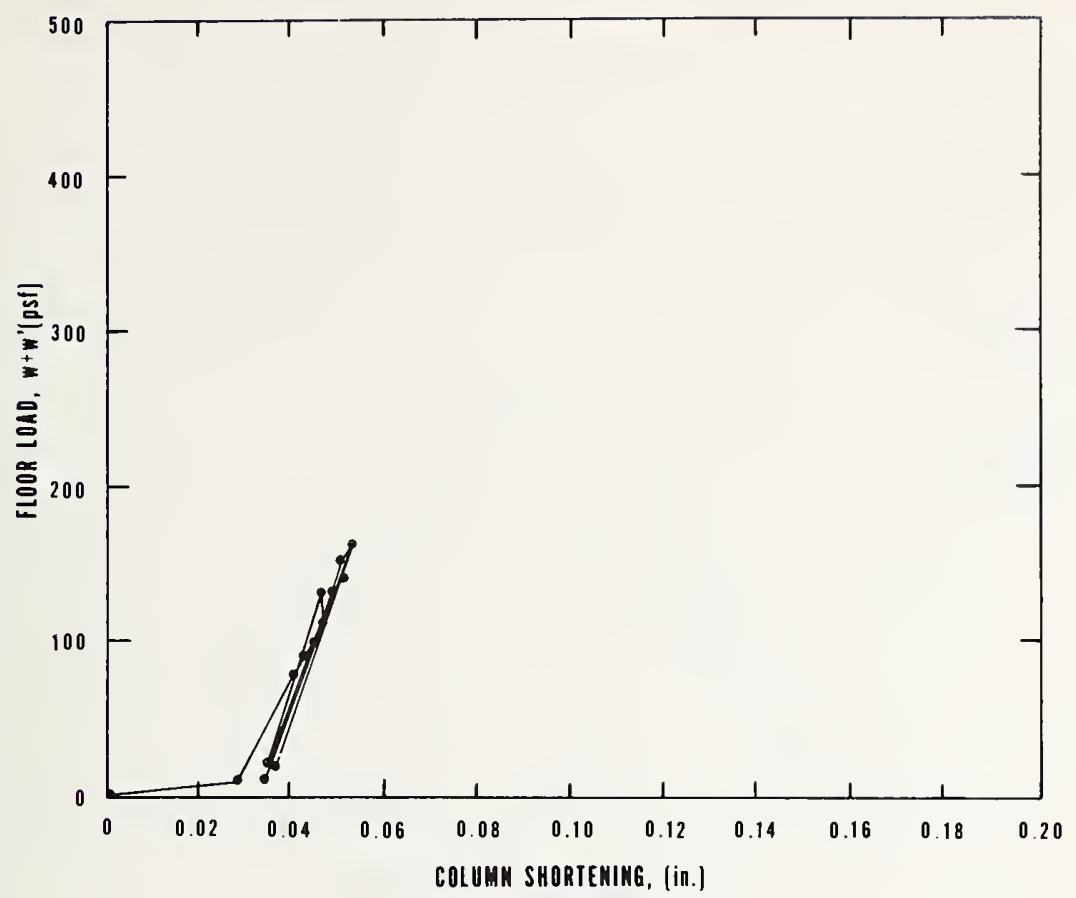

Figure A. 35. Test No. 9A, floor loads versus column shortening. (Output Channel 73)

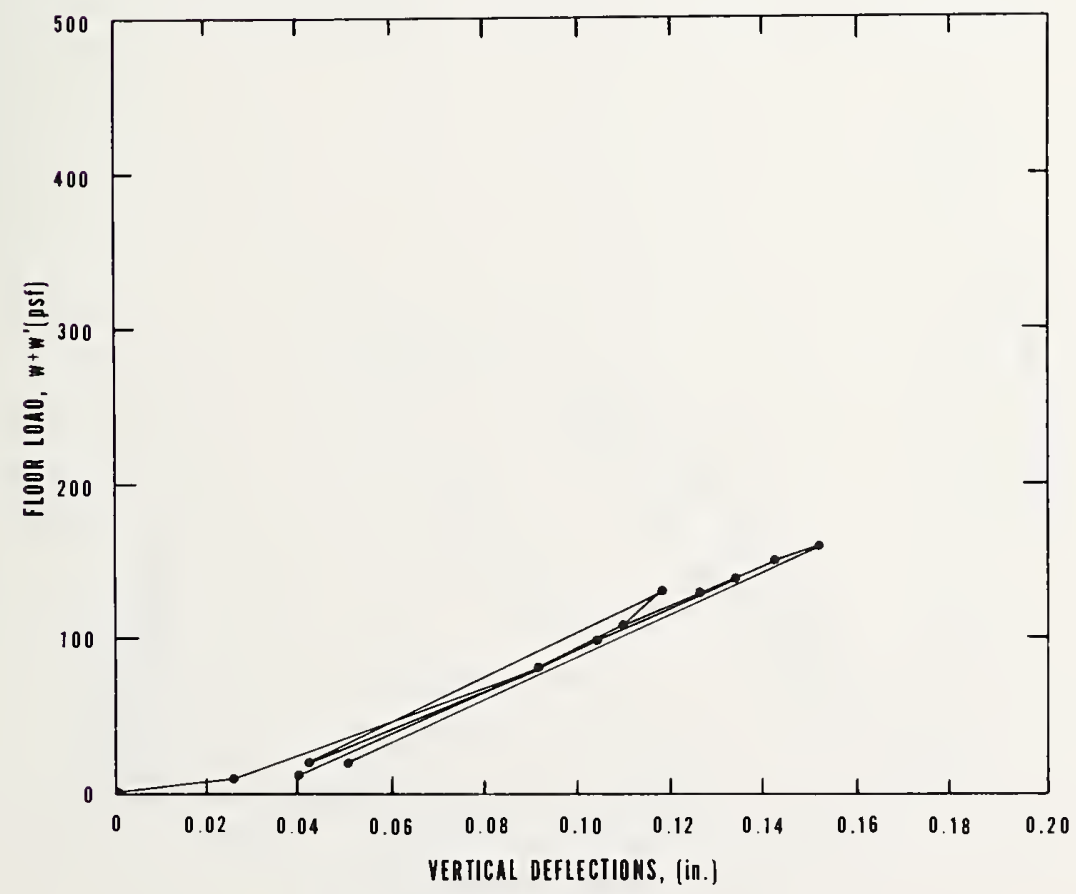

Figure A. 36. Test No. 9 A, floor load versus slab deflection. (Output Channel 76 ) 


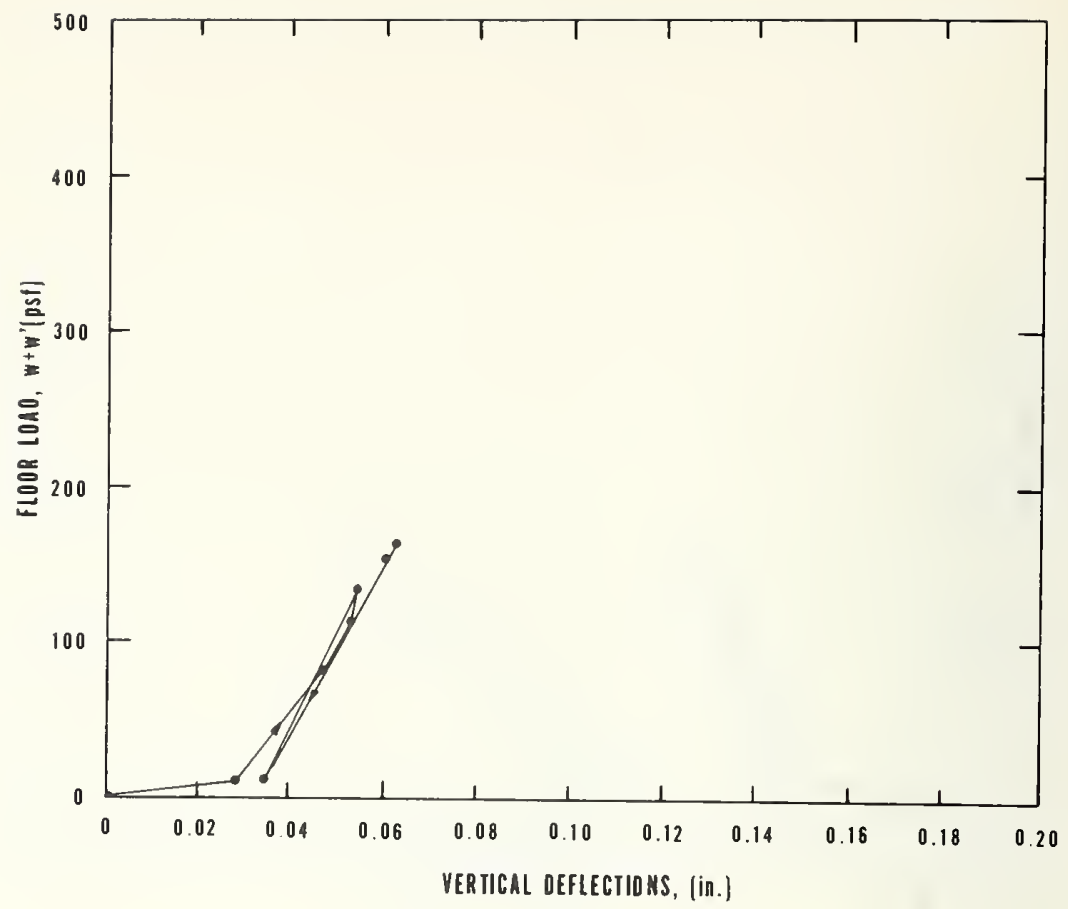

Figure A. 37. Test No. 9A, floor load versus beam deflection. (Output Channel 77)

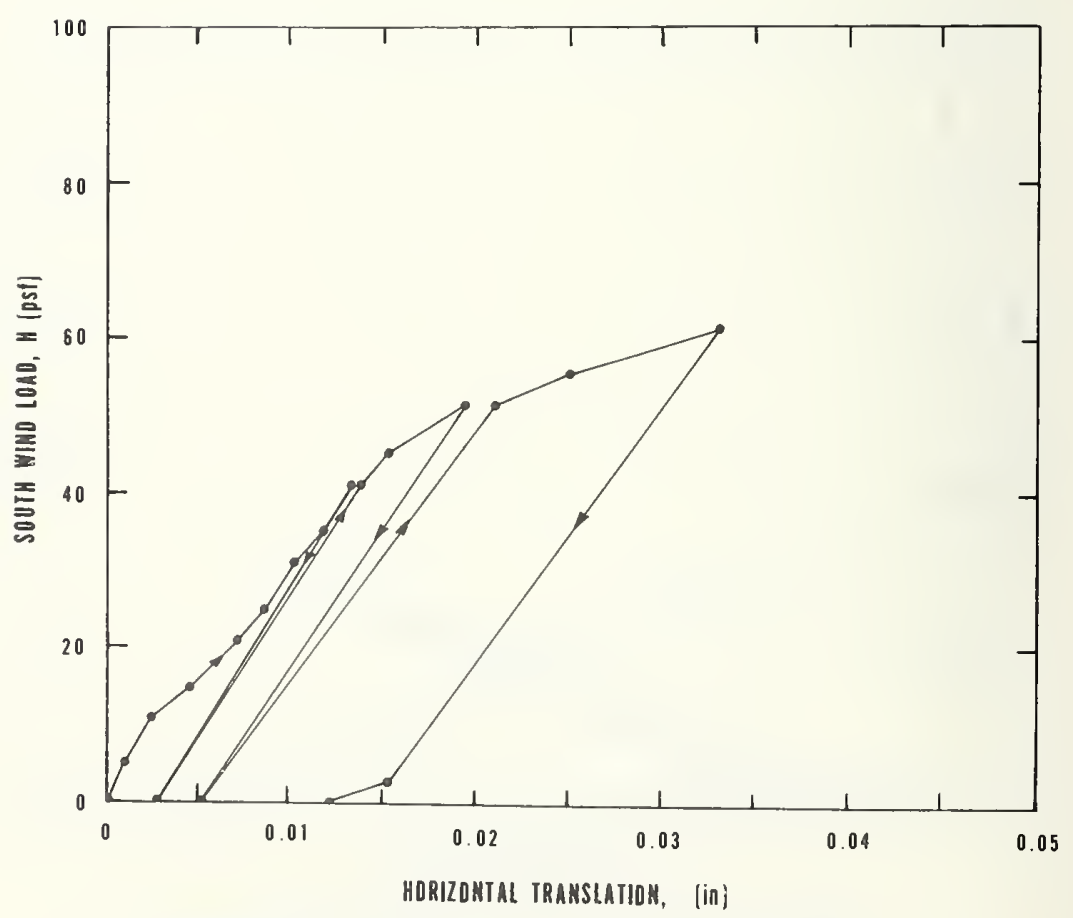

Figure A. 38. Test No. 10, south wind load versus translation. (Output Channel 43) 


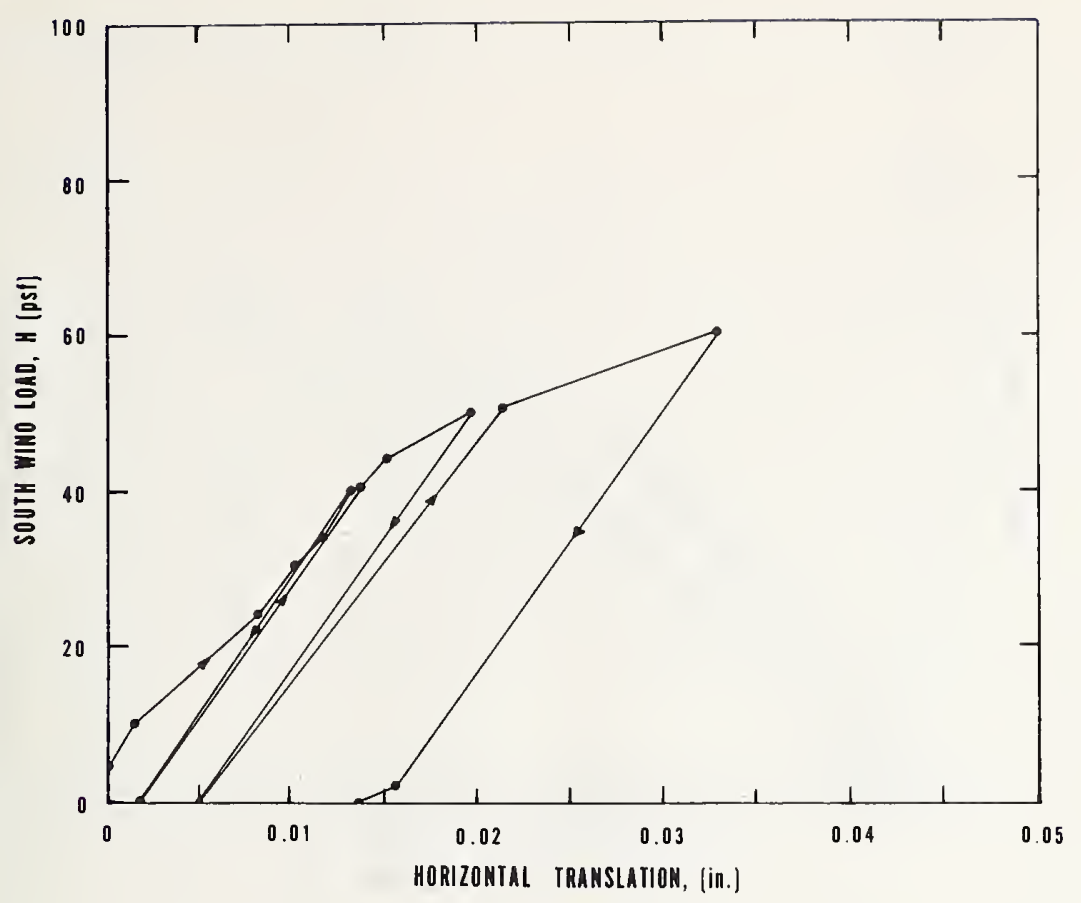

Figure A. 39. Test No. 10, south wind load versus translation. (Output Channel 44)

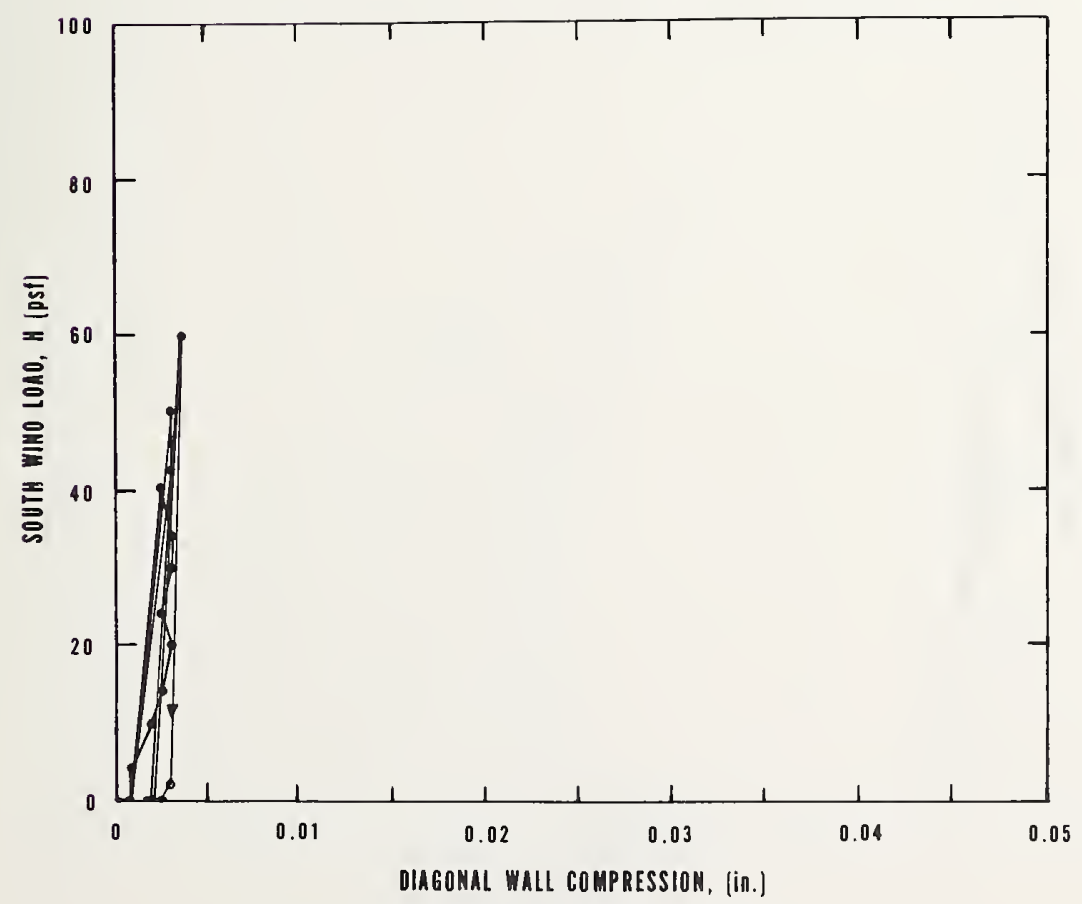

Figure A. 40. Test No. 10, south wind load versus wall compression. (Output Channel 56) 


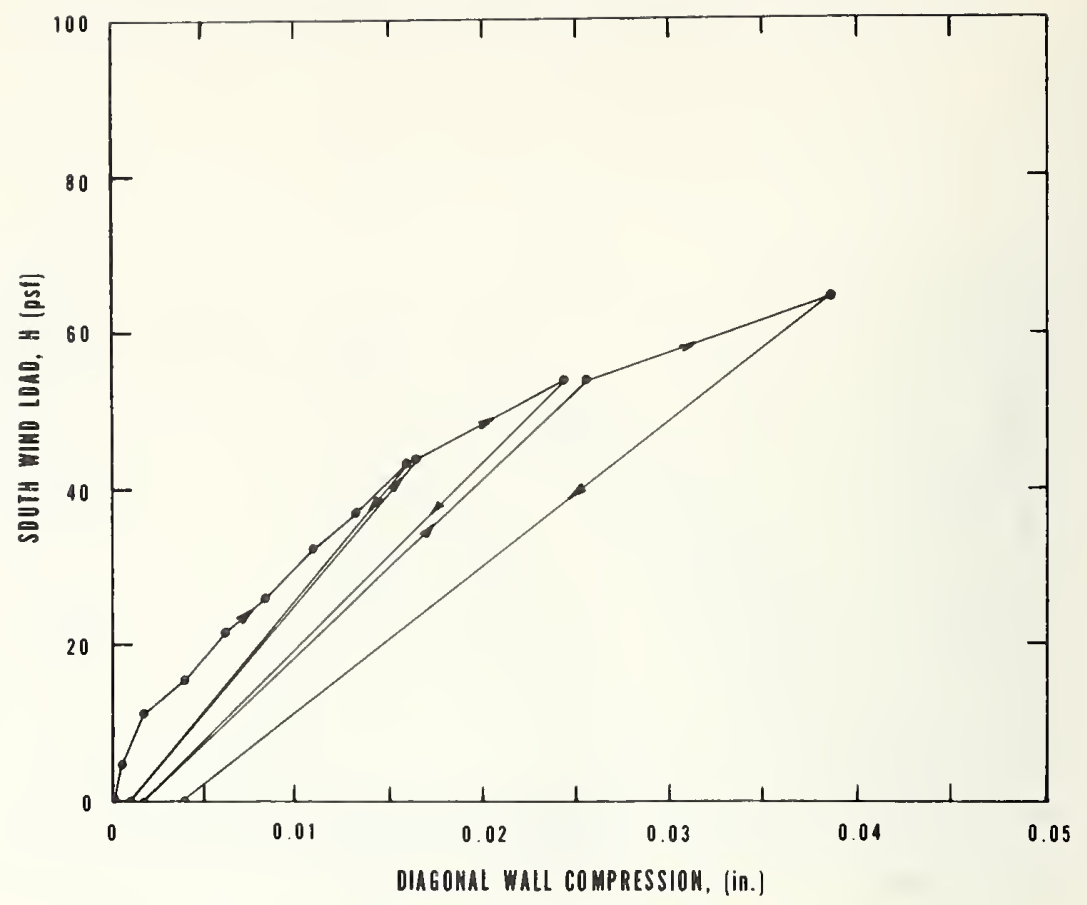

Figure A. 41. Test No. 10, south wind load versus wall compression. (Output Channel 57)

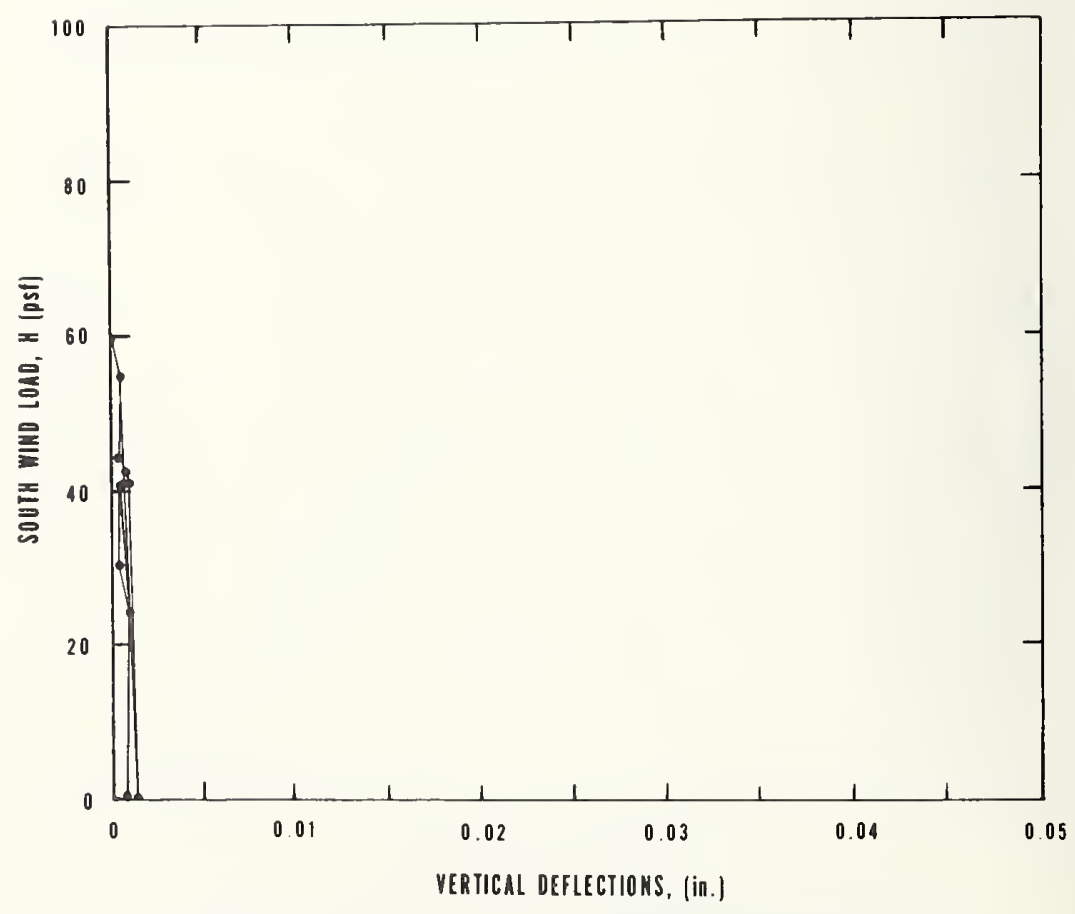

Figure A. 42. Test No. 10, south wind load versus beam deflection. (Output Channel 72) 


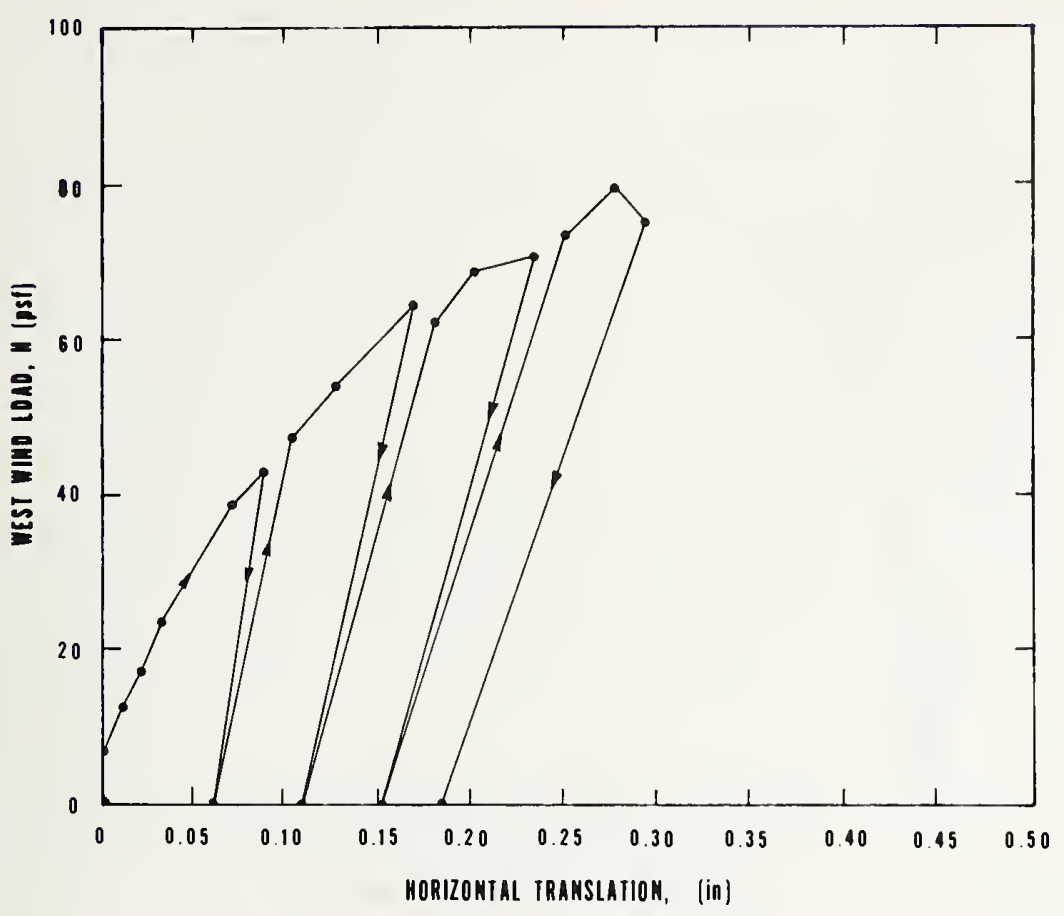

Figure A. 43. Test No. 11, west wind load versus translation. (Output Channel 46)

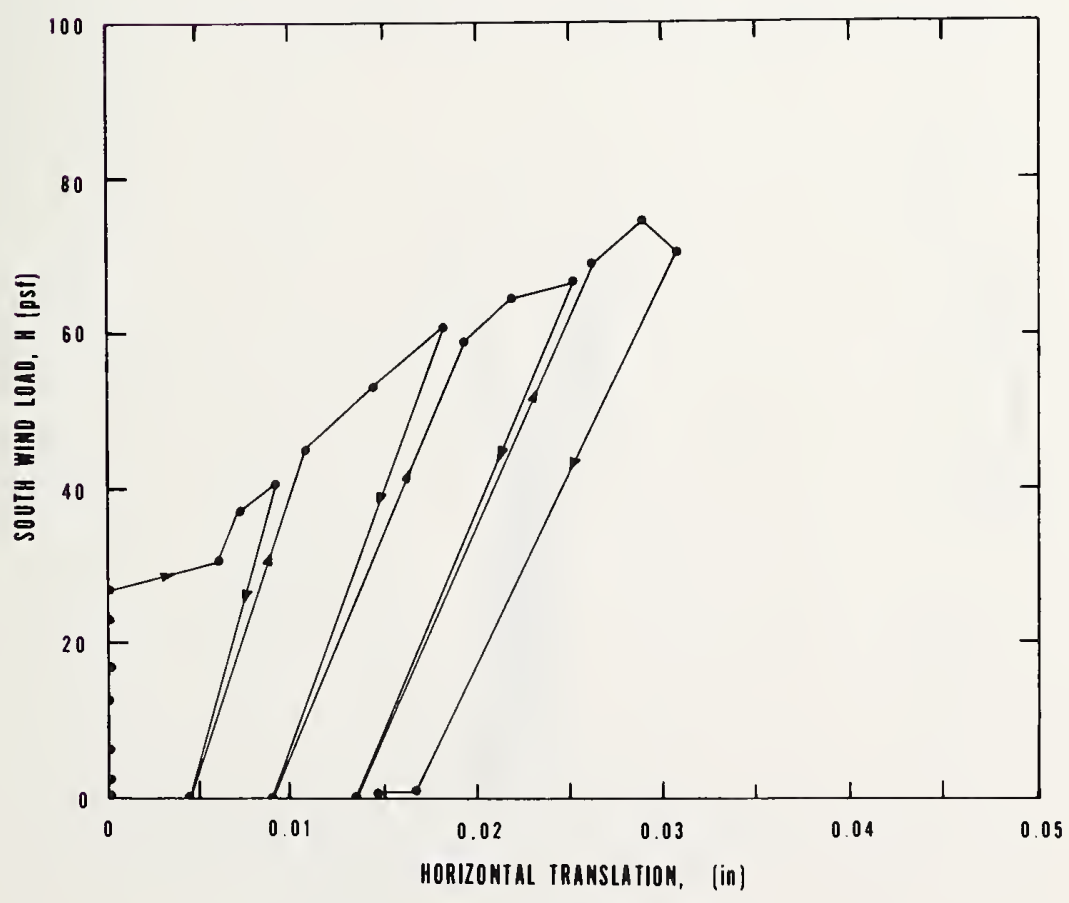

Figure A. 44. Test No. 11, west wind load versus translation. (Output Channel 47) 


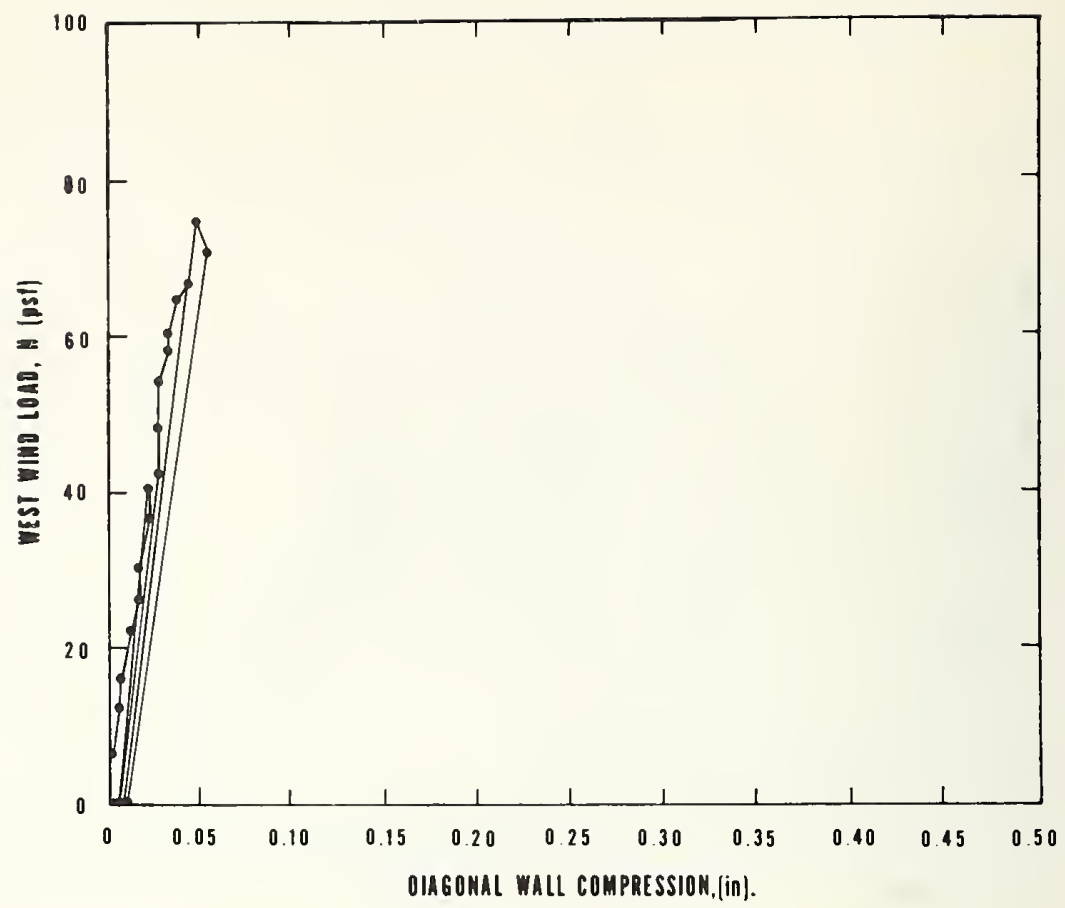

Figure A. 45. Test No. 11, west wind load versus wall compression. (Output Channel 52)

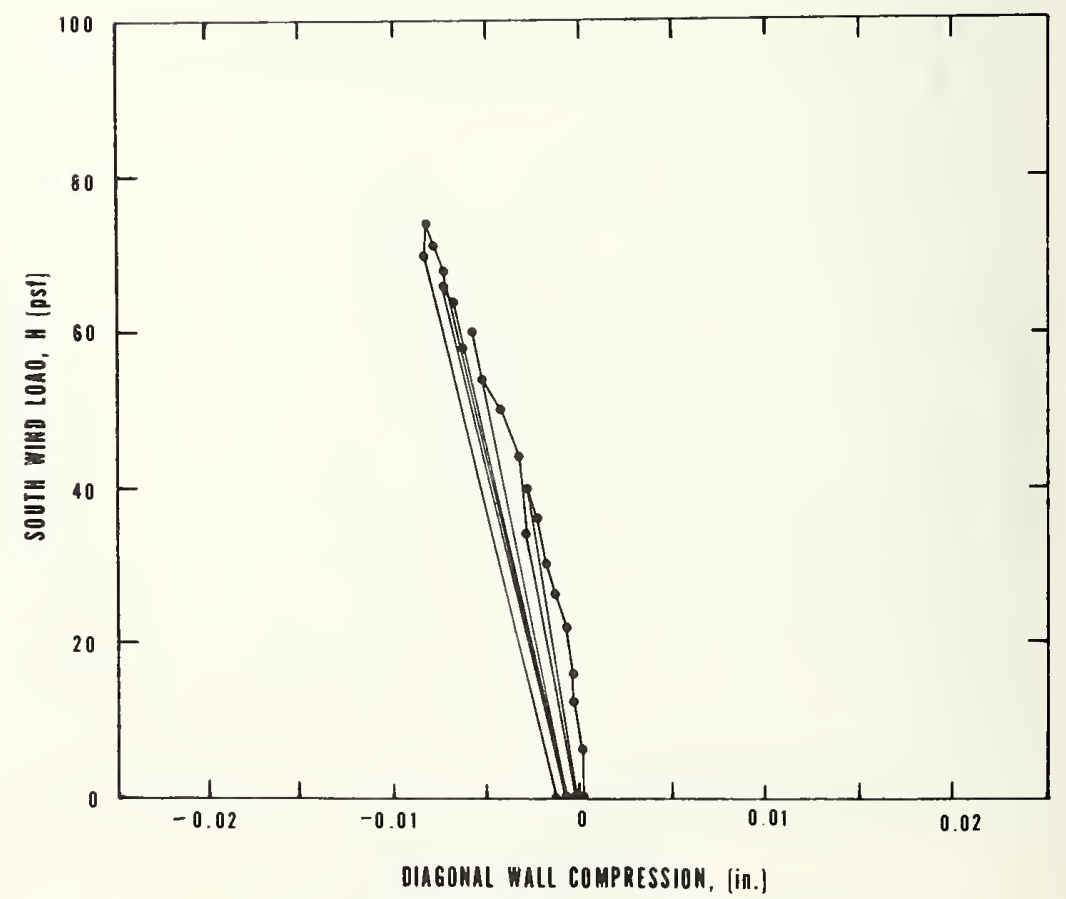

FIGURE A. 46. Test No. 11, west wind load versus wall compression. (Output Channel 53) 


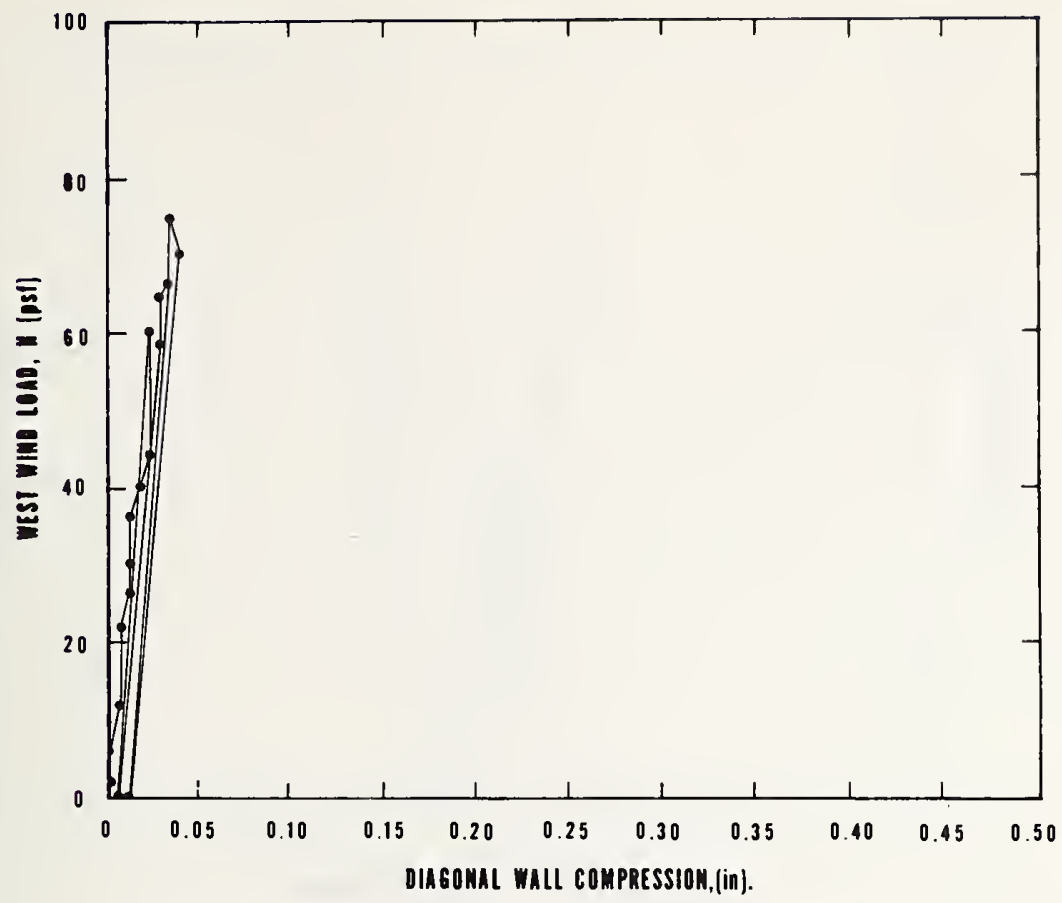

Figure A. 47. Test No. 11, west wind load versus wall compression. (Output Channel 54)

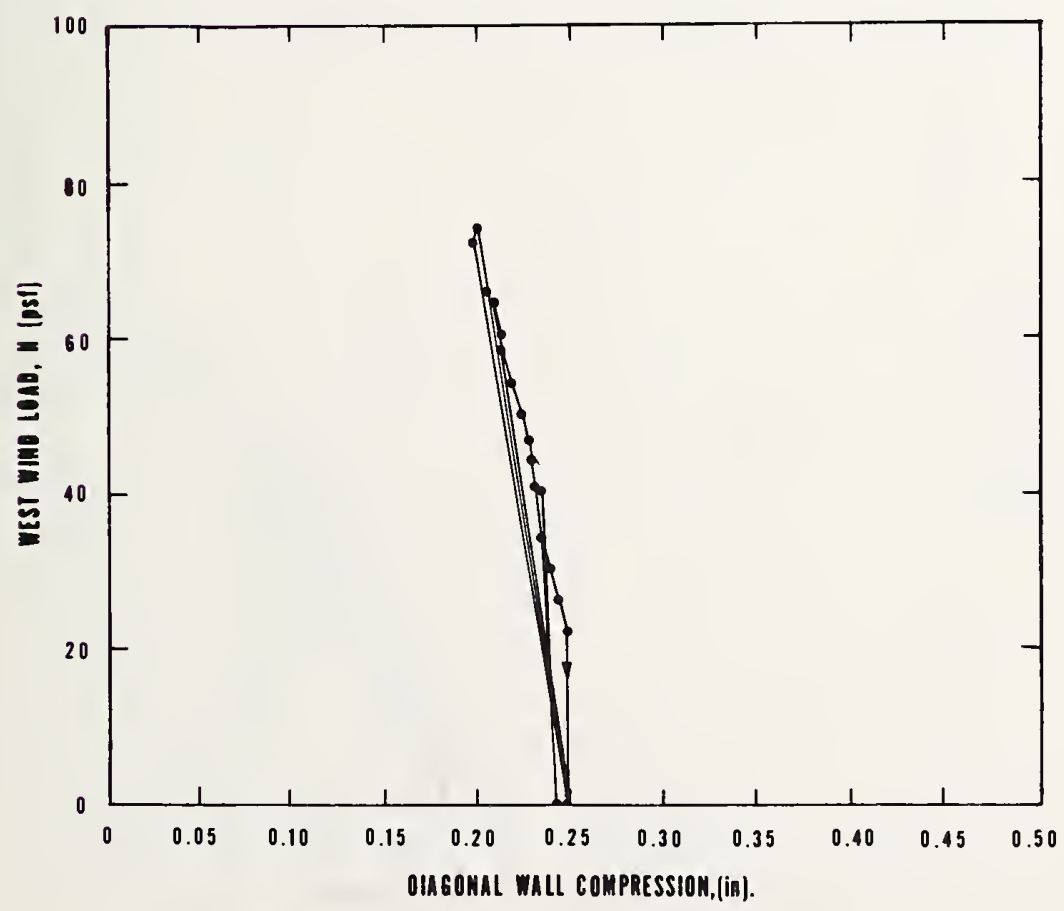

Figure A. 48. Test No. 11, west wind load versus wall compression. (Output Channel 55) 


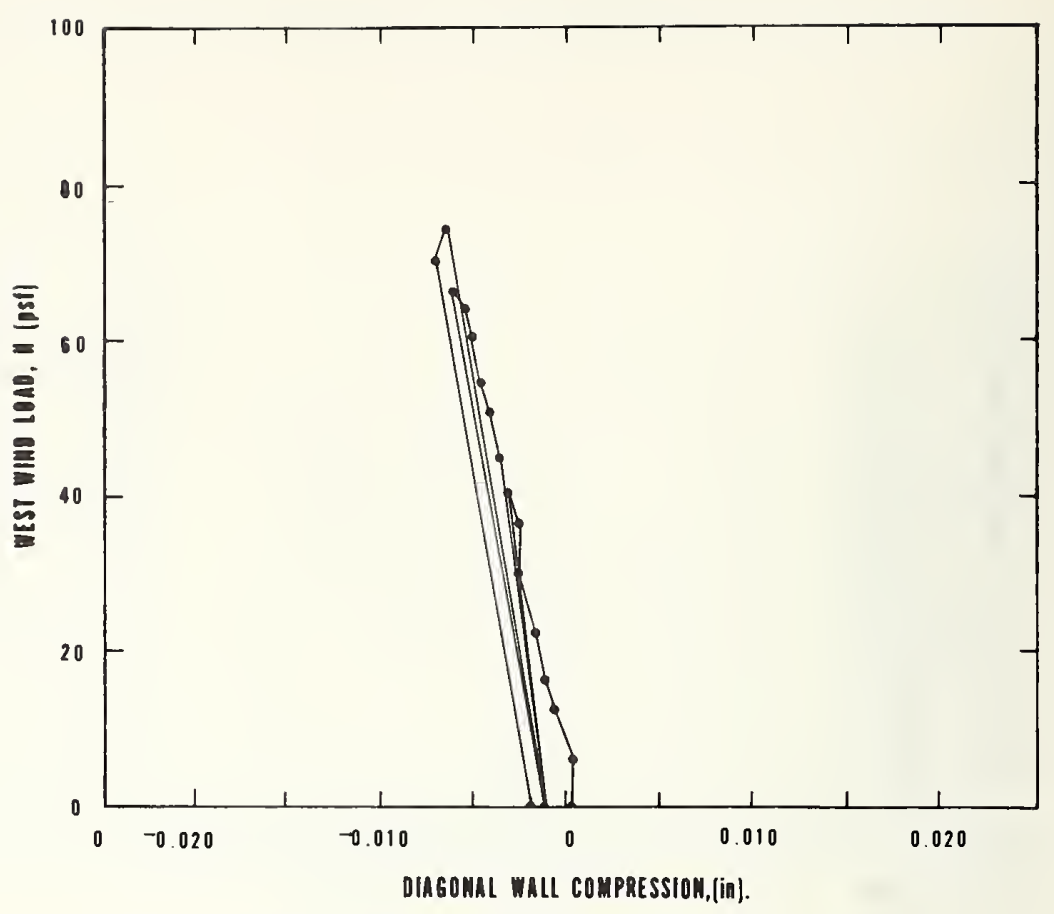

Figure A. 49. Test No. 11, west wind load versus wall compression. (Output Channel 58)

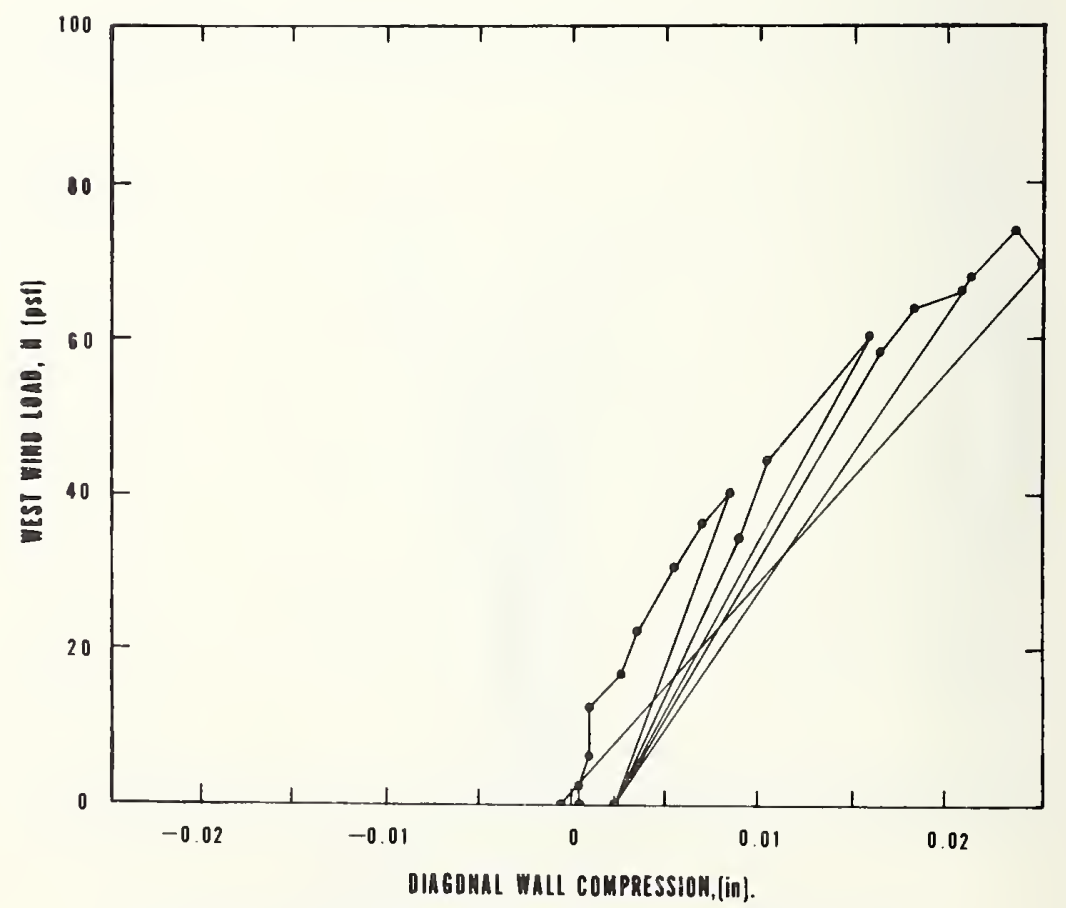

Figure A. 50. Test No. 11, west wind load versus wall compression. (Output Channel 59) 


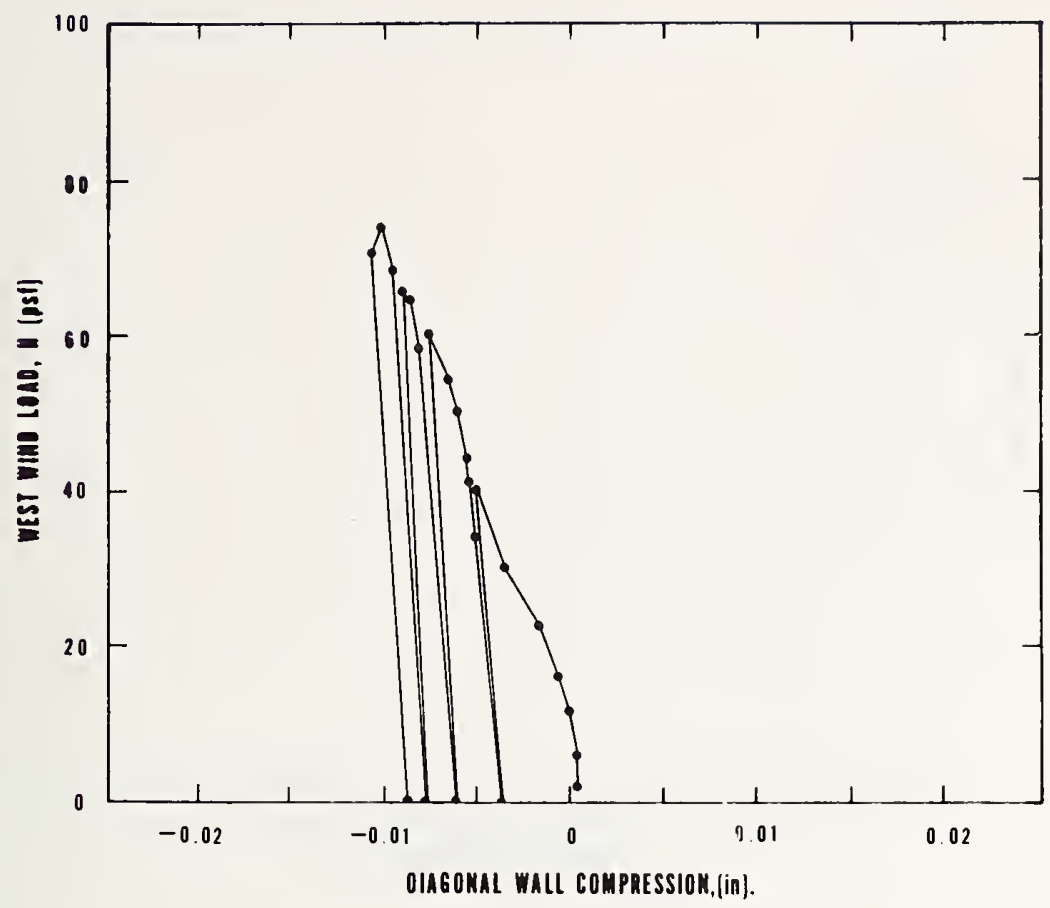

Figure A. 51. Test No. 11, west wind load versus wall compression. (Output Channel 60)

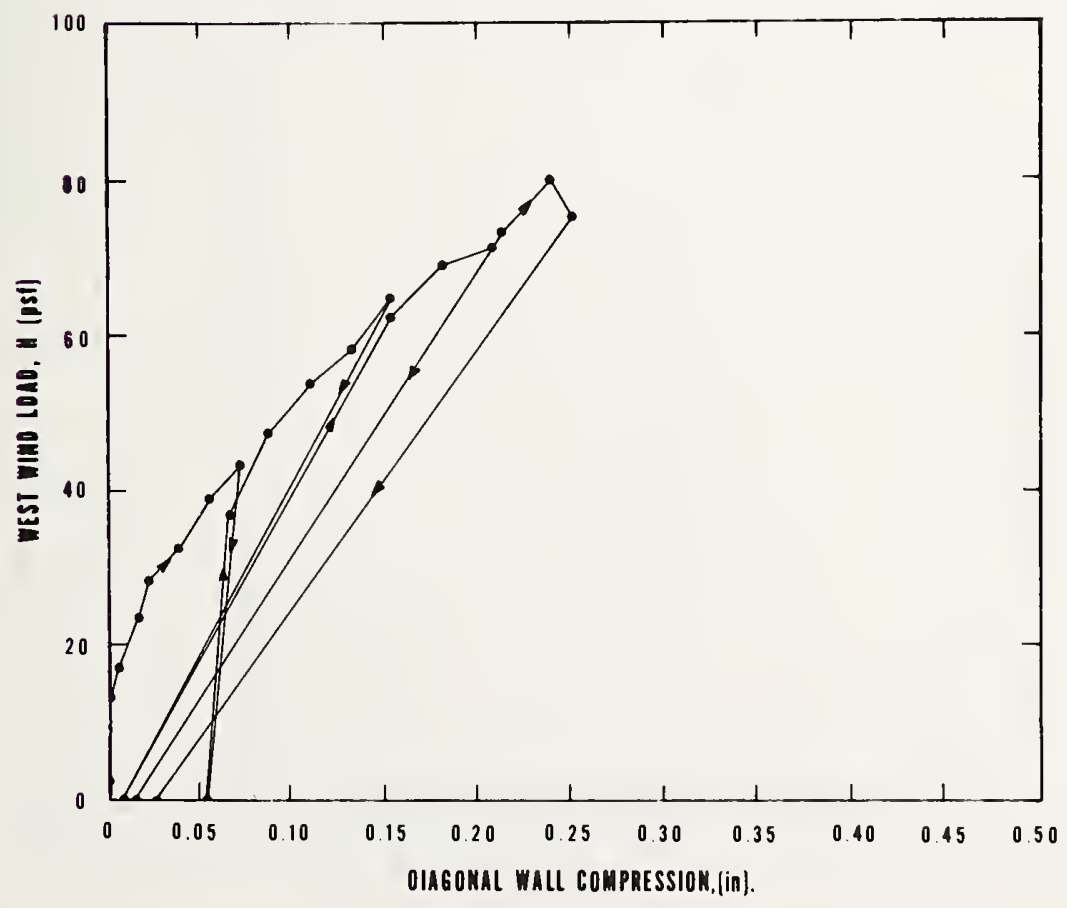

Figure A. 52. Test No. 11, west wind load versus wall compression. (Output Channel 61) 


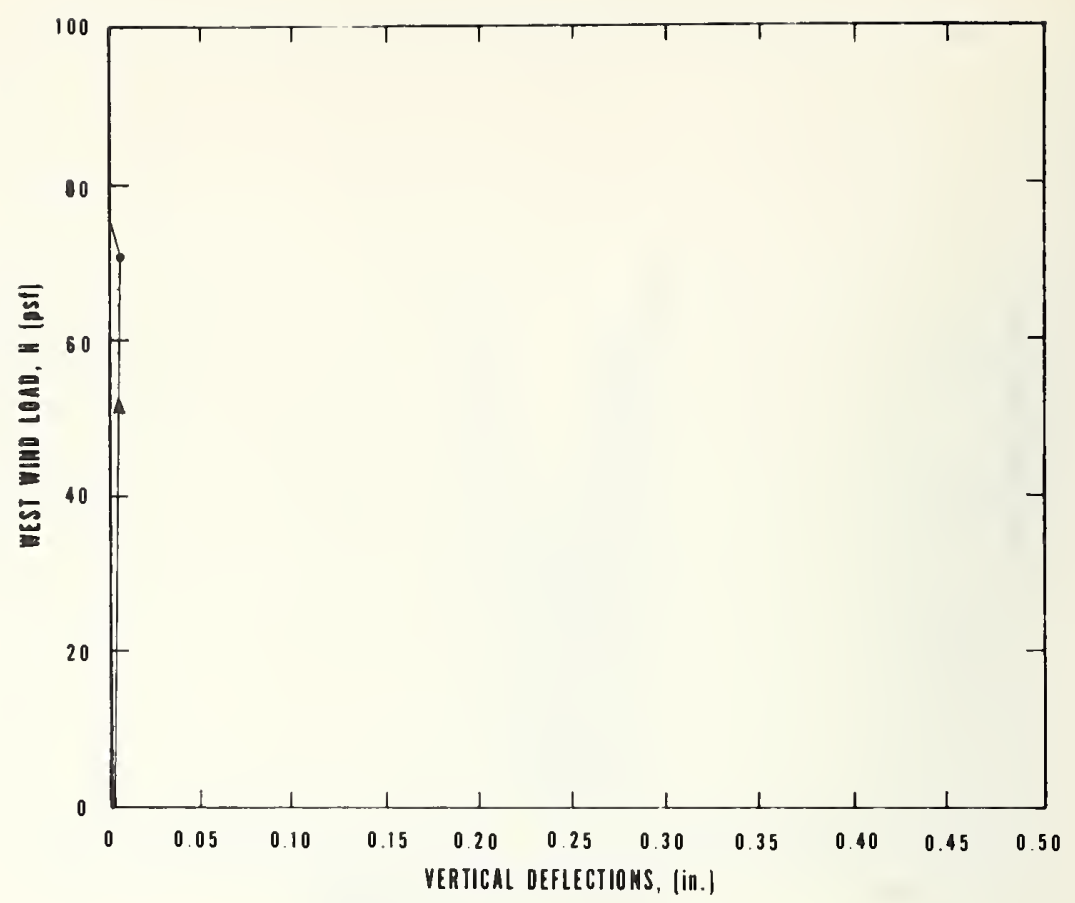

FIgure A. 53. Test No. 11, west wind lond versus beam deflection. (Output Channel 72)

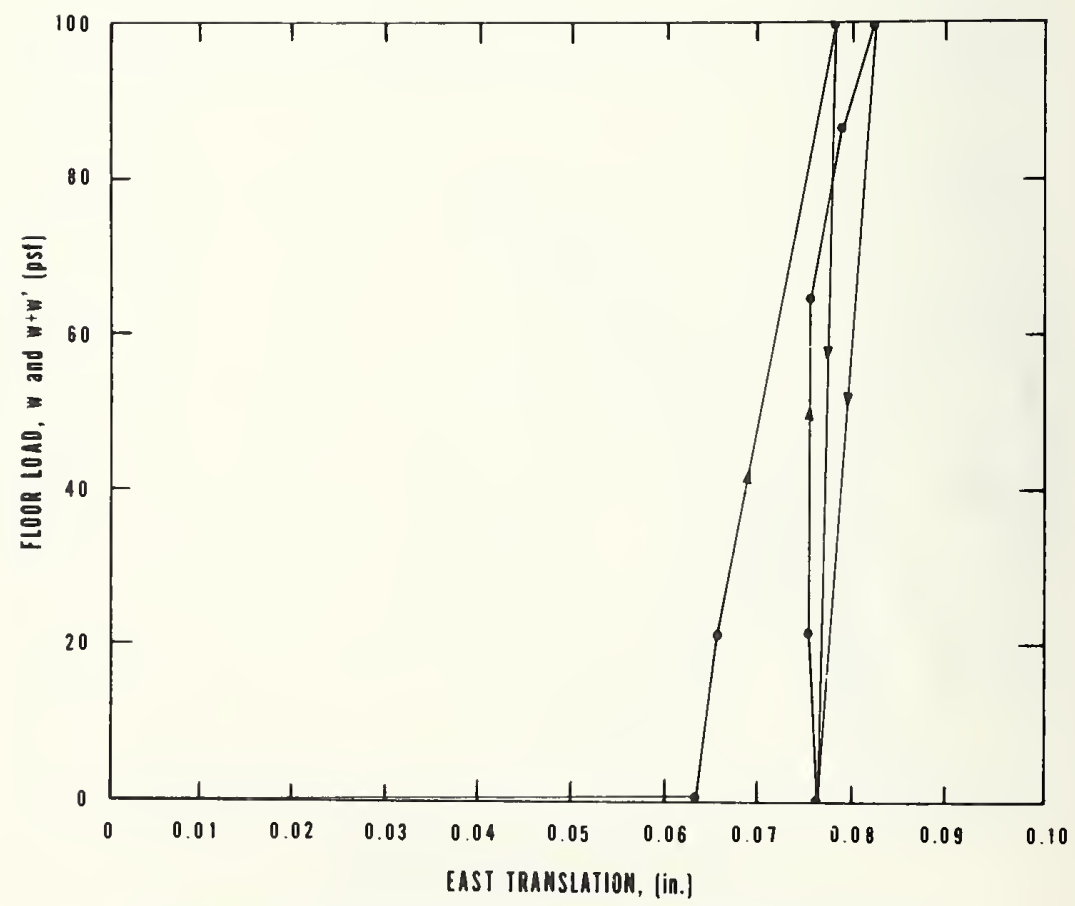

Figure A. 54. Tests No. 12 and 13, vertical load versus east translation. (Output Channel 46) 


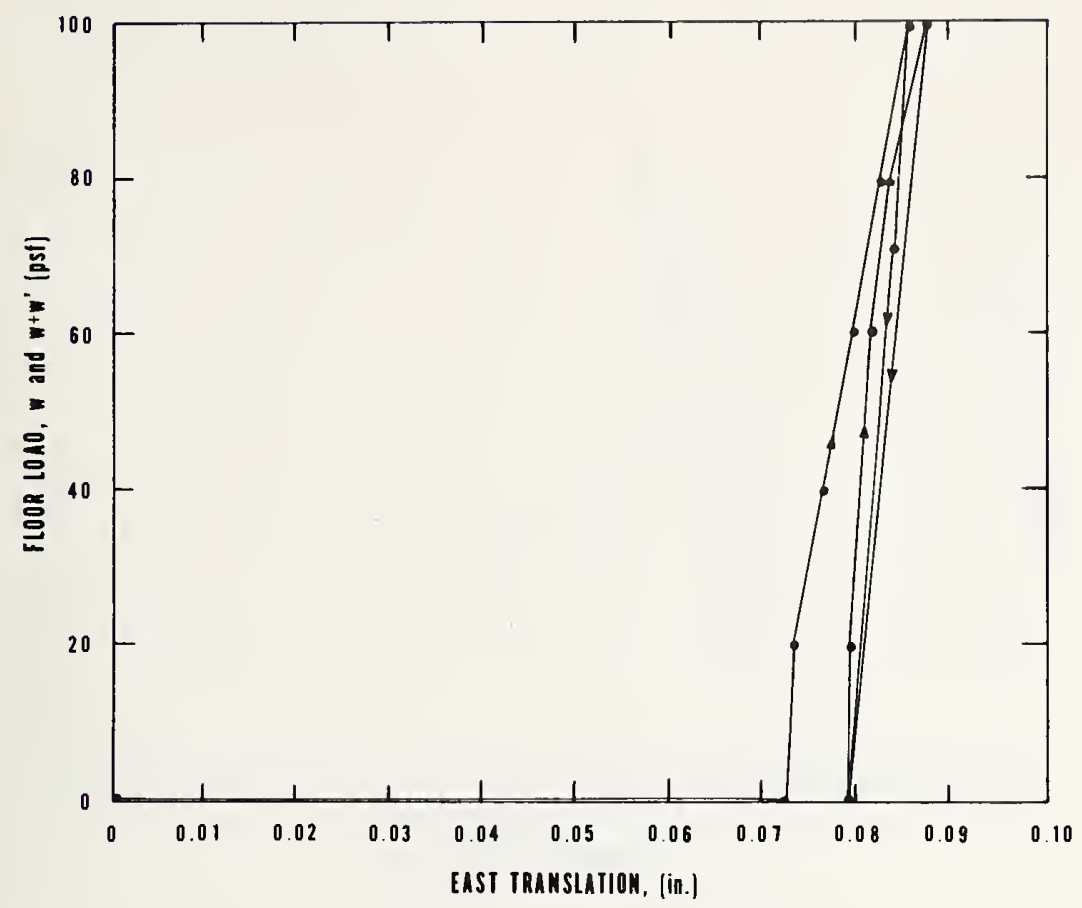

INIGURE A. 55. Tests No. 12 and 13, vertical load versus east translation. (Output Channel 47)

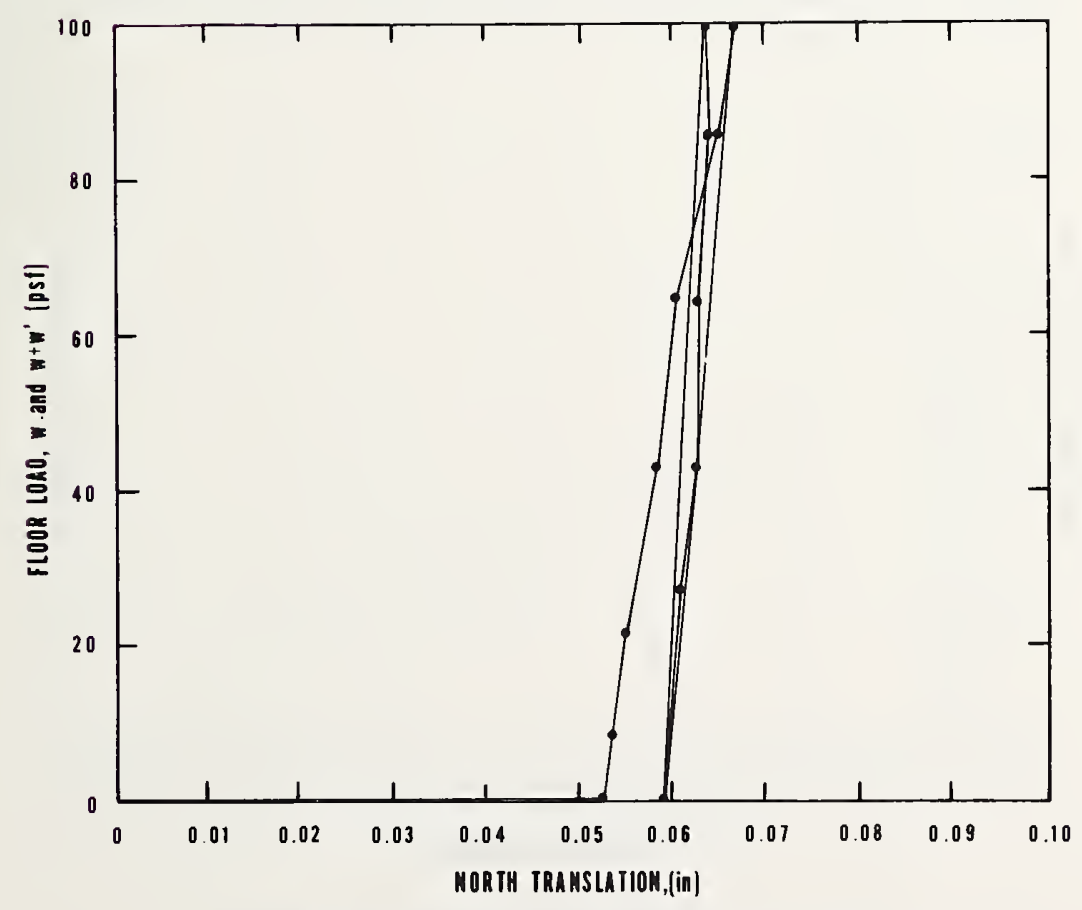

Figure A. 56. Tests No. 12A and 13A, vertical load versus north translation. (Output Channel 43) 


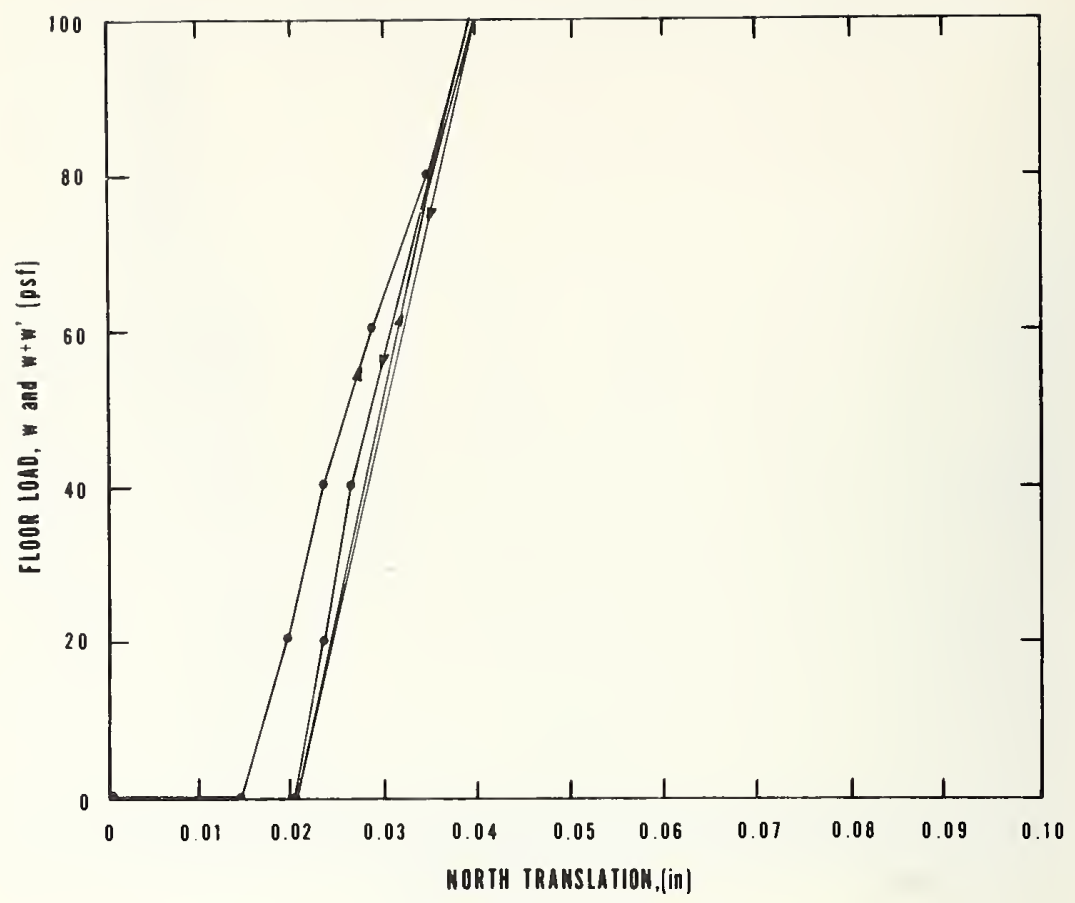

Figure A. 57. Tests No. 12A and 13A, vertical load versus north translation. (Output Channel 44)

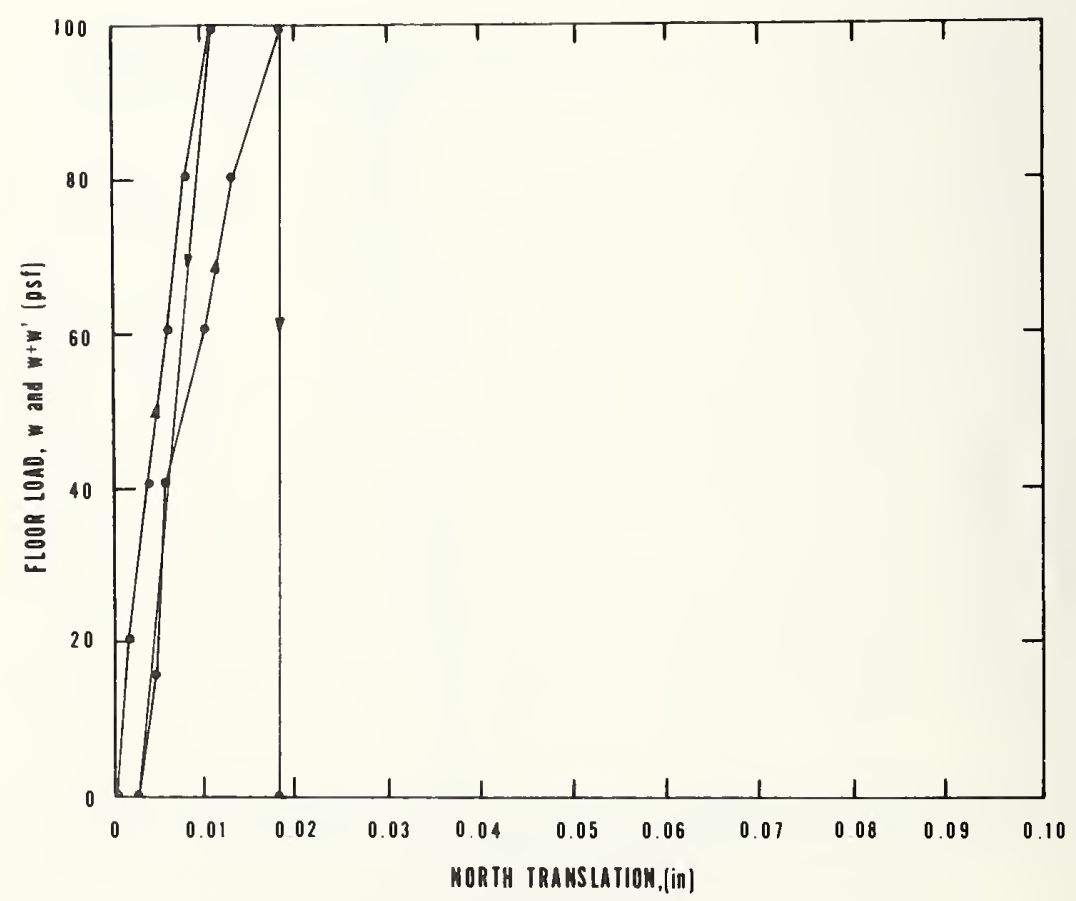

Figure A. 58. Tests No. 12A and 13A, vertical load versus north translation. (Output Channel 45) 


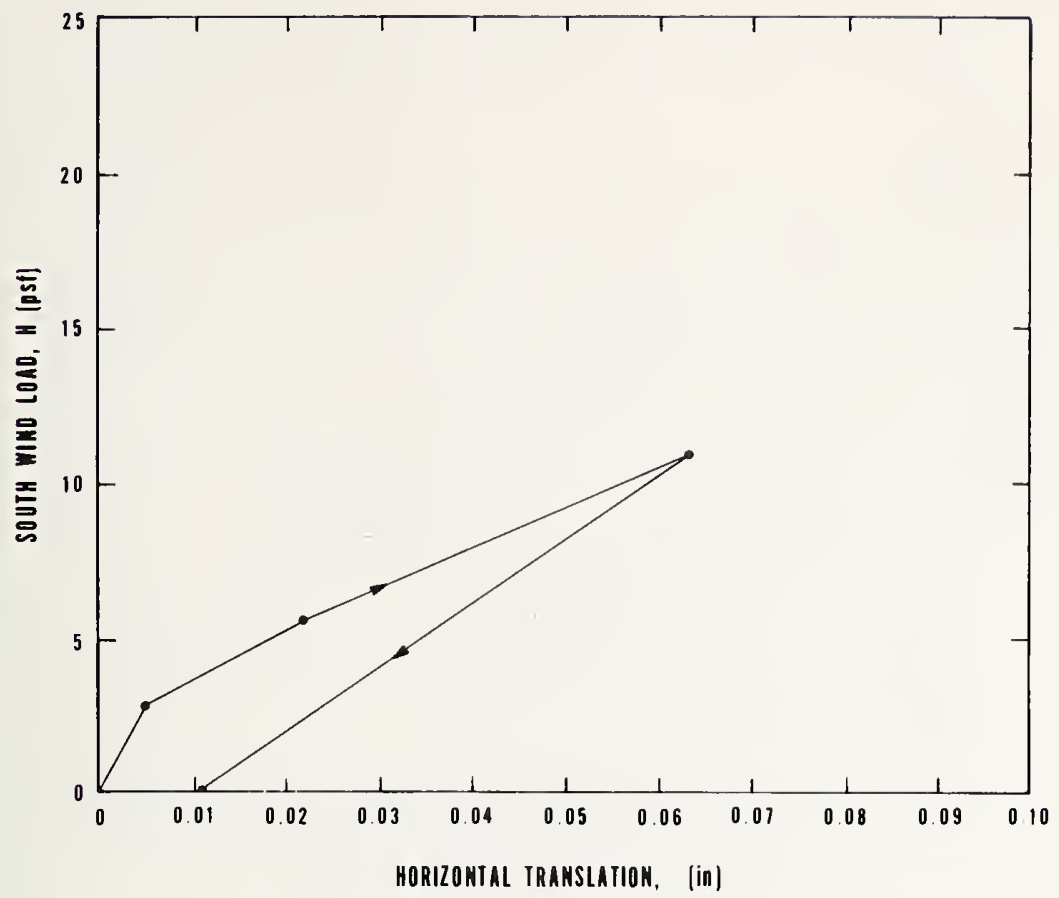

Figlike A. 59. Test No. 14, south wind load versus translation. (Output Channel 43)

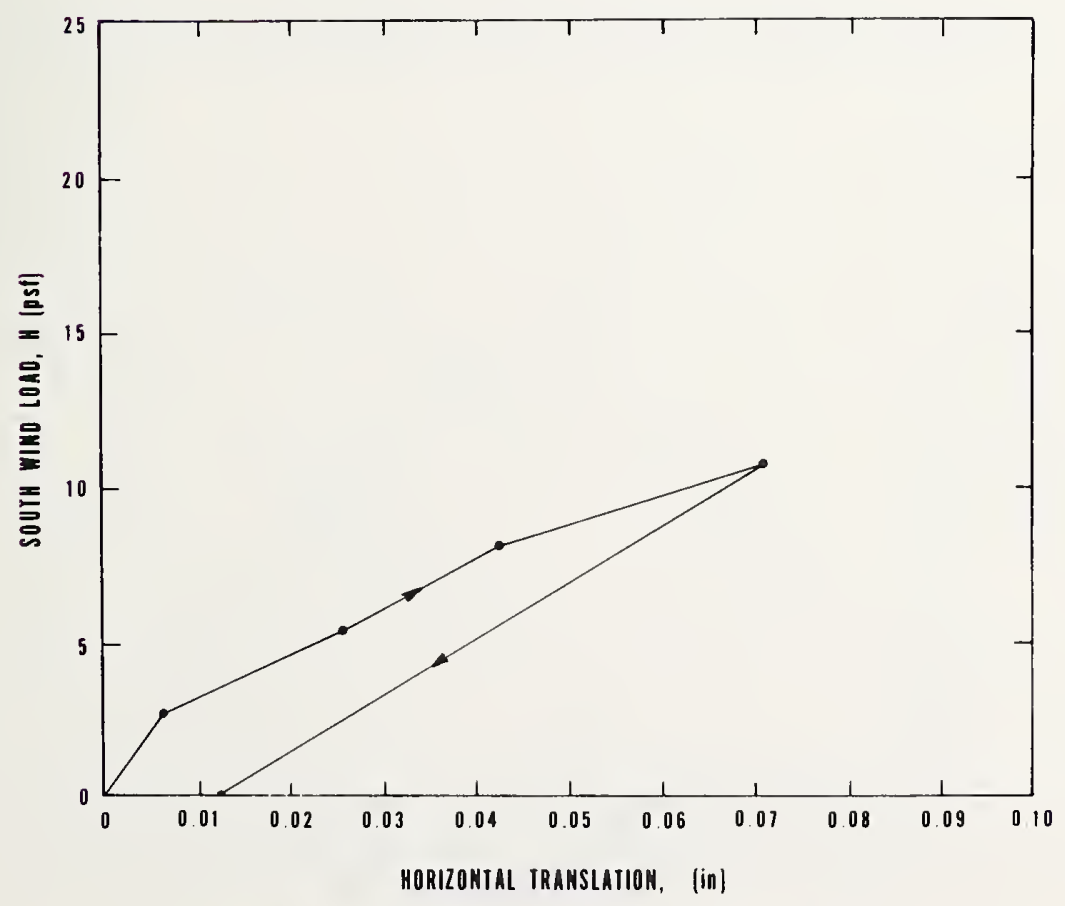

Figure A. 60. Test No. 14, south wind load versus translation. (Output Channel 44) 


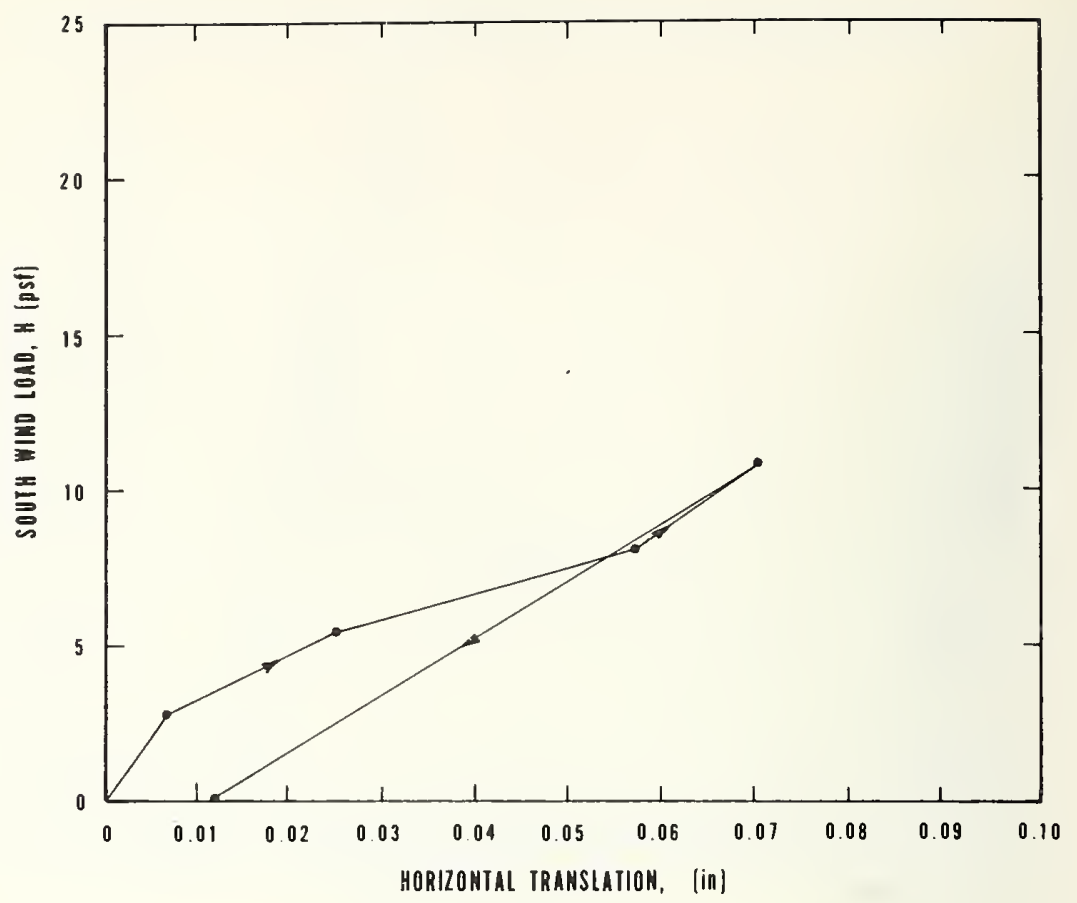

Figure A. 61. Test No. 14, south wind load versus translation. (Output Channel 45)

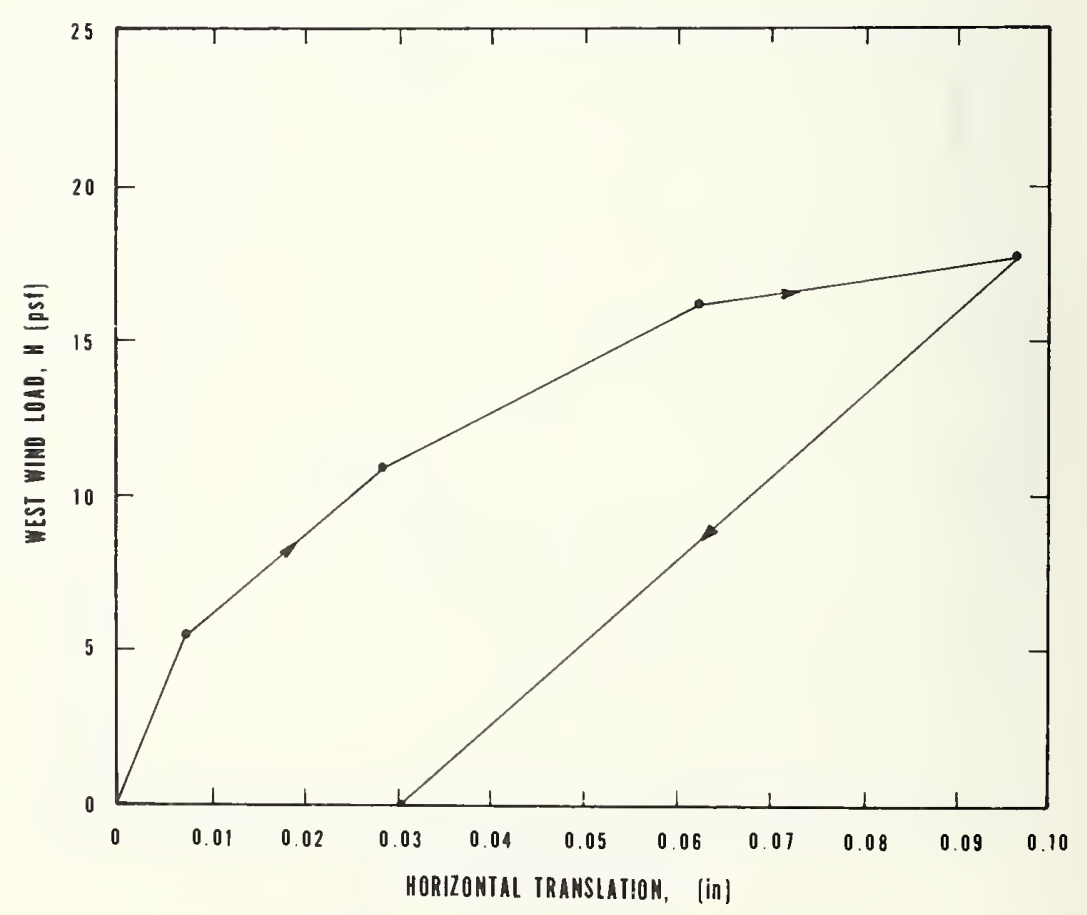

Figure A. 62. Test No. 15, west wind load versus translation. (Output Channel 46) 


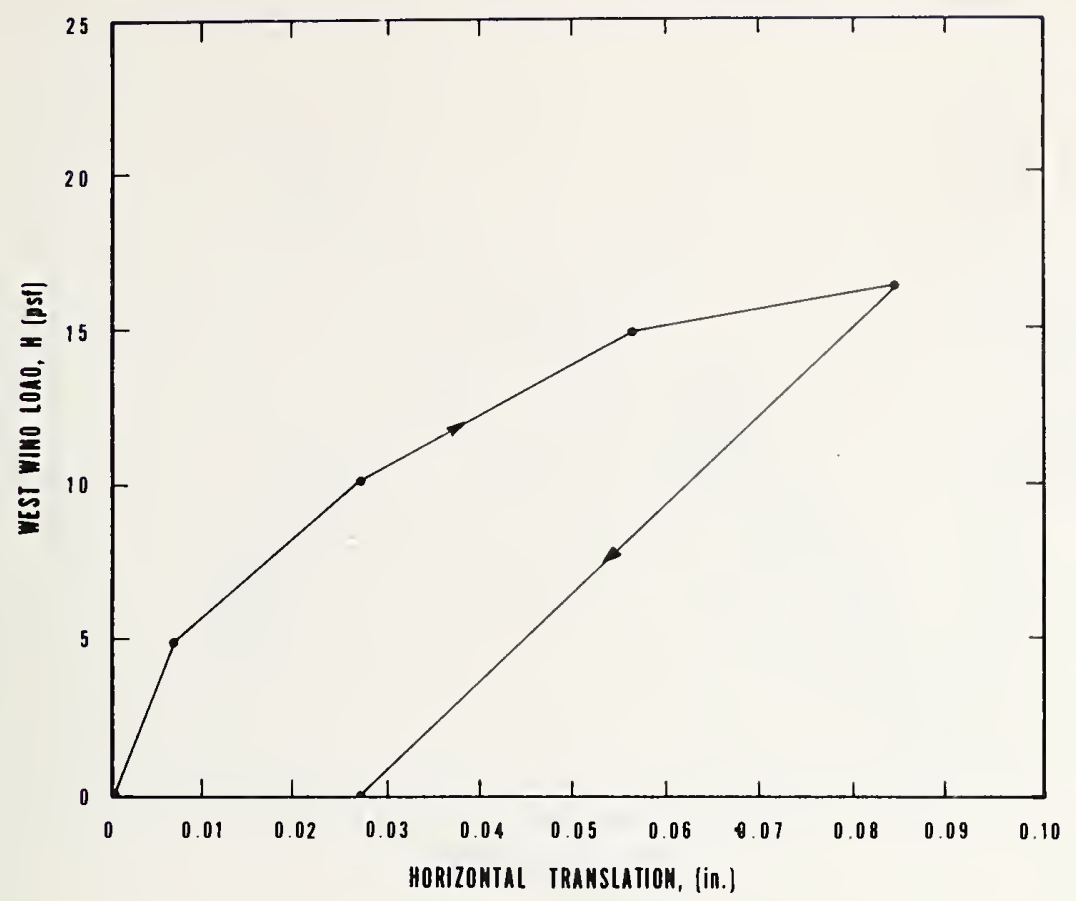

Figure A. 63. Test No. 15, west wind load versus translation. (Output Channel 47 )

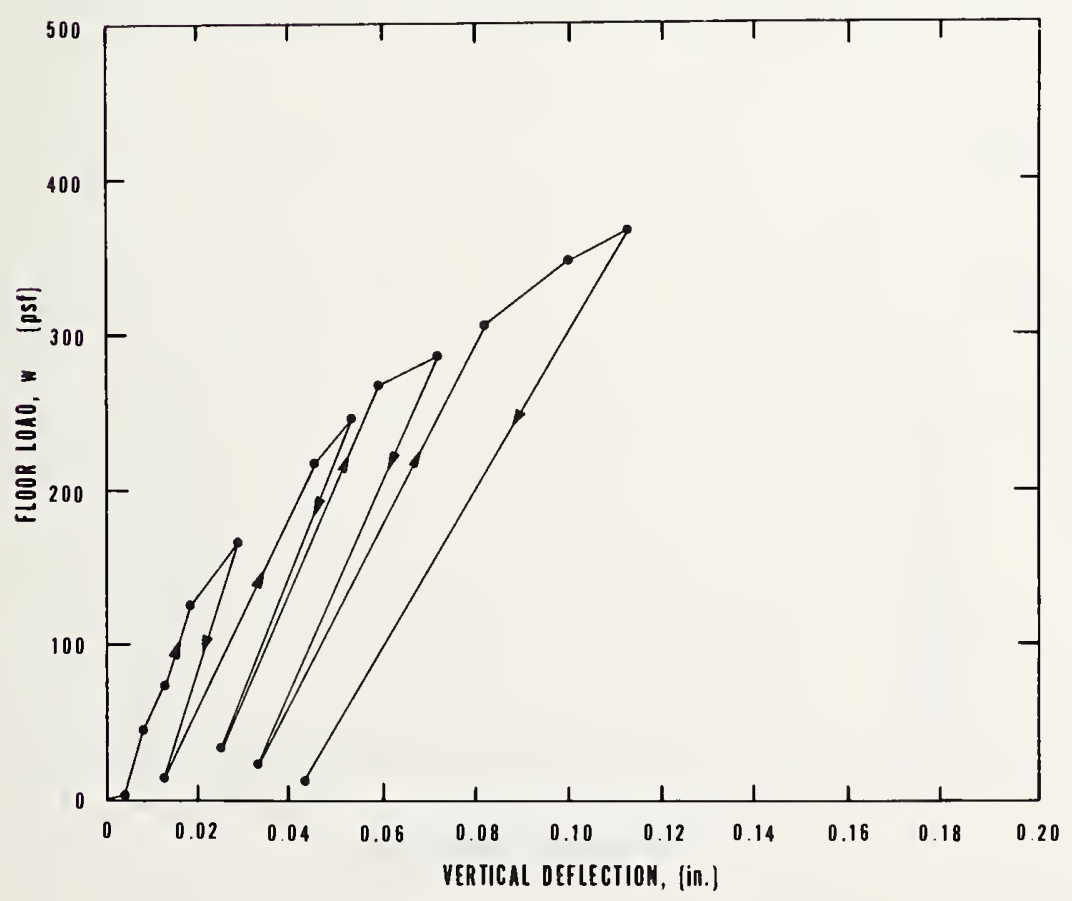

Figure A. 64. Test No. 16, major floor load versus beam deflection. (Output Channel 40) 


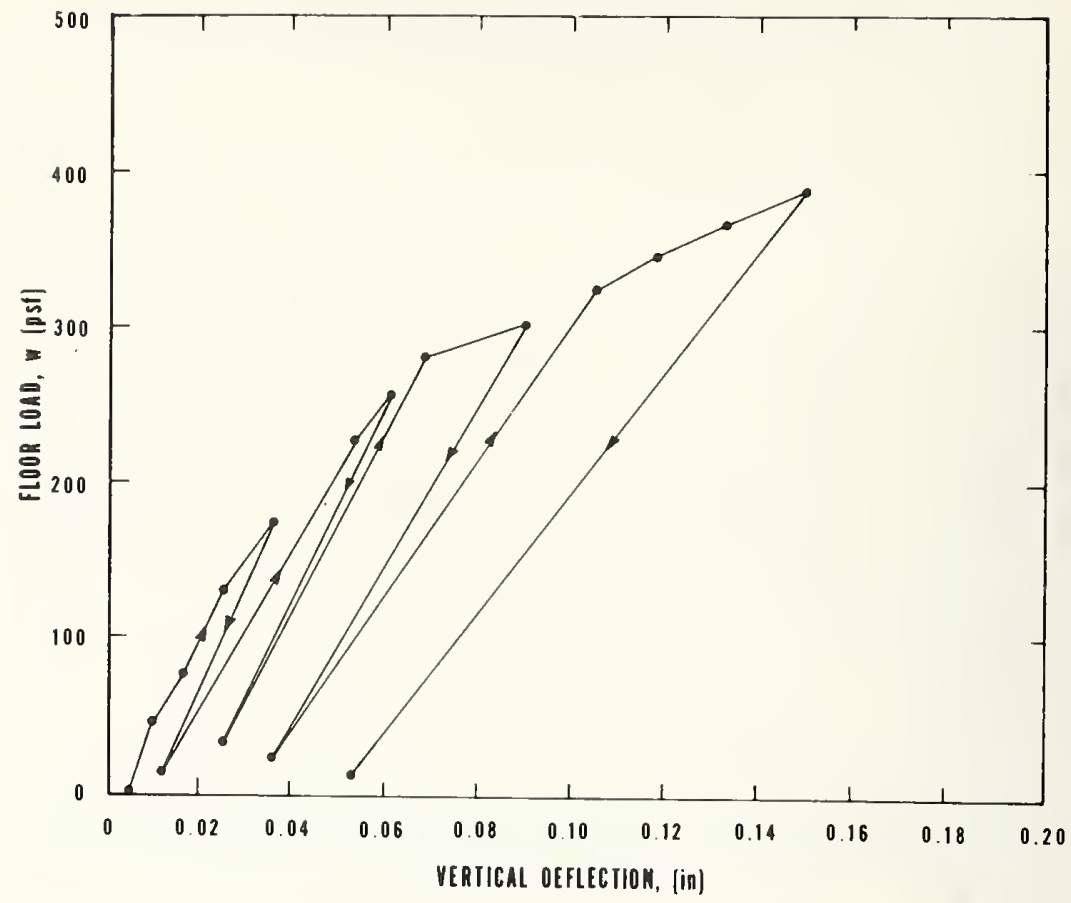

Figure A. 65. Test No. 16, major floor load versus beam deflection. (Output Channel 72)

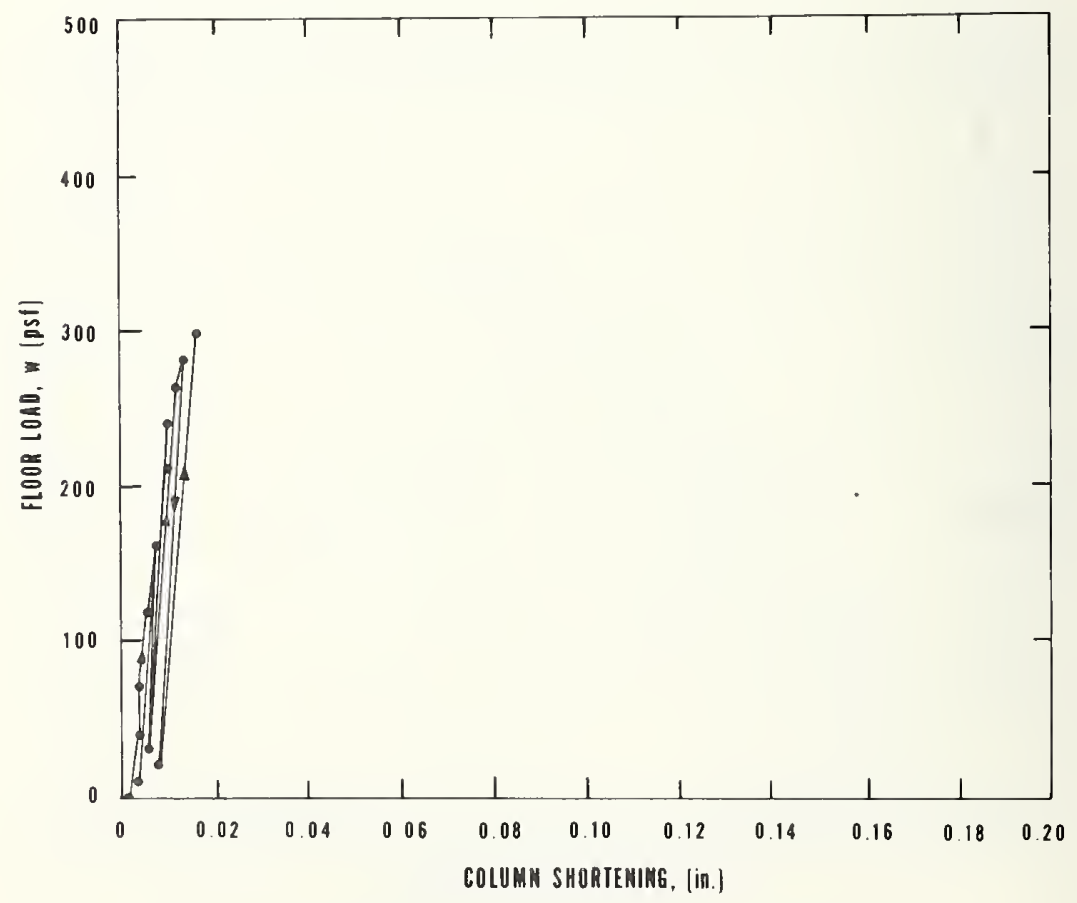

Figure A. 66. Test No. 16, major floor load versus column shortening. (Output Channel 73) 


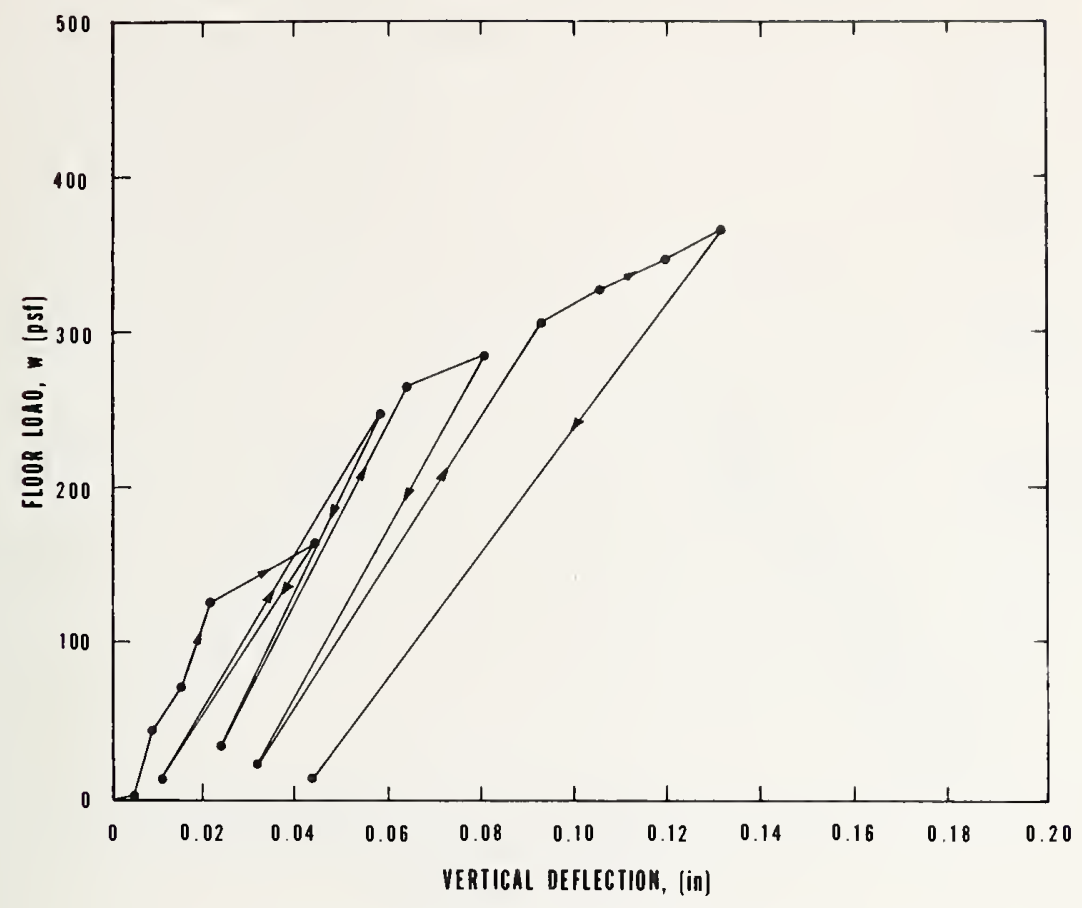

Figure A. 67. T'est No. 16, major flood load versus slab deflection. (Output Channel 76 )

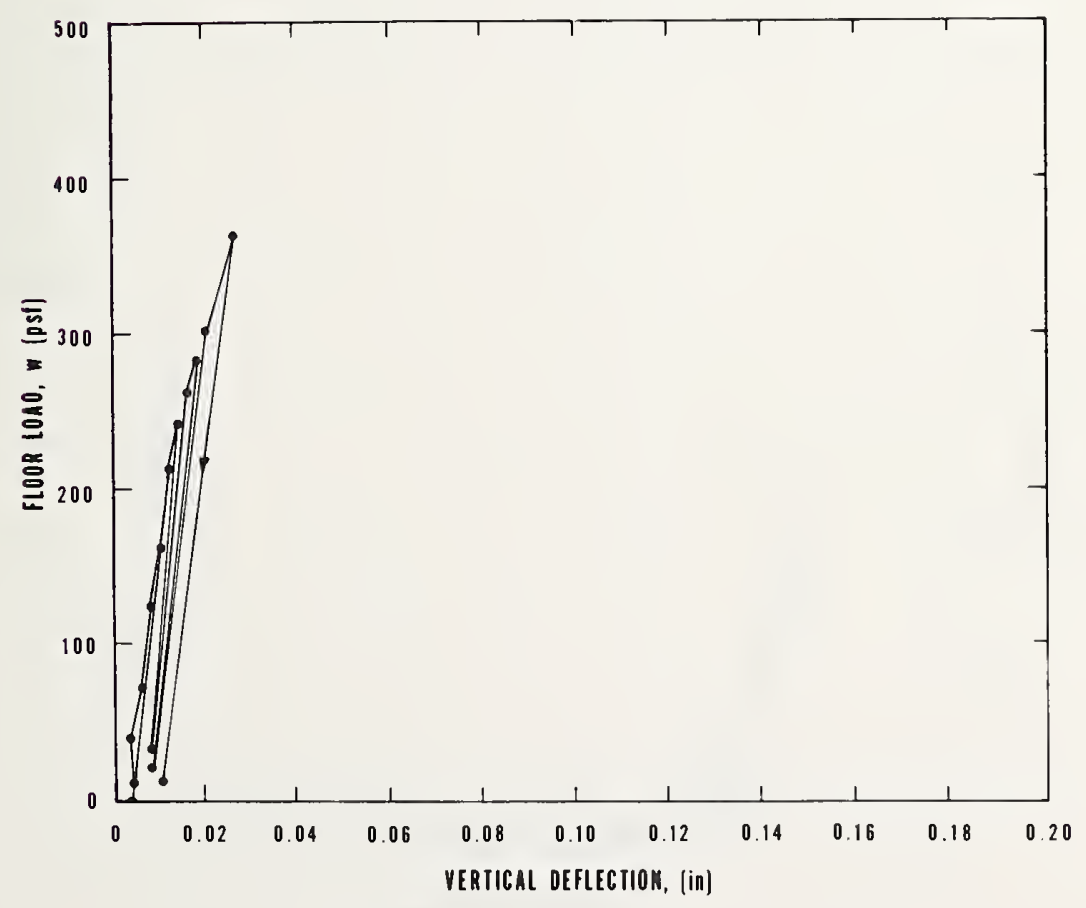

Figure A. 68. Test No. 16, major floor load versus slab deflection. (Output Channel $7 \%$ ) 


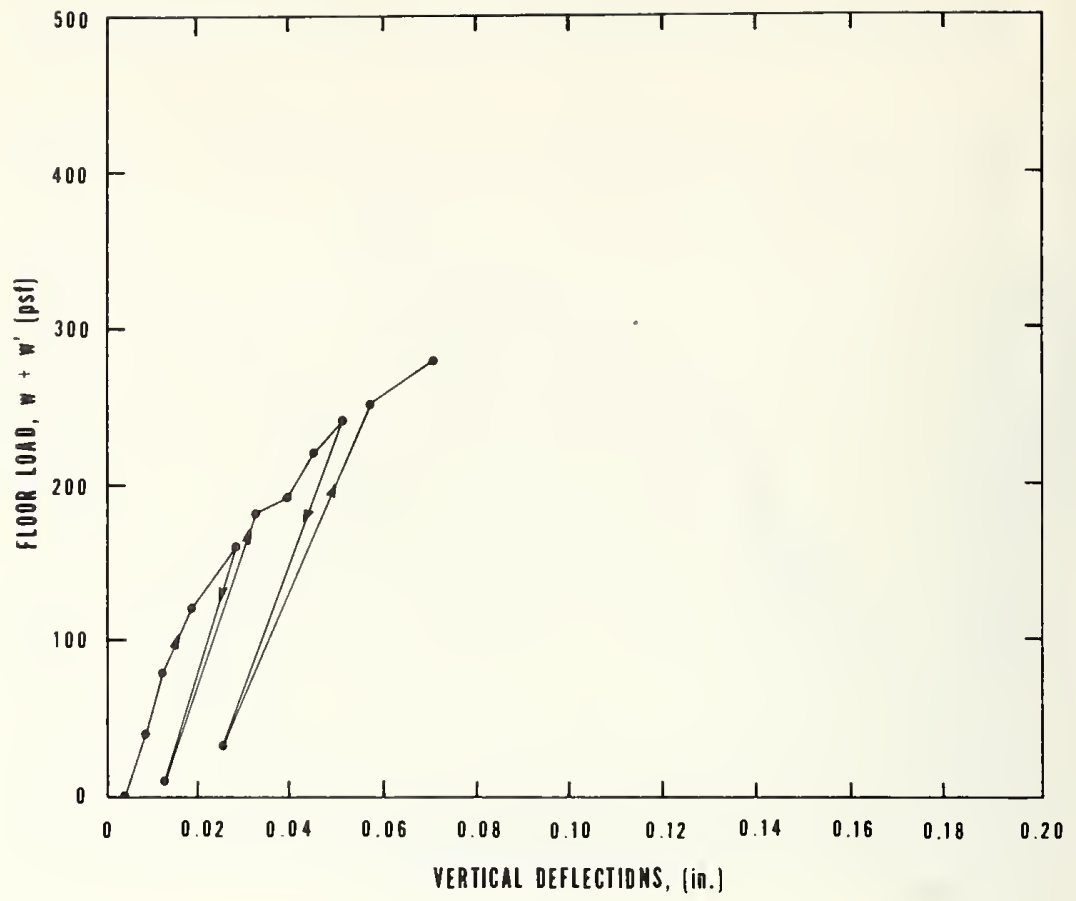

Figure A. 69. Test No. 16A, floor loads versus beam deflection. (Output Channel 40)

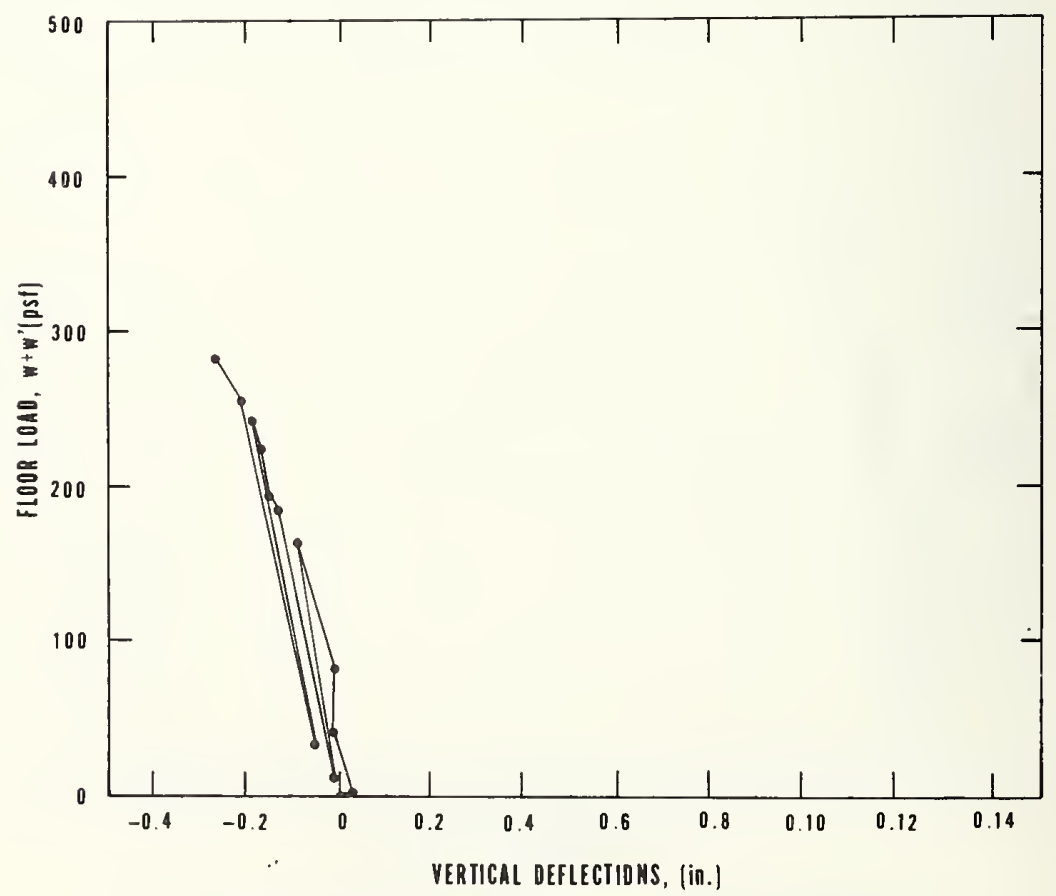

Figure A. 70. Test No. 16A, floor loads versus beam deflection. (Output Channel 70) 


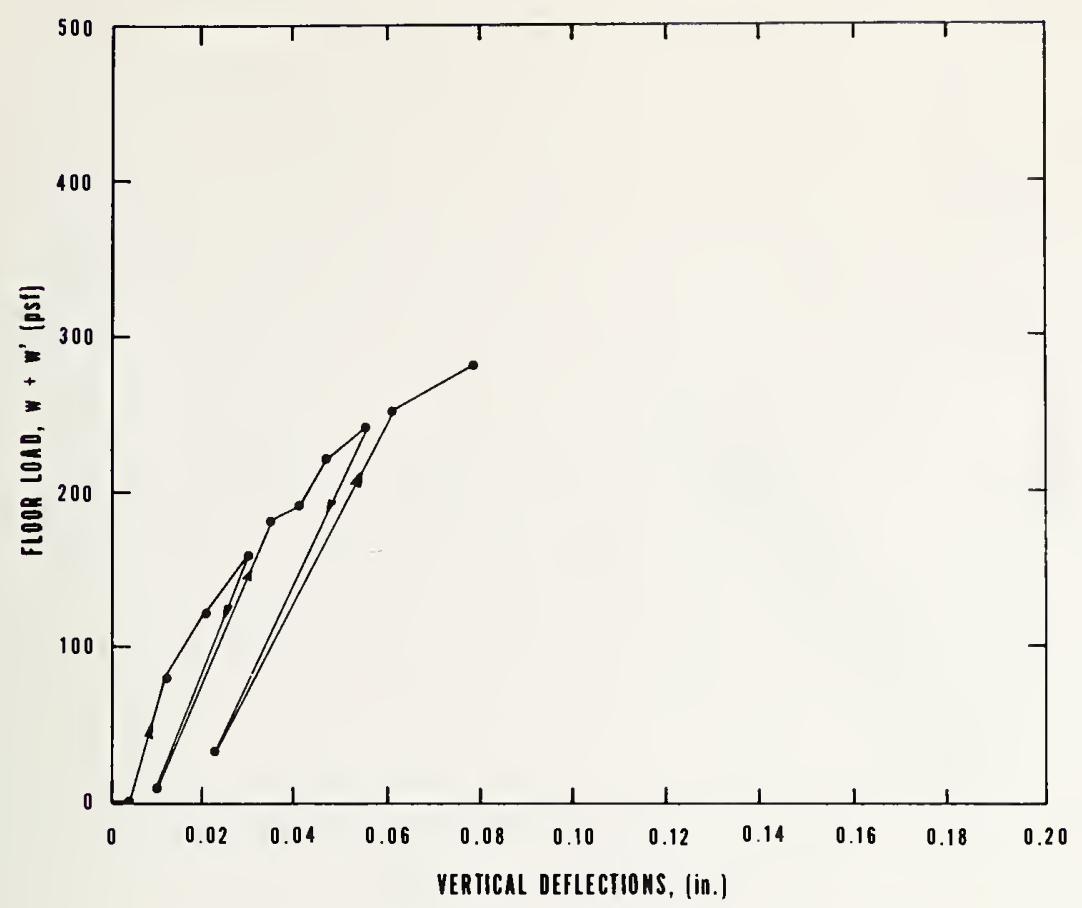

Figure A. 71. Test No. 16A, floor loads versus beam deflection. (Output Channel 72)

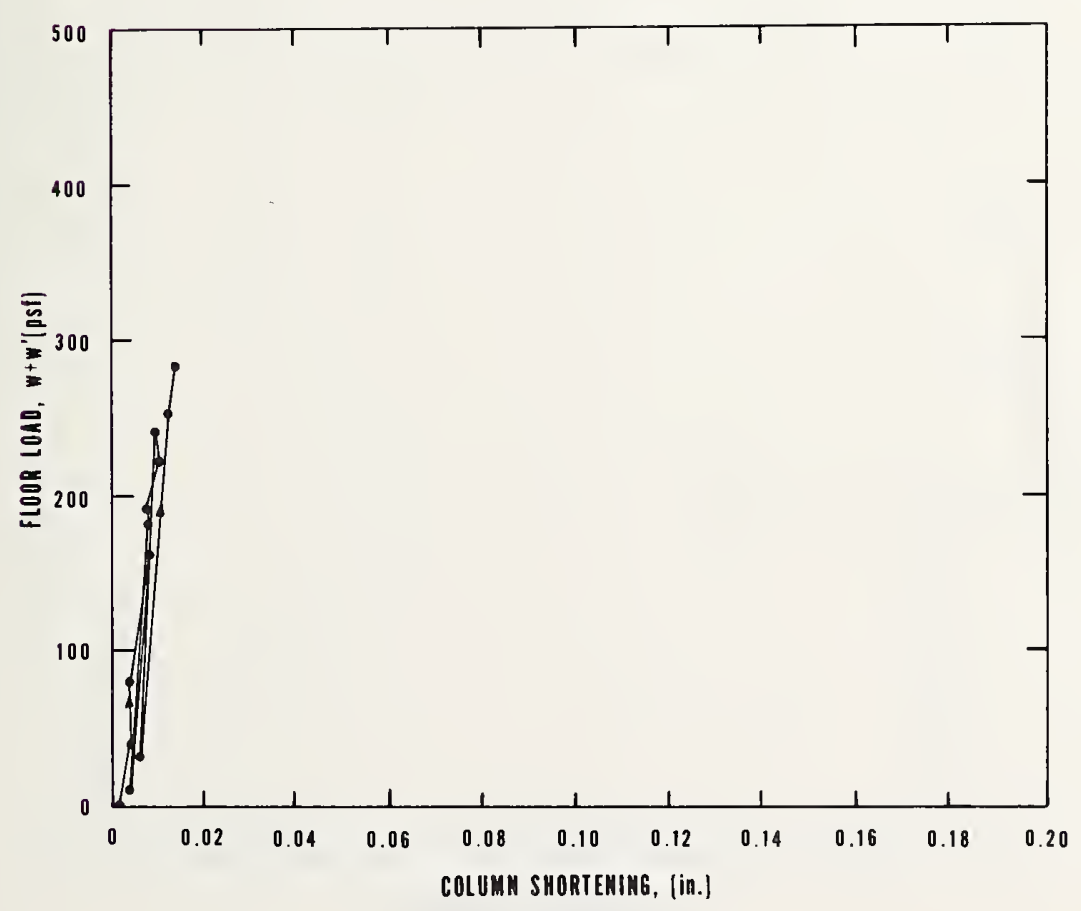

Figure A. 72. Test No. 16A, floor loads versus column shortening. (Output Channel 73) 


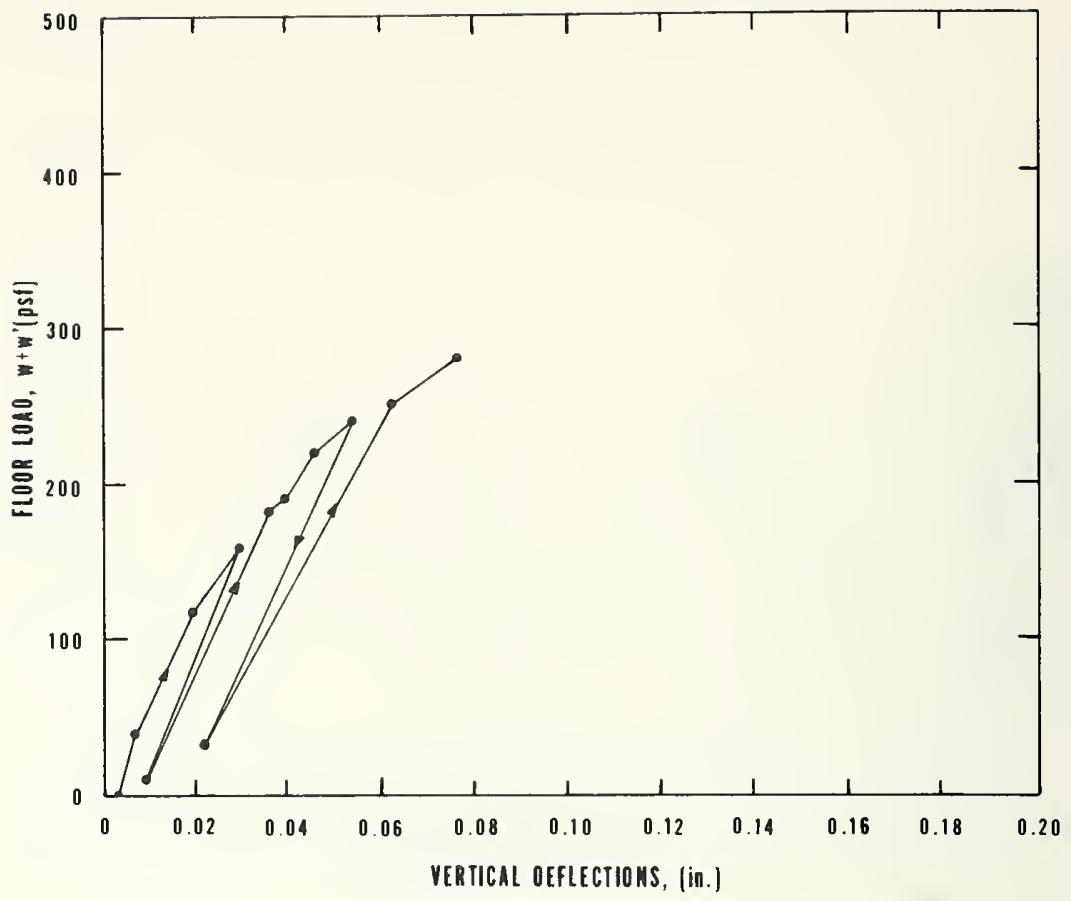

Figure A. 73. Test No. 16 A, floor loads versus slab deflection. (Output Channel 76)

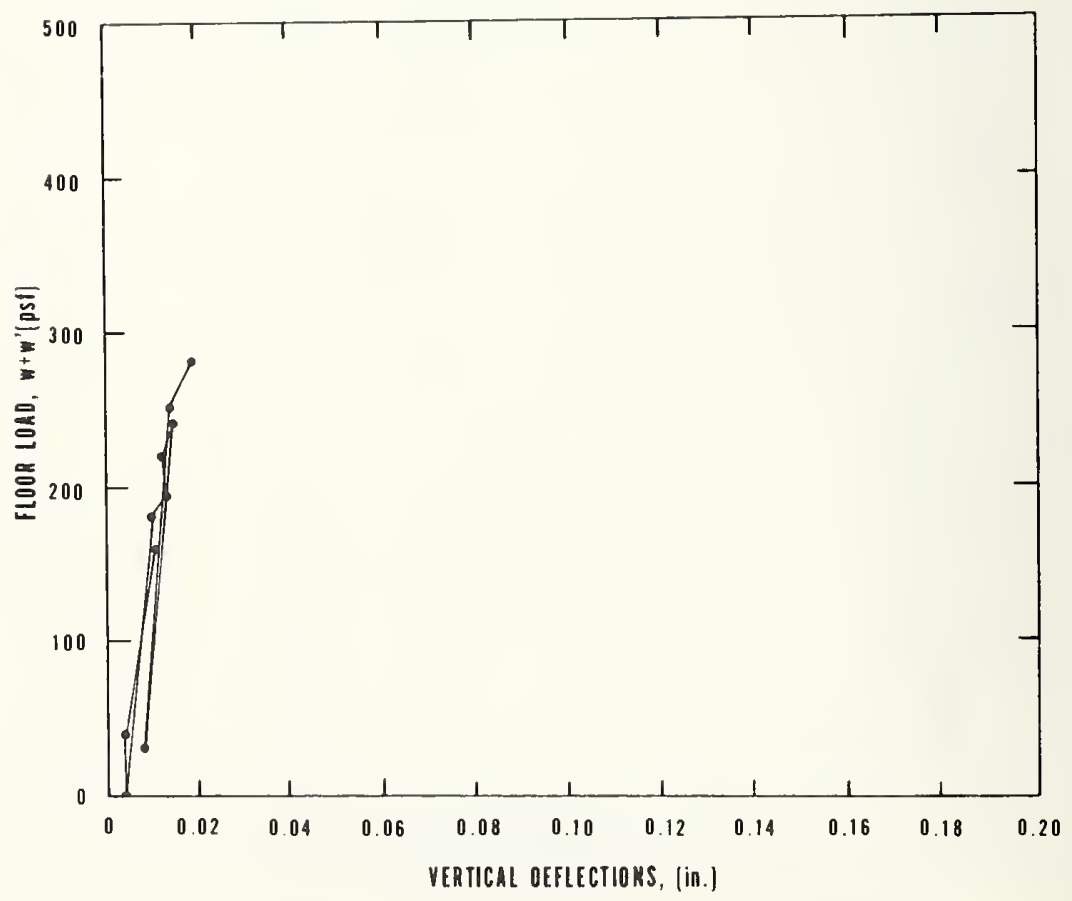

Figure A. 74. Test No. 16A, floor loads versus beam deflection. (Output Channel 77 ) 


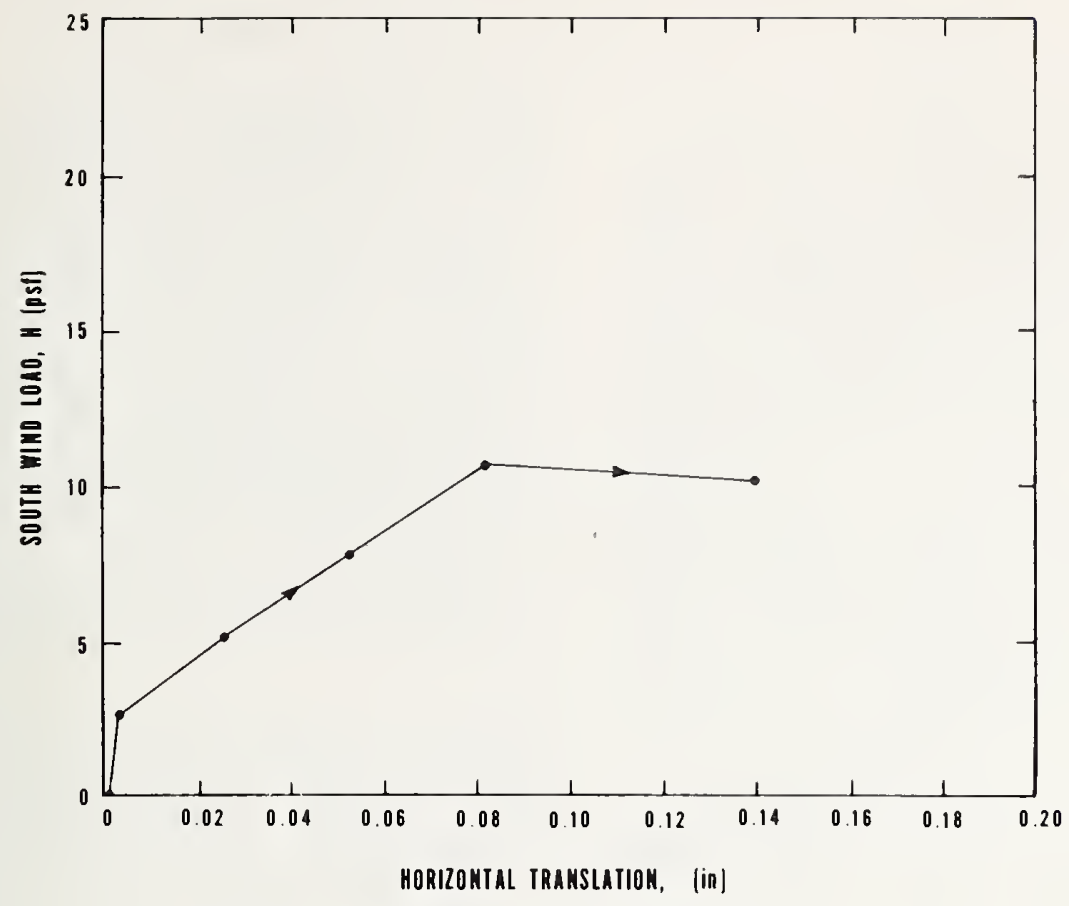

Figure A. 75. Test No. 18, south wind load versus translation. (Output Channel 4.3)

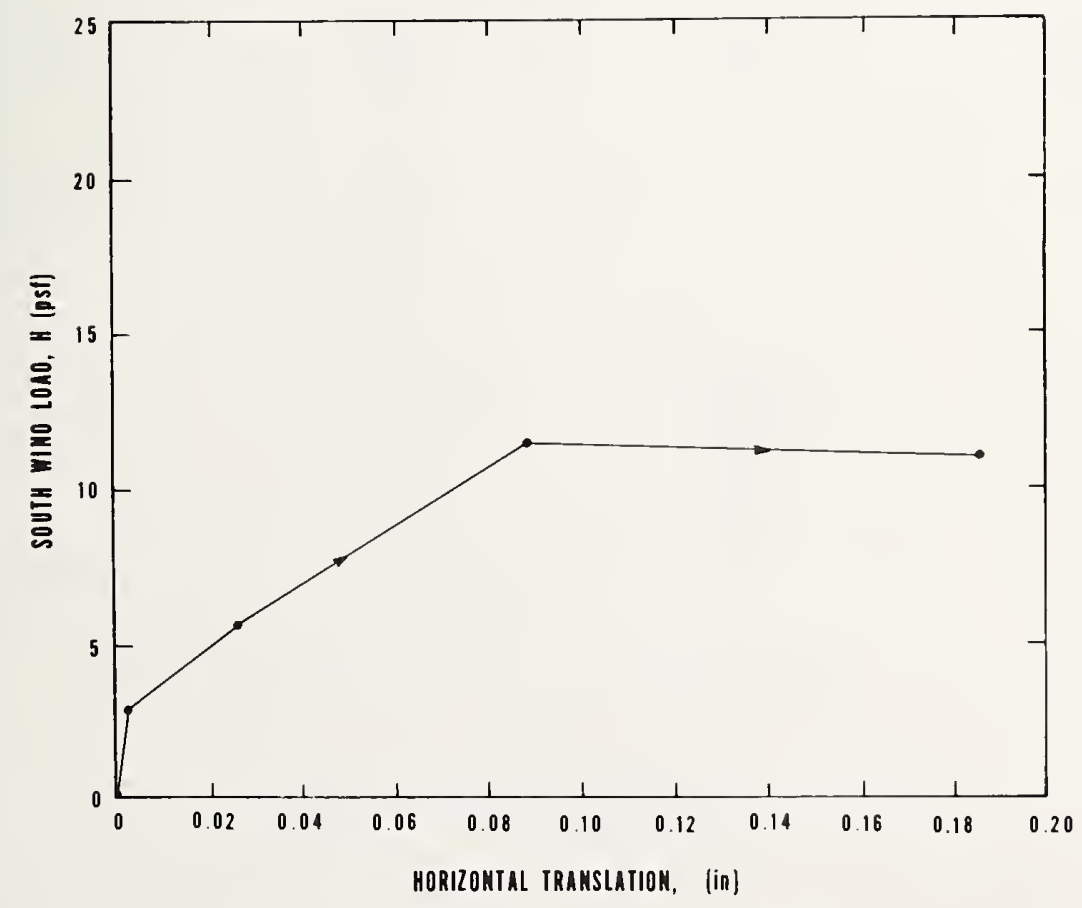

Figure A. 76. Test No. 18, south wind load versus translation. (Output Channel 44) 


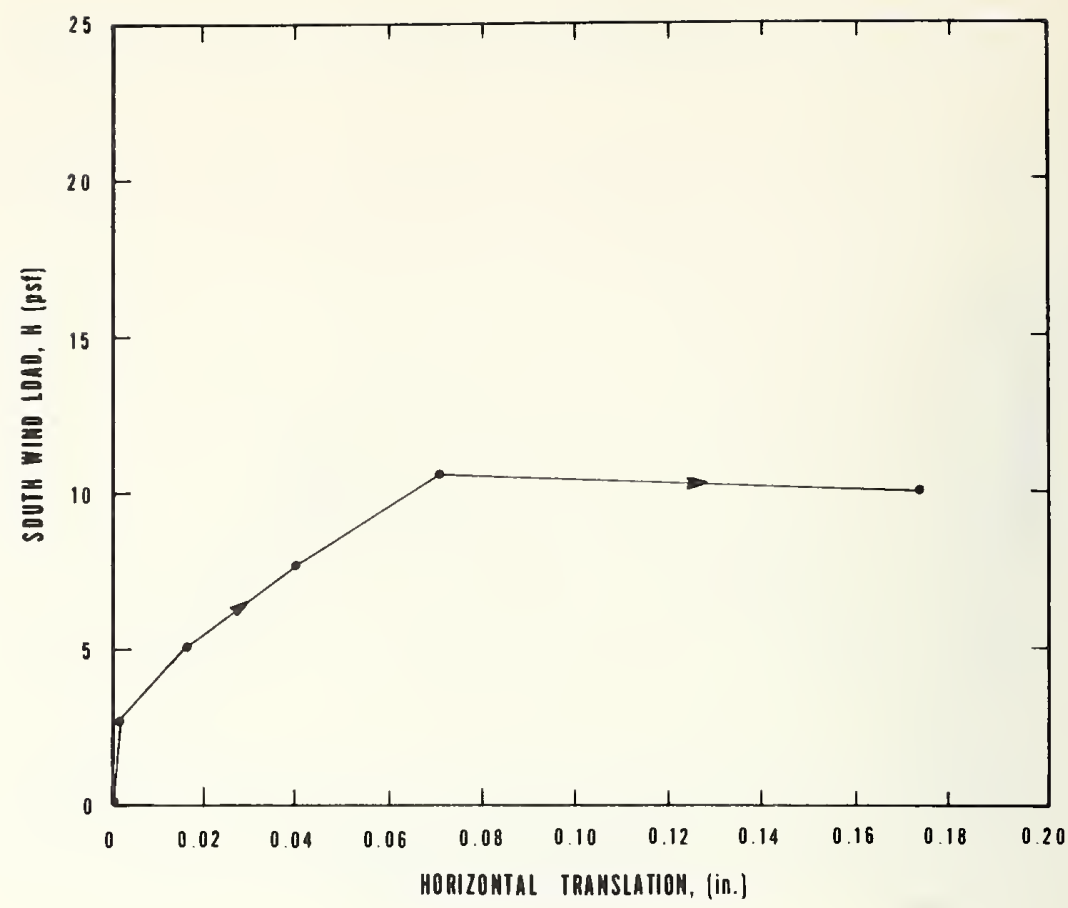

Figure A. 77. Test No. 18, south wind load versus translation. (Output Channel 45) 


\section{Appendix B. Discussion of Column Load Simulation}

Figure B.1 illustrates a comparison between column-beam connection moments due to simulated loads, and the moments anticipated in an actual structure. Figure B.1(a) shows the connection rotation direction due to actual loading of the middle span (12-ft span). Figure B.1(b), a detail of connection "A," shows the connection moments and axial forces caused by the actual loads. Figure B.1(c) illustrates the manner in which moments and forces actually applied by an upper story column may be exactly simulated, while figure B.1(d) shows the moments and forces applied in the test structure. The equations in figures B.1(c) and B.1(d) demonstrate qualitatively that the presence of moment $P a$ would:

(1) increase the negative moment in the main beam;

(2) decrease the lower story column moment.

This statement is generally valid for the case where column fixity in the test structure and in the real structure are equal. In this test it was decided to simulate foundation conditions by a "hinge" at the base of the column, since this was conservative in terms of column performance.

The introduction of this hinge decreases the column stiffness and therefore causes a decrease of the column connection moment $\left(M_{3}^{\prime}\right.$ in fig. B.1).
To summarize, the upper story column load simulation, as applied, tends to increase the column moment, while the foundation simulation tends to decrease it. The net effect in the case of this test structure is illustrated in figure B.2. Figure B.2(a) shows the moment distribution in a three-story structure (comprising half of the real structure) caused by one (1) live load applied to the column strip. Figure B.2(b) shows the moment distribution due to the same loading in the test structure.

By comparing joint " $\mathrm{A}$ " in figure $\mathrm{B} .2(\mathrm{a})$ and figure B.2(b), it may be seen that at joint " $A$ " in the test structure the column moment is increased. Also, the negative main beam moment is decreased, while the positive main beam moment at the center of the span is increased. Thus, the simulation of column loads in this test:

(1) Produced the most severe condition in the lower story column;

(2) Produced maximum dead and live load deflections and maximum positive beam moments, since midspan deflection and moment increases with decreasing negative moment at beam ends;

(3) Did not produce maximum negative moments at beam ends. However, negative moment capacities were adequately tested in Test 16 where the floor loads were increased to $370 \mathrm{psf}$. (a)

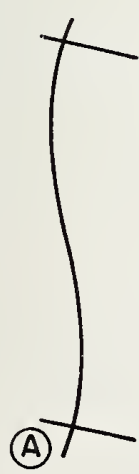

(b)

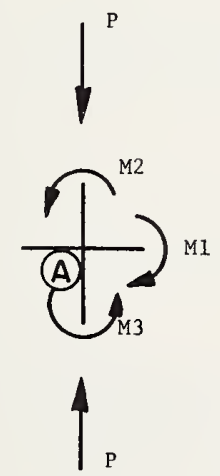

$\mathrm{M} 1=\mathrm{M} 2+\mathrm{M} 3$ (c)

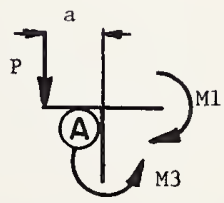

$\mathrm{P} \times \mathrm{a}=\mathrm{M} 2$

$M 1=M 2+M 3$

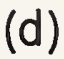

(d)

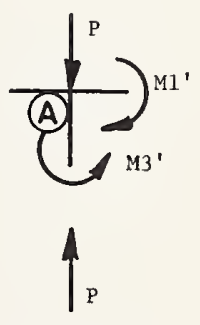

$M I^{\prime}=M 3^{\prime}$

$M 1^{\prime}<M 1$

$M 3^{\prime}>M 3$

FIGURE B. 1. Column simulation effect on connection moments. 


\begin{tabular}{|c|c|c|c|c|}
\hline & \multicolumn{3}{|c|}{$30 \mathrm{psf}$} & \multirow[b]{2}{*}{14} \\
\hline 14 & 14 & 47 & 14 & \\
\hline 15 & \multicolumn{3}{|c|}{$40 \mathrm{psf}$} & 15 \\
\hline \multirow[t]{2}{*}{15} & 30 & 51 & 30 & 15 \\
\hline & \multicolumn{3}{|c|}{ (A) } & \\
\hline 16 & \multicolumn{3}{|c|}{$40 \mathrm{psf}$} & 16 \\
\hline 11 & 27 & 54 & 27 & 11 \\
\hline 5.5 & & & & 5.5 \\
\hline \multicolumn{2}{|c|}{$m$} & & & \\
\hline
\end{tabular}

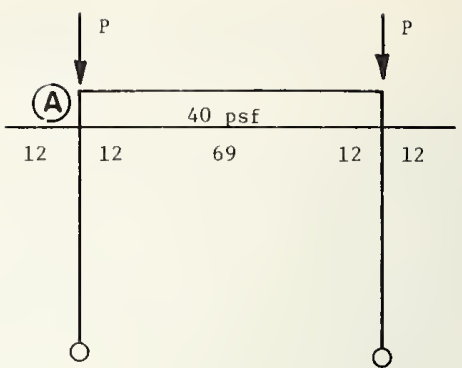

(b) Moment Distribution (kip-in ) due to one live load on test structure.

Figure B. 2. Moment distribution. 


\section{Appendix C. Load Computations and Load Schedules}

\section{1. Load Computations (refer to figure 6.1 and table 6.1)}

I. Notations (see section 3 )

$D=$ Service dead load

$L=$ service live load

$H=$ service wind load

$P=$ simulated $2 \mathrm{~d}$ story column load

$\mathrm{w}, \mathrm{w}^{\prime}=$ simulated distributed dead \& live loads exerted by air bags

$H s=$ simulated S-N wind load, at wall

$H s^{\prime}=$ simulated $\mathrm{S}-\mathrm{N}$ wind load, between walls

$H w=$ simulated $\mathrm{W}-\mathrm{E}$ wind load

II. Summary

(a) Simulated loads on test structures.

\begin{tabular}{|c|c|c|c|c|c|c|c|c|c|c|}
\hline & $D$ & $L$ & $.9 D$ & $H$ & $.8 H$ & $1.1 H$ & $1.6 H$ & $D+L$ & $1.3 D+1.7 L$ & $1.25(1.5 D+1.8 L)$ \\
\hline $\begin{array}{l}P-\text { kip } \\
H s-\text { kip } \\
H_{\mathrm{s}}-\mathrm{kip} \\
H w-\mathrm{kip} \\
w \text { or } w^{\prime}-\mathrm{lb} / \mathrm{ft}^{2}\end{array}$ & 10 & 43 & 9 & $\begin{array}{l}4.05 \\
0.9 \\
2.05\end{array}$ & $\begin{array}{c}3 \\
0.7 \\
1.5\end{array}$ & $\begin{array}{c}4.5 \\
1 \\
2.3\end{array}$ & $\begin{array}{l}5.7 \\
1.3 \\
2.9\end{array}$ & 17 & 100 & b 144 \\
\hline
\end{tabular}

a Allowance for dead weight of partitions and fixtures.

b Includes dead weight of test structure (i.e., $43 \times 1.07)$ multiplied by appropriate factor.

(b) Simulated loads on lower column for component tests of columns.

\begin{tabular}{c|c|c|c|c|c|c}
\hline \hline & $D+L$ & $.9 D+L$ & $1.3 D+1.7 L$ & $1.25(1.5 D+1.8 L)$ & $D$ & $L$ \\
\hline P-kip & 25 & 24 & 37 & 51 & 14.4 & 11 \\
\hline
\end{tabular}

(c) Simulated load on main beam for fatigue test in kip per ram, (see fig. 10.23).
$1 D+1 L=2.5$
$1 D+1.5 L=3.125$
$1 D+2 L=3.75$
$1 D+2.5 L=4.375$
$1 D+3 L=5.00$

III. Vertical Load Computations

(1) Conversion factor accounting for incomplete air bag coverage

area of bags $=2(9.915 \times 15)=297 \mathrm{ft}^{2}$

area of roof $=21.21 \times 15.5=320 \mathrm{ft}^{2}$

320

$\overline{297}=1.07$; convert all loads applied by bags. 
(2) Floor load elements $(D)$ converted to "per square foot" on total floor area.
(a) 4 in floor channels: 16.3 psf $\times \frac{18 \times 20}{19 \times 21.21}$
$=14.5 \mathrm{psf}$
(b) Topping slab: $2.25 *$ in. $\times \frac{1 \mathrm{ft}}{12 \mathrm{in}} \times 110 \mathrm{lb} / \mathrm{ft}^{3}$
$=21 \mathrm{psf}$
(c) Flooring and utilities (Mitchell)
(d) Partitions (Mitchell)
(e) Columns (prorated, see below)
$=1.75 \mathrm{psf}$
(f) Beams (prorated, see below)
$3 \mathrm{~d}$ floor unit load $=a$ thru $f$
$51.58 \mathrm{psf}$
loof unit load $=a+b+f$
$41.28 \mathrm{psf}$
added dead load on test structure.

$$
\text { not transmitted by columns }=c+d \quad 8.75 \text { psf }
$$

(3) Columns and beams prorated per unit area, say, $100 \mathrm{lb} / \mathrm{ft}^{3}$ concrete (includes reinforcing weight).

T-beams: $\frac{43 \mathrm{in}^{2}}{144 \frac{\mathrm{in}^{2}}{\mathrm{ft}^{2}}} \times 19 \mathrm{ft} \times 100 \mathrm{lb} / \mathrm{ft}^{3} \times \frac{1}{200 \mathrm{ft}^{2}}$

Ties: $\frac{42 \mathrm{in}^{2}}{144 \frac{\mathrm{in}^{2}}{\mathrm{ft}^{2}}} \times 20 \mathrm{ft} \times 100 \mathrm{lb} / \mathrm{ft}^{3} \times \frac{1}{200 \mathrm{ft}^{2}}$

$$
\left.=2.86 \mathrm{psf} \mid \begin{array}{l}
5.78 \mathrm{psf} \\
=2.92 \mathrm{psf}
\end{array}\right\}
$$

Columns: $\frac{(6 \times 4.75) \mathrm{in}^{2}}{144{\frac{\mathrm{in}^{2}}{\mathrm{ft}^{2}}}^{2}} \times 2 \times 7.83 \mathrm{ft} \times 100 \mathrm{lb} / \mathrm{ft}^{3} \times \frac{1}{200 \mathrm{ft}^{2}}=1.55 \mathrm{psf}$

(4) Converted floor loads for air bags.

(a) Live load $=40$ psf $\times 1.07$

(b) Added dead load $1 D=8.75 \times 1.07$

(c) Combinations: $1.3 \mathrm{D}=1.3 \times 9.35=12.1$

$$
\begin{aligned}
& =43 \mathrm{psf} \\
& =9.35 \mathrm{psf}
\end{aligned}
$$

$$
+0.3 \times 1.07 \times 42.8^{* *}=13.7
$$$$
=25.8
$$

$$
1.7 L=1.7 \times 43
$$$$
=73
$$$$
1.3 D+1.7 L
$$$$
=98.8, \simeq 100 \text { psf }
$$

$$
\begin{aligned}
1.5 D= & 1.5 \times 9.35=14.1 \\
& +0.5 \times 46^{* * *}=23
\end{aligned}
$$

$$
1.8 L=1.8 \times 43
$$$$
=37.1
$$

$=77.5$

$1.25(1.5 D+1.8 L)=1.25 \times 114.6$ 114.6

$=143.5, \simeq 144 p s f$ 
(5) Simulated second-story column load.

(a) Dead Load: Tributary floor area $=10.39 \times 9.5=99 \mathrm{ft}^{2}$

Column + partition: $99 \times 8.55$

$3 d$ floor: $99 \times 51.58$

$$
\begin{aligned}
& =850 \mathrm{lb} \\
& =5,150 \mathrm{lb} \\
& =4,050 \mathrm{lb} \\
1 D & =10,050 \mathrm{lb}, \text { say } 10 \mathrm{kip} \\
& =6,900 \mathrm{lb}, \text { say } 7 \mathrm{kip}
\end{aligned}
$$$$
\text { roof: } 99 \times 41.28
$$

(b) Live Load: [40 psf (floor) $+30 \mathrm{psf}$ (roof)] $\times 99$

(c) Combinations: $0.9 D=9 \mathrm{kip} ; 1 D=10 \mathrm{kip}$

$$
\begin{array}{ll}
1 D+1 L & =17 \mathrm{kip} \\
1.3 D+1.7 L & =25 \mathrm{kip} \\
1.25(1.5 D+1.8 L) & =35 \mathrm{kip}
\end{array}
$$

(6) Full lower story column load. (For component tests.)

(a) Dead Load: 2d story

$$
3 \mathrm{~d} \text { story }
$$

roof

$1 D=$

(b) Live Load: $2 \mathrm{~d}$ story $=99 \mathrm{sf} \times 40 \mathrm{lb} / \mathrm{ft}^{2}=$

$3 \mathrm{~d}$ story $=99 \mathrm{sf} \times 40 \mathrm{lb} / \mathrm{ft}^{2}=$

$5,150 \mathrm{lb}$ (See 5a)

$5,150 \mathrm{lb}$

$4,050 \mathrm{lb}$

roof $=99 \mathrm{sf} \times 30 \mathrm{lb} / \mathrm{ft}^{2}=$

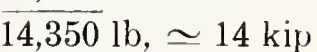

$3,960 \mathrm{lb}$

$3,960 \mathrm{lb}$

$1 L=$

$2,970 \mathrm{lb}$

(c) Combinations: $1 D+1 L$

$=25 \mathrm{kip}$

$\overline{10,890} \mathrm{lb}, \simeq 11 \mathrm{kip}$

$$
\begin{array}{ll}
1.3 D+1.7 L & =37 \mathrm{kip} \\
1.25(1.5 D+1.8 L) & =51 \mathrm{kip}
\end{array}
$$

(7) Main beam loads for fatigue test.

1/4 point loading: $1 / 2$ the load resting on the beam, to be applied by each ram)

Area:

$=65 \mathrm{ft}^{2}$

$1 D:$ Slab: $6.25 \mathrm{ft} \times 7.5 \mathrm{ft}$ (added slab width) $\times 21 \mathrm{psf}=945 \mathrm{lb}($ See $(2))$

Floor channel slab: $16.3 \mathrm{psf} \times 6.25 \mathrm{ft} \times 9 \mathrm{ft}$

Walls, etc: $8.75 \mathrm{psf} \times 65 \mathrm{ft}^{2}$

$=920 \mathrm{lb}($ See $(2))$

1 dead load

$1 L=40 \mathrm{psf} \times 65 \mathrm{ft}^{2}=2.6 \mathrm{kip}, \simeq 2.5 \mathrm{kip}$

$1 / 4$ point loading-Kip: $1 D+1 L \quad 5.00$

$$
\begin{array}{lc}
1 D+1.5 L & 6.25 \\
1 D+2 L & 7.5 \\
1 D+2.5 L & 8.75 \\
1 D+3 L & 10.00
\end{array}
$$$$
=570 \mathrm{lb}(\text { See }(2))
$$$$
\overline{2,435}, \mathrm{lb} \simeq 2.5 \mathrm{kip}
$$

IV. Wind Loads

(1) South wall ( $H s, H s^{\prime}$ ) (refer to fig. C.1 (1))

$a=$ Story height $\times$ panel width $=8.62 \times 10.39 \times 90 \mathrm{ft}^{2}$

at point $A-H s$. at point $B-H s^{\prime}$.

$H s$ is at firewall.

$H s^{\prime}$ is midway between two firewalls.

Assume stiff floor distributes shear between two walls over width of structure, then test assembly carried $1 / 2$ the wind load.

$\therefore$ at $H=20 \mathrm{psf}: H s=1 / 2 \times(4.5 \times 90) \mathrm{ft}^{2} \times 20 \mathrm{lb} / \mathrm{ft}^{2}=4,050 \mathrm{lb}=4.05 \mathrm{kip}$

$$
H s^{\prime}=1 / 2 \times 90 \mathrm{ft}^{2} \times 20 \mathrm{lb} / \mathrm{ft}^{2}=900 \mathrm{lb}=0.9 \mathrm{kip} .
$$


Therefore, $0.8 \mathrm{Hs}=3.24 \mathrm{kip}^{*}$

$1.25 \mathrm{Hs}=5.1$ kip.

(2) West Wall $(H w)$ (refer to fig. C.1 (2))

$a^{\prime}=$ story height $\times 9.5 \mathrm{ft}=8.62 \times 9.5=82 \mathrm{ft}^{2}$

Assume $1 / 2$ the wind load carried by wall panel (conservative)

$\therefore$ at $H=20$ psf: $H w=1 / 2 \times(2.5 \times 82) \mathrm{ft}^{2} \times 20 \mathrm{lb} / \mathrm{ft}^{2}=2,050 \mathrm{lb}=2.05 \mathrm{kip}$.

Therefore, $0.8 \mathrm{Hw}=1.64 \mathrm{kip}^{* *}$

$1.25 \mathrm{Hw}=2.56 \mathrm{kip}$.

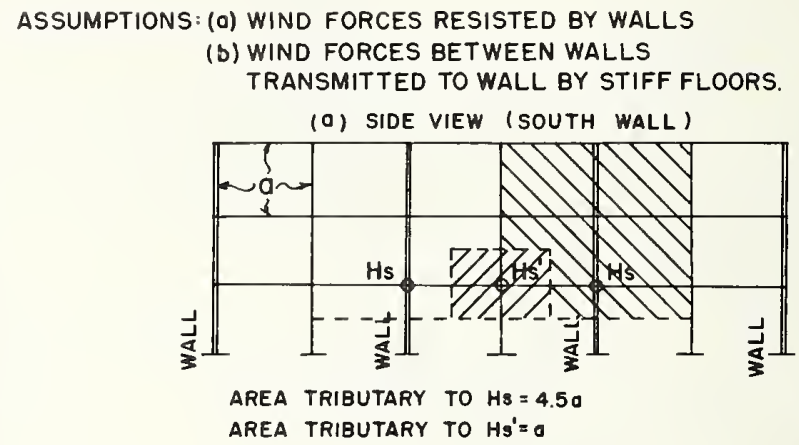

(b) END VIEW (WEST WALL)

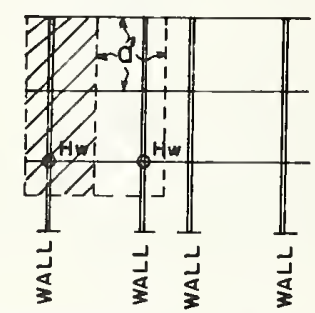

AREA TRIBUTARY TO HW $=2.5 a^{\prime}$

Figure C. 1. Wind loads.

\section{2. Load Schedules}

For an explanation of symbols, refer to fig. 6.1, tables 6.1 and 6.2, appendix $\mathrm{C}(1)$

I. Tests conducted on complete test structure with walls installed.

(a) Test 1: Column Loads to $0.9 D(0.9 D)$

Start of test:

Completion:

Loading:

Increments:

$$
\begin{aligned}
& \text { 5/10/68 9:09 A.M. } \\
& 5 / 10 / 68 \quad 9: 41 \text { A.M. } \\
& \mathrm{P}=0.9 D=9 \mathrm{kip} \\
& 9 \text { in 1 kip increments }
\end{aligned}
$$
$* 3 \mathrm{kip}$ was used in test, based on $H=15 \mathrm{psf}$ rather than $0.8 \mathrm{H}$. This is not too low, considering the fact that a service wind load of 20 pst
is extremely conservative for a built up area.

**1.6 kip was used in test, based on $H=15$ psf. 
(b) Test 2: Column loads of $0.9 \mathrm{D}$

South wind load to 25 psf

$(0.9 D+.25 H)$

$\begin{array}{ll}\text { Start of test: } & 5 / 10 / 68 \quad 11: 50 \text { A.M. } \\ \text { Completion: } & 5 / 10 / 68 \quad 1.02 \text { P.M. } \\ \text { Loading: } & P=0.9 D-9 \mathrm{kip} \\ & H s=1.25 H-5.1 \mathrm{kip} \\ & H s^{\prime}=1.25 H-1.2 \mathrm{kip} \\ \text { Increments: } & H s \text { in } 10 \text { increments } \\ & H s^{\prime} \text { in } 10 \text { increments }\end{array}$

Notes: (1) Six cycles of loading and unloading were applied. Residual deflections were read $5 \mathrm{~min}$ after removal of all loads.

(2) $P$ was applied initially and held constant.

(3) $H s$ and $H s^{\prime}$ were applied simultaneously.

(c) Test 3: Column loads of $0.9 D$

West wind load to $25 \mathrm{psf}$

$(0.9+1.25 H)$
Start of test:
5/10/68 9:46 A.M.
Completion:
5/10/68 11:06 A.M.
Loading:
$P=0.9 D=9 \mathrm{kip}$
Increments:
$H w=1.25 H=2.6 \mathrm{kip}$
$H w$ in 10 increments

Notes: (1) Six cycles of loading and unloading were applied at progressively larger loads. Residual deflections were read 5 min after removal of all loads.

(2) $P$ was applied initially and held constant.

(d) Test 4: Column loads to $1.3 D+1.7 L$

Major floor load to $1.3 D+1.7 L$

$(1.3 D+1.7 L)$

Start of test:

5/10/68 3:22 P.M.

Completion:

5/10/68 5:00 P.M.

Loading:

$P=1.3 D+1.7 L=25$ kip

Increments:

$w=1.3 D+1.7 L=100 \mathrm{psf}$

$P$ : 1st increment $9 \mathrm{kip}$

then 2 kip increments

w in 10 psf increments

Notes: (1) Unloaded at completion of test.

(2) $w$ was applied in five cycles of loading and unloading at progressively larger loads. Residual deflections were read 5 min after removal of all loads.

(3) $P$ was applied initially and held constant.

(e) Test 5: Column loads of $1.3 D+1.7 L$

Major floor loads of $1.3 D+1.7 \mathrm{~L}$

Loads sustained for $24 \mathrm{hr}$

$(1.3 D+1.7 L)$

Start of test:

5/10/68 5:25 P.M.

Completion:

5/11/68 5:50 P.M.

Loading:

$P=1.3 D+1.7 L=25$ kip

sustained for 24 hrs 
Increments:

$$
\begin{aligned}
& w=1.3 D+1.7 L=100 \mathrm{psf} \\
& \text { sustained for } 24 \mathrm{hrs} \\
& w \text { in } 20 \text { psf increments }
\end{aligned}
$$

Notes: (1) After unloading, an additional cycle of loading and unloading was applied. Additional reading of recovery was taken $24 \mathrm{hr}$ after final unloading.

(2) $P$ was applied initially and held constant.

(f) Test 6: Column loads of $1.3 D+1.7 L$

Major floor load of $1.3 D+1.7 \mathrm{~L}$

$(1.3 D+1.7 L)$

Start of test:

5/14/68 4:30 P.M.

Completion:

5/14/68 5:00 P.M.

Loading:

$P=1.3 D+1.7 L=25 \mathrm{kip}$

Increments:

w) $=1.3 D+1.7 L-100 \mathrm{psf}$

ii) in 5 increments

Note: $P$ was applied initially and held constant.

(g) Test 7: Column loads of $1.3 \mathrm{D}+1.71$

Major floor load of $1.3 D+1.7 \mathrm{~L}$

South wind load to 15 psf

$(1.3 D+1.7 L+0.8 H)$

Start of test:

$5 / 14 / 68$

5:02 P.M.

Completion:

$5 / 14 / 68$

6:13 P.M.

Loading:

$P+1.3 D+1.7 L=25 \mathrm{kip}$

$w=1.3 D+1.7 L-100 \mathrm{psf}$

$H s=0.8 H=3 \mathrm{kip}$

$H s^{\prime}=0.8 H=0.7 \mathrm{kip}$

Increments:

$H s+H s^{\prime}$ in 10 increments

Notes: (1) $P$ and $w$ were maintained from previous test and held constant throughout the test.

(2) Six cycles of loading and unloading at progressively larger loads were applied for $H s$ and $H s^{\prime}$.

(h) Test 8: Column loads of $1.3 D+1.7 L$

Major floor loads of $1.3 D+1.7 \mathrm{~L}$

West wind load to $15 \mathrm{psf}$

$(1.3 D+1.7 L+0.8 L)$

Start of test:

5/14/68 3:10 P.M.

Completion:

5/14/68 4:15 P.M.

Loading:

$P=1.3 D+1.7 L=25 \mathrm{kip}$

$w=1.3 D+1.7 L=100 \mathrm{psf}$

Increments:

$H w=0.8 H=1.5 \mathrm{kip}$

$P$ and $w$ applied in 1 increment

$H w$ applied in 10 increments

Notes: (1) $P$ and $w$ were applied initially and held constant.

(2) Six cycles of loading and unloading were applied for $H w$ at progressively larger loads. Reading of residual deflection was taken 5 min after removal of all loads. 
(i) Test 9: Column loads of $1 D$

Major floor load to 160 psf

Test 9-A: Column loads of $1 D$

Major floor load to 160 psf

Minor floor load to $160 \mathrm{psf}$

$(1 D+3.5 L)$

Start of test:

5/15/68 12:10 P.M.

Completion:

5/15/68 2:00 P.M.

Loading:

$P=1 D+1 L=17 \mathrm{kip}$

$w^{\prime}=w=1 D+3.5 L=160 \mathrm{psf}$

Increments:

$w$ and $w^{\prime}=$ one increment of 80

psf, followed by 10

psf increments

Notes: (1) Four cycles of loading and unloading were applied for $w$ and $w^{\prime}$ at progressively higher loads. (2) $w$ and $w^{\prime}+w$ were applied alternatively. For the purpose of data presentation then alternate load applications have been designated as Tests 9 and $9 \mathrm{~A}$. Test 9 is taken as though load $w$ was applied alone, while Test $9-\mathrm{A}$ is taken as though $w$ and $w^{\prime}$ were applied simultaneously.

(3) $P$ was applied initially and held constant throughout the test.

(j) Test 10: Column loads of $0.9 D$

South wind load to 60 psf

$(0.9 D+3 \mathrm{H})$

Start of test:

5/16/68 9:30 A.M.

Completion:

5/16/68 10:40 A.M.

Loading:

$P=0.9 D=9 \mathrm{kip}$

Increments:

$H s=12 \mathrm{kip}$

$H s$ in 1 kip increments

Notes: (1) Three cycles of loading and unloading with progressively increased loads were applied. Loading of residual deflection was taken 5 min after removal of all loads.

(2) Walls were racked until 0.35 in drift was reached. Further racking was discontinued to preserve the integrity of the beam-column joints.

(3) $P$ was applied initially and held constant.

(k) Test 11: Column loads of $0.9 D$

West wind load to $67 \mathrm{psf}$

$(0.9 D+3.35 H)$

Start of test:

5/16/68 $11: 15$ A.M.

Completion:

5/16/68 12:00 P.M.

Loading:

$P=0.9 D=9 \mathrm{kip}$

$H w=7 \mathrm{kip}$

Increments:

$H w$ in 0.5 kip increments

Notes: (1) Four cycles of loading and unloading were applied at progressively increased loads. Reading of residual deflection was taken 5 min after removal of all loads.

(2) Walls were racked until 0.3 in drift was reached. Further racking was discontinued to preserve the integrity of the column-beam joint.

(3) $P$ was applied initially and held constant. After this test, all the walls were removed. 
II. Tests conducted on the test structure after removal of the walls.

(a) Test 12: Column load of $1.3 D+1.7 L$

Major flood load to $1.3 D+1.7 \mathrm{~L}$

Rollers under column loads oriented to permit east-west sway $(1.3 D+1.7 L)$

Start of test:

5/21/68 9:12 A.M.

Completion:

$5 / 21 / 68 \quad 9: 30$ A.M.

Loading:

$P=1.3 D+1.7 L=25 \mathrm{kip}$

Increments:

$w=1.3 D+1.7 L=100 \mathrm{psf}$

w) in $20 \mathrm{psf}$ increments

Notes: (1) Rollers under $P$ were oriented to permit E-W sway.

(2) $P$ was applied initially and held constant.

(3) Reading of residual deflections was taken 5 minutes after removal of all loads.

(b) Test 12-A: Column loads of $1.3 D+1.7 L$

Major floor load to $1.3 D+1.7 L$

Rollers under columns oriented to permit north-south sway.

$(1.3 D+1.7 L)$

Start of test:

5/21/68 11:12 A.M.

Completion:

5/21/68 11:45 A.M.

Loading:

$P=1.3 D+1.7 L=25 \mathrm{kip}$

Increments

(1) $=1.3 D+1.7 L=100 \mathrm{psf}$

w) in 20 psf increments

Notes: (1) Rollers under $P$ oriented to permit N-S sway.

$P$ was applied initially and held constant.

(3) Reading of residual deflections was taken 5 minutes after all loads were removed.

(c) Test 13: Column loads of $1.3 D+1.7 L$

Major floor load of $1.3 D+1.7 \mathrm{~L}$

Minor floor load of $1.3 D+1.7 L$

Rollers under column loads oriented to permit east-west sway.

$(1.3 D+1.7 L)$

Start of test:

5/21/68 9:32 A.M.

Completion:

5/21/68 11:09 A.M.

Loading:

$P=1.3 D+1.7 L=25 \mathrm{kip}$

Increments:

$w^{\prime}=w 1.3 D+1.7 L=100 \mathrm{psf}$

$w^{\prime}+w$ in 20 psf increments

Notes: (1) $P$ was maintained from preceding test and held constant.

(2) Rollers oriented to permit E-W sway.

(3) Reading of residual deflections was taken 5 min after all loads were removed.

(d) Test 13-A:Column loads of $1.3 D+1.7 L$

Major floor load of $1.3 D+1.7 \mathrm{~L}$

Minor floor load of $1.3 D+1.7 \mathrm{~L}$

Rollers under column loads oriented to permit north-south sway

$(1.3 D+1.7 L)$ 
Start of test:

$5 / 21 / 68$

11:00 A.M.

Completion:

$5 / 21 / 68$

$12: 28$ P.M.

Loading:

$P=1.3 D+1.7 L=25 \mathrm{kip}$

Increments:

$w^{\prime}=w=1.3 D+1.7 L=100 \mathrm{psf}$

$w^{\prime}+w$ in 20 psf increments

Notes: (1) Rollers under $P$ oriented to permit N-S sway.

(2) $P$ was maintained from preceding test and held constant.

(3) Reading of residual deflections was taken $5 \mathrm{~min}$ after all loads were removed.

(e) Test 14: Column loads of $0.9 \mathrm{D}$

South wind load of $10 \mathrm{psf}$

$(0.9 D+0.5 H)$

Start of test:

5/21/68 2:23 P.M.

Completion:

5/21/68 2:58 P.M.

Loading:

$P=0.9 D=9 \mathrm{kip}$

$H s=2 \mathrm{kip}$

Increments:

$H s$ in 0.5 kip increments

Notes: (1) Racking load was carried to 2 kip and discontinued to prevent damage to beam column connections.

(2) $P$ was applied initially and held constant.

(f) Test 15: Column load of $0.9 \mathrm{D}$

West wind load of $16.5 \mathrm{psf}$

$(0.9 D+0.8 H)$

Start of test:

5/21/68 3:05 P.M.

Completion:

Loading:

5/21/68 3:55 P.M.

Increments:

$P=0.9 D=9$ kip

$H w=2.5$ kip

$H w$ in 0.5 kip increments

Notes: (1) Racking load was carried to 2.5 kips and discontinued to prevent damage to the columnbeam connection.

(2) $P$ was applied initially and held constant.

(g) Test 16: Column loads of $1 D$

Major floor load to $370 \mathrm{psf}$

$(1 D+8.4 L)$

Test 16-A: Column loads of $1 D$

Major floor load to $280 \mathrm{psf}$

Minor floor load to $280 \mathrm{psf}$

$(1 D+6.3 L)$

Start of test:

5/21/68 4:05 P.M.

Completion:

5/21/68 7:15 P.M.

Loading:

$P=1 D+1 L=17$ kip

$w=370 \mathrm{psf}$

$w^{\prime}=280 \mathrm{psf}$ 
NoTES: (1) Loads $w$ and $w+w^{\prime}$ were alternately applied. $w^{\prime}$ was discontinued at 280 psf, recognizing that $w$ alone was more critical. Loading was discontinued at $w=370 \mathrm{psf}$ due to failure of the loading system.

(2) In Test 16-A, three cycles of loading and unloading were applied at progressively larger loads; in Test 16 , four cycles were applied.

(3) Tests 16 and 16-A were performed simultaneously; $w$ and $w^{\prime}+w$ were applied alternately. For the purpose of data presentation, then alternate load applications have been designated as Tests 16 and 16-A. Test 16 is taken as though load $w$ was applied alone, while Test 16-A is taken as though $w$ and $w^{\prime}$ were applied simultaneously.

(4) $P$ was applied at the beginning and held constant throughout the test.

(h) Test 17: Column loads to $60 \mathrm{kip}$ on four outer columns

$(1 D+7 L)$

Start of test:

$5 / 22 / 68$

$10: 30$ A.M.

Completion:

$5 / 22 / 68$

$10: 42$ A.M.

Loading:

$P=60 \operatorname{kip} 1 D+7 L$

Increment:

Continuous increase of load.

Notes: (1) Only the four outside columns were loaded because of test frame capacity.

(2) No deflection readings were taken in this test.

(i) Test 18: Column loads of $0.9 \mathrm{D}$

South wind load to 10.5 psf

$(0.9 D+0.5 H)$

Start of test:

$5 / 22 / 68$

10:50 A.M.

Completion:

$5 / 22 / 68$

11:20 A.M.

Loading:

$P=0.9 D=9 \mathrm{kip}$

Increments:

$H s=2 \mathrm{kip}$

$H s$ in $0.5 \mathrm{kip}$ increments

NoTEs: (1) Racking load could not be further increased.

(2) Loud crack was heard in S-E column at maximum deflection. 


\section{Announcement of New Publications in Building Science Series}

Superintendent of Documents, U.S. Government Printing Office, Washington, D.C., 20402

Dear Sir:

Please add my name to the announcement list of new publications to be issued in the series: National Bureau of Standards Building Science Series.

Name

Company

Address

City State Zip Code

(Notification key $\mathrm{N}-339$ ) 



\section{NATIONAL BUREAU OF STANDARDS}

The National Bureau of Standards ' was established by an act of Congress March 3, 1901. Today, in addition to serving as the Nation's central measurement laboratory, the Burcau is a principal focal point in the Federal Government for assuring maximum application of the physical and engineering sciences to the advancement of technology in industry and commerce. To this end the Bureau conducts research and provides central national services in four broad program areas. These are: (1) basic measurements and standards, (2) materials measurements and standards, (3) technological measurements and standards, and (4) transfer of technology.

The Bureau comprises the Institute for Basic Standards, the Institute for Materials Research, the Institute for Applied Technology, the Center for Radiation Research, the Center for Computer Sciences and Technology, and the Office for Information Programs.

THE INSTITUTE FOR BASIC STANDARDS provides the central basis within the United States of a complete and consistent system of physical measurement; coordinates that system with measurement systems of other nations; and furnishes essential services leading to accurate and uniform physical measurements throughout the Nation's scientific community, industry, and commerce. The Institute consists of an Office of Measurement Services and the following technical divisions:

Applied Mathematics-Electricity-Metrology-Mechanics-Heat-Atomic and Molecular Physics—Radio Physics"-Radio Engineering "-Time and Frequency "-Astrophysics "-Cryogenics."

THE INSTITUTE FOR MATERIALS RESEARCH conducts materials research leading to improved methods of measurement standards, and data on the properties of well-characterized materials needed by industry, commerce, educational institutions, and Government; develops, produces, and distributes standard reference materials; relates the physical and chemical properties of materials to their behavior and their interaction with their environments; and provides advisory and research services to other Government agencies. The Institute consists of an Office of Standard Reference Materials and the following divisions:

Analytical Chemistry-Polymers-Metallurgy_Inorganic Materials_Physical Chemistry. THE INSTITUTE FOR APPLIED TECHNOLOGY provides technical services to promote the use of available technology and to facilitate technological innovation in industry and Government; cooperates with public and private organizations in the development of technological standards, and test methodologies; and provides advisory and research services for Federal, state, and local government agencies. The Institute consists of the following technical divisions and offices:

Engineering Standards-Weights and Measures - Invention and Innovation - Vehicle Systems Research-Product Evaluation-Building Research-Instrument Shops-Measurement Engineering-Electronic Technology-Technical Analysis.

THE CENTER FOR RADIATION RESEARCH engages in research, measurement, and application of radiation to the solution of Bureau mission problems and the problems of other agencies and institutions. The Center consists of the following divisions:

Reactor Radiation-Linac Radiation-Nuclear Radiation-Applied Radiation.

THE CENTER FOR COMPUTER SCIENCES AND TECHNOLOGY conducts research and provides technical services designed to aid Government agencies in the selection, acquisition, and effective use of automatic data processing equipment; and serves as the principal focus for the development of Federal standards for automatic data processing equipment, techniques, and computer languages. The Center consists of the following offices and divisions:

Information Processing Standards-Computer Information - Computer Services - Systems Development-Information Processing Technology.

THE OFFICE FOR INFORMATION PROGRAMS promotes optimum dissemination and accessibility of scientific information generated within NBS and other agencies of the Federal government; promotes the development of the National Standard Reference Data System and a system of information analysis centers dealing with the broader aspects of the National Measurement System, and provides appropriate services to ensure that the NBS staff has optimum accessibility to the scientific information of the world. The Office consists of the following organizational units:

Officc of Standard Reference Data-Clearinghouse for Federal Scientific and Technical Information - Office of Technical Information and Publications-Library-Office of Public Information-Office of International Relations.

' Headquarters and Laboratories at Gaithersburk. Maryland, unless otherwise noted: mailing address Washington, D.C. 20234.

Located at Boulder, Colorado 80302.

Tocated at 5285 Port Royal Road. Sprinkfield, Virqinia 22151 
U.S. DEPARTMENT OF COMMERCE Washington, D.C. 20230

OFFICIAL BUSINESS

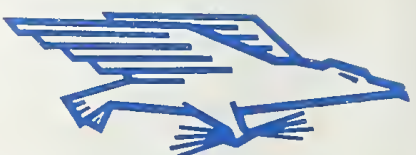

POSTAGE AND FEES PAID U.S. DEPARTMENT OF COMMERCE 